\title{
THE THOUGHT REMOLDING CAMPAIGN OF THE CHINESE COMMUNIST PARTY-STATE
}

Hu Ping

Translated by

Philip F. Williams and Yenna Wu 
The Thought Remolding Campaign of the Chinese Communist Party-state 
(ICAS) Publications Series

\author{
General Editor \\ Paul van der Velde \\ Publications Officer \\ Martina van den Haak
}

\title{
Editorial Board
}

Wim Boot (Leiden University); Jennifer Holdaway (Social Science Research Council); Christopher A. Reed (The Ohio State University); Anand A. Yang (Director of the Henry M. Jackson School of International Studies and Chair of International Studies at the University of Washington); Guobin Yang (Barnard College, Columbia University).

The ICAS Publications Series consists of Monographs and Edited Volumes. The Series takes a multidisciplinary approach to issues of inter-regional and multilateral importance for Asia in a global context. The Series aims to stimulate dialogue amongst scholars and civil society groups at the local, regional and international levels.

The International Convention of Asia Scholars (ICAS) was founded in I997. Its main goals are to transcend the boundaries between disciplines, between nations studied, and between the geographic origins of the Asia scholars involved. ICAS has grown into the largest biennial Asia studies event covering all subjects of Asia studies. So far seven editions of ICAS have been held respectively in Leiden (I998), Berlin (200I), Singapore (2003), Shanghai (2005), Kuala Lumpur (2007), Daejeon, South Korea (2009) and Honolulu, Hawai'i (20II).

In 200 I the ICAS secretariat was founded which guarantees the continuity of the ICAS process. In 2004 the ICAS Book Prize (IBP) was established in order to create by way of a global competition both an international focus for publications on Asia while at the same time increasing their visibility worldwide. Also in 2005 the ICAS Publications Series were established.

For more information: www.icassecretariat.org 


\section{The Thought Remolding Campaign of the Chinese Communist Party-state}

Hu Ping

Translated by Philip F. Williams and Yenna Wu 
ICAS) Publications Series

\section{Monographs 7}

Cover design: JB\&A raster grafisch ontwerp, Westland Layout: The DocWorkers, Almere

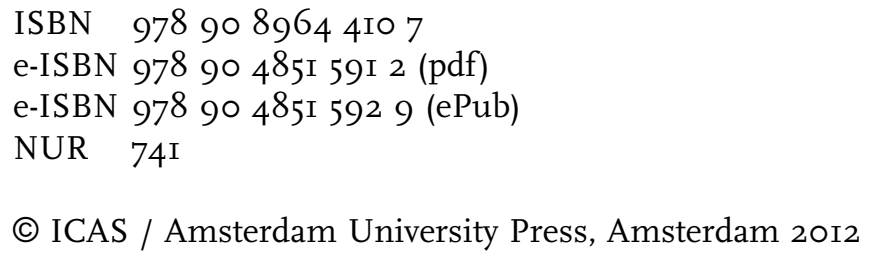

All rights reserved. Without limiting the rights under copyright reserved above, no part of this book may be reproduced, stored in or introduced into a retrieval system, or transmitted, in any form or by any means (electronic, mechanical, photocopying, recording or otherwise) without the written permission of both the copyright owner and the author of the book. 


\section{Table of Contents}

Preface 9

I What is Thought Remolding? 13

I.I Thought Remolding and "Brainwashing” 13

$\begin{array}{ll}\text { I.2 Restrictions upon the Scope of the Problem } & 14\end{array}$

I.3 Did Marxism Ever Discuss Thought Remolding? 15

I.4 Thought Remolding: Totalitarianism with Decidedly
"Chinese Characteristics"

I.5 Does Thought Remolding Have Any Theoretical Foundation? 18

I.6 Absurdity Beneath the Seriousness and Seriousness Behind the Absurdity

I.7 Thought Remolding Differs from the Development of Thought

I.8 Thought Remolding and Moral Self-cultivation are Superficially Similar but Different in Spirit 23

I.9 Thought Remolding as the Negation of Thought 26

I.IO Thought Remolding is a Logical Paradox 27

I.II The Actual Political Function of Thought Remolding 28

I.I2 From "Establishing a Proletarian Weltanschauung" to
"Maintaining Unity with Party Central"

$2 \quad$ How Was Thought Remolding Possible? 31

2.I The I949 Revolution Was Not the Victory of a Political Idea 31

2.2 On "Following a Doctrine without Understanding it" 33

2.3 Is it True that They Were "Completely Convinced"? 34

2.4 Intangible Pressure 36

2.5 From "Killing a Chicken to Frighten the Monkeys" to

2.6 A Monistic System of Value Standards: Concepts and $\begin{array}{ll}\text { Structure } & 39\end{array}$

2.7 Why Was Remolding Aimed at the Intelligentsia? 40

2.8 The Bifurcated Essence of Thought Remolding 42

2.9 The Coercion of Truth 43

2.IO The Utility of Truth 44

2.II The Class Nature of Truth and the Problem of Standpoint 45 
2.I2 Beware of "Begging the Question" 46

2.I3 The Ambiguity of Facts 47

2.I4 The Ambiguity of Values $\quad 50$

2.I5 Conformity 53

2.I6 Consistency $\quad 56$

2.I7 The Belief that the World is Just 57

2.I8 Pursuing Meaning in Life 59

3 How Has Thought Remolding Been Implemented? 61

3.I "With Machine Guns Pinning You Down on Three Sides, You're Allowed to Head off in Only One Direction" 61

3.2 Mobilizing Others to Receive Instruction 63

3.3 "First Impressions are the Strongest" and "Once You Form a Habit, Following it Comes Naturally" 65

3.4 The Power of Oversimplification 68

3.5 "Giving an Injection of a Preventive Inoculation" 72

3.6 The Hierarchical System of "Study" [xuexi] 75

3.7 An Affective Style of Propaganda 77

3.8 The Controlling Function of Collective Rituals 79

3.9 Criticism and Self-Criticism $\quad 81$

3.IO From Prohibition to Renunciation 84

3.II The Transition from Compelled Conduct to Voluntary
Conduct

3.I2 The Strategy of Violating Dignity 88

3.13 The Chastity of Those Who Have Lost Their Chastity 92

3.I4 The Psychology of a Shortage of Rewards 94

3.I5 Thought Remolding and the Chinese Cultural Tradition 96

3.16 Getting Enmeshed in a Cocoon of One's Own Weaving 97

3.I7 Some “Doctor" Indeed 99

3.I8 Various Methods of Punishment 101

3.I9 A Remarkable Effect of the "Downward Transfer to the
Countryside for Manual Labor"

3.20 The First Strategy of Criticism: A Ferocious Clap (I) 104

3.2I A Ferocious Clap (2) 106

3.22 The Second Strategy of Criticism: Isolation within
the Crowd (I)

3.23 Isolation within the Crowd (2) 110

3.24 Spiritual Homelessness, Isolation and the Lack of Support 112

3.25 From Confusion to Submission 114

3.26 The Emotional Need to Identify with One's Oppressors 117

3.27 Self-conscious Sacrifice 119

3.28 The Trap of Toughening and Putting to the Test 122

3.29 The Language Demon 125

3.30 Why Must Self-criticism Be Carried out in Public? 126 
3.3I The Destruction of Self-discipline 128

3.32 The Destruction of External Discipline 130

3.33 Utilizing the Sense of Shame to Shatter the Sense of Shame 132

3.34 A Myth about Laborers 135

3.35 A Reflection - or an Image "in Reverse"? 138

3.36 Filial Devotion and Loyalty to the Rulers 140

3.37 Begin in Obedience and End in Obedience 142

3.38 Getting "Well-Remolded" Amounts to Getting Intimidated 143

3.39 Remolding is Nothing Other than Taming 147

3.40 In Evading Freedom, One Evades Responsibility 148

4 On Evasion 153

4.I Evasion by Foot-dragging 153

4.2 The Rejected and the Weary 155

4.3 Idealists Who Went Astray 157

4.4 Rebellion among Evaders 159

4.5 Between Taming and Rebellion 162

4.6 The Legitimization of Evasion 164

4.7 Evasion as Being Tamed 167

4.8 Evading the Persecuted 169

4.9 Indifference and Forgetfulness 171

4.IO The Rationalization of Evasion 172

5 On Rebellion 179

5.I What is Rebellion? 179

5.2 The Meaning of Writing a Letter to Chairman Mao 181

5.3 Format is More Important Than Content 184

5.4 Regarding Subconscious Rebellion 186

5.5 Opposing Thought Remolding and Opposing Totalitarian Rule 188

5.6 Earthquakes from within the System 189

5.7 The Bankruptcy of Phony Politics 192

5.8 The Rebellion of Liberalism 194

5.9 The Current Condition of Liberalism 196

5.IO Gaining the Privilege of Rebellion 197

6 The Bane of Cynicism 199

6.I Authoritarianism and Cynics 199

6.2 The Communist Party and Cynicism 200

6.3 What Does "the Transition from a Revolutionary Party to
a Ruling Party" Mean?

6.4 Why is It "No to Reform and Wait for Death; Yes to Reform and Court Death"? 
6.5 Cynicism and Fear - and the Notion that You Are "Better-Off Muddleheaded"

6.6 The Idea of Liberal Democracy - Only with Faith in it is it Efficacious

6.7 Hip Cynicism

6.8 Doctrinal Cynicism

6.9 The Political Game of Pretending to Obey

6.Io The Cynic's Self-deception and Deceiving of Others

7 Struggling for the Freedom of Thought

7.I Quandaries of Existence

7.2 An Analysis of Some Peculiar Phenomena

7.3 Why Are There Still People Who Want to Join the Party?

7.4 Why Some Dissidents Are Willing to Remain in the Party

7.5 Why Some Persons Severely Persecuted by the CCP Would Continue to Express Their Loyalty to the CCP

7.6 Why Do Party Members Rarely Withdraw from the Party, and Why Do Officials Rarely Resign?

7.7 Why Would Many Persons Still Remain Within the System Even When Various Exits are Available?

7.8 Why Do Quite a Few People Always Place Their Hopes in the CCP?

7.9 Rational Choice Theory

7.I0 Normative Theory

7.II The Power of Example 254

7.I2 Structuralist Theory 256

7.13 Coercion and Incentives for By-Products 258

7.I4 The Impact of Societal Scale on Collective Action 260

7.I5 The Necessity and Limitations of Drawing on Official Mass Communication Outlets

7.I6 A Struggle for Recognition

7.I7 Desire, Reason and Spiritedness 266

7.I8 Knowledge and Behavior 267

7.I9 The Special Features of Late Communist Totalitarian Rule 270

7.20 Dauntlessly Moving Forward in a Measured Stride 272

About the Author and the Translators 275

$\begin{array}{lr}\text { Notes } & 277\end{array}$

$\begin{array}{ll}\text { Index } & 303\end{array}$ 


\section{Preface $^{\top}$}

The 2oth century was an age of numerous transformations. The broad scope of these changes stuns the observer, whose eyes cannot take them all in due to their rapid influx. This has brought about an extremely odd phenomenon: since we have been through such complex and many-sided transformations, we should have become more mature in behavior, more incisive in thought, and steadier in demeanor than we had previously been. However, precisely because these changes swept over us too violently and with excessive frequency, to the extent that we never seemed to have sufficient time to properly ponder and digest the experience of any one of these changes, we in fact actually became more immature in behavior, more superficial in thought, and especially more impulsive in demeanor. It seemed as though we were always encountering a new and strange way of life that made yesterday appear extremely distant and of no relation whatsoever to today's experiences.

Nietzsche once said, "The last human has the longest memory" of the type of history mentioned above. Yet this is not necessarily the case. If something were to go wrong with the last human, his memory would instead be the briefest. Like a black bear pulling apart an ear of corn, grasping various parts of it while discarding others, in the end the only thing left would be the last piece. To be sure, nobody is willing to cut oneself off from the past, since that would be another form of death ordinary death amounting to being cut off from the future. Because of this, the faster a time machine spins in a given place, the more prevalent the trend of nostalgia in that locale. However, what we refer to as "nostalgia" is often merely a matter of emotion, and does not actually contain any element of understanding.

If we claim that the unexamined life cannot amount to true living, then it would follow that unexamined memory cannot amount to true memory. I realize that after having experienced several decades of jolts and shocks, everyone feels extremely exhausted, and that everyday life is also infused with anxiety and bustle. Under circumstances of this sort, it might be difficult to garner broad support for the demand that we seriously ponder and research our troubled past. We no longer need to mention here the ancient admonition, "If past experience is not forgotten, it serves as a guide to the future." What I want to emphasize is 
that even if we wanted to leave history behind, history would by no means leave us behind merely on account of this inclination. The situation is often like this: when following what seems to be the least strenuous path in order to extricate ourselves from the shadow of yesterday, we in fact are still situated right in the middle of that same shadow.

Totalitarianism contains three faces that emerge in an interlocking sequence. I) Its utopian face is a heavenly ideal that makes a person feel ecstatic, inducing fanaticism, which in turn leads to 2) its face of largescale terror and a hell in this world. Afterwards, once the fanaticism and terror have been exhausted, then 3) its face of cynicism becomes widespread among the populace, who have "seen through it all" and sink into political indifference. ${ }^{2}$ When looking back at history as well as observing the present state of affairs, is this not precisely the way it goes? ${ }^{3}$

This study sets out to engage in research on thought remolding. The Chinese Communist Party-state's campaign to remold thought is without doubt a strikingly unique event in the history of humankind. In spite of the fact that China's thought remolding is not necessarily as hideous and terrifying as either the Nazi concentration camps like Auschwitz or the old Soviet Gulag archipelago, because the number of persons dragged into thought remolding have been even more numerous and the amount of time it persisted was even longer, its influence upon our entire people's spirit has thus been even more widespread and grave. Today, there is no one of over fifty years of age in mainland China who lacks heartfelt experience of thought remolding, especially among the intelligentsia. I refer to thought remolding as "the taming of the human," since from a certain perspective the history of the ascendancy and decline of Communist Party rule in China has been nothing other than the history of the taming of the human, and the responses to it of evasion and rebellion.

Regrettably, in comparison to the mammoth scale of the entire thought-remolding campaign, up to the present day there has still been very little written in the way of full and accurate accounts or in-depth analyses of the thought-remolding campaign. I am not making any sweeping claim that writings about thought remolding are few in number, since in fact there is too much by far of this type of writing. There have been two varieties of writings that have swamped China since I949: one variety has extolled and eulogized the Party and "the Great Leader," while the other variety has consisted of confessing one's own faults and denouncing the faults of others. The latter type of writings could be viewed almost entirely as primary source materials for research. The writers of these documents include people from all walks of life barring none, whether male or female, young or old. However, this type of document has been dogged by two problems. The first is 
that few such documents have been formally published, and the overwhelming majority of them have already been destroyed or lost forever. The second problem is that the documents that remain often lack a sufficient degree of truthfulness. This is not at all surprising. Since the confession itself amounts to thought remolding, the demand is that the writer himself act as his own interrogator. ${ }^{4}$ Even though some such writers have considered themselves to be full of sincerity and "touched to their very souls," I am afraid that we are only able to view their writings as the confessions of the mentally ill - at the same time that they expose certain things, they always cover up a great many other matters. It is precisely as the proverb relates: "You cannot make out the true likeness of Mount Lu because you are on the mountain itself." 5

The political climate changed after the Cultural Revolution. ${ }^{6}$ The number of writings that reviewed and researched thought remolding from a certain type of critical perspective increased noticeably. In addition, the Chinese Communist regime itself announced the abandonment of the formulation "thought remolding," and moreover affirmed that the intelligentsia "falls within the category of the laboring people." Within intellectual circles, criticism of thought remolding grew even more severe, with quite a few persons putting forward the slogan that “intellectuals shouldn't be 'old number nine,' but instead need to be 'number one.' "7 Of course, the liveliest places of ferment on the cultural scene were in literary circles, and include the handiwork of "scar literature," "towering wall literature" (that is, prison camp literature), and "rusticated youth literature" - all of which touched upon thought remolding. ${ }^{8}$ However, for the most part, the above-mentioned varieties of writing were unavoidably evasive in their factual description of thought remolding. Some were quite accurate in their description of overt or external behavior, but unfortunately still smacked of sketchiness in their descriptions of internal behavior, that is, psychological activity. Since thought remolding is basically a kind of internal behavior, this shortcoming is thus not insignificant.

In theoretical analyses of thought remolding, there have been two widespread problems. Many of the analyses have limited themselves to the terminological system of official discourse; and even when occasionally transcending this terminological system, these analyses have been found wanting in depth and meticulousness. Thereupon, this postCultural-Revolutionary period's studies of issues related to thought remolding have been the same as the studies of many other issues during the few decades of this "new period." On the one hand, there has been a welcome expansion of the scholarly discussion; yet on the other hand, the reader has felt a merely superficial satisfaction with the modest results of the discussion. It is as though everything has been discussed, and has been discussed enough. 
In the seven chapters to follow, I offer a fresh departure on the discussion of the problem of thought remolding. My personal involvement in thought remolding, both in terms of individual experience and through first-hand observation of others, is sufficient to constitute the solid experiential basis for this study. The questions I wish to investigate are as follows: What is thought remolding, after all? Why was thought remolding able to occur, and how has it been put into practice? In other words, why could we have accepted thought remolding, and how was our thought remolded? Later on, how did we oppose thought remolding, and how did we extricate ourselves from it? Because thought remolding is connected to a series of weighty problems such as liberty, truth, and the meaning of life, what kind of situation do we finally face in the present day, now that thought remolding has almost come to an end? What kinds of choices should we be making? 


\section{What is Thought Remolding?}

\subsection{Thought Remolding and "Brainwashing"}

Thought remolding is also referred to as xi'nao, ${ }^{\mathrm{I}}$ or "brainwashing." Many Chinese people consider the Chinese term xi'nao to have originated from the English word "brainwashing." In the preface to her novel Bathing [Xizao], Yang Jiang remarks that the term xi'nao is of Western derivation (a view that I formerly held as well). ${ }^{2}$ Even Mao Zedong assigned xi'nao's patent rights to the Americans. Taking a slightly different tack, the scholar Liu Qingfeng viewed xi'nao as something that happened in the U.S.S.R. and was not all that similar to Chinese thought remolding. ${ }^{3}$

However, some Westerners have insisted that what xi'nao refers to is none other than Chinese thought remolding. In I95I, the American journalist Edward Hunter wrote a book entitled "Brainwashing" in Red China. In I956, Hunter came out with another book entitled Brainwashing. ${ }^{4}$ The American psychologist Robert Jay Lifton also used the term xi'nao on many occasions in his I969 study, Thought Reform and the Psychology of Totalism. ${ }^{5}$ We can see from these examples that the Chinese term for "brainwashing" is not actually an imported item, but is instead an example of "goods for export that have been sold back to the home market."

Admittedly, we have never come across the term xi'nao in any of the Chinese Communists' formal documents, articles, or speeches. Nonetheless, everyone is already familiar with similar phraseology. For example, the politically charged term xizao [bathing] was popular as early as the I950s (the subject of Yang Jiang's Bathing is none other than the thought remolding of the intelligentsia during the early I950s). ${ }^{6}$ During the "Four Clean-ups" political campaign of the I960s, a common nostrum was "Cadres go upstairs to wash their hands and bathe." One can infer that xi'nao or "brainwashing" originated from this type of campaign, and while this term did not get written down in formal documents, it nevertheless was a popular oral usage. The amusing thing is that the Chinese Communists themselves seem not very fond of the term xi'nao. Were we to look into the reason for this state of affairs, perhaps it is because the term xi'nao became popular through the Ameri- 
cans' critique of thought remolding, which thus caused the term to be tarnished by suspicions about a certain variety of "anti-communism." Yet in all fairness, "brainwashing" and this special connotation of "bathing" signify similar phenomena. Indeed, "brainwashing" is not necessarily pejorative in and of itself; moreover, it is an even more appropriate and vivid term than "thought remolding."

\subsection{Restrictions upon the Scope of the Problem}

The phenomenon of utilizing various types of methods to implement certain kinds of control over people's minds is possibly as ancient as human civilization itself, and is also every bit as widespread. No matter whether we consider the many rituals and taboos of primitive tribes, or the various practices and strictures of religions, or the modern practices of political propaganda, commercial advertisements, and the treatment of patients under psychoanalysis, all of these practices to one degree or another embody this function of exercising control over people's minds. With regard to thought remolding, I949 does not mark the beginning of the Chinese Communist Party's (CCP) practice of thought control. As early as the so-called Revolutionary War Era, ${ }^{7}$ the Chinese Communists were already gradually developing a set of effective methods to purify the thought of new recruits to the revolution and to strengthen these new members' loyalty to the Party. ${ }^{8}$ The Yan'an Rectification Campaign of 1942-43 is a concrete example of this. ${ }^{9}$ After 1949, the CCP also applied a series of rectification measures to war captives, war criminals and all types of imprisoned criminals. However, in the present study that I am unfolding, I do not intend to encompass such a broadranging area of investigation. I merely wish to investigate the thought remolding that the CCP carried out after 1949 on the ordinary citizenry, and especially on the intelligentsia.

Making the above-noted restrictions on the scope of the material has involved consideration of the following matters. First, unlike ordinary methods of controlling the human mind, thought remolding does not merely signify the importation of a set of ideas, but above all refers to the necessity of transforming a whole range of pre-existing ideas that a person had already internalized. Because of this, thought remolding is bound to encompass quite conscious and explicit conflicts between various ideas. In traditional Chinese society, from an early age people have internalized a certain set of ideas, and there basically does not exist any problem of transforming these pre-existing concepts. Of course, within this process of internalizing a set of key ideas, conflicts also occur. However, the conflicts here are mostly between ideas and desires, not between one idea and another, as is the case with thought remolding. 
What is known in traditional thought as "Foster heavenly principles and discard human desires" obviously belongs to a different category than the Maoist notion of "Foster what is proletarian and extinguish what is bourgeois." ${ }^{\text {IO }}$

The second point is that strictly speaking, thought remolding necessarily restricts people's freedom of choice, and therefore it can only be implemented within a closed society. When viewing the matter in this way, the leftist youth who sought refuge in Yan'an during the late I93os and early I940s are not a typical enough example of thought remolding. Their act of taking refuge in Yan'an stemmed from personal willingness, and it was not extremely difficult for them later to depart from Yan'an, either. In other words, the migrants to Yan'an at that time had a relatively large number of opportunities to make a choice. With respect to an open society's political propaganda and commercial advertisements, because all of these encounter competition, people's scope for making choices is quite broad; this situation contrasts even more with the dearth of choice in a closed society.

The third point is that from a different perspective, the name of thought remolding can match the reality only after the object of remolding has attained a certain kind of willingness to undergo remolding. Because of this, zealous coercion such as sentencing to a forced labor camp or imprisonment that entirely strips its captives of freedom is actually not sufficient in itself to explain the problem of thought remolding.

Finally, I have made the intelligentsia the focus of my study. The reasons for this are very straightforward. First, the CCP originally placed special stress upon the intelligentsia as the object of thought remolding. Second, because the intelligentsia usually had relatively numerous and clearly defined ideas, during the process of thought remolding the conflicts with their internalized ideas were thus unusually deep-seated and observable.

\subsection{Did Marxism Ever Discuss Thought Remolding?"1}

As is widely known, thought remolding, according to the explanation by the CCP, refers to the remolding of one's weltanschauung. This socalled "worldview" originally referred to an individual's complete set of views about the world. Strictly speaking, a person's weltanschauung is still somewhat different from his view of life. This is not merely because the former is connected to the entire world while the latter is merely involved with human existence, but more importantly because the former is simply a type of knowledge, while the latter is instead a set of values. Nevertheless, from a Marxist perspective, these two types 
of views are united as one entity. Of course, if we are to proceed from the recognition that the material world has an objective existence, and then logically make the case that people should behave benevolently and refrain from malevolence, this is obviously a bit ludicrous, and at the very least is a rather strained argument. Hume has long since pointed out the distinction between facts and values. ${ }^{\mathrm{I} 2}$ He has stressed that it is impossible for us to logically infer "what ought to be" from "what is." Marxism repudiates the dichotomy between facts and values, but does not actually provide much of anything in the way of convincing evidence in support of its repudiation. This is a defect in Marxism itself, but for the time being I will not discuss it further. The problem here is that if we uphold the Marxist standpoint, upholding the position that a person's weltanschauung forms a unified whole with his view of life, then it would apparently be impossible to derive a conclusion that demands thought remolding.

A classic proposition of Marxism has been that "existence determines thought." To use more ordinary language to describe this: "Whatever type of vine there is will produce a particular type of gourd, and whichever class a person belongs to will shape what that person says." If a person is situated within the proletarian class, then he will naturally and inevitably have a proletarian-class weltanschauung; and if a person is situated within the bourgeois class, he will naturally and inevitably have a bourgeois-class weltanschauung. In the former case, there is no need for further "remolding"; in the latter case, even if you wanted to remold him, it would be a futile endeavor. If we wanted to transform the thought of the latter, the sole means of doing so would be to transform his existence. If his existence could be transformed at some time or other, then his thought would in turn be naturally and inevitably transformed. Because of this, as a type of ideological work, thought remolding is thus impossible under circumstances in which "existence" has not changed, and is therefore unnecessary under circumstances in which "existence" has changed.

Of course, those who have stressed the determinative function of existence vis-à-vis thought are not actually limited to the Marxist school of thought. The theories of two 2oth-century psychologists, Pavlov and Skinner, also hold to this basic orientation. No wonder that various Soviet Communists and Chinese Communists of Pavlov's day joined in energetically affirming Pavlov's theory, because it is indeed compatible with the Communist Party's "materialism." I3 In contrast, Skinner did not receive plaudits from the Communist Party, probably due to their sense that he was overly "bourgeois." However, in all seriousness, the theories of Pavlov and Skinner are still very different from Marxist theory. The key point of dissimilarity is that behaviorist psychology does not actually advocate historical determinism. For example, according to 
Skinnerian theory, if we were able to create a particular type of everyday living environment, then we could create a person with that correspondingly particular type of behavior. As to whether we would rather create this kind of everyday living environment or create that kind of everyday living environment, it would all depend upon our own choice and design.

It is not difficult to perceive that Skinnerian theory more closely resembles the I8th-century French mechanistic materialism that Marxism inherited and criticized. This type of theory has one foot in the camp of determinism, with respect to the way all people have been placed in certain kinds of circumstances of existence - and the other foot in the camp of free will, with regard to the heroes or geniuses who choose or design the aforementioned kinds of circumstances of existence. Precisely in the manner that Marx criticized, this kind of theory divides humanity into two types: one type is the remolder and educator, and the other type is the person on the receiving end of remolding and education. The latter's ideology and behavior are molded by the former, just as an artisan produces products, as an expert trainer tames a beast, or even as God has created humans. In contrast, the former's ideology and behavior are free, spontaneous and not determined by others.

Marxism is different from this. ${ }^{14}$ According to Marxism, people are not at all capable of transforming society or creating history as the spirit moves them. This is not solely because we are merely able to rely upon pre-existing material objects or materialistic methods. What is even more important is that within our own minds, the desires and propositions for transformation and creation are themselves determined by external forces, and not something that can be altered by our individual will. Marxism is thus an even more rigid variety of determinism. ${ }^{15}$ It causes any person's thought and ideology to become a type of thing that the person has no way of choosing or determining on his own. As was pointed out previously, if we are to say that the only way to transform someone's ideology is to first transform that person's mode of existence, then thought remolding would either be impossible or else unnecessary. Were we to affirm one day that even the ideology of transforming the mode of existence was itself also determined by the mode of existence, how would thought remolding not thus be doubly impossible or doubly unnecessary? When Marx said that he and his followers were not engaged in moral proselytizing, what they meant was precisely this. Even if we were to add the two supplementary hypotheses: "It is possible for ideology to temporarily fall behind advances in existence" and "Ideology can have a certain counter-reaction in its relation to existence," notwithstanding the fact that these two hypotheses themselves amount to a certain contradiction with the tenet that "the mode of exist- 
ence determines thought," they still cannot provide any reliable theoretical basis for implementing a universal thought-remolding movement.

\subsection{Thought Remolding: Totalitarianism with Decidedly "Chinese Characteristics"}

A prominent feature of communist totalitarian rule is its ideological dictatorship. On the one hand, such a regime brands its dissidents class enemies and subjects them to dictatorship; on the other hand, the regime forcibly instills its doctrines amongst the general public. It should be said that brainwashing (that is, thought remolding) is a shared feature of all communist countries, but in comparison with the communist totalitarianism of the former Soviet Union and Eastern Europe, it is especially within Chinese Communist totalitarianism that thought remolding has been a major feature. This is due to the fact that it was only under CCP rule (precisely speaking, under Mao Zedong's rule) that thought remolding was elevated to a high position within the system of rule, and moreover was implemented as a major strategic goal within an extremely broad framework. To be sure, there were also propagandistic instructional activities related to molding the "new Soviet man" in the former Soviet Union, but the Soviet Communists never actually demanded that every person "struggle against selfishness and criticize revisionism" or "make revolution burst forth from your innermost soul." ${ }^{16}$ Furthermore, except for the dissidents among its ranks, the Soviet intelligentsia never came down in the world to the lowly position of "stinking number nine." ${ }^{17}$ In discussing China's campaign to remold thought, the other countries fall short in all these areas, whether it be in terms of the length of time it persisted, the broad assemblage of human objects at which it was aimed, the sheer volume of discourse that it encompassed, or the complexity and variety of the methods and techniques that it employed. We can reasonably affirm that thought remolding is the most prominent characteristic of CCP totalitarianism.

\subsection{Does Thought Remolding Have Any Theoretical Foundation?}

If we advance a step forward to further investigate the Mao Zedong Era, we can also discover that within the nearly thirty years of the history of thought remolding, quite a few changes occurred. You need look only to the intelligentsia to find an example of these changes. In the beginning, discussions about thought remolding were aimed primarily at the "old" intelligentsia. The reason provided for this was that under the 
"old society," they were supposedly in the service of the bourgeois class, and thus belonged to either the bourgeoisie or the petty bourgeoisie. Although their social status underwent a fundamental change after having entered the "new society," it was nonetheless impossible for their weltanschauung to have suddenly undergone the commensurate transformation; therefore, they still needed to undergo remolding. Here, the theoretical basis for undergoing thought remolding is the doctrine: "It is possible for ideology to temporarily fall behind the mode of existence."

We know that during the beginning of its rule over China, the CCP categorized every person within a certain social class, based upon the circumstances of each individual's mode of existence during the three years prior to "Liberation." ${ }^{\mathrm{I} 8}$ Zhang Third would thereupon be classified as an agricultural landlord, while Li Fourth would be labeled a rich farmer. ${ }^{\text {I9 }}$ Yet in the wake of land reform and the movement to amalgamate individual family landholdings into jointly run cooperatives, landlords no longer owned any land and rich farmers were no longer rich. In fact, both types of formerly well-to-do rural residents became "manual laborers who enjoy the fruits of their own toil." Is it not absurd to have continued referring to them as "landlord elements" and "rich farmer elements"? At the outset of its nationwide rule, the CCP was still discussing class labels somewhat logically, and decreed that landlords and rich farmers would have their class status changed after three years. After the third year, agricultural villages would no longer utilize the rankings of landlord, rich farmer, middle farmer and poor farmer, but would instead classify all residents as farmers henceforth.

Yet after the three years had passed, the CCP did not actually make good on its promise; once a class label was fastened onto somebody, it would remain there for thirty years. This sort of categorization by class thus became a lifetime classification system. Mao Zedong said: "Since it is the same old person who has been here all along, his old ways of thinking will have not died." Whereupon thought, that is to say ideology, became a thing that was entirely impervious to changing in accordance with the changes of a person's social existence.

Let us return to the question of the intelligentsia. According to Maoist theory from the early I950s, the targets of thought remolding consisted primarily of the old bourgeois intelligentsia, which did not include those members of the intelligentsia who had long since participated in the revolution. As for the new generation within the intelligentsia "who were born in the new society and grew up under the Red Flag," they had never served the exploiting classes, so naturally they could not be considered to harbor a bourgeois weltanschauung. Because of this, they were not initially targeted for thought remolding, either. Yet no more than a few years passed before this new generation within 
the intelligentsia had also been grouped within the category of thought remolding's targets. As soon as the Cultural Revolution erupted, the "seventeen years" of education in the new society became characterized as "the bourgeois educational line." ${ }^{20}$ For better or worse, the idea that the intelligentsia within this generation of ours had to undergo thought remolding located its theoretical basis in this alleged bourgeois taint. It was assumed that since the education we received was bourgeois, our weltanschauung was basically still a bourgeois weltanschauung. Here, one's weltanschauung is not determined by one's class status, but has become determined by the type of education one has received; and ideology is not determined by one's existence, but has become determined by someone else's ideology (education of course belongs to the realm of ideology, not to the realm of existence). This type of theory has already departed even further from Marxism. ${ }^{2 \mathrm{I}}$

Nevertheless, the problems with this theory do not stop here. If we were to claim that the generation of the intelligentsia prior to the Cultural Revolution unfortunately had a bourgeois weltanschauung on account of the education they received, then would not the newer generation of intellectuals that came of age during the Cultural Revolution necessarily be a proletarian intelligentsia? Since their social existence had nothing whatsoever to do with the bourgeois class, and even the education they received was the most proletarianized that has ever been witnessed in the history of humankind, how could they still have a bourgeois weltanschauung? Yet precisely in keeping with what we know about their overall situation, this generation of the intelligentsia still did not escape the fate of thought remolding. Here, we can no longer find any theoretical basis that would provide even the slightest plausible justification for this course of action.

When all is said and done, Marxism differs from Christianity in that it does not consider "Original Sin" to be a part of life or a factor in what it means to be human. Marxism also differs from many other types of theories of human nature in that it does not actually believe that certain evil tendencies are innately present within human nature or that one must strive to overcome them in one's own life. Given this situation, on what basis does thought remolding have to be carried out on the newest generation of the intelligentsia?

Perhaps there are those who would remind us of what Lenin once pointed out: through its own devices, the proletariat cannot actually give rise to Marxism, which is to say the weltanschauung of the proletariat; because of this, it is necessary to "immerse" the proletariat in this weltanschauung from somewhere "outside" the ambit of the proletariat. That is to say, even though a person's status within society would be that of a proletarian, he would still not naturally or inevitably possess the proletarian weltanschauung. It is still necessary that persons partici- 
pate in studying and immerse their thought processes in these study materials before they can attain this weltanschauung. Because of this, thought remolding is consequently held to be necessary.

However, immersion is immersion, and remolding is remolding the two processes are not one and the same. In immersion, one has simply assumed that the human object of transformation begins with the lack of a correct proletarian weltanschauung. In thought remolding, in contrast, one has assumed that the human object of transformation begins with already having harbored an erroneous bourgeois weltanschauung. And it is even more the case that when Lenin says that the proletariat cannot give rise to the proletarian weltanschauung on its own, ${ }^{22}$ what he is referring to is the proletariat within a bourgeois society. According to Marxism, a society's ruling ideology is nothing other than the ideology of that society's ruling class. Because of this, even though some of the people who are situated within a bourgeois society are proletarians, their ideological tendencies - assuming that these are spontaneous as claimed - will still remain within the system of bourgeois ideology. Aside from the fact that this kind of viewpoint and the notion that existence determines consciousness are mutually contradictory, there is one point that is always obvious, to wit: when socialist relations of production have already been established, and when the proletarian weltanschauung (i.e. Marxism) has already become society's ruling ideology, the notion of "immersion" has basically lost its theoretical grounding, and we are at even more of a loss as to knowing how we might begin to discuss "remolding."

\subsection{Absurdity Beneath the Seriousness and Seriousness Behind the Absurdity}

The above analysis is no doubt an instance of "attacking your shield with your own spear." 23 This analysis indicates that the so-called movement to remold thought is not only entirely lacking in any foundation within Marxist theory, but that it even similarly lacks any basis in Mao Zedong Thought, owing to the way the latter is riddled with inconsistencies. This incongruity greatly contrasts with such matters as the centrally planned economy. Indeed, the planned economy is a logical product of Marxism, while thought remolding is instead a pure absurdity. If one had no personal experience of the way that such an absurd matter had unexpectedly come into being, developed and lasted for thirty years, with so many intelligent and benevolent people surprisingly believing in it, putting it into practice and moreover paying an extremely heavy price on its behalf, it would truly be hard to believe. 
Now that we have realized that our serious efforts during those years had actually been erected upon a foundation of extreme absurdity, this realization would no doubt occasion much grief among people. Yet conversely speaking, what makes absurdity absurd is precisely the way in which the things that are behind it are rather serious. Pointing out the absurdity beneath the seriousness, along with the seriousness behind the absurdity - this is nothing other than the focus of my analysis to follow.

\subsection{Thought Remolding Differs from the Development of Thought}

Before clarifying what thought remolding is, I shall first clarify what thought remolding is not. Above all, thought remolding is not the normal development of thought or the evolution of thought.

A person's thought often undergoes change, and during periods of great fluctuation this is especially the case. This type of normal and ubiquitous development of thought or evolution of thought is not at all the same thing as so-called thought remolding. Mao Zedong once came up with a parable based on his personal experience, discussing how he had formerly despised the masses of workers and farmers as "dirty" and "stinky," and only later came to the realization that it was precisely the masses of workers and farmers who were actually "the cleanest" and "the most fragrant" amongst the various social classes. Citing this example, Mao Zedong explained that everyone needs thought remolding. However, what should be noted is that Mao Zedong's "thought remolding" that year was actually not thought remolding, but was instead the development or evolution of his thought. This was an independent and autonomous set of thought processes, prior to which there was no set of pre-ordained conclusions that he was required to embrace. Within the overall process of the development of thought, it is possible that a person may undergo major changes in all sorts of concrete viewpoints, but from beginning to end he has considered his own sense of right and wrong as a serviceable measure of right and wrong, and has never negated his own ability to think. In the struggle between the so-called "present self" and the "past self" (in Liang Qichao's phraseology), although there is a distinction between the present and the past, what still connects these in the middle is the same "self." ${ }^{24}$ In other words, the process of the development of thought is nothing other than a process of independent thinking.

Yet thought remolding differs from all this. Thought remolding signifies the negation of independent thinking. We all still remember that during the I957 campaign for the blooming of a Hundred Flowers and 
the contending of a Hundred Schools of Thought, there were a lot of people branded as rightists for having promoted independent thinking. So-called thought remolding demands that a person admit from the very beginning that "my" thought is wrong, and that only the thought of the Party and the thought of the Leader are correct. "I" must change my thought to accord with the thought of the Party and the thought of the Leader. That is to say, thought remolding demands that one adopt other people's sense of right and wrong as one's own, along with negating the independence and autonomy of thought.

This process may be likened to an elementary school student's math assignment; after completing the assignment, you hand it in to the teacher to be corrected. Only if the teacher says that your answer is correct is it correct; if she says that it is incorrect, then it is incorrect. If you were to try to find where your mistake was on the basis of the teacher's answer, this would no doubt prove that you were originally in error; if you could not find where you had been in error, you would still have to admit that only the teacher was correct, and that you yourself were certainly wrong. Normally speaking, the more you are unable to uncover where your mistake lies, the more correct you would consider yourself to be. Yet the meaning of thought remolding is precisely that you affirm from the start that the teacher's answers are always correct, and if there is a discrepancy, the one in error is certainly yourself. The more unable you are to find out where your mistake lies, the more you have proven that your mistake is serious. From this we can see that thought remolding is precisely the opposite of the development of thought.

\subsection{Thought Remolding and Moral Self-cultivation are Superficially Similar but Different in Spirit}

Thought remolding also differs from individual moral self-cultivation. To begin with, thought remolding does not refer to elevation of the quality of individual morality, but refers to a transformation in political standpoint or political ideas.

Contrary to the way traditional culture moralizes politics, the CCP politicizes morality. The relevant Confucian theory proceeds from the concept of "self-cultivation," and moves on to "establishing order within the family," "ruling the state" and finally concludes with "pacifying the empire." From the perspective of Confucianism, if a person is of lofty moral fiber, then in politics he will be correct. The CCP's theory is precisely the opposite. According to the logic of the CCP, only if a person is correct in politics would it be possible for him to be of lofty moral character. As for the exemplars of this kind of "Communist warrior" such as Lei Feng and Jiao Yulu, their ability to win the admiration of 
ordinary people is no doubt due to the broadly recognized benevolent qualities that they possess, such as finding joy in helping others, working hard and bearing criticism, and being honest and frugal in their official tasks. ${ }^{25}$ However, the CCP lumps all of these benevolent qualities under the rubric of political principles such as "following what Chairman Mao says" and "being loyal to the Revolution and loyal to the Party." Contrary to this, as in the case of the personage Chen Shizhong in Liu Binyan's "The Second Type of Loyalty," aside from the way he is something of a dissident politically, his other qualities can all rival those of Lei Feng. ${ }^{26}$ Yet merely because of this bit of dissidence, the CCP views him as a "class enemy," and in this connection also negates all of his excellent qualities of individual morality. This situation differs very much from the way of the ancients. In ancient China, people sometimes express their admiration for public figures of lofty moral fiber, even when in political terms the latter belong to the enemy camp, as is the case with Kubilai Khan's respect for Wen Tianxiang. ${ }^{27}$ You would never find something as benevolent as this from the CCP. If the CCP considered you to be politically "reactionary," then the more outstanding your individual moral integrity was, the more the Party would simply hate you, purge you, and denounce you. At the very least, the Party would not respect you on account of your sterling qualities.

The CCP negates the universal nature of morality, instead emphasizing the class nature of morality. In dealing with instances of the same sort of behavior, the Party must first determine where you stand with regard to a political viewpoint, and only afterward can it finally ascertain whether or not the behavior accords with morality. For example, speaking amiably and treating other persons politely had originally been viewed all along as being moral. Yet the CCP nonetheless insisted that such behavior could be considered moral only when directed at comrades; if you were also being polite to enemies, such courtesy would place you under serious suspicion of having lost your class standpoint. In a high official who is honest, frugal and devoted, these qualities have all along garnered praise. Yet according to the logic of the CCP, if you belong to a "reactionary class," the more incorruptible you are, then the more hypocritical, the more fraudulent and the more capable you would be of paralyzing the laboring people - and thus the more vile you would be, to the extent that you would be even more evil than a corrupt official. At the same time, the CCP also considers that as long as a person is correct politically, even if he has some major problems related to individual morality, it would not matter much. This is nothing other than the so-called theory that "there is no harm in trifles." Although this theory emerged from Lin Biao's mouth, it is actually a principle that is a commonly-held belief within the CCP. ${ }^{28}$ 
Second, as for the self-cultivation that Confucianism advocates and the training of temperament that Christians pursue, their gist does not extend beyond the scope of developing the potential for benevolence within the human mind in order to overcome the latter's tendency to slip into wickedness. Here, both benevolence and wickedness are inborn, and standards of good and evil are innate within the human mind. Communist theory is precisely the opposite. It not only denies that either benevolent or wicked thoughts are inborn, but also denies that standards of good and evil are innate within the human mind. Socalled thought remolding is actually not equivalent to the traditional curbing of evil and promoting of good. The CCP never believed that the struggle between the proletarian weltanschauung and its bourgeois counterpart was a manifestation of the struggle between good and evil. In fact, within the CCP the very discussion of good and evil in abstract terms belongs to "the bourgeois theory of human nature," and thereby is itself part and parcel of what should get remolded. For example, both Confucians and Christians place much emphasis upon conscience, while the philosophy of Communism bluntly negates conscience. It considers a conscience that transcends class distinctions to be utterly non-existent, thereby causing the term "conscience" to bear certain dubious features of the "bourgeois class" or "petty bourgeois class."

From a superficial perspective, thought remolding indeed resembles moral self-cultivation. The Chinese Communists not only hanker after the mouthing of simplistic slogans, but also have a knack for changing the definitions of words. Phraseology such as "destroy selfishness and establish public-mindedness" and "struggle against selfish concerns and criticize revisionism" easily causes people to think back to the recommendations of moralists and religionists who have demanded that people discard selfishness and desire. Jin Guantao and Liu Qingfeng believe that the CCP's theory of thought remolding is a kind of "Confucianized Marxism" - it appeals to the tradition of moral introspection among the intelligentsia in Confucian cultures. Perhaps there is indeed a group within the intelligentsia that has approached thought remolding with this sort of attitude. Yet that would unfortunately be a grave misunderstanding. Among all of those who considered thought remolding to be the equivalent of humanistic moral cultivation, there has not been one person who has not met with the harsh reality of repeated failure. I suppose that all things considered, the great modernday Confucian Liang Shuming was a personage whose humanistic moral cultivation was impeccable. ${ }^{29}$ However, Liang Shuming was never considered a positive exemplar in the practice of thought remolding, but was instead taken to be a negative example of someone who opposed thought remolding. As was mentioned above, the CCP's thought remolding has for one thing emphasized the transformation of stand- 
point and political views, and for another has negated mankind's universal sense of intrinsic morality. Therefore, if comparing it to traditional Confucianism's moral cultivation, one observes a similarity in outward appearance but a difference in spirit. This is precisely the basic reason why the Chinese intelligentsia with their strong tradition of moral introspection always made for a poor fit within the CCP's thought remolding movement, in which they could not please the authorities, no matter how hard they tried.

\subsection{Thought Remolding as the Negation of Thought}

Then what is thought remolding, after all?

Thought remolding refers to the remolding of one's weltanschauung. According to Marxism, the so-called weltanschauung is actually a set of understandings - a system of value judgments. That is to say, it is a group of beliefs concerning what is right and what is wrong, what is good and what is bad, what is correct and what is incorrect, what is "progressive" and what is "reactionary," and so on.

When you acknowledge that you must thoroughly remold your thought, it means that the things you once believed to have been right are actually wrong, and the things that you once believed to have been wrong are actually right.

However, a problem presents itself: if you already know that what you once believed was right is actually wrong, and that what you once believed was wrong is actually right, this realization reveals that you already have acquired a correct weltanschauung, and that your thought has already been remolded. Therefore, you have no further need of thought remolding. Conversely, if you still do not know that the seemingly right things are actually wrong, and that the seemingly wrong things are actually right - that is to say, if you do not believe that your original weltanschauung is wrong and that the weltanschauung which the Communist Party advocates is right, then you would not feel that there is any necessity for thought remolding, and you would not bother with remolding your thought. No matter which type of abovementioned circumstances is pertinent in a given case, thought remolding always appears to be an impossibility, whether it is conceived as a type of thought process or as a state of mind, because it appears to be self-contradictory in and of itself.

I recall that during the early stage of the "Cultural Revolution," there was a passing fad for the following slogan: "If the father's a reactionary, his son's a scoundrel." At that time, I strongly disapproved of this slogan. Later on, upon reading Yu Luoke's critical essay, "On the Bloodline Theory [of Evaluating a Person's Political Status]," I could not help 
feeling deep sympathy for his line of argument. ${ }^{30}$ I gave a copy of "On the Bloodline Theory" to an intelligent classmate to read, for he also came from "a bad class background." I had originally thought that his views about this issue would be mostly similar to mine and had actually not expected that after he finished reading it he would immediately exclaim: “This is a big poisonous weed!" After a certain number of years passed, he gave me an explanation of his psychological state during that time. He said:

Actually, at that time I also felt disgust for that slogan. Yu Luoke's essay was argued in such a rigorous and penetrating way that it was impervious to refutation. After reading it, I also felt his essay was extremely reasonable. Yet at that time, I always felt that my own weltanschauung had problems, and that my thought, my feelings, and my standpoint were all problematic as well. Therefore, I thought that whatever matters I felt were right were probably bound to be wrong. Precisely because my psyche believed that "On the Bloodline Theory" was right, I said that this very same essay was wrong.

Perhaps the case of this classmate borders on the extreme. However, this kind of extremity amounts to nothing more than the full-blown development of a type of widespread tendency, and thus precisely reveals ordinary people's commonly shared vague feelings in an immediate and complete way. The CCP has stated very clearly that the key to thought remolding is the transformation of one's standpoint. This consists of nothing other than requiring you to look at problems from a standpoint that is diametrically opposed to the one that you yourself hold - that is to say, it requires you to self-consciously oppose yourself. In short, to remold one's own thought simply means to oppose one's own thought and to negate one's own thought.

\subsection{Thought Remolding is a Logical Paradox}

There is a famous Liar's Paradox, in which a certain person announces that he is lying. ${ }^{3 \mathrm{I}}$ Is what he said true or false? If we assume that his announcement is true, then we would deduce that what he said is false. If we assume that his announcement is false, then we would deduce that what he said is true.

As the above sections of this chapter have related, thought remolding is also a paradox. Having admitted that my thought is incorrect, is my thinking now right or wrong? If my thinking is correct, then you would 
deduce that my thought is incorrect. If my thinking is incorrect, then you would deduce that my thought is correct.

Bertrand Russell has pointed out that both of the above-mentioned paradoxes arise on account of a vicious cycle. ${ }^{32}$ He has mentioned a principle for avoiding this kind of paradox: anything that is about a certain group entity must not be a unit of the aforesaid group. When a person announces that he is lying, this sentence itself should not be included within the group entity of lies. By the same token, when I admit that my thought is erroneous, this utterance should not be included within the group entity of my erroneous thought. In other words, when I admit that my thought embodies a bourgeois weltanschauung and thus must be thoroughly remolded, in this thinking of mine I have already definitely moved beyond a bourgeois weltanschauung; obviously, I actually do not have "a headful of the bourgeois weltanschauung." Lenin once said that in politics, recognizing one's mistake is to have gone halfway down the path of correcting the mistake. You would not even be able to say that I "basically" still had a "bourgeois weltanschauung," because there was at least half of it that was no longer a "bourgeois weltanschauung." This is still somewhat different from the Liar's Paradox - a person is able at whim to alternate between telling lies and speaking the truth, but cannot have a "bourgeois weltanschauung" one moment and a "proletarian weltanschauung" the next.

The CCP demands that people who have a "bourgeois weltanschauung" undergo thought remolding. However, everyone who has a "bourgeois weltanschauung" would be bound to reject remolding; and everyone who is willing to undergo remolding certainly no longer has a "bourgeois weltanschauung," or "basically" no longer has a "bourgeois weltanschauung." This situation precisely resembles that of the fairy tale "The Emperor's New Clothes": those who are fools certainly cannot see the new clothes, while people who have seen the new clothes are certainly not fools. Viewed in this light, we not only cannot find any suitable theoretical basis for thought remolding in Marxism, but even in terms of logic it is a self-contradictory notion.

\subsection{The Actual Political Function of Thought Remolding}

Thought remolding is actually not what many people imagine it to be something undertaken merely for the sake of a kind of abstract, idealized goal: training a "proletarian intelligentsia," or rearing "the new Communist man." First of all, it contains a more direct, more concrete, and more realistic goal, which is to bring about people's identity with and loyalty to the CCP's authoritarian regime. 
Max Weber pointed out that a national regime signifies monopolistic, legal, or normal violence. ${ }^{33}$ This is to say that if a regime wishes to maintain its existence, it must not only grasp the tools of monopolistic violence to suppress people's rebellious actions, but for the sake of its own existence it also needs to seek out a set of theoretical foundations that prove its legitimacy or normality in order to negate people's rebellious awareness.

The CCP has a set of unique theories or philosophical doctrines. According to the CCP's own theories, I) socialism and communism are the manifestations of "objective laws" in the development of humankind's history - this idea thereby negates the traditional concept of "Heaven's will," yet at the same time plays the same role played by "Heaven's will" in a bygone age; 2) the Communist Party amounts to humankind's most advanced class, that is, the vanguard within the ranks of the proletariat - on the surface, this affirms the consciousness of ordinary folk while also anointing themselves as a cut above other people; and 3) the CCP represents the aspirations and interests of the people in its entirety, and the dictatorship of the proletariat has manifested the loftiest and greatest democracy - thereby stealing and repackaging the concept of democracy, and once and for all effecting a takeover of "the people's will."

Therefore, the CCP regime does not resemble those other forms of authoritarian regimes within its same epoch. As the latter have implemented an authoritarian system, they have always had a guilty conscience, become discouraged, left their work partly unfinished, and in defending themselves have still suspected that they were not up to the task; how could they maintain the lofty aspiration of forging ahead? In implementing an authoritarian system, the CCP has spared itself that kind of psychological burden in which the despot feels shamed in the world by comments among the honest and worthy, and is ashamed upon contemplating the disapproval of spirits and deities. The CCP has implemented its authoritarian system with the assurance that justice is on its side, considering itself to be entirely justified in its actions. Because of this, the CCP has often been overbearing in its self-righteousness. The reason for this lies in the way that it has provided itself with a set of self-evident, absolute, and "legal" foundations.

The pity is that in order to cause this set of CCP theories to fulfill the functions of expounding upon and proving the legitimacy of the regime, it will not suffice if merely the CCP leaders themselves believe in this. Nor is the latter necessary, either, since the crux of the matter is that the rank-and-file citizenry, and first of all the intelligentsia, must believe in all this. There has thus been an endless series of thoughtremolding campaigns that have tried to arm (or remold) the people nationwide with Marxism. ${ }^{34}$ 


\subsection{From "Establishing a Proletarian Weltanschauung" to "Maintaining Unity with Party Central"35}

Matters did not actually stop at this point.

Since the CCP's theories are a type of theoretical construct, it would be difficult for them to avoid the common shortcoming in which different accounts of these theories are at variance with each other. Believing in the CCP's philosophy is merely a necessary condition of identifying with and proffering loyalty to the CCP regime, but is not a sufficient condition. If your understanding of this set of theories differs from that of the leaders, you may criticize, or even go so far as to oppose, that existing Communist regime. The true goal of thought remolding is certainly not to transform everyone into Marxists. Ever since the birth of Marxism, the internal debate amongst various viewpoints within Marxism has never ceased. For the Marxism that serves as academic theory, this situation would be extremely normal. Yet when Marxism serves as something that explains and proves the legitimacy and appropriateness of an existing regime, this situation would be extremely abnormal. ${ }^{36}$

Therefore, from the apparently rather idealized, complex and internally ambiguous sacred goal which it flaunted of "establishing a proletarian weltanschauung," the thought-remolding campaign had to descend to the level of being directly materialized as this highly realistic, extremely simplistic and entirely non-negotiable political demand of "maintaining unity with Party Central." ${ }^{37}$ I believe that having arrived at this awareness, all types of unfortunate misapprehensions of thought remolding - such as misperceiving it as the development of thought, as moral cultivation, or as the rearing of Marxists - should be completely clarified. 


\section{How Was Thought Remolding Possible?}

\subsection{The 1949 Revolution Was Not the Victory of a Political Idea}

If the thought remolding campaign was in fact absurd - and indeed it was so - then how was it actually able to take place? Were not we ourselves the ones who carried out thought remolding with extreme earnestness during those years? Nowadays, when people discuss their own behavior during the "Cultural Revolution," they sum it all up with such epithets as "immaturity" and "fanaticism." Yet these two expressions cannot really explain much of anything.

At this juncture, the discussion needs to begin from how Marxism had become so popular in China, and how the Communist revolution gained victory in mainland China. ${ }^{\mathrm{I}}$ Of course, this section can present only an explanation in outline.

Ever since the late Qing Hundred Days' Reform of $1898,{ }^{2}$ an antiquated China has continually harbored the impulse to fervently pursue modernity or modernization. This sort of impulse easily prompts the ordinary person to adopt the attitude of "whatever's new is worth pursuing"; if it is new, it is good - if it is new, it is correct. The Chinese people discarded the view of history as cyclical or reverting to a distant past, and accepted an evolutionary view of history. According to this latter type of view of history, the movement of history is seen as a process of accumulation of humankind's achievements. When Marxism and socialism were first brought into China, they were crowned with the laudatory title of "the newest theories." Very few people realized that these two isms were destructive and negating with respect to the Western system of liberty and democracy. Most people mistakenly thought that Marxism was a cure that was based on preserving the achievements of the past (and they viewed this preservation as a matter of course), and a remedy that offered effective treatment for the major shortcomings of their existing society so that society could attain a more perfect condition.

Without a doubt, the Russian October Revolution played a decisive role in strengthening the dissemination of Marxism within China. This is what is meant by the saying that "the cannon blast of the October Revolution delivered Marxist-Leninism to us." It is a theory that comes from the West and yet is anti-Western, and thus is able to simulta- 
neously satisfy the contradictory emotions of some Chinese who both want to learn from the West as well as maintain their national pride. Lenin's views about "an advanced Asia and a backward Europe" have catered to the run-of-the-mill less advanced nationalities' aspirations for quick success and instant benefit, whereby these nationalities would try to become vanguards in history all at once.

The founding theory of the CCP provided a set of doctrines about an elite organization that ran everything in the name of the masses; on the surface, this reconciled the rift between the elite and the masses. The awe in which the effectiveness of science was held led to "the superstition of scientism," which was nothing more than an unscientific attitude towards science. Yet Marxism nonetheless flaunted itself as the crystallization of science. In Marxism, there was not only a giant system that was unintelligible and obscure, but also dogmatic tenets of faith that were simple and straightforward - this then provided the necessary spiritual rearmament for intellectuals who yearned for action. On the one hand, Marxism affirmed the highly idealized goal of a perfect society which was similar to that of the traditional Chinese aspiration for a "society of Great Harmony." On the other hand, it also affirmed a set of extremely shrewd tactics of struggle in the style of Machiavelli, which led to people being able to repudiate societal realities by means of a strict moral standard at the same time that they were also capable of disregarding the most basic moral restraints in their own behavior. Moreover, since the beginning of China's Republican Period (I9III949), there was both domestic unrest and foreign encroachment; part of the intelligentsia was becoming marginalized; World War I caused quite a few people to lose their illusions about Western civilization; and World War II brought about a global inundation of leftist currents of thought - all of these circumstances are part and parcel of the numerous factors that made Marxism popular in China.

However, there is a point of caution that one needs to make: it is inappropriate to exaggerate the effect of the various factors above. An obvious fact is that up until I949, those intellectuals who identified themselves with Marxism still constituted but a very small proportion of the intelligentsia as a whole. During the r940s, those within the intelligentsia who became dissatisfied with the existing GMD regime saw their numbers rapidly increase, but those who threw in their lot with the CCP as far as politics and thought are concerned were still very few in number.

The victory of the CCP in 1949 was certainly not some "historical inevitability" or whatnot. Nor was it a victory of socialist or communist ideas. First, the revolution led by the CCP was to a very small degree a so-called proletarian revolution; to a relatively large degree, it was an agrarian revolution. Even the CCP itself has admitted that the revolu- 
tion of I949 was a "New Democratic revolution," not a "socialist revolution." Second, the triumph of this revolution was mainly a military victory, not the victory of a political idea.

\subsection{On "Following a Doctrine without Understanding it"}

As discussed above, the victory of I949 was actually the triumph of the CCP's political ideas in only a very limited sense. However, the CCP has nonetheless made as big a deal as one could imagine about this victory. Striking the pose of a judge in History's High Court of Final Appeal, Mao Zedong came out with the following sort of pronouncement: "All of the other political systems that people have advocated have been tried, and all have failed; only Marxism and only proletarian revolutions led by a communist party have achieved victory." The CCP draws upon its success in I949 as the basis for proving its own correctness; it then proceeds to take this correctness as the reason for demanding trust and compliance from the people. This then constitutes a premise for undertaking its thought-remolding campaign.

Strictly speaking, this premise is actually not so reliable itself. Success in seizing power is not equivalent to success in one's principles; and even if one's principles were successful, that would not actually be equivalent to a claim that one's principles were necessarily correct. History teems with the actuality of correct things encountering failure: as the proverb phrases it, “don't judge right versus wrong on the basis of success or failure." Yet even though people have spoken thusly, it is always easier for winners than for losers to proclaim that they themselves represent correctness, and it is indeed easier for them to make others believe that they themselves represent correctness - there is nothing strange about this.

It is precisely the same as the "superstition of scientism" - the psychology of the "superstition of scientism" derives from persons who do not understand science itself yet who are overawed by science's utility and efficacy. This then gives rise to the attitude known as "believing in something without understanding it." As one of Hou Baolin's comedians' dialogues puts it, superstition is nothing other than "coming to believe something while in a dazed stupor."3 Based on the same principle, because those people who originally did not understand or believe in Marxist-Leninism witnessed the huge victory of the Communist revolution, this would also give rise to the similar attitude of "believing in something without understanding it." This then caused them to proceed to the next step of approving of the necessity and correctness of thought remolding. 
The ordinary process of advances in the knowledge of humankind has been to "believe in something through an understanding of it." Therefore, at first glance, the idea of "believing in something without understanding it" would seem to be nothing other than self-contradictory or impossible. Actually, this is not entirely so. As I pointed out in Chapter One, thought remolding means both that you admit your thinking is incorrect, even though you do not actually know why it is wrong - and that you admit that some other person's thinking is correct, even though you do not actually know why it is correct, either. This situation appears to be extremely absurd, but it is by no means impossible. If you were to discover that your thinking led to misfortune while somebody else's thinking led to success, you would very likely entertain thoughts like those just now recounted. As matters progressed, your confidence in both your thought and your ability to think would waver. When some matter would arise in which your view of it differed from somebody else's, you would very likely suspect right away that you were actually the one in error.

\subsection{Is it True that They Were "Completely Convinced"?}

We have been informed all along that in the early I950s, China's intelligentsia had truly been "completely convinced" by the Communist Party. ${ }^{4}$ However, we have also heard more and more accounts that dissent from that standard Party line. A Beijing University professor mentioned that while together with other urban residents he was welcoming the PLA (People's Liberation Army) troops upon their entry into Beijing, in his private thoughts he actually felt a bit uneasy about this turn of events. When recollecting his thoughts at that same historical juncture, Liu Binyan noted that he received the initial news of the "Liberation" with less enthusiasm than he had originally expected he would feel. ${ }^{5}$

Are accounts such as these two accurate? Admittedly, when reflecting back on their personal reactions to former events, people often project their current feelings onto these past events, and thus it is possible that they are unintentionally distorting their actual feelings at the earlier time in which their memories were formed. Yet we must also be aware that sometimes situations are altered for the better by changed circumstances - people are instead able to perceive more clearly in retrospect a certain type of feeling that they had never stated explicitly or had even consciously suppressed in the past context. Therefore, I am inclined to have faith in these dissenting accounts. Even if we were to acknowledge that the CCP's political accomplishments in the early I950s were fairly impressive - and if we were to say that the intelligentsia was invariably 
supporting the CCP at that time - it would certainly have been impossible that within their minds they lacked even the slightest misgiving or disagreement with the CCP's agenda. ${ }^{6}$

Confucius said: "When moral governance prevails in the world, people do not offer up criticisms." This obviously oversimplifies the relationship between governance and criticism. There are those who argue that the well-educated are by nature inclined to oppose the status quo maybe this is going a bit too far. Yet perhaps there is more truth in this view after all. The problem boils down to the fact that no government truly achieves such perfection that other persons would have nothing they could criticize about it. During their time in office, even leaders as great as George Washington and Thomas Jefferson were unable to avoid the onslaught of political attacks. Another example comes from PRC's Land Reform campaign. ${ }^{7}$ If you approve of allowing impoverished farmers to receive their share of farmland in a given locale, do you also approve of cruelly attacking landlords and the better-off farmers? Even if you were to approve of cruelly attacking landlords and the better-off farmers, could it be that you have no inkling of how many honest and capable farmers were placed in the wrong class category and thereby met with unexpected calamity? Because of this, there is no way that members of the intelligentsia who consider themselves the witnesses or the conscience of society would become so inactive as to know only how to sing eulogies to the government.

Of course, with regard to the way that members of the intelligentsia generally expressed their support for the new government during the I950s, there are certain considerations that apply specifically to the intelligentsia.

First, owing to the influence of traditional cultural patterns, when some members of the intelligentsia criticized the leadership, it was from the perspective of "sharing the burdens of the leaders" or "pleading on behalf of the common people." When the rulers exerted themselves to make the country prosperous and ordinary people's standard of living gradually improved, these members of the intelligentsia seemed to lose any standpoint for offering up criticism of other problems. Indeed, at that time, there were actually few members of the intelligentsia who upheld the principles of liberalism and insisted upon the basic rights of the individual citizen.

Second, quite a lot of individuals within the intelligentsia probably internalized the Communist Party's exhortative phraseology, such as "we must clearly distinguish between the mainstream and side currents," "we must clearly distinguish between Yan'an and Xi'an," and "a giant revolutionary movement cannot avoid giving rise to certain deviations." 8 This type of thinking thereby caused the intelligentsia to assume an atti- 
tude of understanding and forgiveness when encountering the Communist Party's mistakes during those years.

However, even though the above-mentioned factors were widespread amongst the intelligentsia and did a lot to weaken criticism of the Party, they certainly did not make all the voices of criticism disappear. Moreover, over the past couple of hundred years, there have always been personages among the intelligentsia who have considered themselves critics, and who have criticized for the sake of criticism. How could it be that under the rule of the CCP, all of them would suddenly take the overall situation in account and "behave responsibly" along these lines?

There is one point that is perfectly clear: from the very outset of the CCP's assumption of power, the intelligentsia has come to sense a sort of strong pressure. ${ }^{9}$

\subsection{Intangible Pressure}

This type of pressure encompasses quite a few layers. First, a giant and monopolistic authority that relied on military force to become victorious is fearsome in itself. In the face of this kind of authority, people instinctively feel that they cannot afford to offend it, and consequently draw close to it in a seemingly instinctive fashion.

Second, no matter whether it was seven parts true and three parts false or three parts true and seven parts false, during the early stages of its rule the Communist Party always maintained that it had been able to win the support of a substantial majority of the populace. This huge majority in and of itself embodies the force of a deterrent to challenges. We know that even under a democratic system in which individual rights are protected, when a huge majority appears in society, in spite of the fact that it is not implementing any violent measures against the minority, a sense of living under oppression will still likely arise from a minority that has been left out of the mainstream. Because of this, the minority will often adopt an attitude of pandering and submission to the majority.

In actuality, merely on the basis of the above-mentioned two layers of pressure, conditions were already sufficient to prevent the average person from daring to wantonly reproach the Communist Party. However, people in general are furthermore all accustomed to rationalizing their own behavior. Under these sorts of circumstances, all of the facts and writings used to prove that the Communist Party is truly heroic and great would nimbly well up in their minds, and various sorts of arguments implemented to vindicate and explain away the Communist Party's mistakes would automatically surface in their brains. And in the face of those troubling phenomena that would likely throw our inner 
peace into turmoil, our eyes would tactfully shut. In the end, we would finally persuade ourselves that we have indeed been completely convinced by the Communist Party - and that the reason we have not criticized it is because there has actually not been much about it that could be criticized.

It is not merely we among the intelligentsia who have been thinking along these lines. Among the masses of workers and farmers whom we view as belonging to the "majority," are there many people who differ from us in this regard? It is simply that in their eyes, "we," that is, the intelligentsia - have become a portion of what constitutes that "majority." Amidst the fanfare of song and dance, untold millions of villagers have marched towards agricultural collectivism, joined People's Communes, and like us from the intelligentsia, have practically fallen over themselves to be first in line to bare their hearts to the Party. After all, how much difference has there been between all this and the complex, dubious, mysterious and subtle psychology that marked those in circles of industry and commerce during the I950s - when with the banging of drums and clanging of gongs, they heralded the partial and later complete nationalization of the PRC's industry and commerce? ${ }^{\text {IO }}$

\subsection{From "Killing a Chicken to Frighten the Monkeys" to "Killing a Monkey to Frighten the Other Monkeys"}

Clearly, under the rule of the Communist Party, the pressure to obey has not actually been wholly invisible. From the very beginning, the Communist Party told people in the frankest terms what it would mean to oppose the Party.

For the time being, let us set aside both the civil war between the Nationalists and the Communists and the Yan'an Rectification Campaign of 1942-44, and instead simply discuss what happened in China after I949. ${ }^{\text {II }}$ Were we to confine ourselves merely to the Land Reform Campaign along with the Campaign to Suppress Counterrevolutionaries during the early I950s, these campaigns already caused an unprecedented amount of political annihilation. ${ }^{\mathrm{I} 2}$ Of course, this was political annihilation because the overwhelming majority of the campaigns' victims had not engaged in any activities related to opposing the new political regime. The victims included a large number of individuals within the intelligentsia, which is the reason Mao Zedong later announced that the Campaign to Suppress Counterrevolutionaries was a hundred times fiercer than the Qin dynasty's late 3rd-Century BCE crackdown known as "burn the books and bury the scholars." ${ }^{\text {I3 }}$ I would term this type of destruction "killing a monkey to scare the chickens" because in theory its victims were a group who were characterized as "enemies" in accor- 
dance with their class background - on the surface, anyway, there was still an externally distinguishable boundary between the victims on the one hand and other people and other intellectuals, on the other. ${ }^{\mathrm{I}}{ }^{\text {Yet }}$ the terrorizing effects it created had no doubt already left a strong impression on the psyche of all types of people. In Yang Jiang's novel Bathing, ${ }^{15}$ we can read about the expressions of embarrassment from a certain number within the intelligentsia when they faced thought remolding - many of them would eagerly beg for mercy or favor from the Communist Party, often not hesitating to insult themselves flagrantly in the process. The overwhelming majority of those who behaved in this way did not do so to climb higher in status, but merely out of the fear of falling down lower. This was because falling down lower was both too terrifying and too easy. From an account of the I950s PRC such as William Huang's novel Wave-washed Sands, ${ }^{16}$ we can understand how quite a few persons' criticisms during the Hundred Flowers year of "speaking out" in I957 were aimed at several earlier political campaigns: the Land Reform, the Suppression of Counterrevolutionaries, "the Three Antis," and "the Five Antis."17

The fact that these critical views were not publicly aired until the "speaking out" campaign of I957 makes it obvious how severe most people's fears had been. Actually, the process itself of the so-called "speaking out" campaign explains the problem very well. In the beginning of this campaign, the response from those urged to speak out was total silence. The regime had to repeatedly mobilize and encourage citizens to come out with criticism of the higher-ups or their policies before a smattering of gutsy or relatively high-status individuals finally started to openly offer such criticism. At that time, the sociologist Fei Xiaotong wrote an article entitled "Early Spring Weather for the Intelligentsia"; this article was said to have elicited a widely sympathetic response from the intelligentsia. ${ }^{18}$ What else could this mean in the thoughts of the intelligentsia other than compared to this "sudden warm spell during winter," the political climate prior to this had simply been a prolonged and severe winter? This occurrence is sufficient to demonstrate how false the claim was that the early-I950s intelligentsia "all along supported" the Party line. This is nothing other than the effect brought about by "killing a chicken to scare the monkeys."

Not long after having "killed a chicken to scare the monkeys," the Communist Party turned directly to the launching of "killing a monkey to scare the other monkeys." ${ }^{19}$ Beginning with the movement to vilify $\mathrm{Hu}$ Feng, this pattern reached its climax during the Anti-rightist campaign of the late 1950 Os. $^{20}$ Starting from this period, any extrinsic standards with which to distinguish between "the People" and "the enemy" were already being lost. It became possible for any person at any time to change overnight from one of "the People" to one of "the enemy." A 
“crime" connected with one's political status would be blown up out of all proportion into a "thought crime." Moreover, there was not anything in the way of decent legal procedure; being convicted of a crime was in general an extremely arbitrary and extremely willful process. Yet the cruelty of the punishments imposed by the CCP greatly exceeded what citizens had expected at the outset. Thereupon, terror became the only unchanging backdrop on the political stage. One could also say that such terror was the thought-remolding campaign's most basic constituent unit.

\subsection{A Monistic System of Value Standards: Concepts and Structure}

On a nationwide scale, the Communist Party began to construct a monistic system of value standards. This system includes two aspects: an exclusivist ideological framework and a social structure with a high degree of totalitarianism. These two aspects have complemented one another. Marxism was held up as the only correct school of thought, while among other schools of thought there was none that escaped denunciation; and the government became the sole boss of the entire populace nationwide, not proclaiming "those who do not work will not be fed," but rather "those who do not obey will not be fed." What has been supporting the monistic system of value standards behind the scenes is nothing other than violence.

If there were no violence, then there would not be any "dictatorship of the proletariat," either; and as for the monistic system of value standards, even if it were not to collapse at once, at least it would not be able to remain in control of everything. Of course, the rulers could have their own set of ideological theories, and they could naturally also criticize all types of ideological theories of which they disapproved. However, when we turn to the existing Communist Party, the implication of what it terms "to criticize" is actually "to forbid" and "to suppress" and it is only in these processes of forbidding and suppression that have brought about ideological uniformity within the entire realm. The government became the only boss, but if it did not control other people's search for their own livelihood, it would not be able to exert its control over all aspects of a person's fate, either. In particular, the "individual entrepreneurs" who have emerged in the PRC since the death of Mao have indeed not received their employment from the government.

Mao Zedong's parable stating that "the hair would have no place on which it could attach itself if the skin were no longer present" demands that the intelligentsia remain dependent upon the new regime. In actuality, the intelligentsia's mode of existence has always embodied a rela- 
tively large degree of independence. Even in ancient China, the intelligentsia could often exist outside the direct control of the government. Except for those individuals who entered the court as officials or who accepted a post within the government's cultural bureaucracy, the intelligentsia of China's imperial past could at least run a private school or work in a private academy, or could also make a living by selling their belles lettres or their paintings. The famous Song dynasty lyricist Liu Yong, who did not succeed in his attempts to win a government post through the civil service examinations, put the matter quite clearly: "It is not that I seek wealth and honor from others, but that others need to seek out my writings." ${ }^{\text {2I }}$ Liu's words are replete with the sense of selfsatisfaction he expressed.

The truly frightening feature of the system of public ownership does not reside in its monopolizing function, but rather in the violence through which it maintains its monopoly. After the June Fourth crackdown in I989, a large number of democracy activists were dismissed from their government jobs, but their ensuing fate was far better on the whole than that suffered by their counterparts punished with similar severity during the Anti-rightist Campaign of 1957-58 and the subsequent Cultural Revolution. This was because whatever the case might be, they could still engage in business and work as an entrepreneur. In the final analysis, these developments simply indicate that the present communist regime is no longer forbidding individuals from seeking out their own livelihood. In this respect, the Communist Party, as before, cannot match the emperors of China's imperial past. There is no harm in speculating that if these members of the intelligentsia who have had their "iron rice bowls" knocked away could run private schools or operate private academies, even if the content of what they taught was forbidden by decree to contain anything that would amount to "plotting rebellion or being at odds with their superiors," how could such circumstances actually be handled by the authorities?

\subsection{Why Was Remolding Aimed at the Intelligentsia?}

Quite a lot of persons have said in the way of criticism that because the Communist Party looks askance at the intelligentsia, the intelligentsia's social position in China has been extremely low. This is an inaccurate formulation of a correct criticism, yet this kind of inaccuracy has more or less reflected people's lack of a thorough understanding of the actual significance of the monistic system of value standards. Therefore, the matter requires further discussion at this juncture.

Back during the election-related activities at Beijing University in I980, my classmate Yang Baikui put forward the view that "the intelli- 
gentsia is the most advanced social force." Later, there were others who put forward the view that instead of being ranked down at the "old number nine" position in the social hierarchy, the intelligentsia should be considered the cream at the top of society. These views severely assailed the Communist Party, and especially Mao Zedong's absurd notion of belittling the intelligentsia, and on this account were worthy of commendation. Strictly speaking, however, these views were also inappropriate in some areas.

First of all, within a society the rank apportioned to the intelligentsia is not actually determined for the most part by the level of importance it holds in the alignment of values within the mind of the rulers. Unless the rulers are capable of creating this sort of social structure, and thereby are able to cause those types of individuals whom they dislike to be placed in an inferior position - or unless they are capable of using power to suppress those people's dissatisfaction and their expression of it - otherwise, the mere personal likes and dislikes of the rulers do not actually hold much significance. Second, within a truly liberal democratic society, all types of people can develop their own comparative advantages, and it is very difficult to say which sort of person is especially important or unimportant. What we must discard is the entire set of absurd habits of politically determining that a certain group of persons should be ranked at a particular level - not merely to change the existing order of ranking.

In actuality, in China the plight of the intelligentsia does not really have much to do with their ranking within the theory of officialdom. When all is said and done, the epithet of "stinking number nine" has never appeared within the official circulars of the Chinese Communist Party. To be sure, workers as well as farmers of middle- and lowerincome levels have all along been ranked ahead of the intelligentsia, but have the lot of those groups really been a cut above other people? If we speak in terms of these vainglorious titles such as the "working class" and "poor and middle farmers," perhaps this could still bring some miniscule advantage to the children of those so described. However, this minor advantage would have significance merely in comparison with the children of those in the "five black categories" and "stinking number nine" (i.e. intelligentsia) when faced with a small number of opportunities of advancement in admissions to school, cadre promotions, or joining the Communist Youth League or Party. ${ }^{22}$ Within the vast majority of circumstances under which the great majority of workers and farmers exist, official titles such as "vanguard class" and "reliable force" amount to nothing more than empty talk. At times, the actual situation has been precisely the opposite. For example, in the past there have only been cases within the intelligentsia of those who "committed errors" and were thereby demoted to become workers or 
farmers; there have never been any cases of workers or farmers who "committed errors" and were thereby punished by being assigned tasks normally handled by the intelligentsia.

Generally speaking, among ordinary workers and especially among ordinary farmers, it is obvious that their lot has certainly not been superior to that of the intelligentsia. The CCP saying, "no infraction is weighty for a wielder of the hoe," does not mean that farmers are politically safe, but merely that due to the fact that the autocrats have a shortage of methods of punishment for farmers - you have no way of sending farmers further "down to manual labor" than they already are, unless you imprison them in a labor camp. We know that after Liu Shaoqi was toppled from his official post, he suffered the misfortune of being refused his request to return to his old village and resume farming. Of course, that incident nonetheless does not indicate that the social status of high-level Communist Party officials is generally lower than that of farmers. Just as in political power struggles, the losers are mostly Communist party leaders, because they have more political power than other people enjoy; similarly, in ideological struggles, the losers are mostly from the intelligentsia, because they have more in the way of conceptual thought than other people do.

The Communist Party autocracy is an autocracy over concepts. Because of this, various different types of concepts - especially the spirit of independent thought that gives rise to various types of concepts constitute a natural enemy that has the wherewithal to basically bring about the collapse of this kind of autocracy. In truth, autocrats suspect all thinkers and regard them with hostility. If we were to say that autocrats are indeed more suspicious of the relatively well-educated person, that is because they consider that it is easier for this type of person to form independent views. And if we were to say that autocrats always place an emphasis on work units that are "thronged with the intelligentsia" during political campaigns such as the one opposing liberalization, that is because these work units more easily become places where different types of thought are formed and disseminated. There is nothing more to it than this.

\subsection{The Bifurcated Essence of Thought Remolding}

In his novel Nineteen Eighty-four, George Orwell discusses "doublethink." What he means by "double-think" is the ability of a person at one and the same moment to hold in mind and accept two mutually opposed beliefs. Orwell pointed out that the process of establishing double-think "must be a conscious effort; otherwise, when it is put into practice, it will be insufficient in its correctness. Yet it must also be sub- 
conscious, for otherwise it would bring in the sense of a sort of hypocrisy, and for this very reason give rise to feelings of guilt." ${ }^{23}$

The process of thought remolding is also precisely such a process of establishing double-think. It also consists of a bifurcated essence of simultaneously conscious and subconscious thought among remoldees who show initiative at the same time as exhibiting passivity. Were it not for all sorts of tangible and intangible external pressure coming from the Party, it would have been impossible for a large-scale thoughtremolding movement to have occurred. However, if those remoldees on the receiving end of the process had not shown any initiative, it would not have been possible for this movement to have yielded any actual results, either. To put the matter simply, thought remolding itself is nothing other than taking the initiative to accept remolding in a passive manner. In that case, where does this initiative of ours come from?

\subsection{The Coercion of Truth}

This issue touches upon the problem of truth. Rationality pursues truth, but in truth there exists coercion. People in general consider truth to be objective, as with the earth being round and theft being bad. Even if someone were not to acknowledge these as being true, they would still be true. Because of this, if you were not to acknowledge these as being true, you would be wrong, and you would be doing something that should not be done. Truth contains an absolutist component, and thereby contains exclusivity and coercion. Wherever there is truth, there is an absence of liberty. At most, liberty exists only prior to truth having been discovered.

What is referred to here as liberty is merely hesitation. Yet according to Engels, hesitation is based on ignorance. Marxism acknowledges that mankind is forever in need of liberty, because mankind forever needs to discover new truths, including the revision of errors and the casting aside of falsehoods. But this is all that liberty does. The problem is that once truth becomes established, various other types of views and concepts should then be abandoned, and liberty no longer has any space in which to exist. People often say that one should "serve truth" or "surrender to truth," and in doing so make reference to this kind of coercive situation or this situation that is lacking in liberty.

If the above-mentioned reasoning were valid, then the Communist Party's practice of thought remolding would be quite sensible, at least according to principle. Since the Communist Party considers its own philosophy to be the truth, the Party then naturally demands that other people accept its set of principles and reject all manner of other types of mistaken ideas. From the standpoint of the remoldee who is the ob- 
ject of this process, perhaps the philosophy of the Communist Party is something that you do not understand, or else that you have doubts about, or that you even oppose; that is to say, you possibly disapprove of the specific content of thought remolding, but it seems that you have no reason to deny the general logic of thought remolding. This sort of reasoning has caused many persons to accept thought remolding in principle.

\subsection{The Utility of Truth}

Truth contains utility. The utility of truth has further strengthened the logical force of thought remolding.

As was previously mentioned, in accordance with the idea of the coercion of truth, so-called freedom of thought is nothing other than a manifestation of chaotic thought - and is merely a stage that a person must go through prior to the realization of truth. In thinking of the utility of truth, and in contemplating that the goal of people's discovery of truth consists of solving practical problems, then this stage that must be gone through is not necessarily a superfluous matter. Since our forebears have already discovered truth, then it is sufficient that we as their descendants need only take delivery of this ready-made truth and put it into practice. What necessity would there be for descendants to have to duplicate another round of that lengthy process in which their forebears discovered truth?

The Communist Party believes that it has already grasped truth, and is concerned above all with how to make people accept the principles of this truth as quickly as possible. To this end, there would not be much of anything improper about drawing on the power of the regime to forcibly instill this truth throughout society. This is even more the case, the Communist Party believes, on account of the fact that over the past several centuries, people in general - including that most advanced of social classes, the industrial proletariat working class itself - could never on its own produce the correct weltanschauung. Because of this, to spread Marxism by "immersing them in it from the outside" (in Lenin's words) was not only acceptable, but was even necessary. Otherwise, it would be no different from allowing people to be reduced to the state of victims of various types of traditional prejudices of the exploiting classes.

Simply put, if you acknowledge that the goal of humankind's activities in the area of thought is merely to discover truth, then you have already belittled free discussion as a sort of method, even if it is a type of method that cannot be dispensed with. If in proceeding to the next step you acknowledge that the discovery of truth in and of itself is still 
not your goal, and that the goal of discovering truth is merely to utilize truth to solve actual problems, then you will have further belittled free discussion to the level at which it is the method of a method. In this way, the standing of freedom would become less and less important. Consequently, you would feel even less disgusted by the aggressiveness of thought remolding.

\subsection{The Class Nature of Truth and the Problem of Standpoint}

The Communist Party emphasizes the class-based nature of truth. At first glance, this kind of viewpoint varies considerably from the everyday common sense of people in general - people usually consider truth to be universal in nature, though in actuality this is not necessarily the case.

An old proverb states: "Both contesting parties claim to be in the right." 24 People early on discovered that because of the complexity of life as it is actually lived, different persons often make different appraisals of the same thing, because of being situated within a different social status or due to observing a particular problem from different perspectives. In other words, people discovered early on that amongst various types of interests and desires, there possibly existed conflicts for whose resolution no way could be found. With respect to this view that truth had a class-based nature, it arose precisely from this type of conflict.

Originally, it was very easy for an acknowledgment of the class-based nature of truth to lead to the relativism of truth. "Both contesting sides claim that it is a matter of right and wrong," as the saying goes, and thus there is no absolute right or absolute wrong. However, Marxism nonetheless proffers a type of absolutist truth. This sort of absolutism is established upon the foundation of historical determinism. If one were to say that the bourgeois class has bourgeois class interests and bourgeois class truth, and we were to say that the proletarian class has proletarian class interests and proletarian class truth, then on what basis of reasoning could we consider proletarian class interests to be the only correct interests and proletarian truth to be the only correct truth, or could we consider bourgeois class interests and bourgeois class truth to be incorrect? Here, we clearly need an absolute standard that transcends both of the conflicting entities. According to Marxism, that is nothing other than the objective principle of humankind's development. Because the proletariat has embodied the inevitability of humankind's social development, only the interests of the proletariat accord with the interests of humankind's development, and only the truth of the proletariat accords with the truth of humankind's development. 
The class nature of truth extends directly to the so-called problem of standpoint. A correct standpoint achieves the precondition of a correct understanding. According to this sort of theory, if at some point the divergence between two types of views is defined as a conceptual conflict between two classes, then any effort that seeks through free discussion to achieve a conclusion that both sides acknowledge as correct is, in principle, doomed to be unattainable - because the sorts of things that both sides would join together in acknowledging to be correct simply do not exist. In other words, under these sorts of conditions, discussion is not merely a matter of secondary importance, but moreover a matter of no significance whatsoever. Under these circumstances, the action which you need to undertake is not a discussion, but simply to stand on one side and oppose the other side. This, then, in principle has thoroughly negated the freedom of discussion and the freedom of thought. On the basis of these sorts of theories, thought remolding must of course - and only can - depend upon force for its implementation.

\subsection{Beware of "Begging the Question"}

Let us return to the question that was raised at the outset of this chapter. Thought remolding has both its passive and active aspects. The intelligentsia in the broad sense of the word had to agree to accept remolding; aside from coercion forcing its way on them from the outside, there was no getting away from a certain type of internal acceptance on their part as well. In other words, the intelligentsia always had to seek out some justifications that would serve to persuade themselves to accept remolding. These justifications could of course not come from the Communist Party's gaggle of theories themselves. Many articles that discuss thought remolding have committed the error of "begging the question": on the basis of the Communist Party's gaggle of theories about the intelligentsia's need to undergo thought remolding, the writers of the aforementioned articles invariably explain why the broad intelligentsia actively accepted thought remolding. In doing so, these writers took the intelligentsia's acceptance of the Communist Party's theories of thought remolding as an already settled assumption. However, in actuality what we need to explore is precisely this assumption itself. Clearly, for the intelligentsia to have actively accepted thought remolding, those reasons upon which they relied for doing this could have only been certain concepts that they had from the beginning.

As was mentioned above, we consider that a great many members of the intelligentsia believe that truth is objective and absolute, and thereby tacitly considered truth to be coercive in nature. Aside from this, they also all acknowledged the utility of truth. Moreover, they also 
acknowledged that because of having different standpoints, different people would come out with opposite evaluations of the same type of incidents. It was precisely based upon these sorts of commonsensical ideas that they were likely to consider thought remolding to be logically correct and reasonable as long as it was not limited to some sort of special content. However, the Communist Party's huge political success endowed this sort of commonplace logic with special content. Thereupon, the Communist Party's demands with respect to thought remolding received a certain type of active endorsement from much of the intelligentsia.

\subsection{The Ambiguity of Facts}

Thought remolding refers mainly to the alteration of one's political viewpoint. The reason that thought remolding has been possible cannot be separated from certain characteristics of political viewpoints. There would be no harm in our further study at this point of these special characteristics of political viewpoints. Generally speaking, people's political viewpoints involve two types of factors: one involves facts and experience, and the other involves concepts and values. Sometimes, these two factors are sharply differentiated from one another; nevertheless, on even more occasions, the two factors are intertwined.

Let us initially discuss the first type of factor. At first glance, it would seem that people's understanding of knowledge is a straightforward matter, and thus there would be no need to have doubts about what is known. With any matter, if it is there, then it exists; and if it is not there, it does not exist: a deer is precisely a deer, and a horse is precisely a horse. When this involves a matter of fact, the distinction between truth and falsity is crystal clear. The saying that "facts triumph over eloquence" indeed explains the power that "facts" hold. However, the regrettable thing is that this is the case merely with those facts about which we have direct experience. Because the great majority of facts that each of us knows come to us indirectly through being recounted to us by others, there is an extremely strong possibility of our having been deceived on occasion.

There are two major weaknesses in "facts." The first is that facts are not logically self-evident. The second is that there is a lack of solid and reliable logical implications between one fact and another. In Chinese history, there is a legend of the so-called "Candle-light Shadows of an Axe," which recounts the story of how a man named Zhao Guangyi utilizes the pretext of visiting a patient in his sickroom in order to try to kill his elder brother Zhao Kuangyin. ${ }^{25}$ It is not clear at a glance as to 
whether this incident within the story is true or false. This explains how facts are not self-evident.

There is an ancient saying that runs, "a rumor stops spreading when it reaches a person of wisdom." This means that based upon facts that are already known, an intelligent person can utilize inferential reasoning to make a judgment regarding the truth or falsity of a certain matter about which he does not yet know. This clearly magnifies the interrelatedness of facts. We all know that in straightening out other people, Mao Zedong was cruel and merciless, yet merely because of this we cannot directly infer whether Lin Biao's jet actually crashed in an accident or was instead shot down on Mao Zedong's command if we do not have relevant testimony or evidence from other people. ${ }^{26}$ This explains how there is not actually mutual implication in terms of logic between one fact and another. After all, any specific, concrete fact (the two words "specific" and "concrete" are actually superfluous, because all facts are specific and concrete; my having expressed matters in this way was simply to emphasize the specificity and concreteness of facts) is fortuitous, unsystematic and non-deductive.

These two weaknesses of facts lead to an extremely severe consequence, namely that it is possible for a matter which has actually occurred to be distorted, blocked from dissemination, or covered up while on the other hand, a fabricated story can be spread to all four corners of the world. In this way, when on a given day people need to engage in forming a judgment about certain matters that are outside of their direct experience - or based on this judgment, they need to form their own political viewpoints - the situation in which they find themselves can be rather dangerous. For example, if with your own eyes you have seen all of the residents of a village go hungry, yet in the newspapers there has been the wanton propagation of claims that the entire nation is well-clothed and amply fed and that the overall situation of the citizenry's livelihood is excellent nationwide, you would not necessarily be able to discern with complete certainty that those claims were lies. The Communist Party has always emphasized the distinction between the mainstream and minor currents on the one hand, and between nine fingers and one finger on the other. The effect of this has been to make all of us feel deeply apprehensive about the limitations of our own direct experience, and thereby to lose self-confidence in our ability to make judgments about major issues.

There are two points in the Communist Party's authoritarian rule that are unprecedentedly thorough: one is the punishment of people for offenses involving discourse, and the other is in monopolizing the tools for disseminating information. The so-called "discourse" in the punishment of people for offenses involving discourse does not merely refer to the publication of different theoretical views, but also includes the 
discussion of certain facts related to your personal experience - if these facts themselves are not in accord with the line of action in the propaganda of "Party Central." ${ }^{27}$ If you speak up about having witnessed with your own eyes the death of villagers from starvation, it is possible that you will meet with the calamity of imprisonment. The novel Liu Zhidan merely mentioned some stories set in the wartime border region straddling the provinces of Shaanxi, Gansu and Ningxia, yet Mao Zedong proclaimed that this novel was "anti-Party."

As everyone knows, under the authoritarian rule of the Communist Party, frank speaking of the truth often carries a heavy price that the speaker must pay; because of this, we view the daring to speak the truth as an extremely exalted virtue. Of course, this situation reveals a lamentable set of circumstances. However, the complexity of the problem also resides in the way that people who live under autocratic rule do not actually always resemble the officials and populace in the fable, "The Emperor's New Clothes," for they themselves know that they are telling lies.

An even more common situation is that a large majority of people already cannot distinguish clearly between what is true and what is false. Sometimes they even misconstrue truth as falsehood or misperceive falsehoods as truths. This point is clearly even more important than the previous point. After all, in human nature there is a type of strong truth-seeking impulse. If at any time and any place we each realize that we are telling lies, we will be very unhappy and will suffer, and our conscience will continually oppose what we have been doing; we will forever be subject to feelings of shamefulness and wrongdoing. Over the long term, it is impossible to allow ourselves to sink to such a low level of depravity. However, if on a given day we cannot distinguish between truth and lies, the situation becomes very different. Under these sorts of circumstances, it is as if one's conscience has been given a shot of an anesthetic and has become sluggish; we thereupon no longer have strong feelings of self-reproach or guilt, and can then go on with our life in a morally lax way, and sometimes even in a relaxed and happy way. During contemporary times in the wake of June Fourth, ${ }^{28}$ I have heard quite a few people talk of how they mostly approve of the CCP's past achievements, and of how they believe unreservedly in the romanticized legends of the early period of the CCP's struggles; I could not help but acknowledge the CCP's great success in fabricating facts.

With regard to the process of understanding people's opposition to totalitarian rule, generally speaking, it is easier to oppose corrupt officials, but more difficult to oppose the emperor; it is easier to oppose the emperor, but more difficult to oppose the political system; it is easier to oppose the existing political system, but more difficult to throw off the entire ideological setup. Finally - and this is the most dif- 
ficult of all - there is nothing that is more challenging than to overcome their sky-darkening huge net of many types of lies and to reconstruct historical truth.

A number of years ago while another tide of liberalization was beginning to sweep over the former Soviet Union, in its cultural realm there appeared a large group of literary works that delved into the entire seventy-year span of the former Soviet Union's history, including fresh descriptions of Lenin, the Soviet Communist Party's number-one sage (note that these are fresh descriptions and not merely fresh evaluations). There was a fiction writer named Grossman, whose novel The Eternal Flow portrayed Lenin in a wonderfully vivid manner as hankering after power, cruelly killing his political enemies and having an entirely inhuman personal character. The handwritten draft of his novel was completed in 1963, and remained hidden within the writer's drawer for twenty-six years before it could finally be published openly. Clearly, the writer's goal in writing this novel was not at all for the sake of coveting some sort of practical advantage or present-day fame; the writer simply hoped to leave behind a testimonial to posterity. Even in spite of this, it is likely that his readers still harbored reservations about the truthfulness of this novel. Nowadays, people in general have realized that the previous image in our minds of Lenin having been "as pure as crystal" was a sham, but this is not actually tantamount to our having already arrived at a definite and unquestionable knowledge of Lenin's original features. A clear recognition of lies is one matter, while a grasp of truth is a different matter; in a similar fashion, neither of the two can depart from the evidence or experience. Yet "proving falseness" is easier, while "proving truthfulness" is more difficult. There is nothing that surpasses this in connection with the ambiguity of facts.

\subsection{The Ambiguity of Values}

It is not merely facts that are ambiguous. Values are also ambiguous.

Generally speaking, values refer to people's judgments about good versus evil and beauty versus ugliness, or what we call a sense of morality and a sense of aesthetics, respectively. However, the "sense" to which we refer here is a sense of the mind or spirit and not a sense of the sensory organs. We feel that it is evil to murder people and that flowers are beautiful - these are clearly different from the way that we feel candy is sweet and that ice is cold. The latter merely relate to the biological structures of our animal nature, while the former relate to the psychological structures of our human nature.

In two of Kant's books, Critique of Practical Reason and Critique of Judgment, the philosopher separately undertakes research on moral 
judgment and on aesthetic judgment. ${ }^{29} \mathrm{He}$ put forward a categorical moral imperative: "I must behave in this way in order to be capable of achieving my will to have the standard of my behavior become a universal rule." The meaning of this categorical imperative greatly resembles the ancient maxim: "Do not do unto others that which you would not want done unto yourself." 30

Undoubtedly, the categorical imperative's function in political thought is extremely significant. However, according to the analysis of Hannah Arendt, Kant's views about aesthetic judgment are even more insightful..$^{\mathrm{I}}$ In contrast to the widely held viewpoint that merely regards aesthetic judgment as purely an individual matter and simply a matter of taste, Kant considered aesthetic judgment in essence to be a type of public competence. First, among everything that you consider to be beautiful, you would certainly believe that other people would also similarly consider it to be beautiful. Furthermore, it is only under the circumstances of being in the company of other people, even if they are merely companions within your imagination, that you are able to have the wherewithal to achieve a judgment that a certain thing is beautiful. In other words, it is impossible for you to achieve a clear aesthetic judgment from within a condition of total isolation. An aesthetic perception is subjective, yet it is not arbitrary; it is not purely an individual perception, but instead is something that is jointly possessed with others. It is precisely in this area where value judgments in aesthetics greatly resemble value judgments in political thought.

Regardless of whether or not we accept Arendt's analysis in its entirety, we should at least acknowledge that our firm belief in values embodies the following two aspects: first, for everything that we consider to be good, we believe that other people would also agree that it is good; and second, oftentimes it is only through interchange with other people that we are able to firmly establish our own judgments. A proverb states: "There is nothing to debate over the question of what piques someone's taste." ${ }^{2}$ I feel that celery is delicious, while you feel that it is bitter; I would not argue with you about this, as we would be unable to debate such a matter. I could not claim that only my tastes were correct, while your tastes were incorrect. I do not crave in the least that there must be some sort of unanimity on this issue.

Another proverb states that "facts triumph over eloquence"; take a situation in which I claim that objects of the same shape and size fall at the same speed when dropped, while you claim that heavier objects fall faster, compared with lighter objects that fall more slowly. There is no need for us to debate the issue; we need only to perform an experiment in order to resolve the matter. I believe that I am correct and that you are wrong; even if you do not admit that I am correct (for example, were you to suspect that I had performed an underhanded trick with 
the experiment), I would still remain entirely firm in my own convictions.

However, if Xi Shi believed herself to be beautiful while others considered her ugly, this would be a different matter altogether. ${ }^{33}$ First, at the same time Xi Shi believed herself to be beautiful, she also believed that other people would all consider her to be beautiful. If there were some people who considered her ugly, she would then believe that those other people were "wrong." This scenario is different from the above-mentioned question about whether celery is delicious or bitter: beauty demands universal recognition. Second, however, people have been unable to find a means of surveying and testing to prove whether or not Xi Shi was beautiful. Again, this is a somewhat different situation from people's knowledge about the physical world. If Xi Shi had grown up from an early age in a wild and remote region, she would have had no inkling as to whether she was beautiful or not. Furthermore, if all of the people living around her in her home town had claimed that Xi Shi was ugly, it would have been very difficult or wellnigh impossible even for her to believe in her own mind that she was beautiful.

Political matters are similar to this. Upon encountering a political matter, our minds produce a special type of feeling: as to whether this matter is good or bad, benevolent or malevolent, we believe that other people should also harbor the same kind of feelings that we ourselves have about it. Even though this type of feeling can independently arise, were the person with this feeling not to have interactions with other people and receive a sympathetic response from other people, then the feeling could merely be a dim and vague one. If I were to discover that my feeling was not in accord with other people's feeling about this political matter, it would be impossible for me to ignore this kind of discord in the same way in which I handled the issue of purely what piques my taste (or interest). I would inevitably seek out accord, but I would not be able to find a type of objective method of surveying and testing, as was the case with determining the laws of falling objects. My only recourse would be a public airing of the debate. However, this kind of debate would not actually be blindly based on logical inference (even though it could embody logical inferences to a large extent). It would be impossible for me to come up with a type of logic that would force my opponent to admit he was wrong.

In the end, I would only be able to air the dispute before the mind of my adversary through a series of analyses and explanations, in the expectation that the mind of my adversary would then produce the same effect as had earlier occurred in my own mind. Unless I were to obtain approval from other people, it would otherwise be very difficult for me to develop confidence in my own judgments. When Galileo was 
forced by pressure from the Church to abandon his heliocentric theory, he went on to comment: "Nevertheless, when all is said and done, it [Earth] is what is revolving!" 34 That is to say, under the circumstances of the entire world expressing its opposition, a lone person could still maintain firm confidence in his own judgment about a certain area of knowledge. It is a very different matter in the area of value judgments, where if all people oppose your point of view, you easily slip into selfrejection, or at least into self-doubt. A person's sense of right versus wrong and sense of good versus evil ordinarily should be self-evident. However, it is only under the circumstances of having interchange with other people and receiving their sympathetic response that this type of sense or feeling can be both clarified and confirmed; otherwise, the feeling would be ambiguous, and thus actually incapable of being selfevident.

\subsection{Conformity}

The reasons why thought remolding has been possible cannot be separated from certain characteristics and habits that it shares with the human mind such as conformity, consistency and the belief that the world is just.

Let us first discuss conformity. People in general like to maintain a degree of uniformity in their speech and bearing with the people around them - whether friends, colleagues, peer group members or even strangers. As an ancient saying puts it: "In entering another state, one inquires about its prohibitions; upon entering a different region, one inquires about its customs; when entering another household, one inquires about its taboos." The human being is a social animal and lives amidst various types of social relations. Maintaining a degree of uniformity with other people helps lubricate social relations, and makes it possible to bring a person various kinds of convenience; to behave otherwise is likely to cause all sorts of trouble. Each social group within society usually has its own set of rules and patterns of speech and behavior; this constitutes a type of group pressure on any person who hopes to be accepted by the particular social group. What is referred to as conformity is nothing other than a person's striving to align his speech and behavior with everybody else in response to sensing the pressure of group expectations.

One can make a distinction between two types of conformity. One type of conformity is internalized, while the other type is externally submissive. When in your own mind you believe that the norms of a certain social group are correct or normal and thereby adopt them, this is called internalized conformity. When you adopt that set of group norms 
merely in your external speech and behavior but in your own mind hold dissenting views, this is called externally submissive conformity. The majority of externally submissive conformists are situated somewhere in between the two poles of externalized and internalized conformity.

Under many circumstances, the reason that we accept the norms of a certain social group is neither due to our unshaking belief in the norms, nor is it on account of going against our convictions in order to submit to those norms. In fact, on many issues we are often lacking in any clear view that really belongs to us in a fundamental way. We merely go along with the flow, hankering after convenience and tending to repeat what others have said - nothing more. We do not actually consider that "the masses" are necessarily wise, but we believe that standing together with the masses would never be so problematic as to lead us into great error. Moreover, even if the sky were to fall, leaders with stature would be the only ones tall enough to feel the impact, and I would not be singled out to suffer such misfortune. Of course, this is not to say that none of us would have an aspiration to uphold our own views; the problem lies in that we often are unable to form our own opinions. This is so because in order to form our own views, we often need to draw support from other people in free interchange. If other people are all unanimous in their views, it is very difficult for us to develop confidence in our own dissenting viewpoints.

Clearly, the strength of conformity in a society bears a close relationship with its political and cultural environment. The more autocratic a society is - sealed off from external influences as well as monolithic the more difficult it is for the people within the society to form their own independent opinions, and the more onerous a price there is to pay for upholding an opinion that goes against normal practices. Conformity within the entire society is thus strengthened even more.

Some conceptions will intensify conformity. One such conception is that of determinism, and another is the worship of the People. If you believe that various events that occur in real life are determined by fate or are objectively inevitable, and remain unchanged by individual will or individual preference, then you have become accustomed to consciously readjusting yourself, to making yourself adapt both to society and to reality, and to abandoning those inappropriate views that you originally had. Among the currents of Western thought that entered China in the late Igth century, the most influential was Social Darwinism: in any struggle amongst things, Heaven chooses the victorious; the better ones prevail, while the worse ones are defeated; this is the survival of the fittest. ${ }^{35}$ Afterwards, all sorts of later variations on the same theme of historical determinism came into fashion for a time, including Marxism's economic materialism, or the five-stage theory of humankind's historical development. ${ }^{36}$ Even within the Chinese schools 
of thought that advocated freedom and democracy could be found individuals who would raise the big banner of historical determinism in order to boost their own morale: "Those who move along in tandem with the vast currents of history prosper, while others who go against those currents perish." After I949, the idea of historical determinism advanced a step further to become China's controlling ideology. The Chinese Communist Party has referred to itself as the embodiment of the laws of history, and thereby views all of the Party's actions as an objective inevitability. According to the above theory, people's utterances and other actions are not based on their individual judgment of what is good versus bad or right versus wrong, but instead are based on their so-called grasp of the current situation and trend.

There are a few aspects worth noting about the conception of the worship of the People. This conception derives partly from the strain of thought in ancient China that the common people are the root or foundation of the society, and partly from early modern Russian populism. A third source of the conception is from a misunderstanding of what democracy is. This type of misunderstanding of democracy does not view the submission to the will of the majority as necessary, but instead makes democracy directly equivalent to the submission to truth. The democratic concept of the majority has become a personification of truth and a personification of justice. The theory of historical materialism has prettified the mindset of following the latest trend and submitting to authority, the conception of the worship of the People has prettified the psychology of catering to the majority. When the two have been combined together, they have caused conformity to become further intensified.

It is also possible that fiercely anti-traditionalist currents of thought in modern China have led to the strengthening of conformity. At first glance, it would seem as though the situation should be the opposite. Since anti-traditionalism means to break through previous models of thought, it should encourage the spirit of independent thinking. Facts, too, have borne this out. Widely known as being opposed to tradition, the May Fourth Movement in I9I9 is clear proof of this, having initiated a phase in which various modes of sexual liberation and a wide range of new currents of thought came to pass. ${ }^{37}$ However, at the point when anti-traditionalism grew so fierce that it because a total negation of all tradition - the point at which this sort of fierce anti-traditionalism itself became a type of tradition - the situation was precisely reversed and stood on its head. Tocqueville once pointed out that if an individual no longer depends on tradition, he will inevitably observe his neighbors on all four sides in order to seek confirmation of his own judgments. ${ }^{38}$ Therefore, the refusal to accept time-honored opinions along with haste in deferring to the opinions of one's peers constituted two sides of the 
same coin. As to why the May Fourth Movement led to a number of abuses, the reason for it lies within this.

\subsection{Consistency}

Although most people's cognitive behavior does not actually possess consistency, consistency is still an important characteristic of the human mind. At the point where people realize that their own cognitive behavior contains self-contradictory aspects, they will often feel uneasy, and moreover will strive to change this in order to make their cognition preserve its harmony and sameness. We know that one of the forces in debate and theory is the force of logic. If we have proven that Proposition A logically implies Proposition B and logically opposes Proposition $\mathrm{C}$, then a person who at the outset had merely accepted Proposition A would sense that there was a type of force that was compelling him also to accept Proposition B and to reject Proposition C as matters of necessity; this would remain the case even if his attitude toward Propositions $\mathrm{B}$ and $\mathrm{C}$ was originally the exact opposite of the way he had now been compelled to view them. What needs to be pointed out is that the ability of the ordinary person to think logically is often quite limited, and thus the result of the person's process of logical deduction will often be the generation of errors. For example, Proposition A does not actually imply Proposition D, but an erroneous logical deduction nevertheless causes you to mistakenly believe that the two of them are in a relationship of logical implication; therefore, since you have accepted the premises of Proposition A, you have also accepted Proposition D.

The human mind's pursuit of consistency has brought about the functioning of theoretical systems. What is known as a theoretical system refers to nothing other than the logical structure of a large group of concepts. The world's phenomena are too complex; it is impossible for us to establish our own viewpoint from the ground up when encountering each phenomenon. Matters often proceed in exactly the reverse order. Frequently, we first have a viewpoint and then proceed to impose our viewpoint onto external things. The function of theory lies in the way it offers us a series of models and frameworks for observing and thinking about objects. A theoretical system may well be likened to a map. It omits many of the concrete features of the object of inquiry, causing us to focus our attention upon a minority of its features - just a few essential factors. By following a theory, we can more conveniently find the direction and goal of our activity. At the point when we accept a certain type of theoretical system, our subsequent observations and thinking become a series of inferences, one after another. If we discover that contradictions appear between our "inferences" on the one hand 
and our feelings and experience on the other, we do not often make adjustments to our inferences on the basis of our experience. Instead, we will often make adjustments to our experience on the basis of our inferences. This is because making adjustments to our inferences is even more difficult than making adjustments to our experience. In making adjustments to inferences, one slight move can affect the whole train of thought and would involve making adjustments to the entire theoretical system. As long as we do not yet possess the knowledge and resolve to make adjustments to the entire theoretical system, we will be forced by the pressure of consistency into preferring to make our experience fit into a Procrustean bed. ${ }^{39}$

The human mind's pursuit of consistency is also expressed in the force of promises. Zhang Third would marry Li Fourth out of his desire to live together with her. Later on, even though this type of desire had declined a great deal, he would still diligently hold their marital relations together. At the outset, a person makes a promise on the basis of desire; later on, he standardizes his desire on the basis of a promise. This is what is referred to as "loyalty." At the very beginning, what we call "loyalty" is perhaps merely a type of thinking or emotional state - it is a sort of enthusiasm that is freely and openly given. Yet what makes loyalty true loyalty lies in the way it is also the expression of a type of determination; loyalty has the meaning of exercising self-restraint on one's emotions and thought. Generally speaking, what we refer to as "reputation" has the same meaning as well. In commerce, for example, owing to calculations of mutual benefit, the two parties to a business agreement set up and ratify a contract; yet afterwards, a certain party to the contract discovers that handling matters according to the contract will bring his side a loss in profits - but he still adheres to the contract. A contractual agreement is a type of thing that is based on individual material gain, and yet also transcends individual material gain.

The analysis laid out above indicates that proceeding from this tendency of the human mind to strive for consistency, an individual can literally be in opposition to the inclinations of the self. Due to the logical force of a theoretical system, it is possible for us to actively abandon or change certain views of our own. Owing to the force of promises, it is also possible for us to consciously suppress or negate various feelings and desires of our own.

\subsection{The Belief that the World is Just}

We often wax emotional, sighing that the ways of the world are unjust. This explains that we know the real world is not necessarily a realm of justice. On the other hand, however, many people actually hold a very 
deeply rooted conviction: they believe that the real world is indeed a realm of justice. Here, all uses of the phrase "the real world is" at the same time should also be understood as "the real world should be."

A certain Mr. X lost a relative in a fatal automobile crash. Out of an excess of sorrow, he could not prevent himself from asking a question: "Heavens! What sin, after all, did I commit in order to meet up with this retribution?" Do not misconstrue this sort of question as mere nonsense from the mouth of a simpleton - amongst some people who are very brainy and knowledgeable, similarly pointed questions have at least flashed through their minds, if not having actually been spoken aloud. A person strives to understand the world, which is to say that he strives to view the world as an interrelated and unitary entity that is complete unto itself.

Humanity's rational faculty finds it difficult to accept the idea of a world that operates on the basis of sheer contingency and chance. In actuality, the human being is an animal marked by a sense of justice; he often cannot help but project his sense of justice onto his image of the world. Through this projection of the sense of justice, the myriad things of the world are not only related to one another through physical cause and effect, but are also related to one another through moral cause and effect. If you plant melon seeds you will harvest melons, and if you plant bean seeds you will harvest beans. Good deeds shall be rewarded with good effects and evil deeds with evil effects. Under the domination of this sort of belief, if a person encounters misfortune, the first thing he is likely to do is to criticize himself, suspecting that he himself has committed some sort of transgression. If he truly cannot come up with any transgression that he has committed, he will investigate his misfortune itself, and in one way or another find a kind of positive significance to ascribe to his misfortune, thereby proving that the misfortune is not actually a misfortune. This is because he believes that if a given person should receive something, then he will in fact receive that thing; and that if a person has received something, then he should have received that thing. Sheer injustice, like sheer chance, is inconceivable and would be decidedly difficult to accept.

A belief that the world is just leads people to adopt an attitude of meekly enduring hardship in the face of misfortune and calamities. Meekly enduring hardship and submitting to thought remolding have some quite similar features. If you wish to meekly endure hardship, then you must change a number of your original views. For example, you must view your innocence as guilt and perceive the destructiveness aimed in your direction as a test of your mettle. Since you have ascertained that it would be impossible for your misfortune to have been unjust, it is precisely because of this that it should be changed, and thus 
the only thing there is for you to do is to change yourself, and to change your own attitude towards misfortune.

This standpoint is somewhat different from that of fatalistic thought. A person who embraces fatalistic thought will also meekly submit to an adverse situation because he believes that this has been ordained by fate and cannot be avoided. Yet this does not actually prevent him from maintaining a critical view of his adverse situation at the same time that he is submitting to it. Nor does this prevent him from firmly believing in his own uprightness and innocence at the same time that he accepts fate's blows. People who believe that the world is just are different, because they diligently endeavor to make an adverse situation seem reasonable, and they cannot help but turn around and negate themselves with this or that type of method. Therefore, the belief that the world is just is even more similar to thought remolding.

\subsection{Pursuing Meaning in Life}

Among all the world's creatures, the human being is perhaps the only animal that is not satisfied with "living for the sake of living." In other words, humans possess an intense desire to pursue the meaning of life. An ancient Jewish proverb states: "If I did not act on my own behalf, then who would? If I were to act only on my own behalf, then who would I be?" This means that if a person merely resembles an animal in living only for himself, then he has no way of establishing a self, thereby losing the human's meaning of existence as a self. Because of this, a person needs to have something to pursue. A person needs to have some type of goal and some sort of values that can be pursued beyond the scope of his existence at the level of a mere animal, and thereby receive an affirmation of the self and attain meaning in life. Therefore, a person needs to enter society and enter public life. Through his own expressions and activities, and by way of testimony from others in his own group, he needs to receive other people's criticisms, and to make himself leave his own mark behind in other people's minds, and thereby achieve a sense of self. Otherwise, he will sense the emptiness of existence, and sense that he himself has "lived his life in vain."

As Sartre actually said, in order for a person to create himself, he must design an "existence" for himself. ${ }^{\circ}$ However, this does not at all mean that any matter at all would be equally efficacious in imparting meaning to life. With respect to this point, the meaning in life is not, or is not solely, something that is created by us - it is also something that is discovered by us. Moreover, achieving the self does not merely mean to make myself become one or another type of person; it more 
importantly means to make myself become the type of person I should wind up being.

A widespread problem that people in modern times face is unfolded in the following. On the one hand, for a person to live as a human being, he cannot depend merely on instinctual impulses to determine what he ought to do. On the other hand, because traditions have been weakened from the huge pounding they have encountered in modern times, he cannot merely depend on tradition to determine what he should do. Because of this, many people know less and less about what they themselves ought to do. Under these circumstances, it is especially easy for people in general to be forced to take part in the ideology that is popular in society at a given time. Even if his views were originally at variance with this ideology, as long as this ideology occupied a controlling position or even a monopolistic position within society, it would be very possible that he would cast to one side his own distinct views and diligently make his way into the new ideology. 


\section{How Has Thought Remolding Been Implemented?}

\section{1 "With Machine Guns Pinning You Down on Three Sides, You're Allowed to Head off in Only One Direction"}

According to The Encyclopedia of Human Behavior, brainwashing is defined as "a set of intensified propaganda techniques implemented under the circumstances of exerting pressure on someone." ${ }^{\text {I }}$ Here, "exerting pressure" is a totally essential precondition. Just as I explained in Section 2.8, were it not for all sorts of tangible and intangible external pressure coming from the Chinese Communist Party (CCP), it would have been impossible for a large-scale thought-remolding campaign to have occurred.

During the political campaign to "peacefully remold industry and commerce," the CCP put forward the following slogan: "With machine guns pinning you down on three sides, you're allowed to head off in only one direction." ${ }^{2}$ In fact, the CCP adopted the same kind of strategy in their campaign to remold the thought of the intelligentsia. (In Section 2.4-2.6, I have already explained the various types of pressure wielded by the CCP.) The intelligentsia en masse discovered that unless they accepted the CCP's ideology and remolded themselves accordingly, they would have no other way out of their quandary. This situation differed substantially from what happened during a change of the ruling imperial dynasty in Chinese history. In the case of a dynastic change, people merely needed to shift their loyalty to a new political regime, that is, to the new dynasty. Other than that, they could pretty much continue to do what they had already been doing in the other aspects of their life. In contrast, the CCP revolution was a huge, earth-shaking change. In order to adapt yourself to the New Era, you had to make a full-scale adjustment. Seen from this perspective, the reason most of the intelligentsia expressed a willingness to accept thought remolding in the early I950s was not so much their having been inspired by the "new truth" as their merely having sensed society's cataclysmic change and exerted themselves mightily to adjust to this sort of change.

A thin volume published in Beijing in April I950, How My Thought Has Been Transformed [Wode sixiang shi zenyang zhuanbian guolaide], collected the essays written by a group of well-known figures within the 
intelligentsia, including Pei Wenzhong, Zhang Zhizhong, Luo Changpei, Xiao Qian, Li Ziying, Feng Youlan and Xie Fengwo. ${ }^{3}$ Some of the narration in these essays could be quite revealing as to the state of mind of the intelligentsia at the thought-remolding campaign's outset.

Feng Youlan's essay provides an example: "Before Beijing was liberated, I had long prepared not to leave Beijing, but instead to wait for the change to take place. While I had decided not to leave, I did not read more of the CCP's books and documents in order to prepare my thinking for the change, either. In retrospect, this was very odd. Of course, this was a problem caused by a mentality that was unwilling to change." 4

Li Ziying said: "The great New Era had arrived. I wanted to get to know it, to welcome it, and to devise ways of adapting to it. Since I felt that I was inefficient in my studies, I was willing to thoroughly remold myself." 5

Taken literally, these two paragraphs seem far from logical. Since you originally did not want to change, why is it that as soon as the political change arrived, your orientation shifted to a stance of willingness to change? When the "New Era" first arrived, you could not yet even know whether you would be satisfied with it. Why is it that you were determined from the very beginning that you would adapt to it and thoroughly remold yourself? Unless this is because this "New Era" had absolutely no respect for your wishes and would not permit you to raise any objections - and since you had no way to change it into something that suited you, and you could not even preserve your original sense of self while accepting it - therefore, the only way left for you was to change yourself in order to pander to it. This is the true answer to the question.

In a more recent essay, "My Mother's Suicide - a Case Study," ${ }^{6}$ Zhou Duo recounted the experiences of his mother, Yang Jushu. ${ }^{7}$ Yang Jushu was intelligent, capable, highly educated and staunchly dedicated to her profession. In the early I950s, she and her whole family moved back to China from overseas. Originally, she hoped to give full play to her talent in the "New Society." Contrary to her expectation, due to her status of being "the wife of a bourgeois professor" as well as her life story of having formerly been a GMD member for a spell, Yang could not find any suitable job after returning to China. ${ }^{8}$ After muddling through a period of disappointment, Yang suddenly became extremely "revolutionary," going so far as to immerse herself in Mao Zedong's ideology and becoming spellbound by it, obsessively striving to qualify for CCP membership.

At first glance, this kind of immense change in thought, ideology, emotion and standpoint is difficult for us to understand. However, if you consider the matter carefully, the reason for it was actually quite 
simple. In part by nature and partly due to having received everyone's praise during her younger days, Yang Jushu had been eager to do well and get ahead of other people in everything. She thus naturally expected that she could display her talent in the "New Society" just as she had in the past and once again garner everybody's praise. However, she soon discovered that the "New Society" observed an entirely different set of evaluative standards. In the "New Society," Party members were the only persons to receive high honors, and only those who were regarded as politically "advanced" could be appointed to important posts. The sorts of personal qualities that Yang possessed and originally took pride in were no longer appreciated by the "New Society" - nor were there any opportunities for her aspirations and ambitions to be put to good use. After all, Yang Jushu was not of philosophical bent and could not have possibly mustered the sort of firm self-confidence exhibited by the ancient Chinese poet who proudly proclaimed: "Everyone else in the world is drunk; I alone am sober." 9 This is why she would desperately transform herself in order to adapt to a set of new standards.

We should say that Yang's transformation in her thinking was quite representative of the intelligentsia during that period. The CCP had been boasting all along that a person would have a bright future only if taking care to toe the Party line. Since the CCP grasped all of the authority by which to dispense rewards and punishments throughout the whole society, what room was left for any more objections to be raised? This is by no means a self-evident truth; instead, this is merely a nexus of self-validation.

In the sections below, various propaganda techniques will come under discussion.

\subsection{Mobilizing Others to Receive Instruction}

The first step in thought remolding is usually political instruction or "study." As an object of thought remolding, you receive instruction in Marxist theory, ${ }^{\text {IO }}$ in the Selected Works of Mao Zedong, ${ }^{\text {II }}$ from high officials' speeches, from documents sent down from the CCP's Central Committee, from the regime's historical tracts, in the meritorious deeds of heroes anointed by the regime, and so on.

In Chinese, the word for "study," xuexi, can have two meanings. The first meaning is to "get to know, to understand, to become familiar with and to do research on a topic." The second meaning is to "receive instruction" or "receive admonition." In the context of the first meaning, the learner does not adopt a predetermined position vis-à-vis the object of study: he does not firmly believe in advance that the object he will study is an incontestable truth, nor does he firmly maintain that the ob- 
ject or the other party is more brilliant than he. The second meaning is exactly contrary to the first meaning in this regard. In the CCP's vocabulary, "study" basically refers to the second meaning of "receiving study" or "receiving admonition."

This is why some high-ranking members of the intelligentsia were bothered by the word "study" each time they heard it directed at them during the early I950s, when the thought-remolding campaign had just begun throughout China. They remarked: “'Study' is normally limited to students. We are already professors... Even if you still want us to 'study,' you would need to put it in terms of 'doing research' [yanjiu] instead."

The CCP handled this sort of complaint in the following manner. On the one hand, the Party repeatedly reiterated how very advanced and correct its collection of theories were. On the other hand, the Party repeated the time-honored proverb about how a person must "keep learning as long as you live, no matter how old." ${ }^{\prime 2}$ You might be unwilling to hastily accept the CCP's former argument, yet you would find it difficult to reject their latter argument. Furthermore, the study campaigns promoted from above by the CCP had always been mass campaigns. If the broad masses of the people - all the farmers and workers, plus CCP members and cadres - had to participate in "study," how could the intelligentsia very well stay aloof from it? If you were to refuse to participate in "study," would this not make you look arrogant, thereby arousing others' disgust with you? Although in most "study" campaigns the CCP never explicitly proclaimed that "study" was coercive or that whoever refused to "study" would be punished, you could not help but sense an immense pressure to go along with it, since the CCP has had all the power and the "study" campaigns had so much strength and impetus. Hence, unless you had long been explicitly objecting to the CCP's ideology and dared to publicly express resistance, in nine cases out of ten you would participate in the "study" campaigns.

We must not underestimate the significance inherent in the very action of participating in "study," since without this first step of remolding, we would have no way of discussing all the other actions to follow. The first step is at once an extremely shrewd enticement and a rather mild coercion. At this point, the pressure to remold is invisible, the reason for it seems honorable and its demands are simple. However, it is precisely this first step that causes you to enter into a process that you would have not necessarily been willing to embark upon previously. By taking this step, you would have already made yourself submit to the other side. Even though this type of submission is still minor and seems to have derived more from your own willingness than from external compulsion, your entry into the process of remolding is not completely voluntary after all, as it contains a small amount of com- 
pelled submission. What is important here is that the first step begins to establish an imbalanced situation. As the saying goes: "Everything is difficult at the outset." ${ }^{\text {I3 }}$ For example, if the first thing someone says to you is to ask for a loan of ten dollars, you very likely would reject the request. Yet if he is only borrowing one dollar from you, you would likely agree to lend it to him. However, simply because this precedent exists, the next time he asks you to lend him ten dollars, you would find it relatively difficult to reject his request. The reason is that to reject him on the second occasion goes against the precedent you have set - your willingness to lend money to him - which was created by your action on the first occasion.

As mentioned above, when mobilizing everybody to participate in political "study," the Party adopted two sets of argument by mingling them. This can be compared to adding food coloring to a beverage. When you drink the beverage, you also imbibe the food coloring that has been mixed into it. Perhaps it was merely on the basis of understanding and researching the Party's regimen of "study" that you took part in the latter. However, the very action of your participation in "study," at least from its outward appearance, indicates that you responded to the Party's call, and thereby accepted the Party's arguments in their entirety. You appear to have already acknowledged the Party's superior standing as an instructor, as well as the correctness of the Party's ideology. The fact that everybody participated in "study" could not but give people a strong impression: the Party's teachings enjoyed the support of the masses, and the Party's call struck roots in the hearts of people. You would thereupon discover that even though you had some reservations about political study at the outset, these reservations were gradually dissolved in the wake of your participation in the campaign together with numerous other people.

\section{3 "First Impressions are the Strongest" and "Once You Form a Habit, Following it Comes Naturally"}

Participating in political study would also trigger a series of other effects. If you had neither biases nor pre-established opinions because you originally "did not understand and were not familiar with" Marxism, and if you basically had not subscribed to any complete system of social thought at the outset, then Marxism would have been the very first body of social theory that you would have encountered. ${ }^{\text {I4 }}$ According to the principle, "first impressions are the strongest," it would be very easy for you to accept this body of theory. ${ }^{15}$ In addition, assuming Marxism is the only body of theory that you would have encountered (the CCP's political study is of a closed nature and does not allow you to 
hear other types of voices), this body of theory would then possess the huge advantage of its monopolizing quality. In light of the combination of these two points, you can well imagine this body of theory's captivating effect on the human mind.

Furthermore, the CCP drummed up political study into a mass campaign and mobilized numerous people to engage in political study. As we know, the less training in theoretical thinking a person has, the more easily he would accept the doctrines that have been drilled into him. This then created the situation that could be characterized by the metaphor, "a city surrounded by farming villages": ${ }^{\mathrm{I} 6}$ a small number of people capable of high-level analytical and theoretical thinking are now caught within a powerful ambience of oversimplification, vulgarization, and a doctrinaire mindset. As the folk proverb puts it: "Even if a scholar has right on his side, he can't reason with a soldier." ${ }^{17}$ Take, for example, the criticism leveled at the theory of "two combining into one" in those days. ${ }^{\text {I8 }}$ Initially, the criticism of this theory's proponents was limited to what were referred to as academic circles. However overbearing, dogmatic and imperious the critics might be, they would still have to implement the procedures of philosophical exposition and proof. In any case, the person being criticized would still have the opportunity to defend himself by quoting from authoritative works and undertaking meticulous analyses. Yet once the campaign of "the broad masses of workers, farmers and soldiers to indignantly denounce the absurd argument of 'two combining into one' " got underway, what else could the person being denounced say in his defense? ${ }^{\text {I9 }}$

As indicated by various historical sources, during the initial stage of the launching of the campaign for political study, there was not a lack of objections to this campaign from within the intelligentsia. In How My Thought Has Been Transformed, Pei Wenzhong wrote: "Some people thought that if my study arose out of my own initiative, then I was being opportunistic; still others thought that if my study was not voluntary, then it was a humiliation for me." Pei added: "Seeing me attending meetings, some people criticized me as an overzealous and staunch 'sedan-chair bearer.' "20 We can see from the above passages that at that time there were still some members of the intelligentsia who resisted the so-called political study campaigns to some extent - owing partly to an educated person's self-respect, and due in part to disgust with individuals who play up to the powerful. As has been widely known, even up to the I960s and I970s, we could still hear some people sarcastically refer to those who actively participated in political study as "fake activists." At that time, however, such criticism had increasingly become something that could not be voiced in public, and thus it could not resist that powerful trend. 
The broad-ranging, deep and continuous study campaigns exerted a profound impact on people's minds. No matter whether you had undertaken a stint of independent pondering about it, and no matter whether you had sincerely accepted it, a direct effect of the political study campaign is that it ushered people into its own discourse system and its allencompassing, self-enclosed conceptual labyrinth.

Once a voice has been constantly ringing in your ears too long, it gradually becomes your own voice. I have a friend who loves to sing. During the era when revolutionary songs were being sung by everybody each day, he strongly disliked those popular revolutionary songs. He much preferred to sing folk songs from China's past, as well as foreign songs from the Soviet Union and other places abroad. However, he told me that many times when he was alone and mindlessly humming a song, he would suddenly realize that the song he had just been humming happened to be one of the popular revolutionary songs that he heartily disliked. What can be done about this? He was even someone who self-consciously boycotted revolutionary songs. There is no need even to mention the effect that such repetitive indoctrination has on the rest of the populace.

As we all know, when it comes to inventing a set of neologisms with a unique style, Mao Zedong was naturally the champion in this area, and Lin Biao must be counted as having come in a close second. After the eruption of the I3 September (I97I) Incident, Lin Biao's set of neologisms was banished in its entirety to a forbidden zone. ${ }^{2 \mathrm{I}}$ Nevertheless, within a period of time that would not be considered short, a number of Lin Biao's neologisms still appeared from time to time in many people's speeches and writings, so much so that those people working in propaganda organs had to carefully seek out those neologisms and excise them. This illustrates how powerful the habit formed through repeating certain words and deeds can be.

In fact, in those days when one campaign of political study followed on the heels of another, and thought remolding was in full swing, each of us was speaking and thinking according to that body of popular conceptual jargon; the words and sentences we generated were permeated with that ideology's formulaic patterns. The official system of discourse not only controlled our entire sphere of public life, but also occupied the realm of our private life. It would suffice to cite just one example. During that period in history, when a person wanted to ask a new acquaintance if the latter had a prospective spouse or had gotten married, he would often ask: "Have you solved your personal problem?" Were we to check our diaries and daily conversations dating from that period, not to mention those formal speeches and essays, we would surely discover that all of our vocabulary and ways of speaking were so uniform, formulaic and rigidly stereotypical that even we ourselves now 
find it hard to believe. Indeed, all the way up to the present day, even the statements that staunch dissidents blurt out still often consist of that bygone array of neologisms, sentence patterns and style. What really matters is that thought and language are inseparable. How a person speaks is related to how he thinks.

\subsection{The Power of Oversimplification}

In order to intensify the force of political study, the CCP spared no effort in oversimplifying the content of political study.

Liu Qingfeng wrote:

From I949 to the Cultural Revolution, we could see such a process in which canonical texts were continuously being oversimplified. $^{22}$ "Studying Marxist-Leninist classics" later became "studying selections of Mao Zedong's works." Subsequently, everyone had to "study Mao Zedong Thought by putting it into practice immediately," and the process further turned into "studying and memorizing quotations from Chairman Mao," and finally it even became "obeying the most recent directives from the Commander-in-chief." ${ }^{23}$

In fact, from the very beginning, the CCP never advocated that people study the Marxist-Leninist classics. During the early I950s, while the CCP was implementing the policy of "leaning to one side," Soviet-style Marxism was important in political study. ${ }^{24}$ The major content of study contained such canonical works as the History of Soviet (Bolshevist) Communism, which was compiled in response to Stalin's "imperial edict." 25 Stalin could already count as a master of oversimplification, yet Mao Zedong surpassed even his Soviet master. Therefore, the process of canonical texts being continuously oversimplified, as described by Liu Qingfeng, was indeed in existence.

According to Liu Qingfeng's analysis, the oversimplification of canonical texts resulted from nothing other than the combination of Confucian-style authoritarian orthodoxy and modern-style authoritarian rule. Mao Zedong is not only the supervising teacher, but also the military commander. Mao's speeches and writings are not merely theory and thought; they are also directives and orders. As I pointed out above in Section I.I2, the goal of political study and thought remolding is certainly not to transform everyone into Marxists; instead, it is to create contingents of absolutely obedient troops who have internalized the imperatives of "let's do exactly what Chairman Mao directs us to do" and "let's maintain unity with the Central Committee of the Party." There- 
fore, in the midst of this process, employing one's rational faculties and acquiring knowledge are actually of no importance whatsoever. In other words, the nature of the goal of political study has determined the nature of the content of the study itself.

There is another significant point about oversimplification. The more complicated informational input is, the more difficult it tends to be for the recipient to grasp. In contrast to a complex message, a simplistic message can convey a much stronger impression, thereby more forcefully inducing the recipient to make a direct response. A brilliant commercial advertisement usually obtains its effect by repeating a few simplistic and direct slogans many times. For example, the slogan "any entity divides into two" is simplistic and easy; no one would forget it, even after having read it only once. ${ }^{26}$ The CCP has been extremely adept at coming up with all sorts of simplistic slogans. Even today, all of us who lived through that era can still effortlessly recite from memory a huge pile of slogans. This demonstrates how effective these slogans have been.

Yet another feature of oversimplification is that it can powerfully obstruct the emergence of a critical mentality. Lin Biao once said that when receiving directives from the highest authorities, "we must implement the directives that we comprehend, and we must also implement the directives that we do not understand; our comprehension will be deepened through the very process of implementation." According to this view, comprehension is of greater benefit to the implementation of a directive than is incomprehension, and therefore it would seem that the more sufficiently expounded and the more understandable the directives from the top are, the better. In fact, this is not necessarily the case. The less a viewpoint or demand is explained or proven, the more unquestionable it appears to ordinary people. The speaker's explanation of a viewpoint would make the listeners feel that they were on an equal footing with the speaker, whereas refraining from the explanation of a viewpoint would highlight the authority of the speaker. This is because the former appeals to reason, while the latter expresses the will of authority.

Some scholars in elementary education recommend that when educating one's children, a parent should use imperative sentences more often, while refraining from giving children explanations as to why they should do what the parent advises. Reasoning on one side would stimulate reasoning on the other. The more you explain the reasons behind your actions to other people, the more you stimulate other people to explain the reasons behind their actions to you. The more detailed your explanation is, the more dynamic other people's thinking will be, and the more easily they would find problems in your explanation, argue with you, and deny and reject your viewpoint. 
An analogy for this is that in solving a mathematical problem, the teacher not only provides the solution, but also writes down in detail every step of the process of the calculation or proof. In this situation, if you as the teacher make a mistake in a given step, your students would easily discover it. Conversely, if you give only the problem's solution but not its process of calculation, or if you give a very sketchy process in which one step leaps disjointedly to the next, then even if a student obtains a different solution through his independent calculation, he will not be able to clearly see the reason for the disparity between his solution and the teacher's, since he cannot ascertain exactly at which step his calculation has departed from the teacher's. As a result, the student would not dare to rashly negate what the teacher has said, but would merely doubt himself time and time again.

Let us attempt to compare Mao Zedong's earlier writings with his later ones. On the whole, in Mao's earlier writings there was a relative abundance of explanations for his viewpoints, as well as analysis and argumentation. Moreover, the author's relationship with the reader was one of relative equality at this early stage. Yet the later in Mao Zedong's career that his writings appeared, the more he occupied a commanding position, using force to compel his readers to submit. When he gave speeches in the latter part of his life, Mao was completely unconstrained and his ideas were lacking in logical exposition. His writings also grew shorter and shorter. By the time of the Cultural Revolution, Mao no longer bothered to write fully formed essays. Each of the socalled "directives from the highest level" consisted merely of a phrase or two, and the reader could no longer find any context in which to place these directives. On the one hand, this kind of oversimplification was the result of suppressing opinions that differed from Mao's own. On the other hand, such oversimplification was a major reason why the emergence of different views was prevented.

Since by the time of the Cultural Revolution Mao Zedong enjoyed unchallenged, absolute power, he no longer needed to explain or demonstrate the validity of any of his viewpoints. Yet this sort of unanalyzed and unexplained "directive from the highest level" also impeded the recipient's attempt to employ his own reasoning to analyze and judge such viewpoints. Based on the attitude of "whatever Chairman Mao instructs us to do, we'll follow it to the letter," most people would merely need to earnestly put Mao's directives into practice. What need would there be for them to go to all the trouble of trying to understand his directives?

As for the precious few who insisted on rational thinking, while subjectively they would have very much liked to have understood Mao's words in depth, those quotations from Mao that were in the style of holy precepts were nonetheless supposed to be unthinkingly swallowed 
down whole without the least bit of chewing. So even if this small minority would have liked to have understood these directives from Mao, they would have had a hard time finding any clues or route to an understanding.

Out of wishful thinking and on behalf of the "Great Leader," we thus sallied forth in search of all kinds of evidence, proof and justifications for his directives. Since at that time ordinary people had already confirmed beforehand their positive standpoint in accepting directives from the highest level, just as students tend to assume from the beginning that the answers provided in a textbook must always be correct, such a standpoint thus determined from the very start that our various kinds of analytical thinking would proceed in the direction of working hard to verify the directives as true, and not in the direction of trying to prove them to be false.

The old parable about "suspecting that a neighbor has stolen your axe" tells us that the more you suspect a certain person of thievery, the more that every action you see this person take makes him come across as a thief to you. ${ }^{27}$ Conversely, the more you trust that the Great Leader is wise and correct, the more you would conjure forth numerous reasons to justify his each and every directive. Let us take an obvious example. In December I968, Mao Zedong issued a directive from the highest level: "It is very necessary for educated urban youths to go to agricultural villages and receive reeducation from poor and lower-middle farmers." As soon as this directive was sent down for implementation, many people were extremely puzzled. One asked: "The Cultural Revolution has not yet been triumphantly concluded; why would Chairman Mao want us to be sent down to agricultural villages?" Another queried: "Haven't we already received the baptism of class struggle and become proletarian revolutionary warriors? Why do we still have to receive reeducation?" A third wondered: "Weren't we supposed to take the road of forming a united front with both the workers and the farmers? Why would Chairman Mao now tell us to form a united front with only the farmers?"

The pity is that the Great Leader did not give us any explanation or hints to clear up our various types of puzzlement. Hence, while imagining ourselves to be clever, each of us could merely rack his own brain to seek justifications for the directive on behalf of the Great Leader. Some people thought: "Is this a way to disperse the population due to the need for our country to prepare for war?" Others speculated: "Is this about the Cultural Revolution having reached a new stage, and so the Venerable Leader again has some new strategic deployment in mind?" There were also people who wondered whether the directive aimed at reducing the pressure from problems in urban employment, or else sought to break up the ranks of the students' Rebel Faction and over- 
haul the overall situation; the list of possible motives behind the directive went on and on. If you thought you had found a sufficiently persuasive justification for the directive, then all was well and good. Even if you cudgeled your brains and yet could not find a convincing justification for the directive, you still would not have dared criticize or oppose the directive, because you would not have had the self-confidence to do so.

Oversimplification makes people feel that such a directive is unfathomably profound. This sort of feeling obstructs you from boldly and effectively employing your own rational faculties.

\section{5 "Giving an Injection of a Preventive Inoculation"}

Nevertheless, a human being is an animal that can think, after all. It is impossible for a human being to unthinkingly accept in wholesale fashion a set of theories with which someone else has been imbuing him in the way that a robot would when accepting directives from an external source. A successful incorporation of such a set of theories must take into account the critical faculties that are characteristic of the human mind; hence, there arose a measure that has been called "giving an injection of a preventive inoculation." Mao Zedong discussed the example of vaccinating against smallpox. On many occasions, he directed that cadres must be proficient at utilizing negative examples among both writings and persons that may be held up for denunciation and thus serve as a cautionary lesson to others - thereby helping others to enhance their ability to distinguish between the correct and the false, and among writings to distinguish between "fragrant flowers" and "poisonous weeds." 28

We all know that during a smallpox vaccination, a tiny amount of vaccine is first injected into you so that your own body will later produce antibodies. With regard to ideology, to give an injection of a preventive inoculation means to use the method of making you come into contact with negative or cautionary examples so as to strengthen all of the positive viewpoints and positive standpoints that you originally had. At first glance, you might assume that since this method makes you come into contact with both positive and negative examples, it would thus be fair, as well as conducive to independent thinking. In actuality it is not, because in this context the negative-example materials that have been issued to you have gone through a painstaking and detailed selection process. In addition, what is even more important is that they have been stamped with the label of "negative-example materials" from the very beginning. In my essay "On the Freedom of Speech" I wrote the following: 
If the negative-example materials that they selected to make the masses improve their abilities in discernment have already been stamped with the words, "to be critiqued," then their commendable intention would be practically unattainable. If you read a certain author's work solely for the sake of refuting a viewpoint in it, there will be nothing that you would gain from reading it. This can be likened to watching a movie with a complex plot in the counter-espionage genre. Informing the audience beforehand as to whom the spy is would not in the slightest help enhance the audience's ability to reason and make inferences. The effect would be even worse if, in particular, we are also at the same time arresting those people who express opinions of the negative-example type. To do so is no longer inspiring people to distinguish between which thought is correct and which is incorrect. Instead, proceeding in this fashion is to warn people about what they are allowed to think and say, and about what they are forbidden from thinking or saying. Instead of liberating thought and enhancing cognitive ability, what this does is to demarcate forbidden zones and to stifle the intellect. ${ }^{29}$

Yet it is not entirely correct to say that the effect of "giving an injection of a preventive inoculation" is merely to stifle the intellect. I am not saying here that negative-example materials would foster an oppositional psychology - that is something that would only happen later on. What I would like to say is that if the effect of "giving an injection of a preventive inoculation" is merely to stifle the intellect, then it would be difficult to explain why such "inoculations" would be accepted by rational people. Obviously, we need to explain this in a more nuanced way.

In the process of "giving an injection of a preventive inoculation," you receive the following warning in advance: those viewpoints with which you will come into contact are erroneous and reactionary. However, unless you have already acknowledged the validity of these warnings -that is, the judgment about those views being erroneous and reactionary - the warnings would not be of sufficient effect. Therefore, the CCP has been quite meticulous in its choice of negative-example materials for adoption. The Party would always select a "vaccine" from those materials that had already been regarded as reactionary by people at that time. The earliest negative-example teacher in the Thought Remolding Movement was probably $\mathrm{Hu}$ Shi. ${ }^{30}$ There was no controversy in classifying $\mathrm{Hu}$ Shi as "reactionary," since $\mathrm{Hu}$ Shi was politically anti-communist and left China for Taiwan in I949. Conversely, if from the very beginning the CCP had instead targeted members of the intelligentsia who were reputed to be "progressive" and "revolutionary" (such as "the Four Stalwarts" and "the Three-Family Village"), people would have 
found it difficult to accept the CCP's premises, and the Party's strategy would have not proven effective. ${ }^{3 \mathrm{I}}$

However, "giving an injection of a preventive inoculation" does not amount to a circular argument. It must draw forth a new conclusion from its pre-established premise. Once the CCP confirmed that Hu Shi was a reactionary, it could then draw the conclusion that all facets of $\mathrm{Hu}$ Shi's thought, including his scholarly thought, were also erroneous and reactionary. This new conclusion would then serve as the premise of a subsequent inference. Since all those facets of $\mathrm{Hu}$ Shi's thought were reactionary, then other people with a similar mode of thought such as Zhang Third and Li Fourth were suspected of being reactionary as well. ${ }^{32}$ And since Zhang Third and Li Fourth were reactionary, then every facet of their thought, including the facets of thought that were not similar to $\mathrm{Hu}$ Shi's, also took on a reactionary coloration. When this kind of inference was conducted repeatedly, the yardstick for measuring what counted as being "reactionary" became ever widening in its expanse.

Needless to say, this process of inference and extension is illogical. Yet it utilizes a kind of inertia of the human mind, namely, a sort of shifting of the object that results from the mentality of "love me, love my dog." ${ }^{33}$ In the end, we wound up accepting many things that we had actually not intended to accept in the beginning. From 1949 to the Cultural Revolution, the ideological net was drawn more and more tightly around us, and the extension of what counted as "reactionary" and "counterrevolutionary" became wider and wider. All of these results are the successful outcome of the Party's ingenious employment of its strategy of systematically guiding and luring people forward one step at a time, and pressing them on harder and harder at every stage.

"Giving an injection of a preventive inoculation" not only brings about the effect of stifling the intellect, but can also stimulate a certain sort of invigoration of the intellect. In this context, however, such invigoration of the intellect proceeds to move in a prescribed direction. The Party would proclaim that a certain mode of thought was reactionary and then would inspire us to seek out evidence that would indicate how and why the mode of thought was reactionary. This has nurtured a habit of unidirectional thinking in us.

Later on, as long as the Party would toss a sentence down to us such as "so-and-so's thinking is reactionary," we would automatically exert ourselves to search for all types of arguments and evidence that would prove this conclusion. You cannot but admit that such activity in which people automatically look for evidence to prove the Party's conclusion is also a type of active employment of the intellect, and people can also derive from this activity a sort of enthusiasm and pleasure similar to what they achieve from puzzling something out with their brains. Particularly 
during the initial stages of the Cultural Revolution, there was such a large number of people who hankered after digging out "poisonous weeds." The reason for those people to have done so was not only to exert themselves in showing how politically "revolutionary" they were, but also to display how superior they were in intellect. There were times when we zestfully pointed out that "so-and-so's essay is a big poisonous weed, both anti-Party and anti-socialist." It was not because we harbored thoughts of personal enmity or public indignation about the author, nor because we hated the views expressed by the essay we were denouncing. Instead, it was because we were anxious to make ourselves known as having "abilities of discernment" that were superior to what others had. In retrospect, it is not difficult for people to discover the following absurd paradox: We were stupid, because we wanted to parade our abilities! We were dimwitted, because we were fond of imagining that we were clever.

\subsection{The Hierarchical System of "Study" [xuexi]}

In society under CCP governance, "there are three colors in clothing and five grades of food that are apportioned according to a person's rank." Even in political "study," the participants are ranked within a hierarchy. Under CCP rule, everybody has had to participate in such "study." 34 However, the amount of content incorporated within "study," the scope of the material covered in "study," as well as the priority and sequence of "study," could vary a great deal from one person to another.

Newspapers exemplify this hierarchical pattern. The People's Daily is for anyone and everyone amongst the populace to read, yet Reference News is restricted to cadres of a certain minimum rank, while cadres of an even higher minimum rank can also read the so-called "Upper-level Reference News." Furthermore, in terms of circulars from the Party's Central Committee, some of them are stipulated to be issued to military-region headquarters and provincial government departments; others are to be issued to divisional military headquarters and to district government departments; still others are to be issued to regimental military headquarters and to county government departments; while some others are to be circulated all the way down to ordinary civilians. The issuing of one and the same circular sometimes has to follow the sequence of first sending it to the central government and only later distributing it to local governments, or first sending it to Party members and only later to non-Party members. This sort of arrangement is significant in a number of different ways.

First of all, this type of arrangement embodies differences in rank resulting from the hierarchy of political status. The higher a person's 
political status is, the more information he would obtain, and the faster he would obtain it. Of course, the situation is not always consistent. For example, the status of the intelligentsia was originally lower than that of workers and farmers. However, in accord with the general practices of administrative organization, most of the intelligentsia (including even elementary school teachers and ordinary technicians) has belonged to the category of official "cadres," so in various respects their salary and working conditions have been better than those of ordinary workers and farmers among the masses. This sort of arrangement has naturally infused many people with a sense of superiority. They would regard it as a sort of honor to be able to participate in more political "study," to acquire an earlier understanding of the spirit of Party Central, and to come into contact with more abundant "study" material, in comparison with the ordinary rank and file. These feelings of honor and superiority would thereby further kindle their interest in "study" and enthusiasm for it.

On the one hand, the CCP adopted semi-coercive measures to make everybody participate in "study," so that even those who did not originally wish to take part in "study" felt it would reflect poorly on them if they held back from participation. On the other hand, the CCP apportioned "study" into a number of different rankings and grades, thereby making those who could gain entry into more highly-ranked grades of "study" feel favored by the higher-ups, while making those who could not gain admittance to such privileged circles feel envious.

"Study" has thus been both an obligation and a privilege. Both the strategy of exerting pressure and the tactic of exclusion have been employed. In so doing, the CCP strengthened the forcefulness of "study" from both directions.

There is an additional level of significance in such a hierarchical system of "study." It has created a multi-layered "onion bulb" structure that is a special feature of totalitarian societies. The core of the onion bulb is the leader, while its outer layers are the masses. Whenever members of society belonging to any given layer of the onion bulb look outward toward the onion's skin, they would experience a sense of their own superiority; yet whenever they look inward toward the onion's core, they would feel lacking in self-confidence.

Many individuals within the intelligentsia have had the following experience: When interacting with ordinary workers and farmers, we normally adopted two types of standpoints, or rather, two types of observational perspectives. On the one hand, since we had long been accustomed to theories that extolled the revolutionary and advanced qualities of the social classes of workers along with poor farmers and lowermiddle farmers, we did our utmost to find evidence in real life to confirm this assemblage of theories. If a certain worker or farmer came 
out with a few revolutionary statements, we immediately expressed our great admiration, believing that sure enough, this worker or farmer was indeed revolutionary and advanced. Sure enough, they were our good teachers, and we should have been their primary school pupils. Yet on the other hand, if any of these workers or poor and middle farmers happened to come out with some "backward statements," we would actually not have grown skeptical of that assemblage of theories on this account, nor would we have thereby awakened ourselves to the reality that the Party's voice was actually not the voice of the workers and farmers. Instead, at these moments we would toss to one side our status as "primary school pupils," and, because we felt superior to workers and farmers in terms of knowledge, we would naturally take up the role of an interpreter of the Party's policy. We mistakenly thought that we were operating at a higher theoretical level, but this sense of superiority arose precisely from the fact that within the onion-bulb structure of political knowledge, we in the intelligentsia were closer to the core of the onion bulb than were the ordinary masses.

It was difficult for us to realize how self-contradictory these two perspectives were. The result was that due to our social status being both low and high at the same time, we would conveniently explain away whatever sort of remarks we heard from workers and farmers so that they corresponded to the pre-existing ideological system. At the same time, on occasions when a certain type of skeptical thought arose in our minds, it was difficult for us to muster self-confidence. We did not dare form rash judgments, for we worried that our perspective was not lofty enough, that our grasp of related materials was insufficiently complete, and that we thus could not fathom the situation in its entirety. We always presumed that people located at layers closer to the onion bulb's core than our own layer had more of a right to speak than we had. Bacon once said: "Knowledge is power." 35 To a certain extent, this remark applies even to a communist society. The hierarchical system of "study" has led to an unequal distribution of the resources of political information and knowledge, thereby intensifying people's dependency in their political understanding and judgment on persons who are closer to the core layers inside.

\subsection{An Affective Style of Propaganda}

An affective style of propaganda is a prominent feature of the CCP's inculcation of its ideology among the citizenry. "Political study" in the broad sense of the term not only includes study of abstract and dry theories and regulations, but also encompasses study of various kinds of vivid and concrete affective materials. These affective materials have 
adopted various forms of affective representation such as literature and art. Facts have shown that an affective style of propaganda is often far more effective than simple theories and concepts, for it influences the recipient's emotions and imagination through its fabrication of stories and portrayal of images.

We must admit that when pondering questions and making judgments, many people often depend upon images and their imagination instead of rational analysis or evidence-based argumentation; and they depend upon stories, not theories. In comparison with theories and concepts, the obvious advantage enjoyed by stories and images is that it is easier for the latter to spark people's interest and garner their acceptance. Such stories and images can be directly impressed on a person's consciousness without having to go through a rational thought process first. Once these stories and images have been impressed on a person's consciousness, they can in turn serve as a substitute for that person's rational thought processes and influence his judgment and behavior.

Stories and images have yet another convenient advantage in achieving the desired effects of propaganda: it is more convenient to draw upon stories and images than rational thought processes if your aims are to disregard logic, to present one aspect of a matter as if it were the entire matter, and to engage in hyperbole and exaggeration. For example, the opera entitled The White-haired Girl became well known to practically every PRC household. ${ }^{36}$ Upon any mention of rural landlords, many people would immediately connect this in their mind with Huang Shiren, the evil village landlord character in the opera, and would instantly brim with indignation about rural landlords in general. ${ }^{37}$ Yet if we were to analyze this issue conscientiously, we would find that Huang Shiren's various evil deeds were in fact not necessarily related to his status as a rural landlord. There is actually no reason for us to lump all rural landlords together with Huang Shiren and regard them as all made of exactly the same stuff as Huang. Nevertheless, the sort of "revolutionary literature and art" as exemplified by The White-haired Girl rather successfully achieves this type of illogical extrapolation, so much so that in the end many people would unthinkingly extend their fury at Huang Shiren to include all rural landlords.

This sort of effect obviously cannot be achieved by studying theories alone. Solely on the basis of theory, you cannot prove that all of humankind's virtues are concentrated within the proletariat, while all of humankind's vices are concentrated within the bourgeoisie. However, "revolutionary" literature and art can easily portray the image of a proletarian hero endowed with all of humankind's virtues, as well as the image of a bourgeois villain endowed with all of humankind's vices. The reality of a given situation would originally be complex, yet the "story" 
of it could thoroughly oversimplify the reality and in turn be substituted for the reality.

No wonder Mao Zedong set forth extremely strict decrees on the problems of "eulogizing" versus "exposing” at the Yan'an Forum on Literature and Art - and no wonder the CCP has all along attached great importance to endeavors in literature and art. $^{38}$ The reason is that only through images and stories can the CCP provide vivid explanations for its theories and concepts, and make up for the deficiencies of those theories and concepts, thereby bringing about a more direct and effective control over the human mind. For those of us who grew up in Communist society since childhood, we were already on the receiving end of a huge quantity of stories and images that were provided by the CCP even before we came into contact with the CCP's assemblage of theories and concepts. Even after that assemblage of theories and concepts has already lost its persuasiveness for us, those stories and images might nevertheless still remain in our hearts and continue to maintain a certain type of power to move us.

\subsection{The Controlling Function of Collective Rituals}

Collective rituals provide yet another type of affective approach within the methodology of propaganda. I might as well briefly analyze it at this juncture.

Over two thousand years ago, Aristotle pointed out that a tyrant would typically be fond of assembling the common folk at the public square in front of his palace, so as to display his authority and reinforce the submissive mindset of the common folk. Regardless of their identity as communists or fascists, the totalitarian rulers of our time have all along shown great enthusiasm for orchestrating various types of majestic, stately, dignified and solemn collective rituals. Every Chinese person who has lived in the "New Society" has been left with a strong impression of such rituals: the broad expanse of Tiananmen Square, magnificent parades, seas of flags fluttering in the wind, resounding and magnificent songs, one volley after another of shouted slogans and cheering that reverberates through the skies, along with group calisthenics, choral singing, dances in the formation of the character for "loyalty," mass brandishing aloft of Mao's “Little Red Book" of his sayings, ceremonies in front of a portrait of Mao in which his acolytes "ask the Chairman for instructions in the morning, and report back to him in the evening," camp and field training and marches, mass struggle meetings, mass public trials, mass collective "study" sessions, and so forth. 
The enormous impact exerted by collective ritual on the human mind is obvious. In the book How My Thought Has Been Transformed, more than one writer mentioned this point. The Islamic-studies scholar Li Ziying remarked: "On the anniversary of the Marco Polo Bridge Incident, several hundred thousand people gathered at Tiananmen Square for a mass meeting. This made me experience the power and enthusiasm of the tide-like masses," and this made people "extraordinarily excited." 39 The educator Xie Fengwo said: "The film of the Soviet Union's May Day Military Parade exerted quite an impact on me. For a nationality to be strong, it must certainly be of a highly organized nature. And it is only through collectivism that such an organizational quality can be manifested." He also indicated that at the outset, he "was the most afraid of organizations, for fear of losing his 'freedom' "; but he now understood that within an organization as a member, he "would always be better off than being alone by himself." 40 The sociologist Fei Xiaotong also mentioned how touched he was by the following scene: one evening, he caught site of a column of stevedores who were carrying grain for delivery; carrying lamps as they continued to move forward in the depth of the night, "from afar the workers resembled a row of red stars." ${ }^{\mathrm{I}}$ All of these vignettes were written in I950.

Even up until the current era, half a century after I950, the philosopher and journalist Wang Ruoshui still vividly remembered how deeply moved he was during his participation in the magnificent scene of the grand founding ceremony of the PRC:

On that day (I October I949) I was standing right there in Tiananmen Square. Mao Zedong waved his hand once, and in his Hunanese accent said: "The Chinese people have stood up." The entire country cheered, and the thunderous applause went on for a long time. At that moment, I felt that the Chinese people had indeed stood up. After over a hundred years of striving, our efforts had finally borne fruit. Mao Zedong was indeed a great personage of our time. ${ }^{42}$

The first impression that such a magnificent spectacle of the masses on parade seems to give an observer is to make you keenly aware of the power of both the masses and the assembled collective, and because of this to make you feel how tiny and insignificant the individual is in contrast. However, since you cannot help but realize that this kind of highly unified deployment of personnel results from the subordination of millions of individual wills to one single will, you would be bound to feel that the individual who rules over the myriad common folk possesses an incomparable power to inspire. That is why at the grand founding ceremony, Wang Ruoshui would heave an emotional sigh and proclaim 
that Mao Zedong was a great personage of our time. In other words, instead of saying that this sort of grand spectacle displays the power of the masses, it would be more accurate to say that it displays the leader's power.

Furthermore, although the spectacle of the masses on parade is certainly made up of individual persons, whenever each person joins in with the ranks of the masses and obeys their unified will, making himself but one unit within the broad masses, he has also dissolved his own unique personality. In such a large-scale mass scene, just as each person's face is indistinct and it is difficult to distinguish Zhang Third from Li Fourth, each individual's personality is also blurred. Without any distinctions between people being made, everybody's personality is being channeled into a sweeping picture of the whole. Each person thus becomes a small part within a huge machine, and can be arbitrarily replaced. Facing such a colossal entity that consists of many anonymous people, any spectator would be greatly shaken. If he has harbored views marked by dissent, he would surely feel intensely intimidated by such a scene. He would discover that only by causing himself to merge into that scene as well could he develop a sense of security. This is because at this time, the part of him that was unique had already gone into hiding and been abandoned. Therefore, the main function of mass ritual is to make the individual consciousness dissolve into the sentiment of the group, and to give rise to the illusion that your small individual self is disappearing and being dissolved within the greater self. This kind of experience is no doubt very useful to thought remolding.

\subsection{Criticism and Self-Criticism}

Criticism and self-criticism have been one of the fine work styles of which the CCP is very proud. However, experience has taught us that for the CCP, the so-called criticism and self-criticism actually amount to the following practice: "I criticize you, and you criticize yourself." For the CCP, criticism always refers to a leader criticizing the masses, higher-ups criticizing their subordinates, the top official in command criticizing the number two or the number three in the hierarchy, or the current top leader criticizing his predecessor. If one were to say that there have sometimes been cases in which the masses criticize their leaders (such as during the Cultural Revolution), that would be nothing other than a case in which the masses, responding to the call of the top leader, were criticizing other leaders of lesser rank. In actuality, such cases still belong to the category of higher-ups criticizing their subordinates, or the top official in command criticizing the number two or the number three in the hierarchy. If situations have occasionally occurred 
in which other leaders criticize the highest leader (such as in the criticism of Hua Guofeng during the Third Plenum of the CCP Eleventh Central Committee in December 1978), that would merely indicate that the top leader had become a leader in name only - the real power had already been seized by someone else. ${ }^{43}$

As mentioned above, the prerogative of launching criticism always belongs to the more powerful side. Conversely, self-criticism always falls on the weaker side - on the masses, on subordinates, or on leaders who have lost power. Mao Zedong committed an awful crime by initiating the Great Leap Forward, yet he still refused to issue "an imperial edict accepting personal blame." 44 Nor would Deng Xiaoping ever be willing to admit fault for the June Fourth Incident (I989). Some people have attributed this to Deng Xiaoping's stubbornness, yet if we recall how under Mao Zedong's rule, Deng Xiaoping had repeatedly conducted "in-depth self-criticism" and promised "never to reverse the verdict" on his own case, then we would know that the issue of whether to criticize himself or not has nothing to do with his personality, but has everything to do with power calculations.

Seen from this angle, previous and contemporary CCP leaders have been unable to match the quality of Chinese emperors from imperial times, since a number of those emperors would readily accept advice in the form of criticism from their ministers and other officials. These emperors permitted their high officials to criticize them in public, and occasionally would even acknowledge their mistakes right in front of these officials. However, the difference here is perhaps not so much due to different people as due to different systems. Under the monarchical system, the legitimacy of the ruler's power was based on the assumption that "he who has conquered the world rules the world"; it was derived from the mysterious Mandate of Heaven; and it was considered to be inherited through a blood line or lineage. ${ }^{45}$ The qualitative difference in status between the monarch and his officials had been strictly confirmed in advance. Hence, even if the monarch sometimes openly admitted his own mistakes, he would still remain the ruler.

The system of the CCP is something else altogether. The CCP established its legitimacy as the perennially ruling entity on the premise that only the Party is correct. Theoretically speaking, the reason that a person can enjoy the highest position of power in the land is that he is regarded as the representative of the correct line, the truth incarnate. ${ }^{46}$ Since it began from this premise, the CCP could never admit that it has committed any error; in particular, it could never admit that there is someone else who is more correct than itself. If the CCP were to admit that it committed an error, it would then forfeit the justification for its monopolization of political power. If a certain top leader were to openly admit that someone else was wiser than he himself, since there is no 
longer a clear distinction of status, as was the case between the imperial Chinese monarch on one hand and his officials on the other, the logical conclusion that follows would be to "relinquish one's post to someone better qualified," that is, to let someone else replace oneself. Making a comprehensive survey of CCP history, which of the CCP's highest leaders - from Chen Duxiu, Qu Qiubai, and Li Lisan to Wang Ming, Zhang Wentian, Zhou Enlai, plus Hua Guofeng later on - could continue to hold on to the highest position of power after having admitted his errors? ${ }^{47}$ No wonder that during the Great Airing of Views Campaign in I957 and the Lushan Conference in I959, the clique of highest leaders - headed by the top leader Mao Zedong himself - would be so sensitive and nervous about other people's critical opinions as to insist on slapping its critics with such criminal charges as "usurping the Party leadership" and "seizing state power" - even though at that time the critics themselves may not necessarily have harbored such designs. ${ }^{48}$ Yet in all fairness, if this kind of criticism had been permitted to become public and legal, its consequences would have indeed endangered the ruler's power and status.

There have been times when the CCP regime's errors were so serious and obvious that it would have been impossible to cover them up. At such times, the CCP would then trot out "history" as its scapegoat, claiming that since the socialist revolution was unprecedented and the progress of history would not as a rule be straight and smooth, thus a mistake by the Party was not the Party's responsibility, but was due instead to historical limitations. In a similar fashion, the faults of the leader were not due to the leader's defects, but were instead an inevitable process in the development of human knowledge. While the Party and its leader might occasionally make mistakes, this by no means indicates that at the same time there would be another person or party that was wiser and more correct. Therefore, the Party and its leader have still remained the wisest and most correct, relatively speaking. After the Cultural Revolution, the CCP went on to invent another new set of excuses. It claimed that although the CCP had made mistakes, the Party was itself capable of correcting its own mistakes. Actually, the subtext of this remark is that the Party does not permit other people to correct the Party's own mistakes.

In sum, under the rule of the CCP, criticism has all along been a type of method for those in power to exercise their authority. On the other hand, self-criticism, as a rule, has been a manifestation of the weak and powerless people who are required to obey that sort of authority. Only when we clearly fathom this point can we be considered to have a clear understanding of the true essence of "criticism and self-criticism." 


\subsection{From Prohibition to Renunciation}

Thought remolding has the double nature of being both passive and active (see Section 2.8). This means that it has been necessary for the CCP to combine the two approaches of coercion and persuasion whenever launching one of its thought-remolding campaigns. Ostensibly, the method of criticism and self-criticism belongs to the approach of persuasion. Yet as I indicated in the previous section, at the same time the method of criticism and self-criticism actually contains elements of coercion. To phrase it more precisely, coercion is the basis or context for putting criticism and self-criticism into practice. We might as well analyze this below so as to see how the method of criticism and selfcriticism combines both coercion and persuasion.

According to Mao Zedong's directive, one must adopt the method of criticism and self-criticism in order to solve the problem of internal contradictions among the people, including the problem of thought remolding. However, in actuality, an orchestrated struggle against this or that enemy has always been the precursor to every single large-scale thought remolding campaign. Two examples of such orchestrated campaigns were the denunciation of $\mathrm{Hu}$ Shi in the early I950s and the denunciation of the series of prose essays known as The Three-Family Village and its co-authors at the earliest stage of the Cultural Revolution. ${ }^{49}$ Mao Zedong said: "Once class struggle is grasped, all problems can be solved." The first step in the so-called grasping of class struggle is to grasp the struggle against the enemy of the moment. A slogan that became very popular during the Cultural Revolution went as follows: "A great denunciation breaks new ground." The "great denunciation" mentioned here does not refer to criticism and self-criticism of an internal nature among ordinary people, but instead refers to denunciations of imperialists, revisionists, counterrevolutionaries and class enemies.

The goal of making the struggle against an enemy the precursor is very obvious: it is to set up a cautionary figure as a negative example, and "to execute one person as a warning to a hundred." ${ }^{\circ}$ Every person who has participated in a struggle against the enemy would realize that if he himself were to dare to openly uphold any of the viewpoints of the person being denounced, he would be reduced to the same situation as that of the denounced person. In order to avoid being designated as an enemy of the people, you must change any such viewpoints you may have held.

Without a doubt, this is coercion. It attempts to create an intense feeling of fear in the mind. What I should point out is that this kind of fear is much more widespread than might be assumed at first glance. There is an ancient saying that goes, "accompanying the sovereign is like accompanying a tiger." This saying indicates that under a monar- 
chy, even high-ranking officials (who were precisely the individuals eligible to accompany the monarch) would lack a sense of security.

Under the authoritarian rule of the CCP, fear has been even more widespread. The following example will suffice as proof of this. If on an informal occasion you share your ideas with an elder whom you trust a parent, a teacher, or a leading cadre at your workplace - and you mention that you have a certain opinion that is at odds with the regime's theories or policies, or merely harbor some doubts about those theories or policies, the party to whom you are speaking would often not discuss the matter with you calmly, but in an extremely nervous manner would instead warn you: “These ideas of yours are very dangerous!" We all understand that the word "dangerous" here does not mean that once these ideas of yours were put into practice, they would bring calamity to other people or to society in general; instead, the word "dangerous" means that once these ideas of yours become publicly known, they would bring extremely severe harm to you as an individual. In this situation, it is not that your viewpoint is dangerous because it is wrong, but rather that it is wrong because it is dangerous. It is not because the other party is judging your ideas with the yardstick of right and wrong that he is refuting you; instead, it is out of consideration of your personal interests that he is dissuading you from thinking in that way. Clearly, the reason why people in general reject unorthodox thought is based upon fear above all else - the fear of being punished.

The sense of fear naturally derives from having been coerced. However, the interesting thing is that when fear has intensified to a certain degree, and when coercion has persisted to a certain phase, we often forget about the existence of fear and coercion at a self-conscious level. The human mind is accustomed to pursuing advantage and avoiding disadvantage. Once we realize that a certain idea is strictly forbidden, we will often banish it from our thoughts, ignore it and not think about it anymore. Hence, the coercion that we passively accept combines with the renunciation that we actively initiate. Since out of fear we do not dare set foot in an ideologically forbidden zone, we consequently no longer set foot in such a forbidden zone and thus we no longer feel afraid.

This point has been manifested especially prominently during the years that have passed since the June Fourth tragedy in I989. The June Fourth Massacre gave rise to an intense fear among the Chinese. Out of fear, many people have felt it necessary to detach themselves from politics; once they have detached themselves from politics, they have been unable to sense the existence of oppression any longer, and therefore they themselves have believed that they have been leading a free and unrestrained life. In the present day, if you were to remind them 
that they are actually living under fear, many of them would probably not admit it.

I recall how we believed in Mao Zedong in the past. Our belief did not result from critical thinking; instead, it arose from the fact that we never doubted his ideas. The reason we never doubted his ideas was that we subconsciously knew that doubting Mao's ideas would lead to terrifying consequences. That is to say, because we did not dare to doubt Mao's ideas, we never doubted them, and because we never doubted them, we had no doubts whatsoever. In the end, even we ourselves mistakenly considered that we really believed in Mao one hundred percent.

\subsection{The Transition from Compelled Conduct to Voluntary Conduct}

The goal of unfolding a struggle against enemies is to "execute one person as a warning to a hundred." So far as this point is concerned, for each person whose thinking resembles that of one of the targets of denunciation, his attendance at the struggle session of those denounced individuals may be likened to being escorted to the execution ground together with some death-row prisoners whose time is up. For such a person who is about to witness the execution of the death-row prisoners, a big denunciation meeting is equivalent to "pointing at the monk while hectoring the thief for his bald pate." ${ }^{\text {II }}$ It is self-evident that such struggle sessions exerted intense mental pressure on many attendees. However, when the CCP was organizing struggle sessions, it rarely placed ordinary members of the intelligentsia or run-of-the-mill citizens directly in the defendants' dock. On the contrary, the CCP always summoned us to participate in a chorus of denunciation; it made the vast majority of people join together as collective plaintiffs, serving as joint executioners who together punish "a small handful of enemies." ${ }^{22}$

I recall that during the campaign to denounce $\mathrm{Hu} \mathrm{Shi}$, the CCP once mobilized one of Hu Shi's sons (who resided in Beijing at that time) to participate in denouncing his own father. ${ }^{53}$ When the news spread abroad, as might be expected, some of Hu Shi's friends expressed indignation over his son's act of betrayal, but $\mathrm{Hu}$ Shi pointed out that it was merely the result of the CCP's coercion. Hu Shi further indicated that under CCP rule, people not only enjoyed no freedom of speech, but did not even have the freedom to remain silent. This critical remark indeed hit the nail on the head. However, the problem is a bit more complicated than this.

Let us not assume erroneously that under the above-mentioned circumstances, the Party would brazenly threaten you or openly lure you 
by promising to profit you in various ways. To be sure, the Party holds the immense power of punishing or rewarding a person, and completely controls your fate. However, it is precisely because of this that the Party need not directly issue any threatening words, nor does it need to reveal in explicit terms the personal gains or losses you would incur through toeing or not toeing the Party line. Instead, the Party is happier to adopt a congenial pose, using sincere words of warm encouragement and earnest advice, and to regale you with avowals of the righteous cause of revolution. While in reality you are being compelled to submit to the Party, its pose and strategy actually make you feel as if you were carrying out an awe-inspiringly righteous and magnificent feat that is completely of your own volition.

As a self-taught master of psychology, the CCP not only has a deep understanding of the weaknesses in human nature, but also realizes what a huge role self-esteem plays in resisting external pressure. Therefore, the Party often adopts a circuitous strategy. It does not actually inflict a direct violation of your self-esteem; instead, it diligently offers up various kinds of honorable and dignified excuses so as to enable you to achieve that sort of undignified transformation in a seemingly dignified manner. As suggested by the ancient saying, "if you refuse to drink a toast, you'll have to drink a forfeit"; some of the so-called "toasts" were in fact nothing more than "forfeits" under a cloak of respectability. ${ }^{54}$

Yet the issue does not actually end here.

We know a person's point of view and attitude can influence his conduct. Conversely, a person's conduct can also influence his point of view and attitude. Once people have taken part in struggle against enemies as well as in the denunciation of hostile forces' thought - even if their participation was not entirely voluntary - people would try to find various grounds that would justify their participation, going to great lengths to persuade themselves and force themselves to believe that their conduct was entirely correct. They would thereby earnestly eliminate their original resistance or objections, because people are not willing to get caught in self-contradiction or self-negation. Since people have not been able to calibrate their own conduct to line up with their point of view in advance, they would be very likely to calibrate their own point of view to line up with their conduct after the fact. This is also a typical pattern that combines compelled conduct and voluntary conduct. Consequently, compelled conduct gradually becomes more and more like voluntary conduct.

We might as well explain this point further below. 


\subsection{The Strategy of Violating Dignity}

The famous Chinese playwright Cao Yu visited the U.S. in $1978 . .^{55}$ At a symposium, an American sinologist named Donald Gibbs asked: "Mr. Cao, in your play, Bright Sunny Skies, you criticized the situation in which American missionaries were doing missionary work in China. ${ }^{56}$ May I ask, when you were writing Bright Sunny Skies, did you write it this way out of your own volition or at your government's suggestion?" Cao Yu's face took on a stern expression, and he solemnly insisted: "It's what I wrote myself; it was with my own pen that I wrote it." 57

Upon first hearing this, one would feel that Cao Yu's reply had a truly authoritative ring to it. A creative writer should indeed write down his own thoughts with his own pen - this is what has been called the dignity of a writer. However, the question arising from this is as follows: Over the past several decades, have Chinese writers really been "writing down my thoughts with my own pen"? Based on his personal experience, Cao Yu naturally knew that the quality of the missionary work performed by American missionaries in China - at least with regard to the great majority of these missionaries - was not as awful as what he described in his play. That is why he would defend himself in a rather forced manner, saying: "There would invariably be some scoundrels among the missionaries." For the moment, let us set aside our concern about the phrase, "there would invariably be some scoundrels," which is obviously at odds with the so-called principle of realism in literature - "typical characters in a typical environment."

The major issue at hand lies instead in the fact that without exerting ourselves in the slightest, we can perceive the author's political leanings in each and every act of the play Bright Sunny Skies. I believe that in recent years, even Cao Yu himself would have admitted that Bright Sun$n y$ Skies was not a successful play, and that when writing it he was influenced by the extreme-leftist line prevalent at that time. In fact, one can detect the signs of an obvious extreme-leftist line - if we may utilize this term for the moment - in most, if not all, of the literary works of that time. This is certainly not some secret or whatnot. Did not most writers at that time reiterate how self-consciously they were following the Party line? The crux of the matter is not so much the fact that our writers had spared no effort in writing in accordance with the Party line. Instead, the key issue for this kind of "literature produced by command" lies in how much of the given work emerged from the writer's free will - and how much stemmed either from the Party's intimidation or else from its promises of gain.

Professor Gibbs' question was sharp, and yet was also naïve. He assumed that the relationship between Chinese writers and the CCP regime was about the same as that between the White House press 
secretary and the U.S. president; that the former merely served as the latter's ghost writers; and that it was the latter who directly instructed the former what to write and how to write it. To be sure, the type of slogan represented by "The Three Combinings" had formerly been popular in China: "The leadership provides the guiding principles, the masses generate life experience, and writers produce literature." When Jiang Qing was guiding the composition and revision of Model Operas during the Cultural Revolution, she indeed gave out an earful of advice, and her directives were carried right down to the grass-roots level..$^{8}$ Yet after all, this sort of situation belongs to an extreme. In the great majority of cases, relations between the Party and writers were far more complicated than this.

To state it simply, in implementing its complete control over writers, the CCP adopted a comprehensive set of measures as follows:

- The CCP monopolized all avenues for publication, thereby preempting opportunities for the publication of works that the Party disliked.

- The CCP would in all cases carry out a severe persecution of authors who had written so-called "reactionary" works, as soon as this was discovered.

- The CCP would greatly commend the works of which it was fond and would often bestow extremely handsome rewards of fame and profit on the writers of those works.

- The CCP employed all of its propaganda tools to instill its line and viewpoint throughout the entire society, and explicitly proclaimed that Party ideology would guide all creative activities.

Under such circumstances, when an author would "write with his own pen," he would possibly be speaking insincerely out of fear of punishment - or would possibly be going out of his way to curry favor, owing to his desire to be rewarded. Of course, there was also the possibility of his having spoken sincerely. At this point, we can distinguish between two types of sincere speech. One type of sincere speech reflects firm beliefs that derive from a writer's careful and in-depth ponderings and repeated tempering of his cognitive skills. The other type of sincere speech reflects a writer's complete acceptance of the Party's one-sided statements under the circumstances of lacking any other authoritative statements for making comparisons and distinctions.

For example, during the era of "The Great Leap Forward," many people wrote articles eulogizing "fields that produce ro,००० catties of crops" per mou and steep increases in production that were likened to "satellite launchings." ${ }^{\text {9 }}$ Some of these writers clearly knew that such claims were false, yet they deliberately boasted about such matters. However, an even larger number of writers actually believed that the 
propaganda in the newspapers was true. These two types of "sincere speech" are different in nature, yet it is difficult to make a clear distinction between them; the reason being that in terms of the authors' subjectivity, both types of praise arise from sincerity. As is widely known, the famous philosopher Feng Youlan once wrote quite a few preposterous articles that closely follow the extreme leftist line, and later came under criticism for having done that. Feng Youlan's daughter, Ms. Zong $\mathrm{Pu},{ }^{60}$ defended her father, saying: "Not all of the intelligentsia were in the same situation. Some of the intelligentsia were then serving as high-ranking officials, and thus could see the state of affairs more clearly, whereas those who were not serving in the government could rely only on newspapers and public reports, and could believe only in what was in the newspapers and public reports." ${ }^{\text {"I }}$ What she actually meant by this was that although Feng Youlan had been wrong about what he had said, this was not due to some flaw in his character, but instead owing to a problem with his knowledge - that is, he simply "had the wool pulled over his eyes," as the familiar saying goes. Naturally, this sort of kind of defense is reasonable.

However, if we look more closely into the matter, there are two different varieties of the condition known as "having the wool pulled over one's eyes." In the first variety, a person makes a strenuous effort to understand the complete picture and grasp the reality of a situation, and yet in the end cannot help but commit some errors. In the second variety, at the subjective level a person already lacks a sincere motivation to seek out the truth, and deliberately turns a blind eye to the situation. Of course, making a clear distinction between these two types of "having the wool pulled over one's eyes" is not something that is immediately achievable. In fact, the notion of "having the wool pulled over one's eyes" is itself an intriguing topic. We will include a special section to discuss it later on in this chapter (see Section 3.40 below). For the time being, though, we will bring our discussion of this notion to a close.

Based on the analysis above, we can perceive that under the rule of the CCP, no matter whether we are looking at the writings of an author or at the speech of the average person, discourse contains many types of components. There is consciously false speech, as well as inadvertently false speech; there is truly sincere speech, as well as not so truly sincere speech. The proportion that each component represents varies according to differences in the time and nature of the incident in question.

Let us return to the example of Cao Yu. When Cao Yu announced with a straight face, "It was with my own pen that I wrote it," he was endeavoring to make other people believe that what he wrote during those years was all the sincere truth, even though he now no longer considered it as having been completely correct. In my opinion, this kind of rationalization on his part is rather too lacking in any margin 
for error. The power of the Party was clearly omnipresent, and it was impossible for us either not to sense it at all or else to be totally beyond its influence. The issue at stake is not so much the fact that the power of the Party made each of us distort his own self to a greater or lesser degree. The question that gives us much more food for thought is the following: Why have we stubbornly denied that we encountered some sort of distortion of the self, and subsequently denied the existence of the pressure we were under?

This is precisely the extraordinarily ingenious aspect of the psychology of thought remolding. People generally say that thought remolding negates a person's human dignity. This remark is only half correct, because the other indispensable factor for enabling thought remolding to proceed is that it must utilize a person's human dignity. Others have long since pointed out that you should utilize emotion instead of wasting your energy on destroying emotion; this has all along been a tactic for betraying liberty. The human being is a self-respecting animal that is unwilling to be pushed around by others, as well as being ashamed of making peace under the pressure of a strong enemy. Regrettably, however, the human being is also a very weak animal. It is difficult for a person to remain indifferent to great temptation and frightening pressure. Because of this, when temptation and pressure appear through an indirect fashion and manifest themselves in a covert way, it is even more likely that they can achieve their greatest effect.

Under the conditions existing within this sort of environment, you have selected a certain type of standpoint. Your choice appears to have been made upon your own initiative. However, it is not you who have taken the initiative to select the environment that has influenced and even controlled you, leading you to have made this very choice; instead, the environment has been single-handedly forced upon you by the Party. It was under the circumstances of passivity that you took the initiative to make a choice. In other words, your choice is actually not entirely of your own initiative or volition. In fact, your dignity has already been violated and distorted. Yet owing to your sense of self-respect, you are unwilling to admit this. You would rather have all other people and yourself believe that your choice was completely of your own initiative and fully voluntary. You try your hardest to rationalize your behavior. At the same time, you are also rationalizing that environment.

There is a humorous anecdote about "the secret to soliciting donations." First, you should have a smile on your face; second, you should have a pistol sticking out of your waistband. Of course, you do not pull out and aim your pistol at the other party, since you must not let the other party feel that you are directly threatening him. Instead, with a face wreathed in smiles, you instruct him in the righteousness of the cause. The other party inwardly realizes what sort of unpleasant conse- 
quences would be brought about if he were to refuse to donate some money and, while thinking the better of it - after all, what you just said to him was not completely unreasonable - he subsequently makes a generous donation of money. Since he has already donated money, this person would naturally be unwilling to admit that he had been coerced into it. He would surely emphasize how deeply he was conscious of the righteousness of the cause, how willing he was to do good deeds and make charitable contributions, and how self-conscious and voluntary he was. (Incidentally, this is precisely one of the reasons why - in comparison with "peaceful, rational and non-violent" organizations - those organizations that resort to violence seem even better at garnering the support of the so-called masses, at least in areas "where their great army marches").

\subsection{The Chastity of Those Who Have Lost Their Chastity}

I remember how in I979 and I980, PRC newspapers again launched a discussion about whether truth has a class nature. I was surprised to discover that the leading advocates of the group which argued that truth has no class nature - at that time this view was rather significant for revealing the emancipation of thought ${ }^{62}$ - were mostly the middle-aged philosophers who had received their academic training after the "liberation" in I949; whereas some of the old scholars who used to be called "bourgeois-class academic authorities" instead held fast to the conservative standpoint that truth has a class nature. Afterwards, in private, I sought out the protégé of one of these old scholars to ask for clarification, saying: “Didn't Mr. So-and-so (namely, the protégé's advising professor) argue against the dogma of truth having a class nature back during his younger years? How come he has turned into a staunch defender of this sort of claim?" The protégé replied: "Well, Mr. So-and-so already reversed himself on this issue once in the past; how could he avoid embarrassment if he were to reverse himself on this same issue yet again?"

This is precisely the subtlety of this mindset. The second reversal of oneself on a given issue is even more difficult than the first reversal. This is not merely due to the fact that reversing oneself on an issue, as a general rule, is always difficult. What is more important is that if you reverse yourself on a given issue a second time, other people would then suspect that your first reversal of yourself was insincere, and must have happened as a result of your having succumbed to pressure. In order to maintain your dignity as a scholar or save face (these two phenomena are not actually the same, but unfortunately people often speak of them interchangeably, as if they were identical), you must then 
uphold the position that you adopted when reversing yourself the first time. In those earlier years, the CCP made you twist yourself into a weird posture. In order to deny that you had been twisted in such a way, you must resort to continuing to maintain that same weird posture - as if that awkward stance were your most natural and most comfortable posture.

To carry out thought remolding, the CCP on the one hand adopted various measures such as threats, coercion, rewards and the lure of future gain, while on the other hand, bestowed the remoldee with as much of a certain sort of space as possible in order that he might be able to complete that type of coerced transformation in a relatively dignified manner. Once this type of transformation had been completed, the remoldee would rather self-consciously continue to adhere to it, because he would need to prove to other people that his transformation was not compelled, but instead quite voluntary. This may be likened to Newton's universe, whereby after everything was initially set in motion by God, the myriad things would all then "automatically" move along in accordance with their prescribed trajectories. Under such circumstances, if other people were to try to persuade the remoldee to revert back to his original natural posture, how could he not be impelled to reject such an idea in the sternest and most righteous terms?

As the proverb says, "tying up a woman does not make her your wife." Yet there is also another saying that goes, "if you can abduct a woman by force, why bother with taking the trouble to beg for her hand in marriage?" The chief of a band of mountain outlaws once took a fancy to a civilian girl. After venturing forth to propose marriage with her, he met with rejection. He subsequently abducted the girl by force and took her back with him to his mountain fortress. Throughout the entire day, the chief attended to the girl's every need most cordially, showing her the utmost solicitude. The girl's attitude towards him thereupon changed dramatically for the better, and so the outlaw chief and the girl became man and wife. You might suppose that since the girl had originally been forcefully abducted, would she not have later on tried to escape when such an opportunity arose? Not necessarily. Leaving aside the other factors at play, even the girl herself has not been very willing to "lose her chastity." Precisely because she already lost her chastity once, she would be especially unwilling to lose her chastity again. If she were not to lose her chastity a second time, then she could claim that the first time she lost her chastity was not actually a loss of chastity. If she were to lose her chastity a second time, this would be equivalent to confirming her first loss of chastity. In order to gloss over her first loss of chastity, she would need to preserve her chastity for the sake of that first loss of chastity. This is called "the chastity of those who have lost their chastity." 


\subsection{The Psychology of a Shortage of Rewards}

In 1959, two scholars at Stanford University named Festinger and Carlsmith conducted a famous experiment. They instructed the subjects of their experiment to perform the monotonous and boring task of twisting off bottle corks. After the task was completed, the researchers addressed the experimental subjects, saying: "This is an experiment that studies how an individual's expectations can influence his performance. The next group of subjects is waiting outside to participate in the experiment. We require that you try to persuade them that the work they are about to do during the experiment is interesting and enjoyable. We will later reward you a specified amount for having done this." (Some of the experimental subjects were paid one dollar, while others were paid twenty dollars.) The experimental subjects complied with the researchers' instructions to try to persuade the next group of subjects of this, telling them that the experiment was very interesting - not as boring and monotonous as some others had said. In the end, before the experimental subjects left, they were asked to fill out a questionnaire and indicate if they indeed enjoyed the task of twisting off bottle corks.

Contrary to what most people would have assumed, the subjects who received the smaller reward of one dollar often actually took more initiative and worked harder during the experiment than those who received the larger reward of twenty dollars. When filling out questionnaires afterwards, the group of experimental subjects who received the smaller reward were also often more serious about indicating that they truly enjoyed the task of twisting off bottle corks.

According to Festinger's explanation, it is precisely because the reward they received was too tiny that the experimental subjects who received one dollar were especially unwilling to admit that their behavior resulted from the lure of profit. And thus they were even more inclined to persuade others - after having first persuaded themselves that the task of twisting off bottle corks was indeed very interesting. The subjects who received a substantially larger reward were exactly the opposite: there was no way for them to hide from themselves the fact that their own behavior was merely for the sake of obtaining a lucrative reward; therefore, although they were also capable of telling lies to other people, albeit in a relatively forced manner, in the end they were neither able nor willing to lie to themselves. Festinger and Carlsmith concluded: "In short, when an $S$ was induced, by offer or reward, to say something contrary to his private opinion, this private opinion tended to change so as to correspond more closely with what he had said. The greater the reward offered (beyond what was necessary to elicit the behavior), the smaller the effect was." ${ }^{3} 3$ 
This experiment by Festinger and Carlsmith has been publicly acknowledged as being of pioneering significance in research on social psychology. Yet there have also been a few psychologists who have raised doubts about the two psychologists' conclusions. In fact, it is actually not difficult for us to come up with another type of explanation for the results of the above-mentioned experiment. Since the subjects were told beforehand that they would be participating in an important scientific experiment, the event itself could very well make them feel that the task they were told to perform was quite fascinating. The subjects who received the smaller reward would regard this reward as what they properly earned from doing the work - decidedly not some sort of lure of material gain - and hence would have no misgivings about it. As for the subjects who received the larger reward, they were clearly aware that their work was not worth as much as they had been paid, and thus felt uneasy about having received an undeserved reward; they wondered instead exactly how meaningful the tasks they performed were. This is why the former subjects would write positive evaluations on their questionnaires, while the latter subjects would mostly write negative evaluations.

In all seriousness, Western psychologists face a natural difficulty when conducting this kind of experiment. Because these psychologists do not have the wherewithal to fully control the entire social environment, and because ordinary people are accustomed to regarding their participation in a scientific experiment as a special experience that differs from their ordinary experience of daily life, the results obtained from such an experiment are thus not sufficiently persuasive. By contrast, if we examine the thought-remolding movement conducted by the CCP from the perspective of a scientific experiment, we can see that its conditions were far superior (we only hope these superior conditions will never reappear), and on this account it gave rise to far more persuasive effects.

Based on our analysis in the previous two sections, we can discover that the existence of external pressures (including the two aspects of threats and the lure of gain) is a prerequisite for enabling thought remolding to be implemented; yet only when this kind of pressure emerges in more covert forms will it achieve an optimal effect. If the pressure arises in an overly undisguised and intense manner, it would instead be less effective. As is widely known, thought remolding during the I950s was more moderate than thought remolding during the Cultural Revolution, yet the results of the former were even better than what came of the latter. This is obvious evidence for the argument at hand.

Let us also turn to the example of the educated urban youth who were sent up to the mountains and down to farming villages. ${ }^{64}$ After the end 
of the I960s, the CCP exerted much more public, direct and forceful pressure around the issue of middle-school students going up to the mountains and down to the countryside. However, this type of strong pressure turned out to produce fewer effects in achieving the goal of remolding the thought of youthful members of the intelligentsia.

\subsection{Thought Remolding and the Chinese Cultural Tradition}

To carry out thought remolding, one no doubt needs to have an indepth grasp of social psychology and to be adept at flexibly employing its related techniques. Just as Robert Jay Lifton asked in his book, Thought Reform and the Psychology of Totalism: A Study of "Brainwashing" in China, we might well ask ourselves the following question: Where did the Chinese Communists learn their subtle brainwashing techniques? How did the Chinese Communist leaders become such master psychologists? ${ }^{65}$ Lifton believed that in addition to the Soviet experience, China's traditional political culture also provided a rich cultural inheritance for this. Lifton pointed out that ever since ancient times, the Chinese have developed a series of psychological techniques related to human relationships. No other civilization aside from China's has paid so much attention to the conduct of human relationships. He quoted an American anthropologist's comment: "Chinese culture has developed interpersonal relationships to the level of an exquisite and superb art." ${ }^{66}$

We know that as early as over 2,000 years ago, the book Master Sun's Military Strategy already advanced the principle that "the preferred strategy is to make a psychological attack," and went on to discuss several techniques for carrying out psychological warfare. ${ }^{67}$ In books ranging from the twenty-four Chinese dynastic histories to such political novels as Three Kingdoms and Water Margin, we find numerous vivid accounts of how to utilize the other party's psychology and "prescribe a medicine specific to his illness" so as to achieve your own goal. ${ }^{68}$ In Three Kingdoms, for example, after General Yan Yan is defeated and taken captive, the initial decision is that this general must be decapitated. Yet unable to resist the kind words of persuasion from his captor Zhang Fei, who walks down a staircase in order to untie him, in the end Yan Yan winds up becoming a "general who submits to his captor," transferring his loyalty to the captor who accepted his surrender. Again in Three Kingdoms, Lü Bu cravenly clings to life instead of braving death on the Baimen Tower, and is subsequently put to death under the executioner's sword; in contrast, Zhang Liao faces death unflinchingly, and ends up having his allegiance won over by his captor, Cao Cao. 
Episodes of this type are even more numerous in Water Margin. The outlaw chieftain protagonist Song Jiang typically adopts the following strategy in order to make rich merchants, landed gentry and famous imperial court officials come over to his side and pledge their allegiance to his band of outlaws: under the precondition of having cut off the other party's path of retreat and brought him under the outlaw chieftain's control, Song Jiang would then adopt a posture of respect and even flattery toward the other party, thereby winning him over to join the chieftain's outlaw band. With the support of such combinations of hard and soft tactics, behavior of a clearly intimidating character would be overlain with the dignified appearance of persuasion and encouragement. In other words, actions that were in clear violation of personal dignity could somehow make the party concerned deceive himself into believing that others had "given him enough face," and that it would be an affront if he were to decline their offer.

As we all know, moreover, practically all of those people who had gone through the above-mentioned process and shifted their allegiance would usually express their loyalty and submissiveness from then on. Hong Chengchou, the Ming general who surrendered to the conquering Manchus, would thus never show any disloyalty toward the Qing regime thereafter. On the contrary, the general who eventually started an uprising against the Qing was Wu Sangui, who had previously taken the initiative in shifting his allegiance to the Manchus. This demonstrates how far-reaching the effects of these strategies are.

I do not plan to go into further detail about the relationship between the CCP system of thought remolding and the Chinese tradition of political culture. I am merely pointing out here that there are indeed similarities between the many stratagems adopted by the CCP to carry out thought remolding and the various strategies of launching a psychological attack, as adopted by some of the powerful personages in Chinese history to subdue others and bring them under control.

\subsection{Getting Enmeshed in a Cocoon of One's Own Weaving}

Let us return to the topic of "criticism" (also known as denunciation) and self-criticism.

In a previous section, we explained how the Party causes persons who originally held unorthodox views to transform their standpoint by participating in the denunciation of enemies. What effect would this sort of participation in the denunciation of enemies then have on those persons whose original standpoint was already aligned with that of the Party? In each of the denunciation campaigns in the past, there had always been a group within the intelligentsia - for the most part, a 
group of young people who had been groomed by the Party itself - who sincerely agreed with the Party's standpoint, and took the initiative to throw themselves headlong into the denunciation campaign. At least in the beginning, the sincerity and sense of engagement with which this group participated in a given denunciation campaign were unquestionable, or fundamentally unquestionable. Yet even so, the very action of their participation in a denunciation campaign would have still exerted a momentous influence on their thinking.

First, participation in a denunciation campaign could further intensify your original standpoint. Once such a viewpoint had been publicly expressed, it would become part of your very existence. You would henceforth insist on your standpoint even more stubbornly than you had previously done. This point is very obvious; there is no need for further elaboration.

Second, participation in a denunciation campaign could effectively prevent any dissenting thoughts from arising within your own mind. Because you would be unwilling to negate yourself, you would often subconsciously restrain yourself from engaging in critical thinking. Because you would have repeatedly witnessed the frightening circumstances suffered by persons targeted for denunciation, whenever various doubts would begin to form in your mind, you would immediately associate these doubts with the mistakes already committed by the targets of denunciation, thereby giving rise to intense fear in your mind. Only then would you finally discover that the sharp sword you had helped the Party hang over other people's heads would actually be suspended right above your own head as well.

Third, the Party would keep guiding the denunciation campaign to deeper and deeper levels, extending the targets of denunciation to include those people or viewpoints that you originally sympathized or agreed with. Yet by this time, there would no longer be any way for you to back down from the conflict, owing to the force of your inertia or your previous promises (see Section 2.I6). Hence, you would very likely continue to denounce the targets of the campaign, though no longer with sincerity. A bifurcation would then develop between your inner thinking and your outward behavior. In order to overcome this sort of bifurcation, you would very likely turn around and alter your own mode of thinking in such a way as to accord with your behavior. This is what is called "getting enmeshed in a cocoon of one's own weaving."

"Getting enmeshed in a cocoon of one's own weaving" also means that you would be led into a closed conceptual system; from then on, you would have lost the self-confidence you previously enjoyed both in forming true sense impressions of the external world, as well as in your ability to make independent personal judgments about right versus 
wrong. This may be likened to the parable of "cutting the feet to fit the shoes." ${ }^{69}$ At first, you would trace out the size of the shoes based on the size of your feet, yet later you would put more trust in the size of the shoes than in the size of your own feet. Similarly, you would initially accept the Party's theories due to your own independent judgment of right versus wrong, yet you would later depend upon the Party's theories to appraise your own judgment of right versus wrong. Initially, your logic was that since the Party's theories accorded with your own intentions, you believed that the Party's theories were correct. Later, your logic changed to a sense that since the Party's theories were correct, those viewpoints of yours that do not tally with the Party's theories are wrong.

The process of "getting enmeshed in a cocoon of one's own weaving" discussed above was clearly manifested by the so-called Rebel Faction during the Cultural Revolution. As we know, the reason why many members of the Rebel Faction denounced the "bourgeois-class reactionary line" and defended "Chairman Mao's revolutionary line" is that the former accused them of being counterrevolutionaries, whereas the latter exonerated them. In other words, it was originally because the Rebel Faction personally cared about their legitimate individual rights and interests that they denounced the former and defended the latter. However, many Rebel Faction members soon began to regard the very denunciation of the so-called reactionary line and the very defense of the so-called revolutionary line as their key standard and goal, and for this they voluntarily abandoned and sacrificed a great number of their legitimate rights and interests. So long as any demand came from the Great Leader and was couched in the name of the revolutionary line no matter how much the demand may have run counter to people's own interests and viewpoints - people would still "enthusiastically respond to the call and resolutely implement it." No wonder Festinger offered the following pointed remark: "I sometimes like to summarize all this by saying that [rats and] people come to love things for which they have suffered."70

\subsection{Some "Doctor" Indeed}

Struggles against the Party's enemies were no doubt a common forerunner to thought remolding campaigns, yet what thought remolding mainly referred to, in the end, were problems amongst the people themselves. Mao Zedong described the matter in highfalutin terms:

The purpose of our exposure of a person's mistakes and our denunciation of his faults is just like a doctor's treatment of a 
patient's illness: it is entirely for the sake of rescuing the patient, not to put him to death through rectification. If a patient is suffering from appendicitis, the doctor cuts out his appendix, and the patient's life is thereby saved. As long as any person who has committed errors does not conceal his illness out of fear of having it treated, and does not stubbornly adhere to his mistakes until he is beyond cure, but is instead honest and truly willing to be cured and correct his faults, we would then welcome him, cure his disorder, and make him transform himself into a good comrade. $^{7 \mathrm{I}}$

Up to the present day there have still been quite a few people who have believed that Mao Zedong's many speeches were originally pretty upstanding, at least in theory, yet regrettably these speeches metamorphosed into something else altogether once they were put into practice. For example, the principle "learn from past mistakes to avoid future ones and cure the illness to save the patient" comes across as a beneficial idea at first glance. In practice, however, a watchword like "save the patient" again and again turned into an imperative to "straighten out the patient" and "harm the patient."

However, upon careful analysis of this paragraph by Mao Zedong, we would discover that the problem is not quite so simple. Let us take this metaphor of a doctor treating an illness as an example. When we seek out a doctor to treat our illness, this stems from our own initiative; and when we accept the doctor's proposed method of treatment, this proceeds from our approval of the treatment. Yet in the speech by Mao Zedong, the relationship between our doctor and us is precisely the opposite: when treating illnesses, this "doctor" known as the Chinese Communist Party does not have the slightest need to obtain our prior consent. Here, it is not out of our wishes and request that we let the doctor serve us; instead, the doctor one-sidedly makes the decision, and simply forces us to be manipulated by him at will. In real life, we can refuse a doctor's diagnosis and treatment. In thought remolding, however, we cannot refuse the Party's criticism or so-called "help." In real life, if a person refuses a doctor's treatment, Nature might well punish him (if he is indeed ill), but the doctor would certainly not punish him; however, in thought remolding, if a person were to reject the Party's criticism, the punishment he would thereby incur would come precisely from the very Party that compares itself to a doctor. From this we can clearly see that the method of so-called criticism has never amounted to persuasion, but has been downright coercion from the very beginning.

The Party has claimed that it adopted the method of criticism to solve the problem of contradictions among the people. However, this does not mean that the person who has been selected as a target of denuncia- 
tion can regard himself as one of the "people," and thereby sit back and relax. In fact, once you have been selected to be a target of denunciation, the original status you enjoyed as part of the "people" would then be hanging in mid-air and in an uncertain and dubious situation - you would become something that falls into neither of the two categories of "the people" or "the enemy." If you were to indicate that you accept the Party's criticism, and you were also to obtain the Party's forgiveness, then you could once again transform yourself back into one of "the people"; otherwise, you would likely be designated as an "enemy."

There was a slogan during the Cultural Revolution that goes as follows: "The seriousness of the problem does not matter; what really counts is the attitude." The crux of the matter is what kind of attitude you adopt toward the Party's criticism. Criticism is indeed sort of a refined method, but it is merely the "courteous" portion of the overall process in which one "takes courteous measures before resorting to force." The reason why a denounced person has often adopted an air of having been persuaded by the CCP is that he knows very well what it would mean if he were not to be persuaded by them.

\subsection{Various Methods of Punishment}

One of the CCP's methods to compel the people to accept its theories or its criticism has been to charge any of those who dare to publicly reject its theories or criticism with the crime of being an "enemy," and to adopt dictatorial measures against them. However, the CCP was also well aware that if the only punitive measure at its disposal was the imposing label of criminality known as "class enemy" - while lacking multi-tiered punitive measures - it would be just like a country that has nothing but nuclear bombs and no conventional weaponry at all; this would be extremely inconvenient.

Therefore, the CCP went on to invent an extended series of other punitive measures. In addition to the type of crime that was clearly proclaimed as "contradictions between the enemy and us," there was also the variety of infraction known as "contradictions between the enemy and us that are nonetheless handled just as contradictions among the people" (many "rightists" fell in this sort of category). Aside from the dictatorial measure of remolding through labor (laogai), there was also the dictatorial measure of reeducation through labor (laojiao). Besides those convicts whose labels of criminality were affixed directly by Partystate authorities, there were also convicts "whose labels of criminality were in the hands of the masses." In addition to arresting and sentencing someone, there were also such graded punishments as expelling someone from the Party or the Communist Youth League, sacking a 
public employee, demoting an employee and reducing his salary, and the like. With the aid of the above-mentioned multi-tiered punitive measures, the CCP successfully subjected all members of society to its coercive control.

Even though the CCP wielded these abundantly diverse punitive measures, as far as carrying out the task of thought remolding is concerned, there were still areas beyond their control. First, these measures are obviously of a punitive and coercive nature. This then conflicts with the original theory of thought remolding - according to this theory, thought remolding can rely only on persuasion, and cannot resort to coercion. Furthermore, levying a punishment always requires a just cause. If a person has not committed any noticeable infraction, it would be difficult for you to punish him. In order to resolve this difficulty, the CCP had to create a sort of new methodology that was capable of imposing punishment without any need for inventing a special excuse for it, and to inflict a punishment that was not categorized as "punishment" in so many words. What we ordinarily refer to as "issuing someone tiny shoes" on the whole denotes this type of measure. ${ }^{72}$ The concentrated manifestation of this type of new approach is nothing other than the socalled "downward transfer to the countryside for manual labor."

As a type of punitive measure, the "downward transfer to the countryside for manual labor" is of course not the CCP's invention. What can be called the CCP's invention is that the CCP imparted a sort of non-punitive meaning into the "downward transfer to the countryside for manual labor," thereby turning it into something that everyone regarded as honorable, at least at a superficial level. In formalistic terms, a "downward transfer to the countryside for manual labor" was voluntarily taken up rather than coercive in its basis. Party organizations sent out appeals and issued reports, and everybody wrote out applications and pledges of their own determination. Those applicants who were approved for downward transfers would have bright red rosettes pinned to their chests, and their names would appear on the honor roll; there would be farewell parties at their departure and welcome parties at their destination.

Among those transferring to the countryside, some were indeed sincere idealists; there were also those who were motivated by the belief that "only those who are able to endure extreme hardships can rise above other people," and regarded a "downward transfer to the countryside for manual labor" as a pathway to acquiring a higher official position later on. Yet a large majority of the persons transferred to the countryside were those whom the Party considered to be problematic individuals. This type of person was seldom able to avoid being stuck with a downward transfer, even if he had not taken the initiative to sign up for it. At the end of 1968, Mao Zedong issued his newest directive calling 
on educated urban youth to go down to agricultural villages. Beginning at that point, all urban middle-school graduates were gotten rid of completely through these downward transfers to the countryside. After they had been transferred, however, some of them managed to subsequently leave the countryside under a pretext such as recruitment as a factory worker, enlistment in the military, promotion to an official post as a cadre, or enrollment in a school. Of course, we could not claim that a "downward transfer to the countryside for manual labor" was entirely punitive in nature. Nevertheless, it could indeed give full play to a broad range of punitive effects through a vehicle that left no traces of punishment behind.

\subsection{A Remarkable Effect of the "Downward Transfer to the Countryside for Manual Labor"}

Though not categorized as a punishment in name, the "downward transfer to the countryside for manual labor" embodied the reality of punishment. This characteristic allowed it to manifest an even more remarkable effect than those clearly delineated punishments. On the one hand, when adopting this measure of downward transfers, the Party could enjoy an even freer hand in doing whatever it pleased, and decide with ever more flexibility to punish anyone whom it wished to chastise. On the other hand, those who had been transferred down to the countryside were utterly mystified, as if they had gotten lost in a thick fog and had a difficult time identifying the contours of their actual situation.

This was different from other forms of punishment that were clearly spelled out. Take being sentenced to remolding through labor, for example. Although Party rhetoric made remolding through labor seem as though it was something that would help you or even rescue you, in the end it was hardly a glorious or dignified matter; at most, remolding through labor amounted to atonement for a crime, a sort of turning over a new leaf.

A "downward transfer to the countryside for manual labor" was quite different. Many of those who had been transferred to the countryside could not even figure out themselves whether they had gone ahead with it voluntarily or due to coercion. Does the downward transfer indicate that the Party suspected and rejected you, consequently relegating you to "the other register"73 - or that you received the Party's trust and nurturance? Is this something shameful and abject, or is it lofty and glorious?

Nevertheless, the intriguing thing is that even while those youth who had been transferred down to the countryside might hold rather contra- 
dictory views about their transfer, they would very likely respond in very similar ways to their situation. Were you to regard the transfer as having been voluntary and glorious, then of course you should show great initiative in your conduct; yet if you consider the transfer to have been coerced and a punitive, then in order to extricate yourself from this predicament, the best way of handling things is still to show greater initiative, work more diligently, and do your best to adopt a positive pose of regarding all this as honorable and pleasurable. Just as I previously explained, in accordance with the principle of how your behavior can affect your attitude, once you adopt a positive course of action, you may very well be able to truly change your viewpoint - at least in the sense of a rationalization.

If I remember correctly, I979 was the year when the poet Zang Kejia published a few poems eulogizing life in May Seventh Cadre Schools. ${ }^{74}$ Quite a few readers took him to task for being hypocritical in these writings. However, to give the poet his due, perhaps the mode of thought expressed in these poems may after all be accepted as a reflection of the emotions of the many "May Seventh soldiers" at that time who tried so very hard to persuade themselves of the "correct" standpoint. While they did not truly believe in it, they indeed truly hoped that they themselves were capable of truly believing in it. As an effect of the intermingled utilization of coercion and persuasion, that mode of thought was precisely a common mentality among many people at that time.

\subsection{The First Strategy of Criticism: A Ferocious Clap (1)}

Drawing upon Mao Zedong's imagistic metaphor, the first step in criticism is to swing your hands together in a ferocious clap and raise your voice in a stentorian shout at the object of criticism: "You're sick!" This includes two levels of significance. First, you are differentiating the denounced person from all the others present. Second, you are blowing the denounced person's small mistakes up out of all proportion into grave ideological wrongdoing.

After the prelude of struggling with the "enemy" has run its course, the criticism session begins to shift course to focus on "internal contradictions among the people." Theoretically speaking, the purpose for launching criticism among "the people" is to help everyone raise their awareness and remold their thinking, and thus the criticism session should naturally target phenomena (that is, target a certain type of erroneous thinking), not persons. However, out of the need to create a tense atmosphere, the CCP would usually select a few specific personages to serve as its targets - this is called "criticizing someone by name." Needless to say, this sort of "criticizing someone by name" as determined by 
the Party leadership is vastly different from the naming of names that ordinarily occurs when persons are debating or discussing something. This "criticism by name" is both an indictment and a verdict. In November I965, Wenhuibao, the major newspaper in Shanghai, published Yao Wenyuan's article denouncing Wu Han's playscript, Hai Rui's Dismissal from Office. ${ }^{75}$ Both Wu Han and Peng Zhen, who were then in Beijing, immediately became extremely anxious, and began inquiring everywhere about the political backing for this article. ${ }^{76}$ This is because they both knew that if the article had been written at the instigation of government higher-ups, there would not be any leeway for them to pen a retort.

Criticizing a person by name differentiates the target of criticism from the masses. This causes pressure to be concentrated on only a small minority of individuals, while making the majority feel relieved of pressure and thus at ease. This in turn is conducive to mobilizing other people to participate jointly in criticism, thereby forming a so-called mass movement. It is readily apparent that the person facing criticism from both the Party and the masses would be in an awkward situation. Since the Party is "great, glorious and correct," and "the masses are true heroes," were you to rebut the criticism of the Party and the masses, that would be tantamount to opposing the Party and the masses. ${ }^{77}$ Moreover, up to the present juncture, your critics have thus far regarded your shortcomings as falling within the category of "contradictions among the people," and they have criticized you in order to help you it has been for your own good. Therefore, if you were to reject their criticism, it would appear as though you did not even know what is good or bad for you - or else you would seem arrogant, as if you did not even take the views of the Organization and the masses into account. ${ }^{78}$

As we know, each criticism campaign has invariably included an interlude during which the object of criticism was "helped" to "rectify his attitude." This so-called "rectification of attitude" is to require that the object of criticism acknowledge the other party's goodwill and correctness from the very beginning of the campaign and at the same time abandon any argument or standpoint that might be used to resist criticism. Otherwise, the object of criticism would be regarded as "opposing the campaign" - which, in itself, is a horrific crime.

As far as the critics of the targeted individual are concerned, since many of them consider their social status a cut above those persons whom they have been ordered to "help," they typically want to see their objects of criticism treat them with obsequious submissiveness and great respect, thereby indicating that their superiority has been acknowledged. If an object of criticism were actually to begin arguing with his critics, on the other hand, the critics would see this as an affront. If you say that you are correct, is it not tantamount to saying that both the 
Party and the masses are wrong? In that case, would it not be equivalent to claiming that you are wiser than both the Party and the masses? Hence, these people would feel really indignant about what you said. In this way, your predicament would become even more precarious. You cannot fail to discover that you would be better off refraining from arguing with them.

\subsection{A Ferocious Clap (2)}

Once a criticism session begins, the blowing up of small mistakes out of all proportion into grave ideological wrongdoing becomes unavoidable. This might appear preposterous at first glance, yet it is not entirely so. When young children steal a few trifles from others out of petty covetousness, would not most of their parents or teachers usually upbraid them severely, using logic such as the following: "If you steal a needle during childhood, you will steal gold as an adult"? In order to nip evil in the bud, you need to realize that great evil may be lurking behind petty faults. It is only when a problem is escalated to alarming heights that the criticism session leaders can forcefully arouse full political vigilance in the person targeted for criticism. For the sake of making a patient accept medical treatment, they must first exaggerate the patient's symptoms to the point at which he becomes so alarmed as to break out in a cold sweat.

The CCP has claimed that its policy is as follows: "Denounce incorrect thinking severely, while the Organization can handle the case leniently." This surreptitiously encouraged people to feel free to churn out groundless accusations to their hearts' content, blowing small mistakes up out of all proportion into major ideological wrongdoing. Generally speaking, the CCP paid attention to conducting the process of criticism separately from the process of handling the case, thereby preventing the session critics from feeling intense compunction when they were carrying out what they clearly knew to be irresponsible and exaggerated criticism. As far as the target of criticism was concerned, because he had needed to rectify his attitude beforehand and had already mastered the imperative to "hold a correct regard for criticism," he could not demand that the masses' criticisms be entirely free of errors, and had to regard their criticism as assistance and salvation on his behalf; therefore, there was nothing he could do but listen with respectful attention, while continually nodding his head in agreement and saying: "Yes."

What should also be mentioned is that during the process of criticism, the CCP deliberately utilized some extremely crude language. For example, the Party used the crude phrase "take off your pants and cut off your tail" to refer to the matter of exposing one's erroneous 
thinking in public so as to obtain help in remolding. ${ }^{79}$ As we are well aware, if someone deliberately indulges in crude terminology on a solemn occasion that calls for the use of proper and civilized language, it would always produce a certain sort of intense effect. The use of vulgar language is often an expression of special privilege. It indicates that the speaker enjoys the privilege of overstepping the restraints subsumed within the norms of ordinary civilized deportment; it hints at the dominant status of the speaker vis-à-vis the listener; and as public mockery, it is a violation of the listener's personal dignity.

In fact, during the process of criticism, all of your affairs, whether important or trifling, public or private - including your casual chats with your family, relatives, friends, and classmates; including your private correspondence; and including your entire family history, your own life story, and your purely personal habits in daily life - all without exception would be subject to public interrogation, examination, and investigation; and all without exception would be subject to exposure, along with demands for your full confession. This would then cause you to feel the sort of distress and shame you would experience had you been stripped naked in front of a crowd. (In The Gulag Archipelago, Solzhenitsyn wrote that when political prisoners were sent off under escort to a labor camp, the first order of business was to strip them naked and conduct a full-body search. In actuality, the search in such a case was merely for show; the real purpose was to humiliate them.)

With regard to a thought-remolding campaign, personal privacy is entirely absent, because the task of thought remolding not only aims at your outward public behavior, but aims even more at your innermost thinking. The Chinese originally lacked the concept of a right to privacy; men of integrity in pre-modern times often liked to parade their own openheartedness and frankness - "there was nothing that they could not discuss with others." Therefore, thought-remolding session critics could seldom realize how their investigation of other people's private thinking was an insult to those people.

Nor did the targets of their criticism often possess a spiritual prop for resisting this sort of illegitimate invasion. Upon encountering the metaphor of "take off your pants and cut off your tail" for the first time, many members of the intelligentsia instinctively found this phrase disgusting. Each person caught up in a criticism session before the masses felt deeply fearful and uneasy about their private matters being raked over right and left in public. However, because on the one hand it was hard to resist the powerful force of a campaign, and on the other hand there was little or no moral basis on which to resist it, they could merely ascribe their disgust and uneasiness to "bourgeois" vanity, to the intelligentsia's being "dead set on saving face," and to their own lack of determination and courage to thoroughly remold their thought. Having 
suffered an excess of humiliation, they nonetheless also experienced a strong sense of guilt. Naturally, the CCP clearly had an awareness and anticipation of this sort of response, and thus in advance had encouraged its targets of criticism to "fear neither ugliness nor pain." This exhortation touched precisely upon a vital point for the intelligentsia. That is the reason why many persons went on from this stage to accept the set of theories about how the intelligentsia had to remold its thinking.

\subsection{The Second Strategy of Criticism: Isolation within the Crowd (1)}

After unfolding criticism in the style of a "ferocious clap," the CCP's next maneuver is to isolate the target of denunciation as much as possible.

In theory - once again "in theory" - since the point of thought remolding is to cure the illness and save the patient, then the target of criticism is just like a patient, and by dint of that fact should receive more solicitude and care. To be sure, the CCP seldom calls out openly for the isolation of the targets of its criticism; it merely calls for isolation and attacks to be directed at a small handful of "class enemies." Mao Zedong even indicated many times that we must enthusiastically help those comrades who have committed errors. Of course, the Party has always warned us that we certainly must make a clean break with "wrong thinking," but making a clean break with such thinking is not tantamount to making a clean break with a person, nor is it equivalent to ignoring and cold-shouldering a person. Nevertheless, the phenomenon of isolation would still occur in the end.

The reason is quite simple. Some people deliberately shun you because they want to display the purity and correctness of their own thinking. Yet even more people do not dare approach you for fear of bringing trouble down onto their heads. This is especially the case with your relatives and friends; precisely because they have an overly close connection with you, they are particularly in need of distancing themselves from you. Since everybody has seen first-hand that during a criticism session, all of the everyday conversations or routine contact between a given person and the people around him can become important materials for implicating others or forcing a confession, who would want to be drawn into this dangerous relationship? Especially during periods marked by political movements, even those persons without problems in their political background would cautiously reduce their contacts with one another, let alone their contacts with persons who had such problems in their background. Theoretically speaking, making a clean break with someone does not actually require that you shun 
him. However, in reality it is always easier to prove that you have made a clean break with someone if you do in fact shun him.

The impact of isolation on the human mind is enormous. Man is by nature a gregarious social animal. Even for the minority of individuals who are solitary by temperament, the imposition of isolation can also be an unendurable punishment. Solitude and isolation both refer to the state of living in solitude, yet the former is voluntary, while the latter is imposed. Isolation can itself be further divided into two types. The first type is to keep you apart from others, while the second type makes you continue to live amongst others, none of whom pays the slightest attention to you. I refer to the latter type as "isolation within the crowd."

Let us attempt to compare the different effects produced by these two types of isolation. If the regime forcibly keeps you apart from others, at a superficial level you would be thoroughly isolated, yet inwardly you would likely feel instead that you are not actually so very isolated after all, for in your imagination you can still continue to maintain relations with other persons. You can believe that the reason other people refrain from having anything to do with you is merely that they either cannot or dare not approach you, rather than out of any unwillingness to do so, or out of disdain for you. You can believe yourself to still be garnering support and sympathy from others. You could even go so far as to regard yourself as enjoying immense popularity and broad support from the general public. Under this type of isolation, it is relatively easy for you to consign the responsibility for your unfortunate lot mostly to the errors of a powerful few. You can still believe in the masses and maintain faith in your relatives and friends. You would thus feel that you are not actually isolated.

After all, the condition of forced isolation is not a normal condition. Because of this, you could always harbor the genuine or illusory fantasy that once circumstances were to return to normal, everything would change for the better. While these sorts of circumstances indeed cause you suffering, your sense of hope will not necessarily be destroyed so easily.

In contrast, the flavor of "isolation within the crowd" is entirely different. Precisely due to the fact that at a superficial level, this kind of condition seems normal, it can even more ruthlessly deprive you of all of your illusions. Just as before, all day long you still pass your days together with those people with whom you were originally acquainted, yet everywhere you notice all the others casting curious glances in your direction. Everybody seems to be either looking right through you or else revealing their contempt for you. Even friends of former days now treat you as if you are a leper, and shun you out of fear that you might not keep your distance from them. Some people cannot even find a 
friendly face in their own home; even your wife and children want to make a clean break with you.

You could console yourself with the thought that all of the above reactions to you are merely owing to fear, yet you are not too sure about this point, since other people's expressions of aversion do not seem to derive from a lack of daring to acknowledge you, but rather from an unwillingness to do so. You may well believe that some unfortunate misunderstanding must have happened. However, since there is hardly anybody who is willing to listen to your account of your troubles, that cannot but give you the impression that it seems everything is clear-cut in everybody else's mind, and there are no misunderstandings or lingering injustices involved. At this moment, it is not very easy for you to clearly perceive the violence of those in power. Instead, what you have more intensely realized from your own personal experience is the exclusion, rejection and disgust the masses have for you. Thereupon, from the very depths of your heart, you feel thoroughly isolated.

\subsection{Isolation within the Crowd (2)}

A state of isolation will profoundly influence a person's reasoning and cognition.

First, as I have explained above in Section 2.I4, it is only under the circumstances of acquiring resonance and communicating with other people that a person can articulate clear and confirmable value judgments about right versus wrong and good versus evil. Isolation through segregation from others causes you to lose your frame of reference and sink into self-doubt. Isolation within the crowd makes you confront an inverted frame of reference and get mired in self-negation. Either type of isolation causes your perception of values to become blurry and ambiguous, thereby making you submit more readily to the set of viewpoints that others are imposing upon you by force.

The CCP has often demanded that a target of denunciation "reflect on your mistakes in isolation," the purpose of which is to intensify the influence of the CCP's viewpoints. Perhaps someone might remind us of the following at this point: ordinarily, do we not also believe that a person is most capable of achieving a clear and unclouded awareness when he is alone, away from the crowd, and sitting quietly, deep in thought? The ancients said: "Close your gate and ponder your mistakes." Does this not mean almost the same thing as "reflect on your mistakes in isolation"? ${ }^{80}$ It does not, because "closing your gate and pondering your mistakes" is a voluntary condition. When quietly pondering something all by oneself, a person has excluded direct influences from others, but at the same time does not exclude the experiences he 
has acquired from having freely communicated with others. In fact, he is merely on his own while carefully arranging and sorting out the experiences he has previously acquired through freely communicating with others.

By way of contrast, what is euphemistically called "reflecting on your mistakes in isolation" refers to your having been compelled to engage in solitary thought while surrounded with uniformly negative public opinion on all sides. This can be likened to being all alone while consulting a supposedly authoritative but actually erroneous dictionary in order to help you read a book consisting of your inner thoughts. The end result can only be that the more you go on reading, the more muddleheaded you become.

It is said that most Nazi concentration camp inmates during World War II slipped into a state of mental collapse, though there were two types of people who were relatively adept at resisting oppression and upholding their original beliefs: communists and religious believers. This is because both of these types of camp inmate belong to a kind of strong and closely-knit group, and they were not spiritually isolated or helpless. They had their own separate frame of reference or set of spiritual resources, and could thus maintain their self-confidence. Eric Hoffer has pointed out that when an individual is encountering enormous pressure, if he is merely a lone individual, he will be unable to resist the pressure. ${ }^{8 \mathrm{I}}$ "The only source of his strength lies in the fact that he is not merely himself, but is instead part of a certain powerful, glorious and invincible thing." Hoffer is correct in saying: "Here the issue of belief is, first of all, the issue of identification." 82

We know that there have been many old communist cadres among the Party's intelligentsia. These cadres showed themselves to be quite tenacious in the face of GMD repression in the past, yet they metamorphosed into something altogether different when on the receiving end of struggle sessions during their own Party's political movements. Some people have explained this discrepancy as being due to the fact that the CCP was even more violent than the GMD in the punishments it inflicted, but this explanation is not entirely correct. Whatever the explanation, it is always a lot better for a person to merely endure a few sessions of denunciation than to be imprisoned, as long as such denunciation is not accompanied by physical torture. The crux of the matter is that the sense of identity of the person concerned has changed a great deal from the former situation to the latter. In the past, the GMD lashed out at you, rebuking you for being a communist, yet since you felt immensely proud of your communist affiliation, you would of course not suffer a spiritual breakdown. Yet of late, it is precisely the Communist Party that turns around and rebukes you for not being a communist and for being an anti-communist element instead. May I ask how you 
would go about defending yourself? You pride yourself on being a patriot, yet you are being severely denounced by your "country." You believe yourself to be pleading on the people's behalf, yet encounter ruthless spurning from the people. When facing such attacks, if you deeply believe that you are on the same side as the Lord, the Party, the People, or History, then you feel you have a gigantic backer on your side and you have a feeling of power. ${ }^{83}$ By contrast, if you cannot believe in any of these backers, you would find that you are extremely weak and powerless. The reason is that by this time, you would feel that you have already "become isolated from every single thing that constitutes the essence of life" (Bukharin's words). ${ }^{84}$

\subsection{Spiritual Homelessness, Isolation and the Lack of Support}

Solzhenitsyn has pointed out that one of the reasons behind the communist party's penchant for political persecution is to appear so invincible to the great majority of citizens that the latter "have no individual standpoint, and lack a spiritual prop from which to engage in struggle." ${ }^{15}$ This is no doubt an important reason why a broad swath of China's intelligentsia succumbed to the thought-remolding movement.

Since 1949, no mainland Chinese organization has existed in a condition of true independence from the CCP. Each and every one of us has belonged to that one-and-only Party-state. If a day were to dawn when we had been abandoned by the Party-state, we would find ourselves entirely bereft of the backing that we previously relied upon.

Spiritually, we have all along lacked a transcendent religion whose authority extends beyond the secular order. Were we to sum up the various values that we have pursued, they would amount to no more than such secular goals as working on behalf of the nation and the people at the very least, we are not allowed to oppose the aforementioned goals. Therefore, when the CCP has utilized mass movements in the name of the nation and on behalf of the people to accuse the intelligentsia of having committed the errors of being "unpatriotic" and "against the people," we could merely defend ourselves out of desperation, yet without the benefit of an alternative standpoint from which we could bravely resist such attacks.

Could we draw strength for such resistance from our cultural tradition? Unfortunately, this tradition was attacked long ago and lost its authority, its history having been severed. For example, it would be extremely difficult for us to consider ourselves some sort of latter-day $\mathrm{Qu}$ Yuan or Hai Rui. ${ }^{86}$ In addition, our tradition itself has often been grounded on various secular values. The reason why Hai Rui dared to upbraid the emperor was that he knew his actions would garner 
approval from the scholarly and conscientious among the elite, along with praise from the common folk. Why would the CCP spare no effort in manufacturing "uniform public opinion" and repeatedly mobilizing the masses to join in denunciations of its targets? Its purpose has been precisely to deprive Hai Rui-type personages of the cultural capital on which they depend for the wherewithal to stand up unyieldingly to the powerful.

Under circumstances of this type, we could not depend upon our inner voice of conscience, either. The reason is that a person's so-called conscience is nothing more than the human mind's original perception of such values as good versus evil and right versus wrong. Although the voice of one's conscience is internal, it must pass through the stage of your interaction with others before it can be affirmed. When everyone around you is raising their voices to contradict you, your voice of conscience would fall silent, for your conscience itself would have fallen into confusion.

Solzhenitsyn correctly noted that by proclaiming Bukharin's group to be an oppositional faction even before it actually became such a faction, Stalin caused Bukharin's group to lose its political muscle. On the other hand, had we initially made up our minds to "oppose the Party" and only later were accused by the Party of "opposing the Party," then we would not have minded such accusations very much. No wonder those people who had originally opposed the CCP actually appeared relatively unruffled in the face of successive waves of thought remolding.

However, under more careful scrutiny, this kind of reasoning still has its flaws. This is because "opposition" in itself does not amount to a type of independent standpoint, but is instead merely an attitude that is based on a kind of standpoint toward a particular matter. In other words, we would still always need something else to rely upon in order to carry on with our opposition in a forceful and confident manner. In general, this state of affairs would take us back again to the type of goals such as "on behalf of the country and the people." We would be opposing the Party for the sake of the people, and thus would not be afraid of the Party accusing us of "opposing the Party." Yet the Party nonetheless insists that opposing the Party amounts to nothing less than opposing the people. If all of "the people" indicate that they are of the same mind as the Party, we would no longer have any ground to stand on unless we were to assume that the people were being deceived and would someday awaken and suddenly see the light. That is to say, we would need to presume that history is on our side. But how could we be sure that history would be on our side? You have to realize that at that time, the Communist Revolution was surging forward with tremendous force and had just achieved ascendancy. 
It is only if we believe in Heaven and the Last Judgment that we would go on to believe that nothing that has happened in the everyday world would be of sufficient magnitude to shake our faith that we have been in direct communication with God. Some Catholics later told me that during this period in the past, ${ }^{87}$ many Catholics manifested a tremendous spiritual power. This may well be true when all is said and done. Yet on the other hand, such unwavering religious believers - no matter to which religion they belonged - amounted to but a tiny minority, after all. This is the reason why most people in the throes of the thought-remolding movement were unable under most circumstances to resist the type of mental pressures recounted above. The reason for this is that we have very seldom possessed the array of spiritual resources required for such resistance. We were truly homeless, isolated and lacking in support.

\subsection{From Confusion to Submission}

A desire to identify with one's oppressor will generally arise among the oppressed when they are under pressure. The problem was even simpler as far as most of the intelligentsia caught up in the thoughtremolding movement were concerned, for within this context, most people had originally identified with the CCP - or at least had never clearly opposed the CCP - and so when they came under pressure, they would often go one step further and submit to the CCP.

The average person always assumes that oppression leads to rebellion among the oppressed, yet does not realize that oppression may also intensify the loyalty of the oppressed toward their higher-ups. The thought-remolding movement was designed to employ pressure precisely in order to intensify the people's loyalty to their higher-ups. This kind of loyalty can be intensified to such an extent that a person could quite sincerely and yet painfully admit to his commission of a crime - a crime that he actually never committed.

This peculiar process is indeed rather complicated. First, it is often a case in which the theory of the unity between intentions and effects has been given free rein and then taken hold. Originally, you neither opposed the Party nor the people, yet the Party insisted that you had opposed them both, and "the people" also chimed up in unison that you had opposed them both. You pleaded your case hundreds of times, yet the other party remained unmoved and implacable. Consequently, you could not help but realize that although you had not harbored any subjective intention of opposing the Party and the people, you had somehow unfortunately created the objective effect of opposition to the Party and the people. After all, what is referred to as an "objective effect," as 
its literal meaning suggests, does not base its criteria on your perceptions, but instead bases its criteria on the other party's perceptions.

Mao Zedong made use of the following analogy: if a doctor were to concern himself merely with writing out prescriptions and did not bother about considering how many patients' deaths stemmed from the medical care he provided for them, would this be acceptable? Of course it would be unacceptable. In fact, this analogy from Mao Zedong about patients dying from a doctor's medical care provided to them, just like his analogy about "treating the illness and saving the patient," is inappropriate for explaining the problem of thought remolding. This is because the issue of whether the results from medical care are good or bad is an objective matter. To say it is "objective" not only means that it must take the patient's condition as standard, rather than the doctor's condition; it also means that even the patient's condition is also objective - which is to say that it can be measured objectively. Whether an illness is cured or worsens as a result of medical treatment, we can neither depend solely upon what the doctor says nor solely upon what the patient says. Neutral and publicly recognized physical and chemical measures of assessment exist within this context. While this may seem to be a matter of value judgment, it is actually a matter of factual judgment, or at least to a great extent it can be transformed into a matter of factual judgment.

Purely ideological distinctions of right versus wrong and good versus evil are very different from this, because they often amount to nothing more than a subjective psychological sensation. Let us say that out of my motivation to protect and care for you, I make a remark that you nonetheless find personally offensive. This is not an ordinary matter of objective effects. From my perspective, your feelings are admittedly objective; yet your feelings themselves are still subjective. You can say that you feel my remark has hurt you - yet on the basis of this feeling, you are unable to conclude that my remark objectively produced a harmful effect on you. Otherwise, there would be no such thing as "misunderstanding" in the world. If you would not listen to my explanation and clarification of my intentions and since I would not wish you to feel hurt by my remark, I would possibly then agree to withdraw that remark. However, this does not mean that I have acknowledged that the remark itself has produced a bad objective effect. ${ }^{88}$

Either the CCP has not understood the above-mentioned reasoning, or else they have not wanted to understand it - or perhaps they have even deliberately pretended not to understand it. A person who has made a remark that backfired may not himself have understood this reasoning very clearly, either. Therefore, when the CCP emphatically asserts that a certain ideological viewpoint of yours has produced vile objective effects, you yourself may mistakenly think that this is indeed the 
case. Consequently, you cannot help but acknowledge that your viewpoint is wrong; though you do not actually know in what way your viewpoint is wrong, you still decide to correct it.

In encountering this obvious contradiction, the concept of "standpoint" (see Section 2.II) emerges with quite persuasive force. You feel perplexed: why is it that a viewpoint that you yourself have regarded as correct should be considered erroneous by the Party and the people? It was likely due to the fact that when you were thinking over the problem, you had not adopted the same standpoint as that of the Party and the people. Yet you clearly realize that originally you had wholeheartedly considered matters on behalf of the Party and the people. Is it due to the fact that while you subjectively wanted to adopt the correct standpoint, you nonetheless objectively still adopted an incorrect standpoint? Does this prove that the deeply ingrained bourgeois standpoint and bourgeois weltanschauung in your brain tenaciously expressed themselves under circumstances of which you were unaware? Regrettably, one's standpoint is not at all like a geographical location; it seems to be playing a practical joke on you and is forever situated on the opposite side of wherever you are. Lenin once remarked that history likes to play jokes on people. You originally wanted to enter this room, yet in the end you entered another room. You pondered this matter repeatedly, yet were unable to come up with any solution to it. At this juncture, societal pressures to conform would come into play (see Section 2.15). ${ }^{89}$ In the end, you would decide to "remold your thought," either from the perspective that "the Party and the people can never be wrong," or else from the angle that "it is safer to follow the mainstream" - or a combination of both.

The matter would sometimes be brought to a close at this point. You would agree to remold your thought, and the Party would then be satisfied with you. Yet at other times, the matter would not end here. Sometimes the Party would go a step further in its minute examination of your case: "Since you have admitted that your thought has been erroneous, obviously you originally harbored wicked intentions." This would make it extremely difficult for you to defend yourself. You would seem to have slipped into the situation of "having said one thing, you must say another," and at this juncture it would seem almost unfair and unreasonable if you were to refuse to admit that you harbored wicked intentions - other people would obviously regard you as having harbored such.

Consequently, you would endeavor to dig into the depths of your heart in order to see if there were indeed any unspeakably wicked thoughts hidden away there. Normally, you would invariably succeed in this endeavor. Even if we do not mention how complicated and subtle the human mind is, who among us has never entertained various 
uncommon and weird thoughts? Some of our thoughts are basically random, and actually not under the control of our conscious will. Nor do we need to mention how ambivalent one's private reflections can be, since Hume has already discussed this. ${ }^{\circ}$ It is precisely the endless accusations formed by external public opinion that alone suffice to fulfill the psychological function of suggestibility. After all, the more afraid you are of finding something, the more likely it is - in a moment of desperation and confusion - for you to assume that you have indeed found that very thing.

A good intention can readily be interpreted as a bad intention. For example, a yearning to work on behalf of the country and the people can be interpreted as showing off or of following the spirit of "everybody out for himself." ${ }^{1}$ An intention that you originally never had can be regarded as something that you once had. You would start to become muddleheaded, no longer clear about whether you are a good person or an evil one. You can believe that your present-day self is a good person - this is self-evident - yet you are no longer very sure about your former self of yore. You can believe that you "want the revolution," yet you may not be clear about whether in the past you had all along been revolutionary, or whether there had been times when you were not revolutionary - or were even counterrevolutionary. You may not go so far as to descend into self-rejection, yet you very likely have fallen into self-doubt. As far as the Party's attempt to make you admit your guilt is concerned, this state of affairs is just about good enough.

Liu Binyan once wrote:

Had I been forced to admit my guilt? Not entirely. Had I been happy to make my confession? That wasn't the case, either. While signing my name to each of the six copies of my Rightist Verdict, I felt apathetic and almost numb. I seemed to truly believe that I was indeed the culprit who had committed those crimes - yet within the depths of my heart, there was not one of the crimes about which I was not half in doubt. $9^{2}$

In actuality, once a person reached this final stage of confession, it no longer mattered whether he signed his name or not. Most people would sign their names. A person is always easier to manipulate once his selfconfidence has been repeatedly torn to shreds.

\subsection{The Emotional Need to Identify with One's Oppressors}

Among all of the people who have received thought remolding, perhaps the type mentioned directly above in the section "From Confusion to 
Submission" is the most common. Many people underwent a similar psychological ordeal until they finally admitted that they had been wrong or guilty - whether they had been "capped" with a criminal label or had remained "uncapped" - and whether they had been criticized more, criticized less, or never even directly criticized at all. ${ }^{93}$ It would require a certain amount of time to complete this sort of complicated and tortuous psychological ordeal. At the outset, almost no one could straighten out his thought and find the Party line convincing; only in the end did everyone gradually indicate that he had been convinced and straightened out. To this end, another of the CCP's strategies obviously played an important role - namely, for the Party to give you "a way out" of your impasse. The Party called on each and every remoldee to "cut off your tail" and to "put down your burden." 94 As long as you admitted your mistakes, the Party and the people would welcome you and allow you to return to the revolutionary ranks. Otherwise, you would continue to alienate yourself from both the Party and the people, leading yourself along a ruinous path to annihilation.

We know that it feels awfully agonizing to be isolated, rejected and abandoned. This feeling not only sows confusion in the reasoning faculties, but also leads to anxiety in one's emotional life. Many people would go to great lengths to be spared from this type of terrifying anxiety. Therefore, the situation would often proceed in the following manner: even before straightening out their thought and convincing themselves of the need for remolding, many people had already hurriedly decided to give up their original viewpoints so as to "return to the people's embrace" as soon as possible. With such an intense emotional need predisposing them to give in under pressure, what sort of twist and turn of Party ideology could they fail to negotiate and come to terms with? If the day were to dawn whereby you were fortunate enough to obtain the forgiveness of both the Organization and the masses after expressing your willingness to abandon the old and embrace the new, you would indeed feel a sense of relief. Analogies of this frame of mind include such PRC clichés as "put down your burden and march forward with a light pack," "head downstairs," and "go over the mountain pass" (when a person is trapped upstairs or blocked from traversing a mountain pass and is forbidden from reaching his destination, how anxious he must be!). In fact, all of these analogies hint at existential conditions or emotional circumstances rather than some sort of ideological state of being.

During the early stages of the Cultural Revolution, there was a certain couplet that was commonly brushed on scrolls that were displayed by middle-school students: "If the dad is a hero, the son will be a good fellow; if the dad is a reactionary, the son will be a scoundrel." All of the students who were classified as having a bad class origin were listed in 
the "other register."95 They were not permitted to participate in the October Ist National Day Parade or even to wear buttons displaying Chairman Mao's likeness.

Ordinarily, you would assume that such petty restrictions might not matter: "Not permitted? So what? In the past when we were all allowed to participate in these sorts of activities, were there not quite a lot of people who did not even want to go?" Yet as soon as the regulations forbade a certain category of students from attending, many of those who at the outset had not necessarily wanted to go suddenly changed their mind and decided that they absolutely had to go and would strive to do so. This is because they feared being rejected. Instead of resigning themselves to rejection, quite a few students with bad class origins preferred to mount the speaker's platform and confess that they were "scoundrels" and "sons-of-bitches." Their sole purpose for doing this was to seek acceptance by others; it was better to play even an abject role within a group than to be completely rejected by that group. In other words, while these students were confessing that they were "scoundrels" and "sons-of-bitches," they actually felt more at ease in their hearts because on the whole, they had at that very moment found an object with whom they could identify.

We know that some people kept refusing to confess their guilt until the Party Organization determined and labeled the nature of their offenses (if they had confessed their guilt at the outset, they might have exempted themselves from those punishments). Only after "caps" had been placed on their heads and punishments had befallen them would they finally confess their guilt (having occurred too late, their confessions were thus of no avail) - what was the use of holding out for such a long time? Yet if we ponder the situation carefully, does this not closely resemble the above-mentioned psychological motivation for confessing that you are a "son of a bitch"? When those persons who had not yet received "caps" originally refused to confess their guilt, it was because they resisted rejection by the group; when they finally confessed their guilt, it was for the sake of regaining their identity within the group.

\subsection{Self-conscious Sacrifice}

Compared to the varieties of submission mentioned above in the section "From Confusion to Submission," there is another type of submission that is even more soul-stirring. We can refer to this latter type as "self-conscious sacrifice."

Arthur Koestler has described this kind of self-conscious sacrifice in his famous novel Darkness at Noon. ${ }^{96}$ A veteran revolutionary has been 
purged. While firmly believing in his own innocence, he strives to convince himself that this purge is a historical necessity, that his transformation into an object of the purge is due to the needs of the revolution, and that he must thus self-consciously sacrifice himself on behalf of the revolution. Back when the author Nie Gannu was doing hard labor as a convicted criminal (Rightist) in a forested region of the Great Northern Wilderness [Beidahuang] prison camps, a forest fire suddenly broke out near his camp. ${ }^{97}$ As a "class enemy," Nie Gannu naturally became the lead suspect for arson. After defending himself many times but to no avail, Nie Gannu finally remarked that if the revolution required him to confess that he started the fire, then he would confess that he started the fire.

This type of scenario can also be encountered in ancient Greek tragedy. In Sophocles' play Antigone, Oedipus' daughter Antigone buries her dead brother Polyneices in defiance of the tyrant's order forbidding this and is thereupon executed. ${ }^{9}$ Prior to her death, she says: "If it would satisfy the gods, we would confess that we committed wrongdoing because we had suffered." Hegel criticized Socrates' attitude of resistance during the latter's trial; he feels that whether guilty or not, "the individual must bow to the pure will of all." 99 In classical Chinese fiction and drama or even in genuine historical texts, we can read of accounts in which an ever-loyal official is being wrongly punished by the emperor, yet he still says to the emperor: "Your Majesty is intelligent and capable; your subject's crime is so heinous that I deserve to be executed."

In this sort of narrative, submission to authority stems from a very simple rationale, namely to provide unconditional support and show unconditional submission to the assumption that the top authorities are absolutely correct. In the view of these people, if those top authorities make an erroneous decision, thereby possibly causing damage to the assumption of their absolute correctness, the unconditional support and submission does not thereby become inappropriate, but instead becomes even more necessary. If this kind of erroneous decision unfortunately happens to wreak havoc upon a certain individual, then I am afraid it amounts to a noble action on his part for him to accept the mistake without any complaints whatsoever - this means acknowledging that the authorities' apparent mistake had actually been the correct action to take at the time.

The imperative to "take the interests of the whole into account" originally implies the voluntary sacrifice of an individual's rights; to abandon any claim about one's own correctness in order to safeguard a higher-ranking person's correctness naturally becomes a most precious sacrifice within the public realm. In this type of sacrifice, a person can obtain a special sort of gratification from the enormous intensity of anguish and suffering endured - a kind of stirring solemnity and gran- 
deur, the purity of which is doubly enhanced by the fact that it is not publicly acknowledged in spite of the person's self-abnegating and thoroughgoing sacrifice on behalf of the authorities and the common cause.

When analyzing this thought process, it is not difficult for us to discover that the most important point is that you have to conjure forth an abstract and sacred aura that envelops the other party. No matter what the CCP did, they always did it in the name of the Party, in the name of the Organization, in the name of the nation, or in the name of the people. Sometimes the CCP would also do something in the name of the Great Leader; yet at this moment, the notion of the "Great Leader" itself had become an abstract term: it was no longer a flesh-andblood individual, but rather an insignia, a great and sacred personification or symbol.

The CCP never tells people that such-and-such a resolution was proposed by Zhang Third or Li Fourth, was met with objections from Wang Fifth, received a vote of abstention from Zhao Sixth, and so forth. Instead, the CCP is forever sweepingly announcing to the world that it is the Party's resolution or the Organization's resolution. You could express your dissatisfaction or disagreement with concrete individuals such as Zhang Third or Li Fourth, but how could you possibly entertain the thought of dissatisfaction or disagreement with the Party or the Organization?

Many Party members have long since been accustomed to regarding the Party as a firm and unified entity. it forever represents truth and correctness, and thus we must forever obey it unconditionally. Even many non-Party members have long since accepted this logic. Are we not supposed to obey the Party? In that case, even if the Party castigates you, you have to obey it; and even if the Party mistakenly castigates you, you still have to obey it. In their view, this is what is known as "loyalty." Do not assume that only a very small minority of extremists would utilize this sort of logic in their thinking. This is because when on the receiving end of criticism by the Party, not only is it of no avail to defend oneself - it is even more dangerous to resist. In other words, when it is out of the question to refrain from loyalty, people cannot help but choose loyalty. The problem is that once people have chosen loyalty (even if it is because there is no alternative - that is why we cannot even begin to talk about either true choice or true loyalty under these circumstances), they might very well go on to embrace loyalty for real - until in the end it becomes difficult for us to determine whose loyalty is genuine and whose is fake, or to what degree someone's loyalty is genuine or fake. For quite a few people, their loyalty was initially fake, but later on became almost genuine. 


\subsection{The Trap of Toughening and Putting to the Test}

Hegel once said that while a giant of the "spirit of the age" was striding forward, he could not avoid trampling and thereby damaging some innocent flowers and plants. When Hegel was saying this, he naturally could not be bothered to ponder this matter from the perspective of the damaged plants. Lenin once remarked that when two persons were grappling in a fight to the death, how could anyone determine which particular punch was necessary and which was unnecessary? While Lenin was saying this, he was probably unwilling to consider how a person might have felt after getting clobbered by that unnecessary punch.

Rather surprisingly, CCP leaders have sometimes made a few comments on the questions that Hegel and Lenin omitted from their discussion. For example, Liu Shaoqi wrote about the need to strengthen personal self-cultivation, the ability to withstand slights and mistreatment, and the capacity to endure humiliation in the course of completing an important task. Mao Zedong even claimed that a person who is dealt with unjustly nonetheless enjoys many advantages, quoting a long passage from Sima Qian's "Letter to Ren An" as evidence. ${ }^{\text {I०० During }}$ the Cultural Revolution, the people in power at every level were "bombarded" or "put to the torch" by rebels for a spell. Yet originally the rebels had actually learned how to behave this way from those who had been in power. Has there ever been a PRC political movement that did not damage a vast multitude? Since thought remolding was targeted at all of the intelligentsia, its scope for damage was even more expansive. That being the case, how did everybody endure it? This then touches upon another important concept, namely "toughening" or "putting to the test."

The human being is truly a language-bound animal. Many evil phenomena in the world can circulate unimpeded in all directions as long as they display a nice-sounding label. Why would we have welcomed all sorts of torment with so much energy and enthusiasm during those years? This was because we erroneously regarded all that torment as "toughening." Why would we have accepted those gratuitous punishments without the slightest complaint? This was because we regarded such punishments as "putting us to the test." Alas, how many crimes were committed in the name of "toughening" and "putting to the test"!

What needs to be explained at this juncture is that I am not saying that under the rule of the CCP, all of the "toughening" was trampling underfoot, or all of the "putting to the test" was torment. We should acknowledge that the CCP of that era indeed experienced a high tide of the Spartan spirit. Therefore, under quite a few circumstances, toughening was indeed toughening, and putting to the test was indeed putting to the test - at least from the CCP's point of view. All I am trying 
to say here is that in relying upon the two nice-sounding terms of "toughening" and "putting to the test," it proved extremely convenient for the CCP to implement a great deal of trampling underfoot and torment, both of which we accepted on account of our extreme foolishness.

There are at least two functions that "toughening" and "putting to the test" serve in the process of thought remolding. First, these terms led us to adopt an attitude of meekly submitting to adversity, as well as to accept many things that we had originally been unwilling to accept, such as unreasonable criticism, unjust treatment, and so forth. This level of argument is relatively straightforward and needs no further elaboration. Second, once people had adopted the attitude of accepting the imperatives for toughening themselves and putting themselves to the test when facing those unjust criticisms and punishments - along with paying a heavy and a long-term price on this account - they would be very likely to self-consciously defend those unjust criticisms and punishments that had harmed them profoundly. This is because in doing so, they would also be defending their own tactic of having meekly submitted to adversity.

Consequently, an extremely weird phenomenon would emerge: the oppressed would go out of their way to make flattering comments about their oppressors, and would also strenuously deny that they had ever been oppressed. The subtle nature of this quandary may be summarized as follows: if you were to admit that you yourself had been oppressed at an earlier juncture, then how could you explain why you meekly submitted to adversity back then? Would not such an admission prove that you had either been very cowardly or very foolish at that time? In order to rationalize your former conduct, you cannot help but rationalize that type of irrational experience you suffered as well.

In his novel Mimosa, Zhang Xianliang portrays a young member of the intelligentsia who has been denounced as a rightist and then punished by being sent to a prison camp for remolding through labor. ${ }^{\text {III }}$ In his preface, Zhang Xianliang quotes a sentence that the Soviet writer Alexei Tolstoy once used as a metaphor for the arduous ordeal of the intelligentsia's remolding: ${ }^{\mathrm{IO}}$ they were "soaked thrice in pure water, bathed thrice in a mixture of blood and water, and boiled thrice in an alkaline solution." Zhang quotes this line to explain that hardships and ascetic rigors are necessary for an individual to come of age spiritually. Zhang Xianliang goes on to explain: "As long as a person is self-aware, the more strenuous the environment in which he finds himself, the greater his abilities that will be unleashed"; with the aid of this kind of self-awareness, suffering can also be "transformed" into joy "anywhere and at any time." When discussing the misfortunes endured by numerous members of the intelligentsia during that period of time, the author 
comments that these travails simply amount to "the price that History demanded we pay."

It is not difficult to perceive that these viewpoints of Zhang Xianliang fit the bill exactly in providing confirmation for my analysis above. He explains away the sufferings from persecution and being trampled underfoot as the wherewithal for toughening, and prettifies it as a necessary process that an individual must pass through in order to come of age spiritually. Of course, the author's attitude does make sense to a certain degree. When a person has no way out of a quandary, he has to acknowledge this state of affairs and take things philosophically. When a person cannot alter the circumstances of his misfortune, he should courageously face his misfortune, endure it and strive to extract significance from it. Yet no matter what might be said about coping with adversity, misfortune is after all misfortune, not good fortune; in particular, the misfortune in our context here is purely man-made and amounts to one-hundred-percent persecution. Therefore, no matter how positive an attitude we might adopt in enduring such a misfortune, we must still maintain our spirit of resistance to it.

True, under the circumstances in effect during those years in the past, many victims lacked a sober understanding of their own predicament. Even if they were aware that they were innocent victims, they had no way of initiating an investigation into either the origins of their victimization or the persons responsible for it. Therefore, the only thing left for them to do is to brandish "History" as a prop for understanding and explaining away their misfortune as an unavoidable minor error in History's grand march forward. In his status as a human counterpart of the innocent flower or plant that has been trampled upon and damaged, Zhang Xianliang relegates the responsibility for his severe persecution to that solemn and abstract "History," thereby absolving his persecutors of any personal responsibility.

Another prominent example is Ding Ling. ${ }^{103}$ After undergoing persecution and attack for over twenty years, Ding Ling returned to the literary scene, publishing quite a few essays and making many speeches. When she was asked about her punishment of remolding through labor at a chicken farm in the Great Northern Wilderness, Ding Ling did not even mention the suffering that a writer who had been forbidden to write would experience. Instead, she spoke at great length about how interesting and beneficial her work at the chicken farm had been. Ding Ling went on to proclaim that during the past twenty-odd years, she "seldom felt life was meaningless," and had all along been full of confidence in the CCP. If we think of how Ding Ling was still able to do a conscientious job of raising chickens in the Great Northern Wilderness even while under severe political attack - there is no doubt that this is a very touching endeavor. However, in light of the fact that in her later 
years she was never willing to solemnly condemn the persecution she suffered in the past, we cannot help but feel disappointed.

The stance of meekly submitting to adversity gives little cause for criticism; to maintain a positive attitude even in misfortune is especially commendable. However, if this leads to the prettification of evil conduct, then that is quite another matter. This is precisely the reason why demands for "toughening" and "putting to the test" can generate a beautiful trap.

This sort of effect is fully displayed in the famous saying, "A mother wrongly spanked her child." Some "Rightist elements" who had been groundlessly persecuted by the CCP for over twenty years (an example is $\mathrm{Qu} \mathrm{Xiao,} \mathrm{also} \mathrm{known} \mathrm{as} \mathrm{"the} \mathrm{horse} \mathrm{herder")} \mathrm{did} \mathrm{not} \mathrm{denounce} \mathrm{the} \mathrm{op-}$ pressors' savage cruelty when they talked about their experience of that period. ${ }^{104}$ Instead, they likened it to a mother who "wrongly spanked her child." We should realize that when they said this, they did not necessarily merely wish to please the CCP; to a fairly large extent, it was out of the need to defend themselves. You have been wrongly beaten up, yet you neither cried out nor shouted, nor did you protest - much less would you dare raise your hand and hit back - and you even continue trying to cotton up to the very person who just beat you up. Unless you had been forced to endure the beating without a peep of complaint, your silent acquiescence would be very difficult to explain. If you want to explain why it was reasonable for you not to have minded this wrongful beating, you will have to explain the incident away as purely a misunderstanding - and what is more, the most unavoidable sort of misunderstanding involving the dearest of people with the best of intentions. There is an old saying that parents sometimes quote to the child they are punishing: "To smack you is to dote on you; to scold you is to love you." Even when a beating has been wrongly administered, it is still supposed to be accepted as a sign of the punisher's love and concern for the target of the beating. Since this sort of persecution is not regarded as persecution, neither is the target's submission to it understood as submission.

\subsection{The Language Demon}

The analysis in the section above is suggestive of a major problem: the enormous function performed by language in socio-political life. While we are thinking about any entity or any behavior, we are often not thinking about the entity itself or the behavior itself, but merely considering the label for that entity or behavior. Or to put it another way, we always draw support from language in order to carry our thought processes forward. This means that whatever kind of name we give to a 
certain entity or a certain behavior can exert a huge influence on our thinking. Different designations imply different inclinations in value or different emotional colorations. Therefore, when people choose to couch their thoughts in one mode of discourse instead of another mode of discourse, their final conclusion is often already embodied within the mode of discourse that they adopted from the very beginning.

The vocabulary of the Chinese language is extremely rich. One and the same matter may be expressed by means of several different vocabulary items. Whether the intent is to praise or to censure sometimes comes down to a difference in only one Chinese character. "Murdering your sovereign ruler" [shi jun] is of course the gravest possible offense, while "killing a guy" [zhu yi fu] is wholly right and proper - even though both phrases refer to the same matter, namely the killing of an emperor. ${ }^{\text {IO5 }}$ To say "oppression," "persecution," "punishment" and "torture" would evoke a certain type of feeling, while to say "help," "education," "toughening" and "putting to the test" would evoke a different kind of feeling. In fact, both sets of vocabulary often refer to the same subject matter. The richness and the intense nature of praise and censure within the vocabulary of the Chinese language are perhaps of great benefit to literary artistry, yet are detrimental to rational analysis. Chinese people lack the habit of couching their thought in neutral vocabulary - this can lead to numerous obstacles in analysis and communication. We must devote a certain amount of attention to this problem.

\subsection{Why Must Self-criticism Be Carried out in Public?}

Self-criticism is an extremely important link in the thought-remolding movement. The goal of study and criticism - or denunciation - consists of promoting the transformation of a person's thought. Self-criticism is an explicit proclamation of a person's acceptance and achievement of this sort of transformation.

Simply by inspecting the external form of self-criticism, we can discover that it has an obvious characteristic: namely, that self-criticism has often been required to take place in a public context. This marks a sharp difference from confession in Christianity or self-cultivation in Confucianism, since the latter two are basically carried out in solitude. In order to make a confession, many Christians seek out a priest, who is nonetheless duty bound to keep such a confession secret. If you wish to make your confession public, that could only be undertaken on the basis of your own free will. The confidentiality and individuality of the confession signify that first of all, your thoughts are your own business and other people have no right to interfere in your thought processes; and second, that confession is for confessing to God, so as to obtain 
God's forgiveness - God alone enjoys this kind of authority. Confucianism is concerned with "learning for one's own sake," and thus the individualistic nature of Confucian self-cultivation also goes without saying.

In contrast with these Christian and Confucian approaches to scrutinizing oneself, thought remolding often requires us to criticize ourselves in public. The reason for this is that as far as the Communist Party is concerned, a person's thought is not merely his own business, but also everybody else's business, as well as the business of society in general. Thought remolding is not undertaken for the sake of saving an individual's soul or for transforming an individual into a sage or a selfsacrificing moral paragon, but rather as a matter of responsibility to society. All that we possess without exception, including the most secret strands of thought within the deepest recesses of our minds, not only belong to us, but also to the Party and the "people" - that is why we should not hide anything. In front of the Party and the "people," the individual has no right to insist upon the independence of his own thought. As early as the beginning of the I950s, the CCP had put forward the slogan, "give your heart to the Party"; the basis and significance of such a slogan pertain precisely to what we have just discussed.

We know that the reason the thought-remolding movement managed to entice many people to sincerely throw themselves into it was that it took advantage of people's psychology of advancing themselves, along with exploiting the typical individual's lofty aspirations to guide and supervise himself by means of an ideal personal character or moral standard so as to elevate himself and achieve his true potential. To put it in Freud's terms, the "ego" would evaluate itself according to standards set by the "super-ego," diligently striving to fulfill the stringent demands of perfecting itself day by day in the realization of that ideal.

However, the problem with all this lies in the fact that within thought remolding, this set of ideal standards had been set forth by the CCP; and even more importantly, it was through the will of the existing fleshand-blood Party and its leadership that the "ideal standards" were being implemented and supervised. The Christian God has its presence on the "Other Shore," and the Confucian exemplar of ideal character has its presence far back in history, ${ }^{106}$ while the CCP is an actual presence right here on this shore. Self-criticism is therefore neither a case of facing up to God or some other supernatural being, nor a case of facing up to the exemplary ancients in my imagination, but is instead a case of facing up to the Party: I have to acknowledge the supreme authority of the Party. In this context, the super-ego is not an internal abstraction, but an external reality. Therefore, self-criticism is not how you make yourself achieve your expectations about your ideals, but how you make yourself conform to the Party's demands. Whether my thought is correct or not - and whether I need self-criticism or not - depends not 
upon my own understanding of the matter, but instead depends upon the Party's judgment. Whether my self-criticism is successful or not depends upon whether the Party expresses its forgiveness and acceptance of me. No matter how wholeheartedly I might engage in self-criticism even if I were to "touch people to their very souls" - as long as I could not receive passing marks from the Party, all of my efforts would wind up being of no account. ${ }^{\text {IO7 }}$ If I were to reject the Party's standards and demands, I would be abandoned by the Party and thereby find myself abandoned by the society that is under the complete control of the Party. For a Christian believer, whether or not he confesses his sins affects whether or not he will be able to go to Heaven after he dies. In thought remolding, if you cannot get through the ordeal of self-criticism, you would have to enter Purgatory even while still alive.

\subsection{The Destruction of Self-discipline}

As has been indicated previously, self-criticism has often been required to take place in public during thought remolding. Precisely because of this requirement, self-criticism has metamorphosed from what in theory is self-improvement to what in actuality is self-mortification.

When comparing Western culture with Japanese culture, the anthropologist Ruth Benedict put forward the concepts of "guilt culture" and "shame culture." She believed that Western culture could be termed a "guilt culture" and Japanese culture a "shame culture." Later on, there were some who also categorized Chinese culture as a "shame culture." The "shame culture" thus came to be regarded as a feature of Eastern civilization. According to Benedict's explanation, “True shame cultures rely on external sanctions for good behavior, not, as true guilt cultures do, on an internalized conviction of sin. Shame is a reaction to other people's criticism... But it requires an audience, or at least a man's fantasy of an audience. Guilt does not." ${ }^{\text {Io8 }}$

We would associate the concept of shame with the concept of "face." John K. Fairbank has noted that face is something social in nature for the Chinese, and individual dignity is obtained through proper conduct and social approval. "To lose face" means to be in an unfavorable position from other people's point of view because you have not been able to follow the rules of proper conduct. For the Chinese, the value of an individual does not reside within each person's own mind, as in the West, but is instead obtained from external validation. Later scholars have put forward some modifications to the above-mentioned views about shame and guilt. For example, Pierce and Singer point out that the consciousness of guilt arises from having done something that transgresses the individual's rules of conduct, while the consciousness 
of shame comes from having failed to achieve a certain ideal goal. ${ }^{109}$ In contemporary Chinese customary parlance, guilt refers to having committed errors, while shame refers to shortcomings in conduct. No matter how we interpret guilt and shame, there is one point that is clear: both guilt and shame can serve the function of motivating people to actively improve themselves.

In the case of thought remolding, what is the relationship between self-criticism and what has been called the sense of guilt or the sense of shame? First, the CCP mingled their utilization of the sense of guilt and the sense of shame in order to compel us to remold our thought. You have said something wrong, or done something wrong, so of course you should criticize yourself - this is utilization of the sense of guilt. Suppose you were to retort: “I didn't do anything wrong; on what basis are you demanding that I criticize myself?" The Party would then reply: "Are you then perfect in every way? Are you already one-hundredpercent proletarian through and through?" This is utilization of the sense of shame. However, no matter whether the Party utilized guilt or shame, in the end the CCP transformed its citizenry into something totally the opposite of what they had originally been.

The reason is simple. According to general opinion, the sense of guilt is a matter of self-discipline, while the sense of shame is a matter of external discipline. Yet this is not entirely the case. I agree with the analysis of Ambrose Yeo-ji King and others who have argued that the sense of shame includes both self-discipline and external discipline. ${ }^{\text {IIO }}$ The Confucians of yore discussed "caution about your conduct while alone" and "examining yourself critically," both of which emphasize the selfdisciplined conduct of an individual as a moral subject.

From the angle of self-discipline, we should acknowledge that no matter whether a person has a shortcoming or has committed an error (the "error" here naturally does not refer to a violation of law or serious misconduct, since guilt is not equivalent to malevolence), we should pin our hopes on him taking the initiative to improve himself rather than taking it upon ourselves to force him to do that. Admittedly, the CCP has also said that self-criticism depends upon self-consciousness. Yet in actuality, the CCP seriously ravaged this kind of self-discipline, for the Party created a set of powerful mechanisms of social reward and punishment that caused people to have to offer up devastating criticisms of themselves on pain of failing to pass muster with the Party and forfeiting whatever trust the Party still had in them, to the extent of suffering persecution at the hands of the Party.

One of the notable bad consequences as a result of this ravaging of self-discipline has been an upsurge of hypocrisy and the confounding of right and wrong. Deliberately exaggerating their shortcomings and errors, some people went to an extreme in denouncing themselves. It 
was certainly not due to their sense of guilt or shame that these people did this; instead, they acted this way to flaunt their supposed contrition and to toady to the powerful. In contrast, those people of integrity who had all along been morally upright were unwilling to belittle themselves in public - they were truly unable to find many errors worthy of selfcriticism - and thus would readily be viewed by the Party as backward and suspect.

\subsection{The Destruction of External Discipline}

To bring one's own errors out in the open and to denounce oneself in public runs precisely counter to the sense of shame and its stress upon external discipline. The function of the sense of shame amounts to the way that a person would endeavor to suppress the darker aspects of his private consciousness and behave properly in his external conduct, thereby obviating the circumstances that might give rise to others' sneering at misconduct on his part. That being the case, if a person were to totally expose the darker aspects of his private consciousness, thereby bringing about his humiliation and descent into an unfavorable position, would this not precisely constitute a devastating blow to his sense of shame?

According to a saying of the ancients, in considering a man's lasciviousness, you should consider his conduct, not his private thoughts; if you were to consider his private thoughts, then the entire world would not contain a single man of noble character. This is to say that if a man of noble character wishes to maintain his image and dignity - what some refer to as "face" - he must not only refrain from engaging in any licentious behavior, but must also hide any lascivious thoughts that may surface in his mind. If he were to display his private thoughts of lasciviousness in public, then even while he might in actuality still be a man of noble character, his image and dignity as such would be completely dispelled. He would feel almost as despised by society and as personally ashamed as if he had truly committed a licentious act.

In addition, one's private thoughts belong to oneself, and to verbalize these in public may influence other people. If a man of noble character were to talk about his lascivious thoughts in public, he would probably be suspected of committing what is called "sexual harassment." The CCP would tell you to "open your heart to the Party," "expose your flesh-and-blood thinking" and "dig deeply into the roots of your thinking" - to come out and verbalize all of your most private thoughts, including your suspicions and dissatisfactions about the Party. Once you have revealed all of this, the CCP would then accuse you of "opposing the Party under the pretext of opening your heart to the Party" as well 
as "spreading poisonous ideas under the pretext of self-criticism." During all of the political movements, innumerable persons stumbled into a calamitous trap on account of having revealed their doubts and suspicions about the Party as well as unreservedly criticizing themselves over such failings. At this juncture, let us not further discuss this sort of malevolent conduct of framing someone.

The general consequence of bringing one's errors out in the open and denouncing oneself in public is that it has forcefully shattered human dignity, or at least it has shattered many a person's "face." As far as shattering a person's face is concerned, the CCP has admitted this without any qualms. For example, Yao Wenyuan long ago wrote an essay denouncing the so-called viewpoint of "face," pigeonholing it under the category of "corrupt bourgeois thought."

Here I am not indiscriminately speaking in defense of "face," nor am I sweepingly denying the significance of open self-criticism. The crux of the matter is as follows: first, all of the processes of self-incrimination and self-denunciation mentioned above were directed against individual privacy and individual thinking, not against a person's behavior within society. Second, correct self-criticism, just like Christian confession and Confucian self-cultivation, should aim at the goal of self-improvement, not at the goal of self-denigration. Self-criticism needs assistance from such motivational factors as the sense of shame. Therefore, once you have destroyed people's sense of shame, to a certain extent you have also destroyed the inner drive that motivates people to actively tread on an upward path. No wonder after each large-scale "open-your-heart" or self-criticism campaign, most of the participants would look crestfallen, disheartened and dejected. At the same time, it was the Party alone that was riding high.

The Party never engaged in this sort of self-criticism - this fact strengthened the intensity of the Party's control over the human mind. Even on rare occasions when the Party had no other alternative but to admit that it had committed a certain error, it never exposed the dark side of its thought in public or blew its small mistakes up out of all proportion into major ideological wrongdoing. On the contrary, it merely kept stressing over and over how it had "served the people," "committed an error out of good intentions," and so forth, thereby keeping its own supreme authority intact. In the "New Society," only the Party had face - and what is more, it was absolute face - while vast numbers within the intelligentsia were deprived of even a barely minimal level of dignity. 


\subsection{Utilizing the Sense of Shame to Shatter the Sense of Shame}

Since everybody has a sense of shame, why would people accept selfincrimination and self-denunciation in public, given that both activities are designed to negate the sense of shame? It is because the CCP very ingeniously utilized people's sense of shame. It used the sense of shame to shatter the sense of shame.

The CCP announced that the weltanschauung of the broad ranks of the intelligentsia was either bourgeois or else basically bourgeois. This then preemptively relegated the intelligentsia to a position which was neither all that honorable nor all that dignified. Since the CCP hoodwinked the public, it was very easy for it to make its own voice become indistinguishable from what was called public opinion. We know that the sense of shame is externally disciplined; that is, its nature is to follow majority opinion. A person with a strong sense of shame is usually concerned above all about public opinion and widely held values among those in his midst. Once he found himself "besieged on all sides" by a new majority, he would be unable to endure it, and would thereupon "abandon the old and follow the new."

Originally, not one of you was willing to negate yourself. Nowadays, however, negating yourself turns out to be a necessary means of affirming yourself. Only when you admit that you are backward can you prove that you are advanced. Furthermore, the more you admit that you are backward, the more you prove that you are advanced. Nowadays when you ignore shame, instead of attracting scorn you win approval and praise, and actually feel honored. In this way, not only did a sense of shame fail to become a hindrance to self-incrimination and self-criticism, but instead became an impetus for these two activities. Of course, there would always be some people who were unwilling to take part in this sort of "self-criticism," yet the pressure bearing down on them would become greater and greater. The pressure came, on the one hand, from the Party that wielded the power of life and death over them; and on the other hand, from those colleagues nearby who had already thrown themselves into self-criticism.

Fei Xiaotong once wrote:

Everybody was in a stir over remolding. ${ }^{\text {III }}$ Consequently, a "remolding competition" was held (...). A worry then arose that the backward elements might implicate the advanced ones, so we initiated the slogan, "slough off our burdens together." While it is true that the advanced ones ought to exert themselves, if the backward elements were not to similarly exert themselves, would they not benefit from their association with the advanced ones? ${ }^{\text {II2 }}$ 
At first glance, this remark seems not to make any sense. Since the backward elements would not meet with the Party's liking, in the end they would inevitably get in all sorts of trouble (at the very least they would not be able to win the Party's trust or receive assignments to important posts). How come he said those backward elements would "benefit from association with the advanced ones"? In actuality, this reveals the hidden jealousy felt by the "advanced ones" toward the "backward elements." The private thoughts of these "advanced ones" were none other than the following: "We have all lost face in public, yet you still managed to keep yourselves looking all clean and unsullied - didn't they let you off too lightly?" Therefore, some of these "advanced ones" were often even more anxious than the Party to exert mental pressure on the backward elements. They emphatically asserted that the reason for your not having yet exposed your shameful thought in public is not that your heart is cleaner than others; instead, this only proves that your heart is darker! To "slough off our burdens together" means to "lose our face together."

As for those who originally would not bring their errors out in the open and denounce themselves, many of them would also begin to get confused. When they saw so many people around them vying with one another to condemn themselves in public, they inevitably would doubt if there was truly something amiss with their original feelings of disgust. Since everybody has owned up to so much bad thought, probably I myself could not be all that much better. In the novel Bathing, after witnessing a round of many people bringing their errors out in the open and denouncing themselves in public, the naïve member of the intelligentsia $\mathrm{Xu}$ Yancheng sincerely remarks:

I have often observed other people's faults in this and that matter, but regarded myself as faultless. Only after having just now listened to a lot of self-criticisms as well as the masses' denunciations have I realized that other people have been as self-righteous as I am. That is to say, I'm just as brimming with faults in this and that matter as other people. I really have to investigate myself objectively, and hope I can get help from the masses. ${ }^{\text {II3 }}$

Since the sense of shame is based on external discipline, it follows that when everybody loses face, it is as if nobody has lost face. This may be likened to a situation in which everybody has stripped themselves naked - you would no longer feel so embarrassed about your own nudity.

Yet shame is, after all, shame. If among the intelligentsia everyone now felt equal to everyone else in having lost face, in the minds of the rest of the people in society, however, the status of the intelligentsia had 
no doubt declined severely - whereas the Party's authority had greatly increased as a result.

There is a need for me to explain the last point in the paragraph above a bit more. We should realize that criticizing oneself in public is not characteristic solely of the CCP's thought-remolding movement. There are similar customary practices in certain aboriginal tribes, religious groups and revolutionary groups. If we talk about how in selfcriticism participants make a fuss out of trifling matters, feverishly blow small mistakes up out of all proportion into major ideological wrongdoing and severely condemn the latter, we would observe that these phenomena also appear in other varieties of self-criticism. As in the case of thought remolding, the purpose for people to do this is to obtain the group's recognition and acceptance, while its effect is to strengthen the group's control over the individual. However, the difference lies in the fact that during such activities among the groups other than the thought-remolding participants, people would not ordinarily experience a feeling of humiliation, but would instead feel some sort of sense of superiority.

Admittedly, true believers always seem very humble. However, just as Feuerbach pointed out, a believer's humility is nothing other than pride in reverse. ${ }^{\text {II4 }}$ No matter how much they enjoy confessing how grievously sinful they are, ultimately they firmly believe that compared to the vast number of mortal beings outside of their group, they are far superior to those mortals in the spiritual realm.

Regrettably, members of the intelligentsia who were engaged in thought remolding under the rule of the CCP did not possess this religious capital of pride, for they had no other group outside the pale of civilization with whom they could compare themselves favorably. Within the "new society," the broad masses of ordinary people were classified as the "revolutionary masses." The reason that the intelligentsia in particular needed to be thoroughly remolded was not because they were deemed a notch superior to others in their ideological awareness, but rather because they were regarded as a notch inferior. Under such circumstances, it would be difficult for the intelligentsia to transform that type of humiliation they knew into glory, unless they were confronting those people in "capitalist society" who had never experienced a revolutionary baptism. This is why quite many within the intelligentsia who had been made to suffer so much by thought remolding as to look crestfallen and dejected would nonetheless perk up a bit and appear rather self-confident when they encountered Westerners.

Some people have been puzzled as to why at different times the intelligentsia could react so differently to the same sort of thought-remolding movements. During the Yan'an "rectification" period, the muchtormented intelligentsia could still easily "slough off their burden and 
march forward with a light pack." ${ }^{\text {II5 }}$ However, members of the intelligentsia who underwent remolding during political movements after the I949 "Liberation" completely collapsed, unable to raise themselves back to an upright posture afterwards. The reason is that the former could still regard themselves as belonging to "the revolutionary ranks," and thereby able to show their disdain for the large number of others who did not belong to the revolutionary ranks, whereas the latter had lost this kind of foil to set them off from the non-revolutionary multitude. The Party stood high above the masses, the broad masses of farmers and workers were regarded as more revolutionary by nature than the non-laboring intelligentsia, while the intelligentsia itself was positioned at the outer margins of the masses of "people." Under such tremendous mental pressures, how could the intelligentsia hold up its head?

\subsection{A Myth about Laborers}

The CCP formally elevated the political status of laborers such as workers and farmers, emphasizing that laborers had a loftier revolutionary nature than the intelligentsia, and thereupon utilized this as an important basis on which to carry out thought-remolding movements and attack the intelligentsia. We know that as early as the I920s and I930s, there was already a group of people advocating the myth that laborers were more moral than the intelligentsia was. This sort of myth is not without some positive significance in rectifying the prejudice whereby the well-educated tended to look askance at laborers. Yet unfortunately, later on the myth also served the function of providing a theoretical foundation for the thought-remolding movements that targeted the intelligentsia. Interestingly, in recent times moving up to the present day when thought-remolding movements have been negated, some people have still continued to repeat a similar myth, albeit in a slightly different version.

In "A Sketch of the Mentality of an Old Intellectual," Xiao Qian wrote: "Many things from the past make me feel deeply that even during the Cultural Revolution, true workers and farmers were still kindhearted. In contrast, a small minority of the intelligentsia were harsh and merciless when they put their confreres next to them through the wringer!" "I6 In the movie The Horse Herder (Muma ren), we see that the educated urban youth $\mathrm{Xu}$ Lingjun has been punitively labeled a rightist and exiled to a livestock-herding region for remolding through labor, yet the local herdsmen there do not discriminate against him. ${ }^{\text {II7 }}$ During the Cultural Revolution when Red Guard rebels from town go to the herding region in hopes of ferreting $\mathrm{Xu}$ Lingjun out and targeting him for struggle, the local herdsmen even devise strategies and take steps to 
protect him. On account of the herdsmen's enthusiastic service as gobetweens, $\mathrm{Xu}$ Lingjun marries a girl - a refugee from a rural village in Sichuan that had suffered a natural calamity. They are the very picture of an affectionate couple. Later, when Xu Lingjun's rightist problem is rectified and his neighbors come to congratulate him on his exoneration, his wife Li Xiuzhi says: "Actually, ever since the day we got married, in my mind's eye he hasn't been a rightist at all." The scriptwriter and the director of the movie try very hard to draw upon this to prove that even during those years when ultra-leftists ran wild and much of the intelligentsia was treated extremely unfairly, the broad masses of the workers, farmers and laborers still showed the intelligentsia deep sympathy, concern and understanding.

While there might be quite a few people who hold the above-mentioned view, it may not necessarily stand up to close scrutiny.

On what basis would we conclude that villagers, workers and farmers have been more kindhearted and fair than urbanites and the intelligentsia in their treatment of people who have "political problems"? One example alone can constitute evidence for refuting this. As is well-known, throughout the vast number of agricultural villages, the lot of those who were classified as landlord elements or rich farmer elements - and especially the lot of their children - had all along been extremely wretched (until the end of the Mao Era). They were by no means more fortunate than the urbanites who had been classified within the Five Black Categories in the cities. ${ }^{\mathrm{II} 8}$ As far as the children of families within the Five Black Categories are concerned, if you were an urbanite, you could sometimes even obtain the kind of treatment that was quite similar to what ordinary people received; yet if you had the misfortune to live in an agricultural village, even if you had never committed any mistake, you would still be a target of the dictatorship. If we regard marital status as a sign of a person's social status - and it is often the case, especially among men - then we all know that the percentage of bachelors among the children of landlords and rich farmers in the agricultural villages was far higher than that of their urban counterparts within the Five Black Categories. The major reason these rural bachelors were unable to take a wife is not that they were more financially impoverished than their neighbors; instead, it is because they were suffering severe political discrimination.

I pointed out in Chapter Two that within China, "among ordinary workers and especially among ordinary farmers, it is obvious that their lot has certainly not been superior to that of the intelligentsia." ${ }^{\text {"I9 }}$ Otherwise, "why is it that in the past there have only been cases within the intelligentsia of those who 'committed errors' and were thereby demoted to become workers or farmers - and there have never been any cases of workers or farmers who 'committed errors' and were thereby 
punished by being assigned work of the intelligentsia"? The officially proclaimed social hierarchy was topped by the class of workers, which was followed by poor farmers, lower-and-middle-level farmers and finally the intelligentsia at the bottom. However, in reality the situation was the opposite of this. Under the great majority of circumstances, the lot of the intelligentsia (including factors such as working conditions and material remuneration, though excluding nominal political status) often was somewhat better than the lot of the workers and much better than the lot of the farmers. The reason that a "downward transfer to do manual labor" is a form of punishment is because it expelled you from the relatively good surroundings you originally enjoyed to considerably worse surroundings.

There are two problems that require explanation at this point. The first problem is that in thought-remolding movements and other political movements in the ideological realm, the intelligentsia was typically classified as the key target of the movement and therefore received far more direct and forceful pressure (including both coercion through punishment and luring by promise of gain). This then led to a serious level of suspicion, disunity and internecine strife amongst the intelligentsia. In contrast, other groups within society - the non-intelligentsia, especially the ordinary workers and farmers who lacked cultural education - could more easily maintain a sort of attitude of non-involvement in these political movements because they were under much less pressure. This does not actually prove the notion that "true workers and farmers" were all kind-hearted and that there was merely a small minority of the intelligentsia who were "harsh and merciless." To be sure, because members of the intelligentsia have a better understanding of one another than an ordinary manual laborer would, if on a given day one such educated person wanted to put another educated person through the wringer, he would be more capable of hitting home at the vital part of his target than a manual laborer would be. In the novel The Water Margin, it is the well-educated official Huang Wenbing who at once detects a serious problem in a poem written by Song Jiang in the Xunyang Pavilion. Huang criticizes this poem to such an extent as to accuse Song Jiang of plotting rebellion against the dynasty, and Song is subsequently sentenced to death. If Huang had merely been a relatively uneducated bumpkin type of official, he probably would not have been so keen and sharp.

However, you cannot go so far as to say that there have never been troublemakers among uneducated bumpkin types, either. Though bumpkin types do not have the ability to adopt subtle ways of framing an innocent person and putting him through the wringer, if they make an effort to pretend to be experts and recklessly blow small mistakes up out of all proportion into major ideological wrongdoing, these 
actions would be equally difficult for the target of these attacks to endure. "When a degree-holder encounters a soldier, even if he is in the right, he would find it difficult to explain his reasoning to the soldier." ${ }^{20}$ When many zealots from workers' and poor farmers' propaganda teams and the People's Liberation Army (PLA) propaganda team were putting the intelligentsia through the wringer during the Cultural Revolution, when did they ever play second fiddle to the "degreeholders" in their arbitrariness, absurdity, brutality and cruelty?

\subsection{A Reflection - or an Image "in Reverse"?}

The second problem is that when a person has been given a "downward transfer" because of "political problems," it indicates that he has been demoted from relatively good surroundings to worse surroundings. Such a transfer already amounts to punishment in and of itself. Because of this, you would feel that in your new surroundings, the tensions in your relationship with the people around you had relaxed somewhat. In your former surroundings, other people discriminated against you either because they felt a cut above you or else they felt you were a cut below the others. Yet nowadays you have indeed fallen to a position that is one or more notches below what you previously occupied; since everybody is of more or less the same status here, the discrimination you experienced would naturally have decreased.

From the perspective of the bulk of low-level manual laborers and poor farmers, they did not regard urbanites who had received downward transfers as being of lower status than they themselves were, even if those former urbanites had been "capped" with some sort of negative political label. Due to the restraints of the system, the majority of manual laborers and poor farmers could seldom hope to escape from their own immediate circumstances. As for those who had received a downward transfer, since they had fallen from a "higher" position, it was not unlikely that they might someday return to that "higher" position. Even if the demoted person could no longer return to a higher position, he simply would at most spend the rest of his life engaged in the same type of manual labor as the farmers and other laborers had been doing all along. Since this was the case, why would they want to discriminate against you?

Furthermore, let us take marriage as an example. In general, we know that it was not really difficult if a man with a downward transfer planned to marry a rural woman - no matter whether he was a downwardly-transferred educated youth, a downwardly-transferred cadre, or even a downwardly-transferred rightist. That is to say, this matter was no more difficult to arrange for a man with a downward transfer than it 
was for a farmer. In general, a downwardly-transferred man was considered superior to the son of either a rural landlord or a rich farmer in a given locale. The reason why quite a lot of downwardly-transferred men remained single was not that the local women would not marry them; instead, it was because the downwardly-transferred men were unwilling to marry these local women. Since there are all sorts of reasons for the men's unwillingness, one must not over-generalize in regard to this issue. For the time being, however, I do not intend to analyze the reasons behind their unwillingness. I merely wish to point out this fact so as to prove that the actual social status of a downwardly-transferred person was not lower than even that of an ordinary farmer.

The movie The Horse Herder attempts to illustrate that when someone in the intelligentsia encounters a ruinous setback, manual laborers have the great wisdom to recognize his worth instead of despising and rejecting him due to his status as a rightist. This illustration assumes that the status of a "footloose migrant" rural woman was higher by far than that of a downwardly-transferred rightist educated youth. Such an assumption is obviously at odds with reality. If it were to be argued that many moviegoers indeed received precisely the impression just now described, that was merely because the actress who starred in the role of Li Xiuzhi was a stunning beauty. As is widely known, no one cares overmuch about the eminence or humbleness of a woman's family background as long as she is beautiful. If Li Xiuzhi had indeed been so youthful and beautiful, not to mention appearing quite intelligent and capable - then, as the poetic line goes, "Heaven graced her with fine beauty, which she could hardly cast aside," it would have been entirely possible for her to have found a far better prospect for marriage than $\mathrm{Xu}$ Lingjun. Why would she have needed to endure the hardships of abandoning her native place and traveling alone for a thousand kilometers in order to seek refuge with a man whom she had never laid eyes on - and later to hastily accept the entreaties of a few local strangers to marry a man whom she had met only once? This story's author, Zhang Xianliang, once remarked that the beautiful and affectionate heroines from the humble working class in his fictional works were none other than "the Luo River Goddess" whom he conjured forth in his dreams. In other words, these musings on the part of the author are not reflections of actual life, but instead are merely images "in reverse" of actual life. In this case, the various meanings derived from such images "in reverse" would naturally combine to form castles in the air.

Of course, I am not denying the fact that during that particular period in the past, there were indeed some workers and farmers who expressed commendable sympathy and understanding to maligned individuals within the intelligentsia. However, conduct of similar loftiness of spirit could also be found amongst some of the intelligentsia as 
well as among people hailing from other social strata. Consequently, there is no reason for us to favor one group while harboring prejudice against the others.

\subsection{Filial Devotion and Loyalty to the Rulers}

Let us again return to our main topic.

Earlier in this chapter in Section 3.28, I pointed out that it is quite absurd for the CCP to liken its attacks on the intelligentsia to "a mother" who "wrongly spanked her child." However, there is much more information about the local political culture lurking behind this absurd metaphor. Within the tradition of Chinese political culture, the relationship between rulers and their subjects has all along been likened to the relationship between parents and their children. Loyalty to the rulers is nothing other than an extension of filial devotion to the political realm. No matter whether coming of age before or after 1949, Chinese people have been taught to be obedient ever since our earliest days of childhood, beginning with obedience to our parents and extending to obedience to our leaders. This appears to be self-evident. We have almost unthinkingly accepted the concept of viewing our leaders as surrogate parents. Lifton emphasized the significance of filial devotion when explaining the cultural origins of the Chinese thought-remolding movement. ${ }^{\text {I2I }}$ That obviously makes a lot of sense.

Filial devotion's implications for political culture are far from simple. Filial devotion is not only manifested by obedience in a person's conduct, but also in the individual's emotional dependence on others. The reason why filial children obey their parents is not only that they feel their parents are more correct than they are, but also that they feel they can please their parents by being obedient, and they obtain a sort of emotional gratification from seeing how pleased their parents are to have been shown deference. When their own inclinations happen to contradict their father's wishes, in general they do not feel all that chagrined about abandoning their own inclinations. Quite the contrary disobeying their father's wishes makes them feel quite a bit more anguished. Therefore, when a conflict is neither too sharp nor too deep, they greatly prefer to abandon their own inclinations and yield to their father's wishes.

Within the environment of Chinese cultural politics - and perhaps not solely in China - it is quite easy to transform the concept of filial devotion into that of political loyalty. For many Chinese people, "loyalty" is both a type of promise and a type of emotion. Such a person is determined to obey the orders of his ruler, and moreover feels happy to do so. Generally speaking, a person who lacks the spirit of independence 
would often be willing to make himself dependent upon one or another strongman. In this way, he can derive a sense of security and a buoyant mood, as well as a feeling of relief from the heavy burden on an individual with the freedom to choose. This type of person is not necessarily bereft of a desire for self-actualization. It is merely that they would prefer to pursue self-actualization under authoritarian rule as it already exists, because they are afraid of the uncertainties that independence would bring forth.

When analyzing the CCP's thought-remolding movement, it is not difficult for us to discover that many within the intelligentsia - especially those who "grew up under the Red Flag" - often adopt precisely this sort of "loyal" attitude in regard to their relationship with the Party and the leadership. Even though the revolution of the CCP violently attacked the traditional concepts of loyalty and filial devotion along with forcefully destroying traditional familial ties, the Party's interventions were merely a case of substituting the nation for the family as an object of devotion - while from the very start causing this extension of filial devotion to political loyalty to be transferred more completely and forcefully onto the Party itself.

At first, the Party cultivated what were referred to as "proletarian revolutionary feelings" within the intelligentsia. Proceeding from feelings of this sort, members of the intelligentsia came to view the imperatives to "obey the Party" and "obey Chairman Mao" as having been heavenly ordained. Although this sense of dependency would eventually be considered shackles on the human spirit, at the outset it nonetheless endowed people in its thrall with feelings of superiority, fulfillment and geniality - which in turn derived from being part of and belonging to a greater whole.

At the beginning of the Cultural Revolution, the Red Guards looked askance at everyone else and were insufferably arrogant. Yet their favorite designation for themselves was "young red soldiers of the Great Commander." Pay attention to the word "young": it refers to something diminutive, thereby indicating a weaker person's subordination to a stronger one; and it also refers to immaturity, thereby indicating a younger person's reliance upon and attachment to a senior person. The Red Guards felt proud of being "young." In front of other people, they tried hard to act like stout grown-ups; in front of the Leader, however, they enjoyed behaving like young children. In their minds, obedience was not something vexing or forced upon them, but instead something that made them feel happy and blessed with good fortune. Unlike other members of the intelligentsia (primarily those of the older generation), the Red Guards acquiesced to the call for thought remolding, seemingly without giving the matter a second thought - at least in the very beginning. 
The reason for this is simple. Remolding signifies reeducation, since its premise is that the remoldee has already received some sort of education previously. Yet as a younger cohort within the intelligentsia, the Red Guards were the direct product of the Party's education. For them, the term "remolding" made almost no sense (see also Section I.5). They were simply receiving an education and nothing more. During later stages of the thought-remolding regimen, if these young people also experienced the same type of internal conflict as what the older-generation intelligentsia had previously gone through - undergoing enormous and inexpressible suffering - to a large extent this was actually a case of an ever-growing body struggling mightily to extricate itself from the tights with which it had been previously clothed.

\subsection{Begin in Obedience and End in Obedience}

To borrow Fromm's concept, the ultimate goal of thought remolding is to instill an "authoritarian conscience" in us. What is referred to as an authoritarian conscience is the internalization of external authority. When a person and an authority are still situated within external relations, he obeys the authority mainly because he fears punishment and longs for rewards. He knows that he is obeying someone else, not obeying himself. The internalization of authority means that the authority has become a part of the self, which makes obeying the authority nothing other than obeying oneself.

We were required to obey the Party and Chairman Mao. Yet the Party was not actually satisfied with our passive obedience, but in addition demanded that we study diligently and remold ourselves conscientiously in order to "self-consciously master the proletarian weltanschauung." We were thus also required to acquiesce to two types of authority at the same time: one was the authority of the Party and the Leader, while the other was the authority of principles and ideology. When confronted with any given matter, we would need both to obey the Party's directives and to adhere to the requirements of ideology. To be sure, we have all along been told that these two types of authority are one and the same. Yet in actuality, the more involved we have gotten in real political life and the more conscientious we have become in studying ideology, the more we have discovered that there are contradictions between these two types of authority.

As is well-known, the chief prohibition of authoritarianism is against allowing an ordinary individual to consider himself an authority. However, if we conscientiously implement the requirement that we "selfconsciously master the proletarian weltanschauung," then the result is precisely that we would regard ourselves as an authority. We know that 
disobedience is the most heinous crime under authoritarianism. Yet when the authority of the Party comes into conflict with the authority of ideology, and obedience to one would signify disobedience to the other, just what are we supposed to do at that juncture? According to Fromm, in tandem with the establishment of the "superego" - namely, the father figure - the real-life father would either retire from public life or else get killed (through the Oedipus complex). Yet this is not the case in thought remolding. The external authority still remains external even after it has been internalized by people. Under such circumstances, the "superego" can never be firmly established.

The result is very clear. No matter how sincerely we believed at the outset that the Party's call to remold our thought was to help us selfconsciously master the proletarian weltanschauung, we would sooner or later discover that what it expected and coercively required of us was merely "obedience" and nothing more. We began in obedience and would end in obedience. The only difference is that if there had been a larger component of voluntary participation in our "obedience" at the outset, then the longer matters would have progressed, the more coercion would have eventually entered the picture.

If we were to say that an authoritarian conscience is an initial stage in the development of the conscience proper, then we would have to say that thought remolding has at best established an authoritarian conscience. Yet what is even more awful is that thought remolding has spared no effort in obstructing the conscience from developing to a higher level. Since the human mind is endowed with a natural developmental tendency to pursue independence and autonomy, thought remolding would need to depend more and more upon threats of violence in order to preserve its so-called achievements. Under such circumstances, a person would express his submission to authority out of fear, yet at the same time would vigorously deny that his submission stemmed from fear. This kind of person would be held up as an exemplar of the success of thought remolding. Who could say that this was not precisely the original goal that Mao Zedong had in mind?

\subsection{Getting "Well-Remolded" Amounts to Getting Intimidated}

Ouyang Xiu (I007-1072) of the Song dynasty once wrote an essay entitled "On Prison Furloughs." During the sixth year of the Tang dynastic reign of the Taizong emperor, there were three hundred prisoners who had been sentenced to death. The Taizong emperor issued a command to furlough them for a visit home with their families before returning to face execution. Sure enough, these three hundred or so convicts were 
all furloughed for a visit back home, and as expected they all returned to their respective prisons on the appointed day.

At first glance, this event fully demonstrates the profundity of the Taizong emperor's magnanimity - even death-row convicts were thoroughly inspired by his example to transform themselves into trustworthy and upstanding subjects of the realm. Yet precisely as Ouyang Xiu pointed out, even a noble-minded man would find it difficult to embrace death without so much as flinching, having scrupulously adhered to trustworthy and upstanding conduct - how could we expect deathrow convicts to behave in this way? The crux of the matter is when the prisoners heard that the Taizong emperor was ordering them furloughs for home visits, they already surmised that if they were to return to their prisons on time, the emperor would surely grant them amnesty. As for the Taizong emperor, he must have expected that the convicts would return to their prisons, and thus intentionally ordered their furloughs. Ouyang Xiu commented: "If the emperor furloughed the convicts only because he knew they would return to prison, then he was seeking to exploit their hopes. And if the convicts later returned to prison only because they were confident that the Emperor would grant them amnesty, then they were seeking to exploit his goodwill. With each planning to exploit the other in order to appear virtuous, wherein lies their supposed beneficence and trustworthiness?"122

A millennium afterward, the CCP repeated the trick that had been played by the Taizong emperor when he had furloughed the convicts. The CCP often let some of those who had suffered persecution - including a few who were still "being remolded" - come out and strike a pose onstage; it let them address the public by publishing essays in newspapers or delivering lectures in on-air broadcasts; it let them receive foreign dignitaries; and it even let them join some highfalutin official delegation and go on a junket overseas.

As expected, for the most part these people "did not fail to live up to the Party's trust." They would never take advantage of the opportunity presented by a public lecture to denounce the CCP's crimes and unburden themselves of their personal grievances against the Party. All they would do was to blindly eulogize the Party's great achievements, repent their former mistakes, thank the Party for its timely rescue of them, and strike back at the "calumny and slander" on the CCP from "class enemies at home and abroad" by using their own experience as an example. Some of them would talk about the unfair treatment they received - but that must be only after the Party had exonerated them. Sometimes they might also touch upon the Party's mistakes - but of course in lockstep with the phraseology that had already been promulgated by the Party. What was most difficult for them to achieve, and yet had to be achieved, was to explain the following clearly to the world: 
though the Party once made some mistakes, it was still "great, glorious and correct"; and though they themselves had suffered some injustices, they had still benefited a great deal from those very ordeals. On the one hand, the Party utilized what these people said in order to display the immense success of their policy of thought remolding. On the other hand, these people utilized the opportunity granted by the Party in order to obtain some sort of improvement in their own circumstances.

The veteran writer Xiao Qian related an interesting episode from the past. In the summer of 1979, the Chinese Writers' Association notified Xiao Qian that they were assigning him to join a delegation bound for a formal visit to the U.S. Xiao Qian recalled that in I950, he had similarly been notified about being assigned to join a delegation bound for the U.K. Prior to the delegation's departure, he and the other members of the delegation had even been summoned to a reception hosted by Zhou Enlai. Yet at midnight on the eve of the delegation's departure, his eligibility as a member of the delegation had been canceled.

On the more recent occasion in 1979, Xiao Qian had again been selected as a delegate to go abroad on a formal visit - that no doubt indicated that "there had been a change" in his "individual political evaluation" by the Party's Organization Department. According to Xiao Qian's own account:

I had not entirely disentangled myself from my psychology of cautious foreboding at that time. During the coming trip, I was positively determined to win credit for others in the intelligentsia whom, like me, the Party had also mistrusted in the past. Throughout this trip, I not only needed to win over friends and dispel misunderstanding on behalf of my country, but at the same time I also had to ensure that I did not make a single incorrect statement. ${ }^{\mathrm{I} 3}$

Over the course of Xiao Qian's visit to the U.S., he was indeed extremely careful and cautious. One day, his host invited Xiao Qian to make a Io-minute speech. While his higher-up in the delegation had not requested Xiao Qian to submit a draft of his forthcoming speech for inspection and approval, Xiao Qian still "wrote down his speech word for word, and submitted it to his higher-up." This higher-up of Xiao's was a senior Party member and Xiao Qian decided to "let him take charge of everything throughout the whole trip." Initially, this higher-up wanted to cast aside Xiao Qian's written speech (even though he himself had just inspected and approved it), and in its stead write another piece himself. Xiao Qian concurred without a moment's hesitation. However, having subsequently discovered later that the higherup's written speech was too lengthy, the delegation decided that Xiao 
Qian should still use his own written speech after all. However, Xiao Qian insisted that his written speech be presented as the two men's joint effort.

Upon his arrival in the U.S., Xiao Qian went everywhere in the company of that old Party member. He declined invitations from some universities that had originally invited only him. Only after they extended their invitation to include this fellow delegate of Xiao Qian's would he finally accept their invitation.

In keeping with precedent, upon his return from the U.S., Xiao Qian had to report on what he had seen and heard as well as his general impressions of his visit there. At this point, Xiao Qian remembered that a friend of his had previously been denounced for making a few remarks about the prosperity of a certain Western country upon his return from a visit there. Consequently, Xiao Qian and his wife Wen Jieruo wrote out every word in each sentence of his report, carefully weighing each word with remarks such as "it's better not to mention this matter" and "that comment needs to be toned down." When subsequently making his report, he simply intoned a verbatim recitation of his written report. After his speech, Wen Jieruo told him that the audience had for the most part indicated their disappointment with his presentation. Xiao Qian said: "That's fine with me. If they'd listened to my presentation with delight, only then would I have had to start worrying." I24

The value of these episodes Xiao Qian recounted lies in how completely revealing they appear to be of his psychology at that time. Xiao Qian's determination "not to utter a single incorrect statement" during his overseas trip was nothing other than a determination to avoid saying anything that the CCP would not like to hear (as for whether these statements in and of themselves were correct or incorrect, Xiao Qian himself might not necessarily share the Party's viewpoint). Similarly, his aforementioned goal to "win credit for others in the intelligentsia whom, like me, the Party had also mistrusted in the past" was nothing other than the use of an opportunity for possible disobedience to the Party to further prove to the Party that he was truly submissive instead. Had his audience (either at home or abroad) been disappointed? Fine, let them be disappointed - because in that event, the Party Organization would not have been disappointed. Behind all of this posturing on Xiao Qian's part, there was hardly any desire for reward, for most of his posturing simply stemmed from fear. This tells us that for most members of the intelligentsia, the state of being "well-remolded" is nothing more than a condition of terrorized intimidation. 


\subsection{Remolding is Nothing Other than Taming}

Perhaps the story of the painter Pang Xunqin can explain the problem even better. ${ }^{125}$ In 1957, Pang Xunqin was branded with the verdict of a Rightist. In the aftermath, he endured some 22 years of cruel persecution. At a large exoneration ceremony held in I979, Professor Pang ascended the stage to give a speech. He loudly recited a poem that he had just composed: this poem bore no trace of either indignation or melancholy, but instead resounded with the vast expanse of his loyalty to the Party. However, it was precisely the selfsame Pang Xunqin who suffered a hallucination while on his deathbed in 1985 : upon hearing a very loud conversation outside of his room in the hospital corridor, he jumped to the conclusion that somebody had again come to ferret him out and drag him away to a struggle session for public vilification and turned pale with terror. Does that not explain how beneath the veneer of his loyal and submissive bearing, free as it was of any trace of indignation or anger, there was nothing other than a heart that had been torn to shreds by fear?

The late historian Cheng Yingliu bequeathed to later generations a diary that recounts the painful course of thought remolding, A Diary of Severity and Castigation, $1957-1960 .^{\text {I26 }}$ One passage in Cheng's diary seems particularly worthy of pondering:

I have often been thinking these days about how wonderful it would have been if only I had figured out a little sooner that the secret to attaining the truth simply amounts to across-the-board submissiveness to the Party! Is it too late for me by now? What actually makes me infinitely excited about the future is an adage from an ancient philosopher, "If a man hears of the right and proper Way in the morning, he can die that very evening without the least regret" (30 September 1959). ${ }^{127}$

This passage from Cheng's diary may be a bit satirical. However, were we to categorically assert that Cheng Yingliu's thought remolding had not been successfully implemented on the basis of what he wrote about "across-the-board submissiveness to the Party," we would not necessarily be accurate. To be sure, if we defined success in thought remolding as a genuine and sincere identification with what the Party deems to be the truth, then it indeed did not come to pass in the case of Cheng Yingliu. However, if we realize that from the very outset, the goal of the CCP's launching of thought remolding was to make people docile and submissive to the Party, then we have to admit that in Cheng Yingliu's case it achieved its anticipated success. 
Let us discuss a relatively recent event. On 27 April i989, in protest against the editorial in the People's Daily on 26 April, several tens of thousands of students in Beijing decided to disregard government warnings and march to Tiananmen Square to hold a demonstration. ${ }^{\text {I28 }}$ At the university gates, some of the teachers strenuously advised against the students' participation in the march. On the face of it, the demonstrators appeared to oppose the CCP more than their teachers who advised against their march. Yet in actuality, the reason why many teachers came out to advise the students against demonstrating was actually not that they disapproved of the demonstration or thought it inappropriate, but rather that they believed that the demonstrators were hurling themselves willingly into a tiger's jaws. In contrast, many demonstrators did not believe that the CCP was as fierce and savage as a tiger. Though the leadership of the CCP was not necessarily completely unaware of the dissuading teachers' psychology, they still preferred to publicly commend the dissuading teachers afterwards. The reason was that what the Party originally expected from the people was submissiveness - even if you were submissive not owing to your affection for the Party, but because of your fear of it. In the novel 1984, the protagonist Winston attempts to resist Big Brother. After he fails, he finally says: "Big Brother cannot be defeated." The fact of his saying this signifies Big Brother's victory, notwithstanding whatever motivation may have lain behind Winston's remark.

I wrote the following passage in my Jottings on Philosophical Ideas: "There were far fewer literary inquisitions in the wake of the reigns of the Yongzheng and Qianlong emperors. That was not because the Qing emperors who reigned after those two men were somehow more enlightened, but rather owing to how fear among the populace had seeped all the way into the marrow of their bones. Have you not noticed how the older animals in a circus rarely give cause for the sting of the lash?" ${ }^{29}$

\subsection{In Evading Freedom, One Evades Responsibility}

Without a doubt, thought remolding amounts to an enslavement of the human mind. At the mention of "slavery," people often associate it with images such as shackles and handcuffs, as well as scenes of beating and kicking. Actually, the reality was not necessarily like that. Unless the slaves were bent on resistance or the master suspected that the slaves harbored rebellious intentions, why would the master bother with frittering his energy away in cracking down on the slaves? Of course, a person would be correct to say: "Wherever there is oppression, there 
will be revolt." Yet it makes just as much sense to add: "Only in case of a revolt would there be a crackdown."

Mao Zedong once said that he wanted to create a political situation in which society would come together around a collective unified will, and at the same time everybody would be carefree and happy under these circumstances. It goes without saying that this imagined situation is self-contradictory and thus impossible to achieve. Yet supposing everyone were to abandon his independent free will, merely aspiring to be "vigorous and lively" under the collective "unified will," it would not then seem too difficult to achieve the outcome Mao had in mind. In my comparison of thought remolding with the taming of the human, on the one hand I am referring to thought remolding's negation of humanity's great spirit of liberty; and on the other hand, I use this metaphor to explain how at first glance, the wreaking of havoc upon the human spirit is not necessarily so gut-wrenchingly shocking as is the wreaking of havoc on the body.

Instead of harboring dissent and feeling worried and insecure about it, certain individuals have actually preferred to forfeit their freedom and welcome being tamed in order to relax and feel happy. In the early years after the PRC's founding, the great majority of the intelligentsia enthusiastically expressed their desire to "obey the Party" and "serve as the Party's tamed tool." Among those who uttered such remarks, it is not as if all of them were besotted with boundless delusions about the Party, this was especially the case with relatively senior and experienced individuals who said such things. They did so out of fear of incurring punishment, and at the same time in an attempt to exempt themselves from inner conflict and personal responsibility. We know that the essence of human taming consists in regarding oneself as a tool for the reception and implementation of someone else's intentions and thought, and thus no longer seeming to bear any responsibility for one's own conduct.

When defending her father Feng Youlan for his error in following the extreme-left line, Zong Pu emphasized that because her father had retired from official life by that time, he could rely only on newspapers and bulletins for keeping up with current events, and could trust only what was said in these newspapers and bulletins (see Section 3.I2). What she actually meant by this was that a "hoodwinked" person is supposedly "innocent." Yet the term "hoodwinked" is well worth pondering. The problem is that as a highly educated and well-experienced member of the intelligentsia, how could Feng Youlan not have known the principle: "Listen to both sides and become edified; heed but one side and become benighted"? If you are only willing to listen to the CCP's one-sided rhetoric, this would indicate that your state of being "hoodwinked" has actually arisen from your own volition, or at very 
least is semi-voluntary. To one degree or another, we have all made the same type of mistake. Before we could be deceived by others, we had to first deceive ourselves.

Not so long ago, Wu Zuguang went to the hospital to pay a visit to Cao $\mathrm{Yu}{ }^{\mathrm{I} O} \mathrm{In}$ an extremely disconsolate mood, Cao $\mathrm{Yu}$ talked about the setbacks in his writing over a lifetime. Wu Zuguang said: "You were too obedient!" To this Cao Yu immediately replied: "You're absolutely right! You said exactly what I'd been thinking! I was too obedient! I always obeyed the leadership. Whatever the leader told us, I would carry out his instructions immediately. Sometimes, I'd even try to figure out the leader's intentions before he said anything... But if you're doing creative writing, how can you obey a leader?"131

Recalling what Cao Yu said to foreign friends sixteen years previously - "it was with my own pen that I wrote it" (see Section 3.I2), we can now see that Cao Yu finally admitted what he had all along been trying very hard to deny. This self-questioning on Cao Yu's part is quite courageous and may be considered profound. "Obeying the Party" is a convenient thing to do: if what you have done is correct, then you get part of the credit for it; if what you have done is erroneous, then it is the Party's mistake. This is precisely the reason why so many people were willing to give up independent thinking in those early years. The advantage of adopting the role of a tamed tool is to exempt oneself from individual responsibility. However, a person has to take responsibility for the very act of his voluntarily forfeiting his individual responsibility. "To obey" is to voluntarily embrace a condition of passivity; since this amounts to an error in and of itself, it cannot serve as an excuse for making erroneous statements and committing erroneous deeds.

Admittedly, obedience is an essential element in the structure of any society and profession. Yet an overriding majority of the ignorant actions and evil deeds in the history of humankind have invariably been committed in the name of "obedience." Only after having wasted the best years of his life and frittered away a vast reservoir of his energies did Cao Yu finally awaken to the realization that "if you're doing creative writing, how can you obey a leader?" Of course, in all intellectual activity and expression of opinion, one should in no case take "obeying the leadership" as a standard - this principle is not limited just to writing, just to literature and the arts, or just to scholarship. This principle is extremely easy to understand - how come it took Cao Yu several decades to finally manage to figure it out? In this regard, Cao Yu's awakening to this principle may still be found wanting; moreover, he did not go on to discuss what had motivated him to mechanically obey the leadership back then. Aside from such considerations as avoiding danger and hankering after personal gain, the obedient person might also har- 
bor the intentions of escaping from freedom (in Fromm's words) and thereby shirking responsibility.

We know that thought remolding incorporates both voluntary and passive factors. The evasion of freedom and responsibility is one of the voluntary factors. If a person harbors such a motivation, he would easily accept thought remolding and would not feel any suffering from it (ultimately, such suffering derives from a remoldee's insistence upon independent thinking); he would even feel a kind of relaxation and pleasure. This situation is precisely what $\mathrm{Hu}$ Shi described in his short poem: "Who does not love freedom? / Yet no one knows what it means: / Someone who'd rather not be free, / Is also practicing liberty." Perhaps this is why quite a few people were able to make it through the ordeal of "thought remolding" quite smoothly. Nowadays, they would naturally feel that their stupidity of yore was laughable; yet they never, or hardly ever, have actually experienced the sort of moral uneasiness that a person would normally feel after having committed a deed that troubles his conscience. In other words, up to now they are still denying the moral responsibility that they should have shouldered with regard to this matter.

Cao Yu was an author. Because he was "too obedient," in the end Cao $\mathrm{Yu}$ was unable to bequeath a fine literary oeuvre to posterity. That sort of thing would invariably leave one with a feeling of despondency. Yet many of Cao Yu's contemporaries who were similarly obedient did not necessarily share his feelings of deep regret. They might have even secretly rejoiced over the fact that they remained safe and sound throughout those several decades. Public opinion is generally tolerant and forgiving of such persons. After all, a "hoodwinked" person is usually considered "innocent." Even if someone were to reproach you with the comment that you were "too obedient," that seems to say that you were too immature or simple-minded, or at most too foolish - none of this actually seems to amount to a major problem or flaw in your personal morality. No, none of these reproaches could count as a major problem or flaw. Yet it was precisely through the support from many of these "banalities of evil" (in the words of Hannah Arendt) that largescale evil deeds were finally able to occur. 



\section{On Evasion}

\subsection{Evasion by Foot-dragging}

What I mean by "evasion" is when a person turns to foot-dragging and passivity as ways of coping with a thought-remolding campaign. It is possible for evasion to arise from a variety of motivations, and to give rise to different manifestations at different stages of its development. Because of these differing circumstances, the significance of evasion varies from one case to another.

Some people are innately lacking in initiative. Such a person "often seems to have a natural immunity to thought remolding from the very outset." The reason for this is quite simple. Unless a person embraces an attitude of taking the initiative to engage with the real world whether it be to cultivate an ideal self of sterling character, to get established in a career and achieve merit, or to "keep up with the times" in pursuit of fame and wealth - he would otherwise simply not participate actively in thought remolding. What people ordinarily describe as "fake enthusiasm" refers to nothing other than the observation that a person's participation in thought remolding stems from "impure motives" - such involvement with remolding has nothing to do with the goal of revolutionizing his thinking, but has merely been for the sake of achieving personal gain in the here and now. Yet there can be no doubt that even "fake enthusiasm" itself amounts to an attitude of taking the initiative to engage with the real world. During the last years of the Cultural Revolution, more and more of the "revolutionary young generals" in both the Conservative faction and the Rebel faction of the Red Guards began to realize that they had been engaging in lunacy as a result of having "been taken in and deceived." Looking back over the recent past, they noticed that their only peers who had refrained from committing errors were members of the "Free-and-Easy" faction, who had remained aloof from the Cultural Revolution's political movements. However, the "young generals" did not admire the "Free-and-Easy" faction at all, ${ }^{2}$ for they felt that the reason why the latter faction committed no errors was not that this faction was somehow wiser than the rest, but simply that it was lacking in concern for worldly affairs. 
Speaking of evasion, some persons might associate this modern-day orientation with the scholarly reclusion of ancient times. In fact, the two are completely different. In antiquity, reclusion was framed as the opposite of "official government service." If you did not serve as a government official, that amounted to "reclusion." Except for a motley crew of fake recluses who resorted to reclusion as a shortcut to obtaining a post in officialdom, all genuine recluses cherished a distinctive ideal in human existence. Some of them did not wish to become an official because of their adherence to some type of transcendental philosophy, while others steered clear of officialdom due to their unwillingness to wallow in the mire of everyday politics. In other words, a genuine recluse chooses not to become an official under the premise that he could if he wanted to. The pursuit of one's own moral cultivation without thought of others is not tantamount to having no aspirations or principles. Furthermore, if a person were to insist on not participating in everyday politics, he would have to withstand interference and intrusions from everyday politics, and thus could not merely drag his feet passively. In Poland, as is widely known, such transcendental groups as church congregations once exercised a positive function as a haven for withstanding the pressures of authoritarianism. The reason lies exactly in this.

However, the psychology of evasion is quite different. The evader has no particular aspirations in life. While willing to lead a commonplace and trouble-free life, he lacks the courage required to insist upon leading this sort of ordinary life. Although an evader would not take the initiative to participate in thought remolding, he would similarly refrain from firmly resisting thought remolding, for he would have to pay a heavy price for such resistance. Here, being "without aspirations" includes lacking the aspiration for even a commonplace life. Since thought remolding was omnipresent and penetrated everywhere, those who submitted to it would prosper, while those who resisted it would perish. Since the evaders had no special principles in life upon which they felt compelled to insist, they would then naturally choose the least strenuous route - drifting with the tide and echoing the views of others. This is to say that during the vigorous phase of the thought-remolding movement, the evaders did not evade it, but instead participated in it. Their only difference with others was merely that they were relatively less serious and less diligent in their participation in the movement.

Let us take the Free-and-Easy Faction during the Cultural Revolution as an example. Few of the "free and easy" ones were free and easy when the Cultural Revolution started. At the very beginning of the Cultural Revolution, the manner of implementing the movement resembled the way such things had been orchestrated in the past: various levels of the Party Organization directly took the lead, and even those individuals 
who would have rather not gotten involved in the movement did not dare to refrain from participation. Subsequently, in tandem with the rising tide of the Rebel Faction and concomitant paralysis of the original Party Organization, there was a reduction in the movement's pressure on ordinary participants to remain involved. As the masses split up into different factions, those persons who generally followed the mainstream trend were uncertain about what to do. It was only under these circumstances that people who preferred to refrain from participation in political movements were provided with an opening to remove themselves from any involvement in the movement. During the latter stages of the movement, the re-unified Party Organization was re-established, and the Free-and-Easy Faction once again found it very difficult to remain free and easy. Finally, when Mao Zedong called on all educated urban youth to go up to the mountains and down to the countryside, none of the Free-and-Easy Faction members managed to elude the ensuing calamity. Clearly, the attitude of many individuals within the Free-and-Easy Faction is purely one of foot-dragging passivity. They evade regimented activity only when they are able to; when they cannot evade it, they merely go along with the flow of the mainstream.

\subsection{The Rejected and the Weary}

There are a few other types of individuals within the ranks of the evaders. Some of them belong to professions within the intelligentsia. They have embraced an intensive pursuit of a special profession or discipline (such as science and technology or art), yet are bereft of any interest in political activities. In terms of personal morality, they have been willing to abide by traditional moral standards. Yet not only have they lacked an adequate understanding of such imperatives as "revolutionize your thinking" and "establish a proletarian class weltanschauung" - they have had no enthusiasm for developing an understanding of these imperatives, either. Their guiding principle could be summed up as: "Do a great job in your profession, and a passable job in politics" (some people might add: "And make a good go of it in your everyday life"). This type of person would adopt an attitude of foot-dragging with regard to the thought-remolding movement. Owing to differences in personality, some people of this type would go along with the flow of the mainstream, while others would engage in one form or another of passive resistance. The CCP has criticized this sort of person as "politically undistinguished" and having "taken the path of political reaction and professional competence." There have been times when this sort of criticism could be delivered with extreme severity. However, such criticism was not very effective overall; it could at most cause 
those persons who had adopted passive resistance to transform themselves into the type of person who goes along with the flow of the mainstream.

There is yet another type of person who originally harbored rather enthusiastic sentiments for thought remolding, but was unable to obtain the Party's trust for various reasons (such as a "bad class background" or problems with his personal "history"), and has thereupon grown disheartened and fallen into low spirits. In theory, thought remolding sets out imperatives for a person's inner life and its goal is for him to achieve the revolutionizing of his own thinking; people should thus refrain from changing their attitude toward remolding merely on account of the outside world's encouragement or cold-shouldering of them. In his essay entitled "On the Personal Cultivation of a Communist Party Member," Liu Shaoqi makes a point of indicating that in order to carry out an important mission, a person must be able to endure the adversity of being wronged, misunderstood or humiliated. ${ }^{3}$

In fact, there was indeed a group within the intelligentsia who doggedly stuck with thought remolding over the long term in spite of encountering much discrimination and cold-shouldering. Precisely on account of having met with discrimination, some people worked especially hard at remolding their own thought, even to the extent of overexerting themselves. Yet for even more of those undergoing remolding, as none of the humongous effort they exerted was ever able to garner any encouragement or affirmation in response, it was unavoidable that their initial enthusiasm would gradually cool down.

Some people have been perplexed as to why so many senior figures in the intelligentsia found themselves repeatedly rejected by the Party after having bared their hearts in all sincerity to the Party back during those early years of its rule nationwide. In fact, the Party has had its own considerations about this issue. Since the CCP has looked upon thought remolding as its "Incantation of the Golden Fillet" for keeping the intelligentsia under control, it was naturally unwilling to casually issue a "quality-assured certificate" to anyone and everyone who might appear to qualify. ${ }^{4}$ Indeed, if anyone and everyone were to be inducted as certified members of the "proletariat class," would the Party's insistence that it was a cut above everyone else not soon fall flat? Under such circumstances, how could the Party maintain the status quo of "generalists reigning over specialists"? 5

Furthermore, let us take the discriminatory policy of equating a person's class line with his class background as an illustration of the Party's selective negativity. If the CCP had treated all young students of varying class background in an egalitarian and even-handed way, how could it have spurred the average child of workers or farmers to feel so thankful and desirous of paying back his debt of gratitude to the Party? 
And how could it have granted special privileges to a small elite of favorite sons under a high-sounding pretext? ${ }^{6}$ This is why it was unavoidable that some other people would be rejected and cold-shouldered. It is thus understandable that having met with repeated setbacks, these people would feel more and more disheartened about thought remolding.

The CCP required the intelligentsia to "keep on remolding yourself as long as you live, no matter how old you may be." However, thought remolding stands in sharp contrast with what has generally been described as "personal moral cultivation." The goal of thought remolding is not to achieve a clear conscience or to feel no qualms upon introspection. Thought remolding means saddling oneself with the sort of harsh demands that would only be put upon a proletarian sage. In ordinary parlance, it requires that a person must evince a dogged determination to be hard on himself. It is difficult to imagine how the average person would not grow weary of remolding over the long run. In order to overcome this sort of mentality of weariness, the CCP had no recourse but to launch a new political movement almost every day, thereby ratcheting up the level of stimulation again and again. However, the result of ratcheting up the level of stimulation was that even though this might have created a bit of excitement over the short term, what necessarily followed on its heels was but an even heavier weariness. According to what we witnessed from the early I950s to the final years of the Cultural Revolution, as the CCP's requirements for thought remolding became more and more stringent, people's enthusiasm for participating in remolding dwindled more and more, dropping rapidly after having reached a climax. In tandem with the growth and spread of the mentality of weariness, more and more people underwent a transformation from enthusiastic participants into foot-dragging evaders.

\subsection{Idealists Who Went Astray}

During the process of facilitating the transformation of enthusiasts for thought remolding into foot-draggers who felt put off by it, the unpredictable twists and turns of the CCP's own political infighting no doubt achieved quite a major catalyzing effect.

Just as recurrent changes to the legal code would likely destroy the law-abiding spirit of the people, so did the CCP's endless changes to the criteria for thought remolding inevitably erode people's enthusiasm for participating in thought remolding. This was manifested in a particularly obvious manner during the Cultural Revolution. Prior to the eruption of the Cultural Revolution in I966, the CCP's criteria for thought remolding were comparatively clear and consistent for the most part. As an example, let us examine the tenet: “Obey the Party's instruc- 
tions." Prior to the Cultural Revolution, everybody generally understood who the "Party" was and what "the Party's instructions" meant. As long as a person obeyed the Party's instructions, he could generally count on receiving praise from the Party. In turn, this sort of praise would further strengthen his enthusiasm for actively striving to obey the Party's instructions.

The CCP set up a whole series of progressive exemplars for people to emulate. While these exemplars differed somewhat from one to another owing to varying individual emphases, at least they were not in contradiction with one another. As soon as the Cultural Revolution erupted, all such matters fell into a muddle. "Obey the Party's instructions" was still an absolute command, yet the issue of "Who represents the Party?" was no longer so clear-cut. A whole slew of Party leaders were denounced as "capitalist roaders," and it was now said that a "bourgeois class headquarters" existed within the Party itself. In that case, was the "proletarian class headquarters headed by Chairman Mao" a surefire thing? No, it was not, either. First, several important members of CCP Central Committee's Cultural Revolutionary Group were toppled from power. After that came PLA Vice Commander-in-Chief Lin Biao's "rebellion against the Party and escape abroad." ${ }^{\prime \prime}$ At various stages of the Cultural Revolution, even Mao Zedong himself issued widely contrasting directives, thereby making it difficult for people to figure out which one they ought to be following at the moment. The same conduct that had yesterday been validated by the Maoist slogan of "rebelling is justifiable" would today metamorphose into a sinister "interference with the grand strategic deployment" of the Party. None of the progressive exemplars in each and every profession escaped vitriolic attack during political movements - they were either denounced as "old fogies," or else accused of "having been led astray." How could people emulate this sort of progressive exemplar?

After all, thought remolding is not the same thing as moral selfperfection. In the final analysis, the issue of whether a person's thought has been thoroughly remolded or not depends on whether he has adhered firmly to the proletarian class's standpoint and toed the Party's revolutionary line in the midst of real-world class struggle. In contrast, if you have "lined up in the wrong group" or "committed blunders," that would necessarily prove that your "bourgeois-class weltanschauung" has not yet received proper remolding. Determinations of whether something is right or wrong could not be based on your own independent judgment, but had to be decided by the Great Leader. ${ }^{8}$ Under such circumstances, the criteria for thought remolding slipped into a morass of contradictions and extreme confusion, in which the ordinary person felt more and more at a loss. 
In the beginning, many people were determined to self-consciously grasp the proletarian-class weltanschauung so as to maintain a correct standpoint amidst the complicated struggle. However, as time went on they could not help but discover that if they wished to guarantee the correctness of their standpoint, it would be better for them to blindly follow along behind the Party (in the words of a rather satirical slogan at that time: "Once Party Central announces its position, I'll then declare where I stand; in the later stages of a movement, I'll become a leftist.") However, even when such persons were blindly following along behind the Party, they had to keep from becoming too enthusiastic. Since the top authorities would often change their mind, it would be safer for their followers to drag their feet a bit.

In other words, people of this type were originally enthusiastic about thought remolding and political movements, yet faced a troubling uncertainty about what they ought to do. Eventually, they could not help but turn passive in their external conduct, and could not help but drift along with the main current. During the latter stages of the Cultural Revolution, there was a dramatic increase in the number of people belonging to the Free-and-Easy Faction. A large component within this group amounted to precisely this type of idealist who had gone astray.

\subsection{Rebellion among Evaders}

Under normal circumstances, evasion is merely evasion. Yet under certain special circumstances, evasion amounts to a form of rebellion. At the point when such evaders discover they have gotten stuck in a difficulty from which there can be no place to hide - and thereby have no recourse but to adopt affirmative measures in order to shake off enormous pressures from their milieu - rebellion will then break out. However, rebellion still amounts to a mode of evasion under these circumstances, since such rebels' sole purpose is evasion. In order to distinguish this activity from the rebellion of bona fide rebels, I refer to it as the rebellion of evaders. Having occurred in the mid-to-late I970s, the educated urban youths' "Great Victorious Escape" - also known as the trend of returning to urban areas - can be considered a vivid example of this type of evaders' rebellion.

According to Mao Zedong's explanation, the reason that educated urban youths needed to head up to the hills and down into farming villages was to obtain reeducation - in other words, thought remolding. Compared with other forms of thought remolding, the campaign of heading up to the hills and down into farming villages was even more directly compulsory in nature. Other forms of thought remolding such as attending study sessions, critiquing one's thought and engaging in 
criticism and self-criticism involved the "mind," but not the "body" - at least that is the way it was for the average participant. Because of this, a person could almost always go through the motions in a merely oral fashion and in a perfunctory manner, while absent-"mindedly" maintaining his original way of life just as it had been before. In other words, a person could superficially participate in remolding, but in actuality evade it, just muddling through absent-mindedly. In contrast, heading up to the hills and down into farming villages directly rendered the remolding regimen into practical action. It forcibly pushed your "body" - that is, your actual life - onto the tracks of its special design. Once you were "trussed up on the war chariot" and no longer had any control over your own body, the question of whether you were actually sincere or not did not seem so important any longer. At this juncture, you could not even begin to talk about "evasion."

There is no need to mince words - the main reason why many of the educated urban youth harbored an attitude of dissatisfaction with heading up to the hills and down into farming villages was that they were reluctant to leave their comfortable urban lifestyle behind. Since your body had truly made its way down into a farming village and its arduous way of life, your hopes for leading a comfortable life were thus truly dashed to smithereens. Some of the educated urban youth drew upon such pretexts as a "departure due to illness" or a "hardship withdrawal" in order to return to the city, while other educated youths managed to leave the countryside on account of receiving admission to college or garnering recruitment as workers or soldiers. This was evasion - if you had harbored the attitude of evasion - because on the surface you did not reject thought remolding in the form of the campaign of heading up to the hills and down into farming villages. The rest of the educated youths could not help but realize that if they wanted to evade the campaign, they would have to reject it directly; they would need to rebel against it.

Originally, the primary desire of these educated urban youths was merely to lead an uneventful life of an ordinary and comfortable sort. However, during those fiery decades of revolutionizing thought - and under the harsh conditions of heading up to the hills and down into farming villages - a life of mediocrity became a luxury. Because mediocrity necessarily and directly rejects those gigantic political pressures that have been exerted in the name of an ideal, to insist upon mediocrity would actually become a rebellion that was far from mediocre. If we were to borrow an ancient saying and designate thought remolding as "the preservation of heavenly principles and the elimination of human desires," 9 then the demands from educated urban youths to return to the city amount to a rebellion against heavenly principles on the part of human desires. 
This was quite a peculiar conflict. The most embarrassing aspect was that most of those who were fleeing back to urban areas still acknowledged - or at least did not oppose - the theoretical undergirding of that big assemblage of official notions about reeducation through labor. These youths were not resisting officialdom's original ideals about reeducation through labor with a different ideal of their own. Instead, they were merely drawing upon ordinary human desires that even they themselves regarded as not all that honorable or just - and were doing so in resistance to heavenly principles that even they themselves acknowledged as great and sublime. The rational basis that they could find for their own rebellion remained so very weak, yet the emotional desire that drove them to rebellion waxed so very strong. They felt as though they were deserters who had lost their courage, and yet to desert their posts in the face of battle required quite a bit of courage in and of itself. Their stance was simply self-contradictory.

In fact, it is not that difficult to unravel this conundrum. When ordinary people made a resolution to throw themselves into a struggle of striving for mediocrity, they had already partially transcended mediocrity. Thoroughly mediocre people would not have participated in this kind of resistance; they would have much preferred to hitch a ride in someone else's car and enjoy the cost-free fruits of other people's resistance. In contrast, none of those who dared to stand at the forefront of the resisters' ranks and lead the resistance could have been mediocre individuals.

Furthermore, opposition to the rustication policy is related to the background of how such resistance occurred as well as the methods used in its pursuit. We know that basically all of the demands to return to the city that were publicly announced by broad swaths of the educated youth occurred after Mao Zedong's death and the collapse of the "Gang of Four." At that time, the correctness and necessity of the campaign to head up to the hills and down to farming villages came under increasingly wide-ranging questioning, while related political pressures to maintain the campaign shrank accordingly. The educated youth from various places who mobilized to resist the rustication campaign typically ran into the thousands and adopted the method of collective action. In accordance with the custom whereby "even the law would not antagonize the crowd," this method minimized the level of risk for any individual among the ordinary participants. Just like all other campaigns of rebellion that lack a sense of moral superiority, the campaign for the educated youth to return to their cities exerted aggressive pressure through public opinion on both non-participants as well as the faction who had long demanded that rusticated urban youth "strike root" in the countryside, thereby giving rise to an atmosphere of fervor and solemnity among the resisters. 
At first glance, this resistance to rustication was merely one in which human desires rebel against heavenly principles and mediocrity rebels against the sublime. However, in actuality it also signified the rebellion of freedom against coercion. After all, coercion is nothing other than coercion, even if it embodies sublime aims and grand ideals. Similarly, freedom is nothing other than freedom, and it includes the freedom to lead a life of mediocrity. This struggle of the rusticated youth proved that the reason for the eventual defeat of the CCP's thought-remolding plan was not merely due to ordinary people's selfishness and mediocrity, which caused these mere mortals to fall short of that assemblage of sublime ideals. More importantly, it was also owing to the fact that the human spirit of freedom could not remain oppressed by an ideological tyranny over the long term. If we have merely noticed the first reason while failing to perceive the second, then our understanding of either human nature or thought remolding and totalitarianism still remains at a shallow level.

\subsection{Between Taming and Rebellion}

The Cultural Revolution was a political movement on an unprecedented scale. It was also a thought-remolding campaign on an unprecedented scale. Ironically, it was precisely within the ambit of this unprecedentedly large-scale thought-remolding campaign where evaders found a larger and larger space for their existence.

First, due to denunciations of the "bourgeois-class counterrevolutionary line" during the Cultural Revolution, local Party organizations at all levels sank into total paralysis. Consequently, the selfsame local Party officials who had been carrying out the most direct supervision of people's everyday lives rapidly disappeared from the scene. Even though Mao Zedong's authority at the very pinnacle of state power was greatly intensified during the Cultural Revolution, the Party-state's central authorities usually possessed nothing more than an indirect control over ordinary people due to the former's remoteness from the masses; the central authorities were even easier for ordinary people to deal with in a perfunctory manner than what one might have expected. This is illustrated by the old proverb: "The county magistrate brings less authority to bear than your immediate supervisor." ${ }^{\text {Io }}$ As we know, the most important factor in implementing thought remolding has been that the Organization must impose strict control over the individual, carefully keeping watch over how every person behaves in public, and rewarding or punishing people on the basis of whether it likes or dislikes what they have done. Yet now that the Cultural Revolution was in full swing, the local organizations that had formerly served as interme- 
diaries between Party Central and the masses had been temporarily destroyed. In this way, the Party lost a great deal of the wherewithal it had formerly wielded for exerting pressure on the masses by means of control, surveillance, rewards and punishments.

Compared with the period before the Cultural Revolution, thought remolding during the Cultural Revolution was carried out in a far more inflammatory manner, with constant demands to "fight selfishness and denounce revisionism," "let not a day pass without reading (the little red book of quotations from Mao Zedong)," and "ask for instructions in the morning and submit reports in the evening." ${ }^{\text {II }}$ However, because there were no longer any local officials to provide direct supervision, there was no other way for thought remolding to occur except by depending even more heavily upon each person's level of individual awareness; this situation thus became even more convenient for people who preferred to evade remolding. Once the direct pressure upon ordinary people to remold themselves substantially decreased, it became all the more possible for them to evade remolding altogether.

As a result of protracted and wildly fluctuating political struggle, the masses' belief in such struggle and their enthusiasm for participating in it could not help but grow more tattered every day, and their attitude toward political movements also grew more negative with each passing day. According to CCP theory, the remolding of the subjective world is inextricably bound to the remolding of the objective world. Consequently, once people escaped from real-world political struggles, they would invariably "relax" their efforts at remolding their own thought. In parallel with the spreading syndrome of political indifference, more and more people began to reorient themselves with a new focus on private life, and started leading quiet lives of mediocrity amidst all the noise and bustle: they played poker, raised goldfish, knitted sweaters, dabbled in carpentry, hummed or sang non-revolutionary songs, and amongst friends circulated novels that the Party had pigeonholed and decried as "feudal," "bourgeois," or "revisionist." ${ }^{2}$ People suddenly discovered that the sort of mundane life with its individual comforts that they had formerly disdained was actually well worth yearning for and pursuing.

At the same time, the fondness for professional skills was also slowly developing. For example, some individuals were learning foreign languages or practicing the arts; others were studying one or another subject on their own, including mathematics, physics, chemistry and electronics. Some people learned one of the professions in order to banish ennui; others did so for their own pleasure; while still others with more foresight believed that China would experience a "knowledge deficit" and "skills deficit" in the near future, so that nobody with one skill or another would have any more worries about whether it could be put to good use. In the past, many individuals within the intelligentsia were 
denounced as "reactionary and professional"; ${ }^{\mathrm{I3}}$ in reality, this was an unjust accusation, because they were not necessarily averse to the imperative of "revolutionizing your thought." Yet by this later stage of the Cultural Revolution, people were instead intent upon becoming "solely professional, not revolutionary." ${ }^{4}$

Each type of response alluded to above no doubt constituted evasion - people were evading thought remolding and evading political struggle. At that time, this type of evasive behavior played a very positive role. Objectively speaking, it amounted to rebellion, even if merely passive rebellion. As I pointed out in Chapter Two, thought remolding is a product born out of the combination of an active element of taking the initiative on the one hand, and a passive element on the other. ${ }^{15}$ Profound changes in the average person's mental state weakened the active element of taking the initiative, while the destruction of the Organization's original control system further weakened the passive element. Consequently, the entire thought-remolding campaign started to go downhill and found itself in an impasse. Even though the CCP reestablished the Organization's control system during the last stages of the Cultural Revolution, the mental state that had been lost could no longer be retrieved; thought remolding retained merely an empty shell of its former self, while no longer possessing any dynamism.

Compared with the process of getting tamed, the process of evasion looks like rebellion. Yet compared with rebellion, evasion looks like getting tamed. This can be observed during the middle and latter stages of the Cultural Revolution. Let us assume that there are two groups of educated youth. One group assembles to play poker and gamble all day long, while the other group gathers together to read books on politics and discuss weighty national affairs. After the Security Section cadres discover what these two groups are up to, they would invariably say: “We needn't bother keeping tabs on the first group, but we've got to impose strict surveillance over the second group." Due to the heightened level of threat from the rebels, the evaders would appear even more harmless in comparison, and evasive behavior would thus garner even more tolerance. At such a time, evasion amounted to nothing other than evasion - merely that and nothing more. In the end, the rulers began to discover that perhaps evasion was actually something worthy of covert encouragement.

\subsection{The Legitimization of Evasion}

During the early I980s, the CCP authorities publicly announced the ejection of the term "thought remolding" from their official lexicon. ${ }^{16}$ The thought-remolding campaign thus died a natural death at this junc- 
ture. In fact, even before this clear proclamation came down from officialdom, the thought-remolding campaign had already become a spent force, existing in name only during its final years.

We all know that thought remolding is a negation of the freedom of thought. However, the end of thought remolding was not at all equivalent to achieving the freedom of thought. During the Deng Xiaoping Era, the CCP was already bringing a gradual stop to the forcible instilling of its ideology into the minds of its citizens. However, at the same time the Party still continued to implement severe prohibitions on the airing or dissemination of political dissent. The space for private activity enlarged rapidly, yet the space for public activity seldom expanded. Apolitical academic research and artistic creation obtained wide-ranging opportunities for development, yet the free-ranging and public discussion of politics remained a taboo area.

A combination of economic openness and closed-off political insularity has become the most salient characteristic of Chinese society at this stage. Under these circumstances, evasion has no longer been subject to any difficulties whatsoever. You no longer even need to repeat whatever the Party says or follow the Party's latest trend. It is now completely permissible for you either to safely go back to your private life and lead your own mundane life in peace and with freedom from interference - or else to immerse yourself all the way up to your ears in your own profession or in money-making. To be sure, the government is still loudly chanting such clichéd slogans as the "Four Upholds," yet it no longer expects that people can sincerely believe in such slogans any more - nor does it still require that people necessarily chime in and chant along in unison with the government. ${ }^{17}$ As long as you do not publicly or directly criticize or oppose the government, it will be almost entirely satisfied with you.

At such a juncture, what sort of significance does evasion still hold? Quite a few people like to emphasize the rebelliousness of evasion. Since evasion signifies disgust and weariness with political struggle, heralds the abandonment and rejection of ideology, and points to a renewed recognition of the legitimacy of individual material interests, it can thus function as a powerful antidote to totalitarianism. In consideration of the fact that the spirit of Mao Zedong still hovers about and has not yet been dispelled, the above-stated view of course makes sense. ${ }^{18}$ Yet this does not resolve the problem at hand.

At this point there would be no harm in quoting a passage from Marx's sayings, with which we Chinese are relatively familiar. When denouncing the Prussian authoritarian government's system of press censorship, the young Marx pointed out: "The only things that have exerted a corrupting moral influence are the censored publications. The greatest evil - hypocrisy - is inseparable from this. Stemming from this 
point of fundamental wickedness are all the other flaws that are entirely lacking in moral conduct, including its ugliest point of wickedness (even from an aesthetic perspective) - negativity. The government hears only its own voice and also knows that it hears only its own voice. Yet it deceives itself, acting as though what it is hearing are the people's voices, and even requires that the people support this type of self-deception. As for the people themselves, if they have not become mired in the government's political superstitions (though sometimes believing in nothing at all), then they live completely separated from the life of the nation, having become a tribe of people who care only about their private life." ${ }^{\text {I9 }}$

It is obvious that in Marx's view, to "believe in nothing at all," to "live completely separated from the life of the nation," and to "care only about their private life" are by no means matters to be celebrated or to feel gratified about. Instead of interpreting evasion as a way of resisting or even overcoming authoritarianism, we would be more accurate in saying that it is precisely a result or a byproduct of authoritarianism. It can even function as an alternative form of support upon which authoritarianism relies for its survival. According to Irving Howe, a person is not at all overstepping the bounds of totalitarianism when he is cynical, has "seen through it all," or is indifferent to politics. On the contrary, such behavior still remains well within the gambit of authoritarianism, and is situated within the final stages of totalitarianism (as previously discussed in the preface).

When considering the danger that a democracy might be transformed into an authoritarian regime, Tocqueville offered his readers a cautionary argument. To wit, the citizenry will have thrown open the gates for a dictator to take over the political stage if one or more of the following conditions apply. The first condition is if people care about only their own work, but are unwilling to bother themselves with public affairs. The second is if we pay excessive attention to our individual affairs while neglecting one important matter, namely that we should be our own masters. The third condition is if people merely pursue the advancement of their material well-being, and so as long as the rulers manage to provide various material advantages within a certain period of time, the people would then allow the rulers to do anything they wanted, no matter if those things were good or bad, just or unjust. The fourth is if before people have discovered how beneficial liberty is to the attainment of material well-being and how the abuse of liberty can lead to the destruction of that selfsame material well-being, they would be ready to abandon liberty as soon as they encountered any societal disturbances - out of fear that public fervor would negatively influence the petty serenity of their private life. "If a people only ask their government to maintain order, they are already slaves in the depths of their 
minds - namely, the slaves of their own wealth - and the person who will rule over them will soon appear." ${ }^{20}$ Totalitarian rule is established by means of popular fervor, yet all it needs to keep it going is for people to maintain a stance of indifference.

\subsection{Evasion as Being Tamed}

In order to explain the issues raised in the previous two sections, it is necessary to supplement the discussion further.

Evasion undergoes a complicated process as it sheds its rebellious overtones. Wearing bell-bottom jeans, listening to songs by Deng Lijun, ${ }^{2 \mathrm{I}}$ talking about Freud, Sartre, the Big Bang Theory, avant-garde art, or individual entrepreneurs, adopting a "money-first" attitude in every matter and exploring a certain sort of sexual freedom - none of these activities originally belongs to the realm of politics. However, if viewed from the perspective of an all-inclusive totalitarian politics, there is not a single one of these activities that does not function as a component of politics, and thus none of them fails to signify rebellion. This is the reason why the CCP regime would denounce and restrict the above list of activities over a relatively long period of time - in the name of "opposing (bourgeois) liberalization" and "eliminating spiritual pollution." ${ }^{22}$

The year 1989 was a turning point. During the late spring and early summer of that year, the world-shaking I989 Democracy Movement erupted in China. The CCP regime encountered its most serious challenge of the previous forty years. The June Fourth Massacre temporarily frustrated the Democracy Movement, yet it also caused the CCP regime to forfeit the legitimacy that it had originally possessed. Roughly speaking, what we mean by "legitimacy" is the justification or basis on which ordinary people accept the existence of a regime. In the past, the legitimacy of the CCP regime was mainly based upon its theory of communism, including its series of doctrines about the proletarian class and the mass public rising to serve as masters of the nation, and about socialist economics being superior to capitalist economics. The June Fourth Incident as well as the subsequent collapse of the international communist camp finally led to the complete bankruptcy of the aforementioned myths. Under such circumstances, on the one hand the CCP continued to rely upon its undisguised brutality to intensify its severe suppression of the liberal democratic movement, and on the other hand accelerated the pace of its economic reforms (not bothering about whether it was following socialist or capitalist economics - in actuality it largely adopted a capitalist mode of production). At the same time, the regime embarked upon a large-scale relaxation of its control over other domains of social life. The CCP regime of today has already abandoned various 
key features of totalitarianism, along with reviving a number of the characteristics of traditional authoritarianism. For example, it has begun to pay attention to the need to respect traditional social customs, and it no longer interferes with private property and family relationships - or at least it has begun to seldom interfere with these things. It was only at this juncture when evasion finally attained a relatively thoroughgoing status of legitimacy, thereby losing its rebellious quality.

The astonishing scope of the 1989 Democracy Movement indicates that it is incorrect to claim that the Chinese people have not pursued freedom and democracy. The collapse of the communist system in the former Soviet Union and the various Eastern European countries no doubt further enhanced people's belief in the triumph of liberty and democracy. It is merely on account of having been compelled through intense pressure that ordinary Chinese people have had no choice but to adopt an attitude of putting up with the current regime. However, just as I pointed out many times when explaining the process of taming, there is a possibility that putting up with something undergoes a transformation into an acceptance of it, whether intentionally or unintentionally. While autocracy is nothing other than autocracy, the stability that may be found under autocratic rule is after all stability. All things considered, economic development is something positive, not something negative. Yet while the long-term vision of freedom and democracy is naturally glorious, their short-term prospects do not appear so welldefined. Consequently, given that some people have proceeded from the two paths of stability and economic development, they have begun to accept the existence of the current regime, and more or less have conferred upon the current regime a certain type of new legitimacy. Considering how that even under a democratic system, there would still be some people who would not mind the emergence of autocracy (see the argument of Tocqueville quoted in Section 4.6 above), we would have no more difficulties in understanding why certain persons under autocratic rule no longer demand freedom and democracy.

When a person is not simply putting up with autocracy but has accepted its existence, whether self-consciously or not - that is to say, he cares only about the serenity and happiness in his private life and has absolutely no intention of concerning himself with society and public life - and it is not a case of his not daring, but rather his unwillingness, to protest against the evil of autocracy's oppression of freedom - then even though he has never participated in any of autocracy's atrocities, this sort of evasion is still similar to having been tamed, or to a form of having been tamed. 


\subsection{Evading the Persecuted}

The varieties of evasion discussed above refer to evading thought remolding and political campaigns. There is yet another frequently encountered aspect of evasion - namely, evading persons who are being persecuted. Havel has remarked upon having formerly been put under surveillance by the police while participating in the Charter 77 Movement. ${ }^{23}$ For some of his friends and companions, this constituted "inconvenience," and so those people adopted a posture of avoidance toward him.

The sort of situation described by Havel is a common occurrence in communist countries. Since communist regimes punish dissidents harshly and often extend such punishment to dissidents' relatives and friends, many of those who have been close to the persecuted person have had no recourse but to distance themselves from the persecuted person out of the need for self-protection - they would "draw a clear line of demarcation" between themselves and the dissident. ${ }^{24}$

True, there was indeed such an era. Back then, some people genuinely believed the government's propaganda; they genuinely considered the persecuted dissident to have been "an enemy of the people" and thus deserving of his punishment. Taking the standpoint of what they believed to be truth and justice, they made a clean break with the persecuted, going so far as to participate in the persecution itself. Their behavior was no doubt foolish, yet their motives were nonetheless likely to have been pure.

In centuries past, the Czechoslovakian religious reformer Jan Hus was denounced by the Catholic Church as a "dangerous heretic." The Church thereupon ordered that Hus be executed by burning at the stake. While he was being tied to the stake, an impoverished whitehaired old lady brought over a few pieces of brushwood that she had found in her house and piously added them to the heap of wood around the stake. Upon witnessing this scene, Hus could not help but sigh, "Sancta Simplicitas!" [Holy Simplicity]. ${ }^{25}$

What I would like to emphasize instead is that even during those years of fervent superstition in the past, this sort of "holy simplicity" was not widespread. Much of the behavior connected with "drawing a clear line of demarcation" embodies a self-centered psychology whereby one fears the powerful and seeks to protect oneself. When we consider the huge pressure that the regime exerted on them, perhaps we should not overly excoriate those who strove to protect themselves, but should instead resemble Havel in extending to them a bit more understanding and forgiveness. A brave man should realize that it is not at all the case that everybody else is endowed with as much courage as he is; he thus cannot demand that everybody else show as much bravery as he has. 
Furthermore, why after all are we impelled to risk danger and struggle on courageously? Is it not precisely for the sake of establishing the sort of society in which an ordinary person would no longer need to bear too heavy a risk when simply expressing his own opinions on politics?

Yes, if a person adopts a posture of avoiding a persecuted dissident merely due to the psychology of fearing the powerful and seeking to protect oneself, this assuredly would not amount to any sort of courageous or high-minded behavior, yet it would still be excusable after all. This is because in such a case, the person's sense of right and wrong has not yet been extinguished. Deep within his heart, he resents the powerful regime and sympathizes with those whom it persecutes. He feels more or less guilty about his own deference to power and cannot help but harbor a certain measure of admiration for other people's courage. However, not every person who evades the persecuted is like this. In his open letter to Vaclav Havel, Joseph Brodsky pointedly asked Havel the following: ${ }^{26}$

Are you so sure you were avoided by those people then and there for reasons of embarrassment and fear of "potential persecution" only, and not because you were, given the seeming stability of the system, written off by them? Are you sure that at least some of them didn't simply regard you as a marked, doomed man, on whom it would be foolish to waste much time? Don't you think that instead of, or as well as, being inconvenient (as you insist) you were also a convenient example of the wrong deportment and thus a source of considerable moral comfort, the way the sick are for the healthy majority? Haven't you imagined them saying to their wives in the evening, "I saw Havel today in the street. He's had it." Or do I misjudge the Czech character? ${ }^{27}$

We should say that Brodsky was not at all off base in his remarks. People of this type may be found within any ethnic group. They are not necessarily unaware of the persecuted person's innocence, yet they would not admire or sympathize with you on account of your innocence - not even while chatting with their wives in private. The CCP regime is fond of nothing more than showing off the power and invincibility of its rule. This causes some people to believe that any type of rebellious behavior would be no different from fighting a hopeless battle due to overrating oneself, and would thus amount to sheer stupidity. The only wise move is submissiveness, or in other words to refrain from provoking the regime. Of course, people of this sort do not necessarily selfconsciously support the powerful regime and knowingly negate the principles of justice. After all, they do not directly participate in persecution, nor do they identify with that ideological system of persecution. 
They merely regard the avoidance of harm and the pursuit of their own interests as the highest principle in life, and thus rarely give any thought to distinctions between good and bad or right and wrong, owing to their indifference to such matters. Consequently, this type of behavior still belongs to the category of evasion, even though this mode of evasion is often less worthy of regard than even the state of being tamed.

\subsection{Indifference and Forgetfulness}

Indifference is not an evil, but it is a condition that enables any evil to occur. This is precisely what is described in the maxim written by Wojciech Jasinski and quoted by Poland's Lech Walesa: ${ }^{28}$

Do not fear your enemies,

Who under the worst circumstances would kill you;

Do not fear your friends,

Who under the worst circumstances would betray you.

Yet you must beware of a crowd of the indifferent,

Only under whose silent consent,

Can slaughter and betrayal exist in this world. ${ }^{29}$

Indifference refers to showing neither support nor opposition to state repression, and neither condemnation nor sympathy for the persecuted. Of course, this refers to a person's external behavior, since it is hardly likely that a given person would have no preference deep down in his heart. Generally speaking, indifference or evasion initially derives from a person's revulsion for state repression as well as sympathy for the persecuted. While it is not wrong to say that silence means tacit consent and thus is an accomplice to injustice, it might be even more accurate to say that silence signifies indignation toward injustice and thus means resistance. However, on the basis of the principle that a person's behavior can influence his attitude, the latter type of evasion might metamorphose into the former type of evasion. ${ }^{30}$ When a person maintains silence in the face of state repression, it might initially be due to his feelings of resentment toward injustice. Yet once a long stretch of time had passed, his feelings of resentment would have gradually lost their intensity, finally transmogrifying into mere numbness and indifference.

Some people would initially feel sympathy for the victims, but on account of their own fears they would not dare to express their thoughts openly, and thus would always harbor some feelings of guilt. In order to overcome this sort of guilt, if such a person were not to proceed to the next step and express his sympathy for the victims, he would turn 
around and try to persuade himself to believe that the victims were not necessarily so deserving of his sympathy. For example, he would blame the victims for overestimating themselves, for behaving unwisely, and the like. While he would still admit that the victims were innocent and had been wronged, by this point he would no longer harbor much righteous indignation; he would merely sigh about others being "down on their luck." At the same time, he would no longer feel ashamed about having failed to participate in resistance to state repression, but would instead congratulate himself for having been able to remain safe and sound. The type of evasion mentioned by Brodsky is precisely of this sort.

A large-scale and brutal persecution of victims would stir up wideranging outrage and an upsurge of sympathy for them. Yet after the event, this sort of outrage and sympathy might very well gradually subside. Of course, that has a lot to do with human forgetfulness. To put it more precisely, the forgetfulness in such a case is actually selective forgetfulness. People forget because they want to forget. Having a knack for forgetting suffering might well be a sort of protective instinct of the human mind, yet it is not lacking in negative side effects. In particular, to forget the suffering discussed here refers to forgetting other people's suffering. Therefore, it has nothing to do with the health of the human psyche, but merely indicates a downward spiral of the sense of justice. This is precisely the level of significance at which we proclaim that humankind's struggle to resist political might is nothing other than human memory's struggle to oppose forgetfulness.

\subsection{The Rationalization of Evasion}

Indeed, the state of being tamed can be expressed through the form of evasion. While evasion is merely evasion, if an evader were to improperly claim that he was actually rebelling, such evasion would in fact metamorphose into the condition of being tamed.

There are a few viewpoints nowadays that rationalize evasion. One such view claims that political indifference is a good thing, not a bad thing.

Not so long ago, Li Zehou and Liu Zaifu published a full-length book of dialogues between them entitled Farewell to Revolution, in which political indifference is mentioned quite a few times. ${ }^{3 \mathrm{I}}$ Both Li Zehou and Liu Zaifu consider the flagging of interest in politics to be a good thing and deem the widespread lack of concern about politics to also be a good thing. Since it is said that such a viewpoint is popular within China, we need to examine it. 
The first issue I would like to raise is that a de-emphasis on politics is not the same thing as an indifference to politics. A de-emphasis on politics means to "give God what is due to God, and give Caesar what is due to Caesar." Economic and academic activities should have their own independence and should not be controlled or interfered with by politics. As far as this point is concerned, a de-emphasis on politics is a good thing. Yet an indifference to politics is quite another matter altogether. Whether he is a businessman or a scholar, a person is first and foremost a citizen. As a citizen, he should cherish individual freedoms and rights, conscientiously perform the duties of a citizen, and take an active concern in public affairs. An indifference to politics means abandoning the identity of a citizen and thereby degenerating into an obedient imperial subject, who "avoids the table for fear of discussing censorship" (being afraid to concern himself with politics) and "writes books merely for the sake of earning a livelihood" (focusing wholly upon making money). How could this approach to life be considered a good thing?

Li Zehou claims that a lack of concern about politics is an indication that people have walked away from the era of phony politics, and thus is a development of immense significance. This is wrong, because the indifference to politics we are now discussing is not comparable to the situation during the Cultural Revolution, but is instead comparable to the situation immediately preceding the June Fourth Incident in I989. Naturally, the sort of "concern about important national affairs" prevalent during the Cultural Revolution was not something worthy of commendation (yet we should not totally reject the concern about politics during the Cultural Revolution - though this is not an issue I will be discussing further here); however, the Chinese people's concern about politics on the eve of the June Fourth Incident no longer belonged to that type of phony CCP politics or the principle of class struggle. The Chinese people's ardent concern about politics right before the June Fourth Incident represents the awakening of the consciousness of one's role as a citizen, as well as the vigorous pursuit of freedom and democracy. Was that not something beneficial?

It has long ago been pointed out that widespread political indifference is one of the disastrous consequences of autocracy. Hence, to shower praise upon this sort of political indifference actually amounts to showering praise upon autocracy. If people in general do not dare show any concern about politics due to suffering from intense tyranny, this would of course be pardonable. However, one must remember that putting up with oppression on account of having no alternative is one matter, while rationalizing oppression away is quite another matter altogether. "No discussion of national affairs" is an admonition that was frequently posted on a wall indoors in times of yore, whereas nowadays 
a segment of the intelligentsia strives hard to inscribe this maxim in people's minds. ${ }^{32}$ Consequently, in one leap passive submission has transformed itself into active identification, while in another leap shame has suddenly transformed itself into glory. No other case of confounding right and wrong has gone further than this.

On more than one occasion, newspapers in China have revealed incidents such as the following: a group of ruffians openly bullies and injures some people in a public place out in broad daylight, yet while bystanders numbering in the hundreds look on, not even a single one of them extends a helping hand to any of the victims. When reading this sort of news bulletin, everyone sighs about the decline of publicspiritedness in society nowadays. However, even such a pathetic display of public apathy is dwarfed by the phenomenon of political indifference. While the focus of worldwide attention in I989, the CCP killed thousands of peaceful citizens. Even up to the present day, the reputation of the dead has not yet been vindicated, their relatives still suffer from enormous discrimination and oppression, and one group of dissidents after another has been kept under surveillance, tortured, or even brazenly tailed by plainclothes police in broad daylight. Yet precisely under such circumstances, many people have turned a blind eye and a deaf ear to it, have looked upon it with folded arms as unconcerned bystanders, have remained aloof and unmoved and have even felt satisfied with themselves, having whitewashed their conduct as a "lack of concern about politics." As I said previously, if people in general temporarily do not dare show resistance to tyranny out of fear, that would still be excusable. Yet no matter what, we must never praise or affirm this sort of "lack of concern about politics."

Tocqueville puts the matter very well:
Among all the evils of the human heart, it is egotism that autoc- racy welcomes the most. As long as the people over whom he rules do not cherish one another, the autocrat readily forgives the people for not loving him. The autocrat will not invite the people under his rule to help him govern the country; as long as those under his rule do not wish to encroach upon his duties of nation- al leadership, he is perfectly satisfied. ${ }^{33}$

Tocqueville also pointed out: "Autocracy causes people to see mutual disregard as civic-mindedness." ${ }^{34}$ If a person proclaims his lack of concern about politics, we must pursue this line of questioning and ask him: "In the event of an autocrat's violation of basic human rights, would you not even show any interest in this?" If the answer is that you would indeed not express any interest, your "lack of concern about politics" is nothing more than mere submission to autocratic politics. 
The October I995 issue of the magazine Dushu (Reading) published a short essay entitled "Is Political Indifference Something Bad?" Claiming to have adopted the standpoint of liberalism, ${ }^{35}$ the author Yan Jirong offers his forceful affirmation of the phenomenon of political indifference. In this short essay, the author puts forward the following argument:

Liberalism has had a political credo, namely, "The government that governs the best is the one that governs the least." "To govern the least" means that the political influence on people's life is the least, and thus it also means that the concern people must have for politics is the least. In this understanding of liberalism, therefore, the sort of politics that ordinary people seldom bother thinking about is precisely the best politics. ${ }^{36}$

In this argument, the author committed a conceptual blunder: he lumped "government" and "politics" together as if they were one and the same thing. In fact, what liberalism adamantly opposes is for government to take charge of politics and to monopolize the political landscape. Liberalism requires government to intervene in fewer matters; its purpose consists in advocating that ordinary civilians intervene in more matters, not that they refrain from intervening in anything. In other words, liberalism advocates that ordinary civilians should strengthen their independent political function as well as supporting both civilian self-governance and political pluralism. From the credo, "the government that governs the best governs the least," you simply cannot derive the following conclusion: "The politics that ordinary people concern themselves about the least is precisely the best politics."

As I pointed out in my article "The Fate of Liberalist Thought in China," 37 various strains of thought in traditional Chinese political culture indeed appear somewhat similar to liberalism, as can be seen in a few lines from an old folk poem - "At dawn I start working,/ At dusk I rest from toil,/ What does the emperor's authority matter to me?" - as well as in the ancient philosophical idea of "ruling the state through inaction." ${ }^{8}$ However, because

the ancient Chinese did not have any concept of "rights," they did not perceive "the prevention of governmental interference in individual freedom" to be an inviolable right. Consequently, in ancient China, individual freedom was not only uncertain, but was also often restricted within a purely personal realm. The Daoist idea of "ruling the state through inaction" surely encompasses the legitimate wish that the ruler not interfere with people, yet as a corresponding request it also requires that ordinary 
people abandon learning and intelligence, stay out of touch with the outside world, and remain completely non-politicized. Major differences obviously exist between this and liberalism. ${ }^{39}$

Incidentally, Mao Zedong once referred to the notion, "when a matter does not concern you, you should not bother with it," as liberalism - of course, this is a laughable misreading of liberalism. In the several aforementioned viewpoints that praise political indifference, the contenders all couch it in the name of liberalism. In fact, their "liberalism" is nothing more than the "liberalism" which Mao Zedong deliberately distorted, and has absolutely nothing to do with genuine liberalism.

The second viewpoint that rationalizes evasion is "No Arguing." This view originally derived from Deng Xiaoping. ${ }^{40}$ "No Arguing" means that one is not supposed to argue whether a policy is "socialist" or "capitalist" in nature, but it also means that one is not supposed to have any other arguments about political viewpoints, either. For the sake of developing the economy, the regime introduced capitalism on a huge scale. When the Extreme Left (a term that I shall use for the moment) demanded to know whether the new economic policies were "socialist" or "capitalist," the regime could not very well reply, and thus simply decided to prohibit further debate on this issue. As Deng would often quip: "No matter whether it is a white cat or a black cat, as long as it can catch mice, then it is a good cat." ${ }^{\mathrm{I}}$

Subsequently, some people came forward to demonstrate the soundness of the directive, "No Arguing." According to them, all of China's calamities in the past stemmed from "arguing," as well as from having forgotten the wise adage of the ancient sages: "Persuasive argumentation is silver, while silence is golden." There were also claims that "idle talk leads to the nation's downfall," that it would be better to expend our energies on more practical tasks, and so forth..$^{42}$

However, a problem with this line of argument is that demonstrating the soundness of the directive, "No Arguing," is itself yet another type of persuasive argumentation. Furthermore, how can there have been "arguing" in China during recent decades in the past? "Even during the 'Anti-rightist' period and the Cultural Revolution era, which were considered to have been inundated with argumentation, could you have tried to argue a little with Mao Zedong or with the Cultural Revolutionary Central Committee? Clearly, what actually happened back then was nothing more than a sort of 'arguing without genuine argumentation.' "43

You might consider the directive of "No Arguing" to be of much significance if it could eliminate the clamor made by the Extreme Left, but this is not actually the case. First, Extreme-Left thinking has ruled over China for several decades, and is familiar to the ear and well understood by everyone in China. The directive of "No Arguing" can merely 
impede the dissemination of new thought, but cannot diminish the influence of outdated thought. In addition, the thought of the Extreme Left has enjoyed a certain type of legitimacy and the "No Arguing" ban does not wield much power of restraint over it. Second, everyone knows that in contemporary China, the Extreme Left is notorious and its social basis weak. Merely on account of the fact that the regime suppresses liberty and democracy, a modest number of people whose resentment cannot find any other legitimate means of expression sometimes cannot help but utilize rhetoric that bears some resemblance to Extreme-Leftist thought. This situation is reminiscent of the old adage: "The old tippler's mind is not on the liquor in his cup." 44

An even more important point is that power is the language of persons in power, while language is the power of powerless individuals. A person in power can naturally be content with having the directive "No Arguing," since he can depend upon his power to impose his own will on other people. Yet a powerless person cannot be content with having the directive "No Arguing," since argument is the only weapon he has available for defending himself against the powerful. Therefore, the socalled "No Arguing" directive is an entirely apt illustration of the proverb: "Only a prefectural official is allowed to set a house on fire, while the common people are forbidden even to light lamps." This is a situation in which the powerful are allowed to exercise out-and-out despotic control without a word of it disclosed to anyone, while the powerless can only submit meekly to oppression, unable either to raise a protest or voice a criticism. Lu Xun once remarked with a sigh: "What a pity that no ruler has yet been able to invent a type of drug that upon injection into the bodies of those he ruled, would make them completely silent, no matter how much oppression the ruler leveled over them." 45 Shifting back to the present day, if the directive of "No Arguing" that Deng Xiaoping invented were accepted by the powerless people as if it were a gift, would this not precisely achieve that drug's function of numbing the human spirit?

In Chapter Three, I discussed how ordinary people who have come under the regime's pressure move from an externally imposed "prohibition" to an internalized "renunciation," as well as make a "transition from compelled conduct to voluntary conduct." It is not difficult to see that the above-mentioned viewpoints that rationalize evasion in fact lump evasion and rebellion together, as if they were one and the same thing. Under these circumstances, evasion is no longer merely evasion, but is instead a form of being tamed. Perhaps that is the ultimate mode of being tamed. 



\section{On Rebellion}

\subsection{What is Rebellion?}

To define rebellion is not as simple as it might seem at first glance.

We can define rebellion as the behavior of publicly expressing a dissenting political view. It goes without saying that rebellion must be public behavior. If a subjective feeling of yours does not turn into concrete public action, then it does not have much significance. Yet it is not always this case. We know that when Hu Feng and his colleagues were denounced as a "counterrevolutionary clique," the private letters they had been sending to one another were seized upon as the primary type of incriminating evidence against them. ${ }^{\mathrm{I}}$

During all of the numerous PRC political movements, many people have been punished merely on account of having privately expressed various viewpoints. Of course, what has been regarded by the Party as rebellion is not necessarily equivalent to genuine rebellion; otherwise, the many travesties of justice that did occur would not have actually happened. However, because totalitarian rule swallowed up the entire domain of private life, anyone with a modicum of experience would know that even the private expression of dissent could be an extremely dangerous activity. Therefore, when a person is fully aware of the risks involved in a given activity and yet still goes ahead and carries it out anyway, that can indeed signify rebellion. I recall how unofficial publications were banned by order of the regime in I980, yet some Democracy Movement participants nonetheless printed essays in the format of "published for internal circulation," and covertly circulated the publications amongst themselves. ${ }^{2}$ This no doubt amounts to one form of rebellious behavior.

Let us turn to further discussion of what are called "dissenting views." Aleksandr Solzhenitsyn once sardonically referred to individuals who strive to toe the Party line as "persons without any dissenting views." 3 Yet since the Party's views are all-encompassing in their broad sweep and unpredictable in their transience, how can a person forever remain "without any dissenting views"? Hardly likely, unless he is bound and determined to abandon all of his own views and merely parrot the Party's views instead. In other words, for the average person, the 
issue of "dissenting views" is not a question of whether you have them or not, but rather a question of the quantity and significance of such views. If this is the case, then except for a group of people who either do not have any views or else are always prepared to abandon their own views in order to conform to the twists and turns of the Party line, everybody else is a political dissident, with the differences between them being merely a matter of degree.

Perhaps this sort of definition of dissidence is a bit too broad. Yet if we were to stipulate that dissenting views must refer solely to those that are aimed directly at the essential nature of communist totalitarianism, this definition would truly be excessively narrow. According to this standard, probably not even Peng Dehuai's Io, o०o-word letter could count as an expression of dissenting views. ${ }^{4}$ Defining dissenting views as self-consciously oppositional viewpoints does not seem to be sufficiently appropriate, either, because there is a type of "naïve communist" in the world: in and of themselves, the opinions of these people (such as Rosa Luxemburg) embody a fundamentally subversive significance with respect to the existing communist regime, yet these people believe that they have been protecting genuine Marxism and insisting on genuine socialism. ${ }^{5}$ It would seem preferable to view "dissenting views" as a synonym of "heterodoxy," that is, unorthodox views. Of course, this definition has its own difficulties, since the CCP has never compiled a detailed list of what it considers to be orthodox opinion, and the CCP's views have been so multifarious as to actually preclude the possibility of compiling such a list.

Furthermore, with the exception of unusual periods such as the Cultural Revolution, under ordinary conditions Party leadership has been implemented through all levels of the Party, from the Central Committee at the top all the way down to local Party branches, with no shortage of differences in implementation between one level and another. Some views that have been regarded as unorthodox by a person's own unit might not appear so unorthodox if considered by another unit or by the Party's Central Committee. For example, if various views of certain rightists during the Anti-Rightist Campaign were shifted forward in time to the context of the Cultural Revolution, such views could very well have been regarded as falling under the category of "rebelling is justified" and thereby approved of by the highest authorities. ${ }^{6}$

Moreover, even at the level of the Party's Central Committee, the content of orthodox views was often undergoing change, and the extent of these changes could sometimes loom quite large. A characteristic of autocracy is that its political power embodies an excessively wideranging arbitrariness. It is difficult for the citizenry in such a system to expect the behavior of the rulers to fall in line with their ordinary commands, since these commands do not exert a restraining force over the 
very rulers who dictate these commands. Strict obedience to ordinary commands issued yesterday, today, or tomorrow might even unexpectedly provoke a response of anger from the rulers, possibly to the extent of incurring a response of retaliation from them. In this way, the distinction between what is orthodox and what is unorthodox could be quite unclear. When we define dissenting views as unorthodox opinion, we should not forget about the sort of difficulties inherent within this definition.

\subsection{The Meaning of Writing a Letter to Chairman Mao}

A scholar of Chinese studies in the U.S. once asked me: "Why would some Chinese dissidents choose the method of writing a letter to Mao Zedong in order to express their dissent?" This is a very interesting question. Conversely, it also asks: if a person uses this method to express his opinion, would he be considered a dissident? Would his behavior count as rebellion?

Naturally, there is no single answer that would hold true in all cases. Some people detest the Chinese Communist Party-state above all else, yet in their frustration over the lack of an ordinary outlet for expressing themselves simply write directly to the highest authorities of the Partystate, pouring out their denunciations to their hearts' content. The CCP Central Committee received quite a few letters of this sort after both Tiananmen Square Incidents. ${ }^{7}$ The majority of people who have written this type of letter have done so anonymously, though some of the writers have signed their letters with their real names. Without a doubt, the latter group has been determined to fully vent their grievances in utter disregard of the risks this entails. These letter-writers have not necessarily expected the despot to suddenly wake up to the reality of the situation, but have merely wished to make the autocrat himself listen to the people's voicing of their outrage. No matter how positive a result such an action would produce, one need not doubt that it expresses a type of intense rebellion.

Of course, most of the people who have written to the Party's Central Committee or to Chairman Mao in order to express their dissent have not been of this type. Most people have still expected that the highest authorities could still muster a certain type of positive response. This approach might appear to belong to the variety of "only opposing corrupt officials, but not opposing the emperor," and thus would seem quite naïve. In actuality, this approach is not necessarily simplistic.

First, because "Heaven is high and the emperor is far away," 8 it is indeed relatively easy for ordinary people to assume that the problems of everyday life have merely resulted from "floating clouds obscuring the 
sun." 9 Consequently, such people imagine that they might persuade the emperor to bring about some sort of improvement in the situation by revealing it to him truthfully and explaining the reasons behind it. ${ }^{10}$ On the one hand, the emperor wields more power than anyone else to change government policies. On the other hand, the emperor is far above everyone else in status and seems transcendent, as if he had no direct responsibility for the problems of everyday life, and thus could very well adopt the posture of an enlightened ruler and bring about some improvement in the situation at hand.

Second, writing a letter is comparable to offering advice in private; it would not cause embarrassment to the highest authorities or put them on the spot. Therefore, even under the most autocratic system, this mode of communication would often be regarded as legitimate in principle and would be protected to a certain extent. In addition, precisely because the letter was written directly to the highest authorities, these authorities would find it inconvenient to crack down on its author, since they would not want to bear the responsibility for such a crackdown. When a ruler wishes to commit an evil act, he always prefers to make use of his subordinates' hands for its implementation. Once the ball lands directly in his own hands instead, he finds himself in an awkward predicament. For the letter-writer, the lack of any response from the ruler is itself a kind of response. If even the highest leader were not to punish him for the views expressed in his letter, other people would seem to have even less reason to punish him. Under such circumstances, if the letter-writer were to go public with the views in his letter, perhaps he would be able to win some more security for himself.

There would be no harm in citing a few examples. Late in the year of I972, Li Qinglin wrote a letter to Mao Zedong that recounted various travails suffered by educated urban youth who had been sent down to villages for resettlement. ${ }^{\mathrm{II}}$ Mao wrote back to approve of Li's views. All of a sudden, Li became a hero famous for "going against the tide."12 Among the several "going-against-the-tide" heroes who achieved recognition at that time (two others were Zhang Tiesheng and Huang Shuai), Li Qinglin was the only one whom ordinary people wholeheartedly praised. ${ }^{\mathrm{I}}$ This is because Li's behavior to some degree indeed signified going against the tide (to have vented the grievances of educated urban youth was indeed taking quite a risk) - and the content of Li's letter was also relatively fair and reasonable (within the scope permitted by the political environment at that time, of course). Yet on the other hand, to discuss something by writing a letter in private to the authorities not only lacks the significance of creating public pressure on the authorities - its content also seldom ventures beyond the scope permitted by the ideology current at a given time. Therefore, it would be difficult to discuss these sorts of action in terms of rebellion or resistance (one could 
also raise the same question about Peng Dehuai's Io, o०o-word letter to Mao).

The famous big-character poster by "Li Yizhe," ${ }^{4}$ "On Socialist Democracy and the Legal System," no doubt could be heralded as a significant masterpiece of rebellion. The subtitle provided by the co-authors of the big-character poster was "Dedicated to the Fourth National People's Congress." 15 While we do not know if this subtitle served any function in protecting the co-authors' personal safety, at least it was a brilliant strategy. Because the expression of dissent by means of an open letter would create the effect of publicly exerting pressure on the authorities, even if the political views therein might seem moderate, the rebellious quality of the open letter could still not be denied. There have been similar examples, such as when some overseas Chinese students published their open letter to the CCP regime leaders at the beginning of I987, expressing their dissent from the Anti-Liberalization Movement and during Spring I989 when Fang Lizhi and later Bei Dao, Chen Jun and others started writing open letters to the authorities requesting the release of Wei Jingsheng. ${ }^{\text {IG }}$

As previously mentioned, writing a private letter to the authorities about political issues is a relatively safe method of expressing dissent, yet under an autocratic system even this type of safety cannot be relied upon. Peng Dehuai's Io,০০o-word letter was originally a private letter written to Mao Zedong alone, yet Mao had this letter mimeographed and distributed to all of the cadre participants at the Lushan Conference; Mao presented this letter as evidence of Peng's crime - "rightleaning opportunism." Among ordinary citizens, ${ }^{\mathrm{I7}}$ there were even more individuals who were put through struggle sessions or imprisoned simply on account of having written to the authorities about a political issue. Ordinarily, this type of letter would not be delivered to the highest authorities at all, but would merely be mailed back to the sender's own work unit by a bureaucratic organ such as the central post office, and would thereby be handed directly over to the local bureaucratic organization to handle. In this way, the highest authorities could task the local bureaucracy with delivering severe blows to the letter writer, while at the same time absolving themselves from any direct responsibility in the matter.

During Deng Xiaoping's reign, we rarely heard about the persecution of ordinary citizens on account of their having written private letters to the authorities. When the Anti-Liberalization Campaign was launched around the beginning of I987, over a thousand Chinese students who were studying overseas signed an open letter expressing their dissent from this movement. Various other Chinese students overseas who shared the signees' disapproval of this campaign would not sign the open letter, but chose instead the method of writing a private letter of 
dissent to the authorities. Because the tide of "counterrevolution" had risen so high at that time, the CCP authorities could not manage to punish even the student signatories of the open letter, and had little choice but to show even more tolerance to those students who had privately written letters of dissent to the authorities.

\subsection{Format is More Important Than Content}

The significance of rebellion in the method of writing a letter to the authorities to express dissenting political views depends on the letter's content, on how far the letter writer's views depart from orthodoxy, and especially on the format of the letter and the degree to which it is made public. The more open and public such a letter is, the more rebellious it is. The important thing is not merely what you say, but especially how you say it. Format here is more important than content.

Of course, the CCP is fully cognizant of this principle. It has established a huge system of organizational control and instituted strict organizational discipline, thereby depriving dissenting political opinions of practically any opportunity for their public expression. In the past, the following watchword was commonly heard among ordinary Party members and cadres: "Better to commit political errors than to make organizational errors." This is to say that the Party might forgive your "incorrect speech and conduct" as long as your actions have remained within the format prescribed by the Party; yet it would never allow you to "nonorganizationally" - that is, independently - express your own dissenting political views. The channels prescribed by the Party for articulating dissenting views are so narrow and sealed off from the broader society as to make the expression of such views almost entirely meaningless.

Nevertheless, the opposite situation came to pass during the Cultural Revolution. At that time, Mao Zedong appealed to the masses with his slogan: "Rebelling is justified," and urged them on with the following exhortation: "We should not unconditionally obey incorrect leaders who endanger the revolution, but should firmly resist them instead." ${ }^{\text {I8 }}$ One after another, those Party members and cadres who had been abiding by organizational discipline were suddenly transformed into a conservative faction that had been pushing a "counterrevolutionary line," while those who breached organizational discipline and constraints metamorphosed into "revolutionary generals." At that point in time, format was of very little import, but content was everything. When people expressed their political views during this period of history, they were even more restricted in terms of content than had previously been the case, yet they obtained more freedom in terms of format. Obviously, if we are to judge whether or not the various utterances and actions that 
took place during this period were rebellious, we need to focus on their content.

In the final analysis, however, this situation was not a normal state of affairs under CCP rule. Mao Zedong dared to "feel at ease about mobilizing the masses" in this way only because he was certain that after having been through seventeen years of brainwashing, the Chinese populace's thought patterns had been tamed to the extent of making Mao feel self-assured about unleashing the populace to lash out at various targets in the Party. Yet even though this was the case, a certain type of liberalization of format has still been "dangerous," since it would allow dissenting political views to develop in a way that could be difficult for the authorities to control. Therefore, under the pretext of strengthening the Party's unitary leadership, Mao Zedong rapidly banned this liberalized approach to format once again - or at least banned a great majority of the aspects of this liberalized approach to format.

After Mao's death, the CCP adjusted its policies on a large scale, gradually relaxing its regulation of speech and its restrictions on political content, while controlling the format of verbal expression in the same way that the Party had previously done. Under such circumstances, breakthroughs in format have been particularly significant. For example, during the Democracy Wall Movement, a number of unofficial periodicals were published. ${ }^{\text {I9 }}$ Were you to look simply at the content of the essays in these periodicals, their content was not necessarily more radical than the content of the essays published in official periodicals at the same time; yet because these essays adopted the format of independent publication, their rebelliousness was much more pronounced than what you could find in official periodical essays purporting to contain "emancipated thought." ${ }^{\circ}$ During the final two or three years of the 2oth century, the CCP further relaxed restrictions within the realm of nonpolitical activities, but various formats that were political - or that the authorities suspected of being political - were still strictly banned. We can thus see that when evaluating a certain viewpoint as to whether it has been rebellious or not, we must pay attention to both its content and its format; under many circumstances, its format has been even more important than its content.

In the discussion below, I do not aim to trace the chronology of the long and tortuous history of how rebellion has been conducted in the PRC. Instead, I merely intend to draw on theoretical perspectives to analyze the processes of knowledge that may explain why various persons entered upon the path of rebellion. 


\subsection{Regarding Subconscious Rebellion}

Since thought remolding, along with the entirety of totalitarian rule, was carried out in the name of a doctrinal or ideological system, a precondition for rebellion is to break free of these ideological fetters.

What needs to be explained is that to break free of ideological fetters is mainly a rational rebellion, not a rebellion against rationality. Admittedly, there is a sense in which we could in fact interpret thought remolding as "the preservation of heavenly doctrine and the elimination of human desire." ${ }^{21}$ According to this interpretation, any opposition to thought remolding would seem to entail the utilization of human desire to oppose heavenly doctrine. In actuality, the problem is more complicated than this would imply. Since it is impossible for a person to act on instinct alone, sensory perception can very rarely resist rationality on its own. What has been called perception's resistance to rationality is in actuality a situation in which with the approval of rationality, perception launches a rebellion against certain rules that rationality had previously established. For the most part, an overflowing of human desire always gets underway only after rationality has proclaimed that human desire is reasonable. In other words, to oppose a given doctrine is nothing other than to have discovered that this doctrine is unreasonable. If you merely dislike this doctrine, yet cannot come up with a sufficient rationale to account for your own dislike of it, then you would at most be engaged in evasion, but not rebellion, or at least not in active rebellion (see also Section 4.3).

Rebellion must be directed against official doctrine. Yet there have been times when the exact opposite situation has occurred. Some people have gone to such pious lengths in worshipping the doctrine proclaimed by the regime that they have come into conflict with the very regime that had proclaimed its doctrine, and have been charged with the crime of "heresy" by that regime. There are those who have said: "The history of Christianity is nothing other than the history of the faithless, who, under the pretext of defending the faith, executed the faithful by burning them at the stake as heretics." I do not know whether or not the history of Christianity is truly like this, but I can affirm with confidence that the history of communist movements has often been like this. Had Marx been born in "New China," he most likely would have been condemned as a "counterrevolutionary" by the CCP regime, and he would of course have been labeled with the crime of "opposing Marxism." This is the same sort of scenario as was illustrated in the novel Brothers Karamazov, in which the return of Christ to the human world results in his being convicted and imprisoned as a "false Christ" by the religious Grand Inquisitor. ${ }^{22}$ This is a common problem in all countries where the realms of politics and religion are 
not kept separate, especially in communist countries. Because communist doctrine covers all aspects of secular life and the Communist Party's power has extended deeply into every domain of everyday society, there have thus been innumerable opportunities for the regime's power to have come into conflict with its own doctrine. The CCP's ideology is primarily a tool for bolstering its own rule, and does not bring to bear any firm restraint at all on the behavior of the CCP itself. Under these circumstances, it is not merely dissenters from official doctrine who likely constitute a challenge to the current regime, but even those who adhere strictly to orthodox doctrine would likely come into conflict with the regime - and especially with the power and interests of various levels of its bureaucracy - when utilizing CCP doctrine to critique present-day realities. Examples of this sort of conflict have occurred repeatedly in everyday life. Such incidents could perhaps be considered to be instances of rebellion, yet the parties involved have not at all been self-consciously engaged in rebellion.

The CCP has repeatedly claimed that its doctrine does not amount to fossilized dogma, but is instead a guide to action, and that its doctrine also requires continuous innovation and development. However, most people realize that the privilege of "creative development" belongs only to the top leaders: only the new viewpoints put forward by the top leaders can be called "creative development"; new viewpoints offered up by other people are merely their attempts to "get up to revisionism" or "pull off liberalization." Yet as a rule, the new viewpoints put forward by the top leaders are sweeping and very generalized. A couple of examples are Mao Zedong's doctrine of "continuing with revolution while under the dictatorship of the proletariat," and Deng Xiaoping's notion of "socialism with Chinese characteristics." 23 These viewpoints thus need to be fleshed out with more concrete detail and substance. Doing so can provide a certain space for others to carry forward with the exploration, interpretation and elaboration of doctrinal viewpoints. Many varieties of thought that were eventually denounced as "heterodox" appeared precisely under such circumstances. Some of these varieties of thought indeed exceeded the scope that could be tolerated by the regime, and thus were condemned as "reactionary"; the viewpoint put forward during the Cultural Revolution by Yang Xiaokai in his pamphlet, Where is China Heading?, is an example of this. ${ }^{24}$

Other branches of thought such as the Marxist humanism propounded during the early I980s were entirely capable of being subsumed into a new orthodox creed (in the same manner as eventually occurred within each of the communist parties of the former Soviet Union and the various Eastern European nations). Yet owing to the CCP regime's incorrigible obstinacy, it instead pigeonholed such types of thought under the pejorative label of "liberalization." Quite a few 
(though not all) of the people who advocated Marxist humanism originally expected that this current of thought would become a new orthodox ideology in the "New Era." 25 Unfortunately, it was mistakenly judged to be a "liberalizing" heresy instead. This is yet another vivid example of subconscious rebellion.

Subconscious rebellion is also a type of rebellion. In fact, subconscious rebellion is often the forerunner of self-conscious rebellion. Many people were originally genuine revolutionaries, yet were later wrongly condemned as counterrevolutionaries, and in the end finally became genuine counterrevolutionaries. Nevertheless, having originated from the perspective of analyzing cognitive processes, our discussion remains largely focused upon self-conscious rebellion.

\subsection{Opposing Thought Remolding and Opposing Totalitarian Rule}

Thought remolding has been merely one component of the CCP's totalitarian rule. Opposition to the former is not tantamount to opposition to the latter. That is to say, opposition to thought remolding is one matter, but opposition to the entirety of totalitarian rule is quite another. This is a distinction that we cannot overlook.

As we know, a theoretical premise for putting members of the intelligentsia through a regimen of thought remolding has been that the intelligentsia's weltanschauung is either entirely or at least fundamentally the same as the weltanschauung of the bourgeois class. It was very easy for this assumption to arouse the discontent of those within the intelligentsia who regarded themselves as revolutionary and proletarian in outlook. As for those within the intelligentsia who had committed themselves to the communist revolution since their early years - the younger generation who "had been born in the new society and had grown up under the red flag," and especially those who had been "born red" and brimmed with a sense of superiority due to their elite communist bloodline - although these people could respond to exhortations for "continuous revolution," it was very difficult for them to accept the requirement for "thorough remolding." This was not due to some sort of opposition to totalitarian rule and thereby an opposition to thought remolding on their part. In fact, it was precisely the contrary: it was because they adamantly supported totalitarian rule, and thus believed there was no need for them to be "reborn" through such thoroughgoing thought remolding. From this we can see that the opposition to thought remolding and the opposition to totalitarian rule are not at all the same thing; under the circumstances just described, the two matters are even precisely the opposite to one another. 
In order to prove that they themselves had no further need for remolding, these persons had to make themselves look revolutionary in all sorts of ways. However, the actual content of "thought remolding" was often so similar to the content of "revolution" that under most circumstances, the public display of someone's revolutionary wherewithal actually became indistinguishable from his public acceptance of remolding. For example, there were actually two lines of argument behind the Party's call for educated urban youth to go up into the mountains and down into the countryside. First, educated urban youth needed to undergo reeducation by poor and lower-middleclass farmers in order to get their thought remolded. Second, "the final distinction between someone of the revolutionary intelligentsia, on the one hand, and of the non-revolutionary or counterrevolutionary intelligentsia, on the other, depends upon his willingness and practical efforts to unite with the masses of workers and farmers." ${ }^{26}$ Were you to agree to go down to live in a farming village, how could that not be tantamount to admitting that you needed to undergo thought remolding? Yet if you were to refuse to go down and live in a farming village, how could you then still prove your revolutionary credentials?

That is to say, the repudiation of thought remolding surely implies the abrogation of a series of tyrannical government policies, yet it is not equivalent to a repudiation of totalitarian rule itself. As long as that big flag of "revolution" is still fluttering up high, most of the components of despotism can continue to exist. Therefore, when investigating rebellion against thought remolding, we have to pay attention to the basis upon which that particular rebellion is predicated, and find out which type of rebellion also signifies a rebellion against totalitarian rule itself. In such rebellions as "red by birthright," which was popular during the early stages of the Cultural Revolution, its proponents neither rejected totalitarian rule nor opposed thought remolding; they merely denied that there was any need at all for their small group of "born leftists" to undergo thought remolding. At the same time, they strongly advocated that the regime carry out even more despotic suppression of others, especially of the so-called "Sons of Bitches from the Five Black Categories." ${ }^{27}$ It is difficult for us to find much positive significance in this sort of rebellion.

\subsection{Earthquakes from within the System}

In the wake of the explanations above, we can clearly see that the most significant expression of true rebellion is the type that regards thought remolding as a form of conceptual despotism and rebels against it as such. It is only this kind of rebellion that simultaneously functions as a 
rebellion against the entirety of totalitarian rule. That being the case, how does this sort of rebellion occur?

Let us first scrutinize the process through which this type of rebellious consciousness emerges. Without a doubt, amidst the throes of the thought-remolding movement, practically everyone felt perplexity and dissatisfaction of one type or another. We found that much of our own thinking and many of our own wishes had been suppressed, and many of our personal interests had suffered damage. No matter how grandiose, awe-inspiring, and highfalutin the official ideology might make everything appear, in everyday life our existence was suffused with a huge amount of ugliness and filth. Yet for a long period of time, these sensory impressions we experienced first-hand were not enough to germinate rebellious thinking among us; instead, we were always plagued with self-doubt. We kept resorting to official doctrine to explain societal realities and interpret our own experience, instead of drawing upon societal realities and our own experience to take issue with official doctrine. This is precisely the magical effect of a theoretical system:

At the point when we accept a certain type of theoretical system, our subsequent observations and thinking become a series of inferences, one after another. If we discover that contradictions appear between our "inferences" on the one hand and our feelings and experience on the other, we do not often make adjustments to our inferences on the basis of our experience. Instead, we will often make adjustments to our experience on the basis of our inferences (quoted in Section 2.I6).

As long as such a system is sufficiently all-encompassing and consistent, and thereby capable of sounding plausible (even if rigid and strained), once we go all the way into the system, it is quite difficult to come back out of it afterwards. Consequently, it is little wonder that persons nestled within such a system often initially discover various contradictions or cracks in the system, subsequently lose confidence in the system, and only after that are able to come back out of the system and finally critique the system itself. No wonder that the earliest groups of rebels were mostly comprised of those who insisted upon theoretical thinking. No wonder, either, that the regime has actually brimmed with suspicion and mistrust of those who have undertaken serious studies of theory, even though the regime has superficially advocated the study of theory. No wonder, finally, that the earliest rebellions have almost always been rebellions within the system.

What I should explain is that the above-mentioned rebellious consciousness is different from what has ordinarily been referred to as revisionism. In the CCP's lexicon, "revisionism" refers to a mode of 
thought from such early figures as Bernstein and Kautsky all the way down to such leaders as Tito, Khrushchev and Brezhnev. ${ }^{28}$ Since the regime had already stuck the label of "revisionism" on the thought of these individuals in advance, none of it possessed any orthodox authoritativeness under CCP rule. What we are now discussing as "within the system" refers to being "within" the system of orthodox theory as proclaimed by the CCP itself; it thus does not include any so-called revisionist thought. At that time, a group of rebels discovered several things in Mao Zedong Thought - and especially in Marxist-Leninist Thought - that were at variance with the populace's usual understanding of these strains of thought. This group of rebels drew upon these inconsistencies as an ideological weapon with which to take issue with standard views of the populace. As I have already pointed out, the reason ordinary people have been unable to resist the enormous pressures of thought remolding is that they have been spiritually homeless and isolated, and have had no other means or resources for spiritual support at their disposal (see Section 3.24). At one time or another, upon the discovery that contradictions exist precisely within the system of official theory, the discoverers have obtained support and a rebellious consciousness has consequently arisen.

There is a certain degree of universality in the sort of process through which a rebellious consciousness comes about. Of course, due to the fact that most people have not been at all accomplished in social theory, they have been unable to directly uncover the internal contradictions within the theoretical system through study of the classics of communist doctrine. However, the regime itself has frequently switched from one theory to another practically overnight and has often been inconsistent about the latest twist in the Party line, so that even an ordinary person who is unaware of social theory has been able to perceive all sorts of holes in the official doctrine. To be sure, just as with all other theories that encounter predicaments, purveyors of the official doctrine continually resorted to the tactic of adding supplementary hypotheses in order to patch up as many of that doctrine's cracks as possible. In general, this sort of patch-up work could achieve results of a certain sort among persons who are not at all accomplished in social theory, even though this was not enough to make them completely convinced, it could at least make them partially convinced, thereby preventing them from gaining self-confidence in the dissenting views that they secretly harbored.

Nevertheless, there were occasions in which these cracks in official doctrine were so obvious that no amount of patch-up work could be of any avail. The September Thirteenth Incident involving Lin Biao is a prime example of such an occasion. ${ }^{29}$ Many people have remarked upon how the Lin Biao Incident had a huge impact on their thinking. 
The eruption of the Lin Biao Incident was too sudden; the regime was caught unawares and was simply unable to handle the incident expeditiously. Word of this incident had already spread all over China through the grapevine before the regime finally managed to fabricate a series of explanations in an attempt to sound plausible. This situation greatly shook people's belief in the system. The nature of the Lin Biao Incident was so grave (that the very Vice Commander who had just been confirmed by the Party as Mao's successor as top leader would go so far as to have drawn up the "extremely reactionary" Five-Seven-One Project scheme and masterminded an attempt to assassinate the Great Lead$\mathrm{er}^{3 \circ}$ ) as to make the regime's after-the-fact explanation and excuses (it made public the letter which Mao Zedong supposedly wrote Jiang Qing on the eve of the Cultural Revolution) appear weak and lame by comparison - even suspicious. ${ }^{3 \mathrm{I}}$ It was as if a large hole had suddenly been punched through a tightly woven tent and everybody inside suddenly discovered that the tent was not at all the same thing as the sky after all. From such cracks in the system, people rediscovered the real world from which they had long been isolated. When the credibility of the system took a blow, the magical power of the system subsequently vanished or was crippled. Consequently, people no longer drew upon theory to readjust their experience; instead, they began to draw upon their experience to readjust theory and to criticize theory.

\subsection{The Bankruptcy of Phony Politics}

Thought remolding caused major damage to people's private interests. Nevertheless, since thought remolding originally possessed the outward appearance of a lofty ideal that transcended private interests, it was very difficult for people to oppose thought remolding merely on account of the point about its damage to private interests. In fact, one of the requirements of thought remolding from early on was to roll back and even sacrifice your private interests. Thought remolding was originally a sort of asceticism, and thus individuals were naturally unable to oppose it with confident self-assurance on the basis of upholding personal materialistic interests. However, communist theory is not merely a variety of asceticism, but at the same time is also a type of utilitarianism. Speculative communist blueprints for the future paradise on earth incorporate completely secularized, utilitarian content such as an extreme abundance of material goods, a high level of scientific and technological development, and the complete satisfaction of the people's (i.e. collective) interests. This contradicts the asceticism that the Party requires every single individual to observe. This also animates the conflicts of politics versus economics, revolution versus production, and red versus expert. 
When an educated urban youth obeyed the requirements of thought remolding and went down to a village to perform manual labor, the arduousness of this way of life and his physical exhaustion might not be enough to shake his belief in thought remolding. He would try hard to persuade himself that this was precisely the best path toward the achievement of self-toughening and the revolutionizing of his thinking. However, what was the significance of abandoning his original superiority in knowledge and culture in order to engage in coarse and crude physical labor? Were he permitted to give full play to his original strengths instead, would he not contribute a great deal more to socialist construction and to the welfare of the broad masses as a result? You said this is for the sake of revolutionizing a person's thinking. But what is the revolutionizing of thinking itself for? After all, the communist school of thought is but a set of theories about secularization and modernization, and in any case cannot shake off all sorts of utilitarian goals. Based upon these considerations, people could not help but gradually grow suspicious of the sort of "spirit" that was completely divorced from the "material," and the "red" that was entirely divorced from the "expert" - and suspicious of what has been termed phony politics. ${ }^{32}$ This type of suspicion was then combined with the individual's deepseated desire to quickly improve the straitened material circumstances of his life, and thus became more and more powerful.

In all fairness, if the CCP had not taken the thought-remolding movement to such an extreme - to the point of laughable absurdity the aforementioned tide of skeptical thinking probably would not have spread widely. Many of those who secretly harbored an attitude of skepticism toward this movement would not necessarily have been able to convert their skepticism into a clearly rebellious consciousness had they not received a sympathetic response from the environment around them. During the latter stages of the Cultural Revolution, "leftist" winds were raging more and more fiercely, the economy was in decline and people were living in poverty; yet the authorities were preaching: "Better to be a socialist blade of grass than a capitalist crop seedling." The intelligentsia had become "Stinking Old Number Nine," and the doctrine that "book-learning is useless" was running wild everywhere. ${ }^{33}$

A sense of dissatisfaction was increasing rapidly throughout society. Two major viewpoints from within communist theory provided a basis for the legitimacy of the populace's sense of dissatisfaction: namely, support for the development of productive forces, along with an emphasis upon science, technology and knowledge in general, including the slogan "Construct the Four Modernizations" that Zhou Enlai put forward at the Fourth National People's Congress. ${ }^{34}$ An invisible alliance began to form between the populace and pragmatists within the Party, thereby leading to the eventual collapse of the "Gang of Four" and the 
fall from power of the "Whateverist Faction." 35 The extensive discussion of the concept that "practice is the sole criterion for determining the truth" did not achieve, nor could it have achieved, a genuine emancipation of thinking or freedom of thought, owing to this concept's inherent utilitarianism and pragmatism. ${ }^{36}$ However, this concept was a major force in bringing about the bankruptcy of phony politics, while facilitating the establishment of the legitimacy of such goals as economic development and improvements in the people's material well-being. Along with the reaffirmation of the value of knowledge, the intelligentsia's social status also climbed back up to levels not seen in many years. The thought-remolding movement was proclaimed as over and done with.

\subsection{The Rebellion of Liberalism}

Among the various forms of rebellion against thought remolding, liberalism might not have been the strongest force. However, the repudiation that issued forth from liberalism was the only one so thorough as to pull the carpet out from under thought remolding once and for all.

As early as the "Hundred Flowers" and Anti-rightist movements, a number of those within the intelligentsia proceeded from the standpoint of liberalism to put forward profound criticisms of communist rule. Yet for a very long time after that, liberalism kept silent and went into hiding. The new generation within the intelligentsia knew practically nothing about liberalism. Later on, they rediscovered liberalism by way of their own thinking and personal experience. Prior to becoming a school of thought, liberalism initially amounted to a sort of gentle and cautious personality for this new generation within the intelligentsia. There would be no harm in taking my own experience as an example here. Two factors were the most crucial in the process of the formation of my liberalist thought: first, my intense aversion to the cruel phenomena in society; and second, a certain kind of skepticism I maintain about humanity's rational knowledge.

Initially, back when I still believed in communist ideology and supported the communist system, at a theoretical level I still approved of what was styled "education" and "remolding" - which in reality was behavior associated with political persecution. Yet the violence and cruelty of this sort of persecution could not help but arouse feelings of disgust from the bottom of my heart.

My first act of "rebellion" during the Cultural Revolution was to let some teachers out of the "cowshed" where they had been confined. ${ }^{37}$ At that time, I still thought that most of those teachers should be denounced and remolded. However, I insisted that they should not be locked up, reviled, or beaten up, but instead should be punished by hav- 
ing to engage in physically damaging and arduous manual labor. As one of the "Five Black Categories" who had suffered greatly at the hands of the "reactionary line," of course I enthusiastically supported denunciations of the "reactionary line," yet I did not approve of taking revenge on teachers and students who had implemented the "reactionary line." Nor did I approve of resorting to violence, no matter if it was aimed at the Conservative Faction or at a rebel faction whose viewpoints differed from our own. I also felt very uncomfortable about even those posters and slogans that bore violent messages such as "smash suchand-such organization to a pulp" and "bash in so-and-so's dog head." In the beginning, I mistakenly assumed that I was merely upholding current government policy, and thereby enjoyed the support of existing official doctrine. Later on, I could not help but discover that all sorts of detestable atrocities were actually the products of official doctrine. Consequently, I altered my political stand to one that was critical of official doctrine.

Like everybody else who lived during that era, I was once a pious disciple of official ideology. I used to expend much effort in studying the Marxist-Leninist classics. I recall that when I was reading Lenin's book Materialism and Empirio-criticism, his views initially met with my approval. ${ }^{38}$ Yet Lenin's dogmatic and absolutist writing style made me feel extremely uneasy. Owing to my intense interest in knowledge, during my bouts of study I did not wholeheartedly strive to arm my brain with revolutionary thought in the way some people did at that time, but instead could not contain my desire to carefully ponder and examine the subject at hand. Since this activity of pondering and examining could go on penetrating ever more deeply into a subject almost endlessly, to my way of thinking it would be very difficult to say that some sort of ultimate truth could ever be achieved. Consequently, I discovered that as far as truth or knowledge is concerned, the very process of pursuing it could perhaps be even more important (and more interesting as well) than the results from its pursuit.

Objectively speaking, even back when my belief in official doctrine was at its strongest, I was rarely fanatical about it. In line with this kind of attitude, I naturally resented various types of simplistic and arbitrary dogma, along with resenting the self-importance of dogmatists who assumed they had already grasped the ultimate truth. Were one to say that during the early stages of this process I was still looking to official doctrine to justify this kind of attitude (e.g. to some of Marx's earlier writings and to Mao Zedong's speech at the Conference of Seven Thousand Cadres in I962), ${ }^{39}$ then later on I became more and more independent and self-confident about upholding this kind of attitude. Right about at this juncture, I began to come across writings about liberalist theory every now and then. Upon reading these works, I found them to be pre- 
cisely in line with my own thinking, and thus became a staunch liberalist. This is probably a quite typical journey in the development of liberal thinking among contemporary Chinese liberalists.

A liberalist is different from other varieties of rebels. A liberalist does not hanker to put forward concrete political dissent. The things he is most concerned about appear to be the least concrete. What he offers is a kind of attitude, not a type of doctrine; and he provides a sort of methodology, not a body of dogma. When I posted my essay "On the Freedom of Speech" on Democracy Wall, owing to the gentle demeanor of this essay, it could not garner much strong interest even from casual onlookers, much less attract the attention of overseas media, which was anxious to discover astonishing viewpoints on Democracy Wall; nor did the regime bother to censure this essay. However, I firmly believe, as do more and more people, that it is none other than precisely this type of liberalist rebellion that will deal a fatal blow to totalitarian rule.

\subsection{The Current Condition of Liberalism}

The results of the thought-remolding movement signify that the curtain has come down on the most absurd acts of totalitarian rule. The CCP regime of today is no longer as aggressive and overbearing as it was before. Under these circumstances, the struggle for freedom of thought could be said to have become easier than before, but could also be considered to have gotten more difficult than it was previously. Our distance from freedom could be said to have narrowed, but could also be considered as having lengthened.

Why could the struggle for freedom of thought be said to have become easier? The reason is that everyone is clearly aware that there is still no freedom of thought in China today. The outrageous lie that the "proletarian dictatorship" makes for the "biggest freedom" has already become bankrupt. Since autocratic oppression is now so undisguised, and the implications of freedom are so clear-cut, all persons who cherish freedom know exactly what they oppose and what they demand. Were we to assemble all of our strengths and pursue our goals courageously, the arrival of freedom would be imminent.

Why could the struggle for freedom be said to have gotten more difficult? One of Solzhenitsyn's comments hit the nail on the head: "A school of fish would never join together in a collective struggle against the fishing industry; they would merely try to squeeze their way out one by one through gaps between the strands of the fishnet." ${ }^{\circ}$ During the Cultural Revolution's attempt to "make a clean sweep of all cow demons and snake spirits," the gaps between the strands of the fishnet shrank so much that the net was transformed into finely woven cloth, 
from which even shrimp and tiny fish could not escape calamity; it was thus perhaps not so difficult for schools of fish to comprehend the necessity of slashing the fishnet to tatters. ${ }^{4 \mathrm{I}}$ Consequently, when the gaps between the strands of the fishnet widened back out to their normal configuration in tandem with developments in the "New Era," ordinary fish could once again squeeze their way out, while fish slightly larger in size could squeeze their way out by means of a little bending and wiggling - only those fish that were too large or else unwilling to bend and twist would remain unable to squeeze their way out of the fishnet. Under such circumstances, would a school of fish still share a bitter hatred of the enemy, collaborate from within with forces from without and resolutely proceed to slash the fishnet to tatters?

Although everybody cherishes freedom, one cannot avoid the necessity of paying a price and taking risks in the struggle for freedom. If the majority of the populace achieves gratification of certain desires they have - and because of this becomes indifferent to the persecution suffered by a minority of the populace - then freedom will remain forever out of reach. A despotic government that goes to extremes cannot endure for long, but a somewhat pliant autocracy can last for a relatively long period of time because it takes pains to avoid stirring up intense and widespread dissatisfaction. At this late hour of history, to be sure, communist ideology has already lost its appeal. Even those persons who speak out in defense of CCP authoritarian rule cannot help but cast aside the original system of CCP official discourse, whether they do so openly or covertly. Just as Francis Fukuyama said, throughout the entire world, liberal democracy has emerged triumphant and peerless within the conceptual realm. ${ }^{42}$ Yet it is still not an easy matter for liberalism to achieve victory in the real world. Thomas Sowell put it very well: "No one can publicly oppose freedom; freedom has no enemy. What freedom has are friends who can share joys but not sorrows, and who regard other matters as their top priority. Yet when it comes to defending freedom, such friends are even more dangerous than enemies: this is the reason why freedom is in danger, while the road to serfdom is always open - and even rather alluring to some people." 43 Because of this, an in-depth illumination of the basic principles of liberalism is still an important and urgent task.

\subsection{Gaining the Privilege of Rebellion}

Rebellion has never truly ceased at any point during the past several decades of the PRC's existence. Particularly during the most recent decade or so, the momentum of rebellion has increasingly accelerated, its liberalist color has become ever more distinct and it has forcefully 
advanced change in China. While causing some of the space for rebellion to temporarily contract, even the setbacks to rebellion have at the same time achieved a wide-ranging dissemination of the significance of rebellion and provided valuable experience, thereby leaving a legacy of inextinguishable accomplishments. The people have not and cannot abandon the struggle for liberty. Prospects for freedom are still brimming with hope.

Without a doubt, rebellion still remains quite difficult in China today. This is not surprising, since the type of rebellion we have discussed here alludes to the freedom to convey various modes of thought. The rebellion before us now is precisely for the sake of gaining the privilege of rebellion. 


\section{The Bane of Cynicism}

\subsection{Authoritarianism and Cynics}

Post-“June Fourth” China has become swamped with cynicism.

As John Stuart Mill long ago pointed out, authoritarianism transforms the populace into cynics. ${ }^{\text {I }}$ (This reminds us of what Wang Fuzhi once wrote: "When the authorities run things in the manner of Legalists such as Shen Buhai and Han Fei Zi, their subordinates invariably turn to Buddhism and Daoism.") ${ }^{2}$

Since communist authoritarianism is an extreme form of authoritarianism, it is even more effective at transforming the populace into cynics. Under communist authoritarianism, both the rulers and the populace over whom they rule can easily turn into cynics. The rulers become cynics because they have long since ceased to believe in the assemblage of doctrines and principles that they have been preaching, and have instead drawn upon those doctrines and principles as a means for defending their own power and as a pretext for suppressing rebellion. As far as the populace under authoritarian rule is concerned, once they realize that notwithstanding the high-and-mighty flag fluttering overhead they are actually in a position of being cheated and oppressed, they readily lose confidence in all of the loftier values in life. This is especially the case after their having experienced severe frustration in the wake of a thwarted attempt at rebellion. In this way, it is highly likely that they abandon their former ideals and aspirations, even going so far as to turn around and sneer at such ideals and aspirations. This is how they become cynics. Of course, the cynicism of authoritarian rulers differs somewhat from the cynicism of the populace under their rule; broadly speaking, however, each shares the same general orientation of cynicism.

According to the analysis of Irving Howe, there are three stages of totalitarianism. The first stage is Utopia, or an intoxicating heavenly ideal, which lures people into fanaticism. Fanaticism leads to the second stage of large-scale terror and a hell on earth. Both fanaticism and terror subsequently exhaust themselves, leading to the third and final stage. At this stage, the populace has grown cynical, "having seen through it all," and is indifferent to politics - that is, cynical. ${ }^{3}$ 
I believe that there is an extra stage within a total of four stages of totalitarianism. Following the first two stages of fanaticism and terror, the third stage of rebellion often occurs. It is only after rebellion is thwarted that the fourth stage of widespread cynicism ensues. Totalitarianism depends on the populace's fanaticism to become established, and it then becomes consolidated through large-scale terror. However, it is impossible for either fanaticism or terror to be long-lasting. In the end, totalitarianism can hold together only by relying upon the populace's dejection and indifference.

In the Soviet Union of the Brezhnev Era, cynicism was also prevalent. ${ }^{4}$ In his book The Russians, the American correspondent Hedrick Smith provides a fine description of this sort of cynicism..$^{5}$ Compared with the situation in the Soviet Union of that era, the cynicism in postJune Fourth China has been even more deep-seated and wide-ranging.

\subsection{The Communist Party and Cynicism}

Let us begin by discussing the Chinese Communist Party's cynicism. I should note that from the very beginning, the CCP has been inextricably intertwined with cynicism.

CCP ideology amounts to an extremely exalted idealism, yet at the same time it is quite a gloomy sort of cynicism. To put it more precisely, CCP ideology is a peculiar concatenation of idealism and cynicism. On the one hand, the CCP is determined to put an end to the entirety of the world's suffering and crime once and for all, as well as to construct a paradise in the human world. Naturally, this is idealism. On the other hand, the CCP believes that since the ends they are pursuing are so exalted and perfect, what means would they not be permitted to adopt along the way? Owing to this rationale, the CCP could launch an extremely cruel and punitive crusade against the so-called old society and old system, while on the other hand ignore the most basic moral restraints in the Party's own behavior. Clearly, this is cynicism.

On the one hand, the CCP proclaims that except for the interests of the proletarian class and the masses of people, the Party has no other special interests of its own. This claim appears to be very modest and full of idealism. Yet on the other hand, the CCP insists that only the Party can "represent" the proletarian class and the masses of people, while the proletarian class and the masses of people whom the Party represents are not necessarily eligible to be considered part of either the proletarian class or the masses of people (Lenin clearly proclaimed that the proletarian class could not spontaneously generate the proletarian class weltanschauung, which must instead be instilled into the proletarian class from the outside by the Communist Party.) This is not only a 
wildly arrogant and presumptuous rationale, but what is even more serious is the way it has opened wide a convenient door for those cynics who believe in nothing whatsoever to seize unlimited power. There is thus little wonder that even though the CCP has utilized its big banner of idealism to summon many idealists to commit themselves to its cause, within the Party itself, idealists have generally been unable to gain the upper hand - it has instead been the cynical opportunists who have managed to gain the upper hand.

In discussing the Communist Party, and particularly with regard to the CCP's cynicism, we must also mention its history of armed struggle. Do not forget that the CCP underwent over twenty years of armed struggle before it could finally seize political power nationwide. Compared with the CCP's history of armed struggle, Russia's October Revolution could almost be considered little more than an armed coup d'état - a seizure of power amidst chaos. Generally speaking, assuming that the level of cruelty of the revolutionary struggle increases in tandem with the length of the experience of violent revolution, it becomes increasingly easy for the revolutionaries caught up in such a protracted process to treat their original idealistic motivations for revolution as a mere afterthought, and instead regard victory and power as the highest goals amongst their fanatical ambitions. This process eventually culminates at the point where they no longer look upon power as a means to the end of achieving their ideals, but instead look upon their ideals as a means to the end of seizing and monopolizing power. Owing to this process, they very readily undergo a transformation from idealists to cynics.

I heard that after the June Fourth crackdown, a certain veteran CCP high cadre said: "Thirty million lives were sacrificed by the Party in order to win its mandate to rule this country. Anybody who would like to overthrow us would have to pay the same sort of price." ${ }^{6}$ Upon its first mention, this remark struck me as nonsensical. Back when the CCP started the revolution, was it not due to wanting the people to take charge of their own government? If the people demand political reform, want to bring one-party authoritarian rule to a close, and wish to achieve their right to take charge of their own country, what reasons could the CCP muster to reject such calls for reform? Yet you cannot use this sort of logic to refute that veteran CCP high cadre, for he and his fellow cadres long ago tossed aside the ideal of putting the people in charge of their own country.

We know that from the very beginning, the CCP rejected the parliamentary path of national advancement and advocated violent revolution instead. This in itself indicates that the CCP does not believe in democracy, nor does it actually believe in the people, either. Generally speaking, when CCP revolutionaries decided to implement their political 
demands by means of violence, this not only indicates that they harbored no illusions about the rulers, but at the same time reveals that they also felt disappointed by the people - disappointed by what they saw as the people's stupidity, ignorance, selfishness and cowardice. During the lengthy and cruel era of revolution, the CCP experienced numerous setbacks; time and time again, CCP revolutionaries were on the brink of falling into a desperate impasse. It is not difficult to imagine how much loneliness, despair and indignation they must have harbored - this would readily cause their views about human nature and the popular masses to become extremely gloomy. However, by adopting the Leninist doctrine about the dictatorship of the proletariat and concerning the Party's role as the vanguard of society, they could easily conceal their disappointment with the people or even scorn for the people under a cloak of what appeared to be idealism.

At the same time, the CCP also discovered that the GMD's lack of democracy provided them with a dignified justification for vilifying the GMD. Moreover, the GMD authoritarian system's lack of thoroughness in its repressive measures provided the CCP with readymade openings for this sort of vilification. ${ }^{7}$ Consequently, CCP revolutionaries struck a pose as fighters for democracy, taking advantage of the GMD authoritarian system's lack of thoroughness to revile the GMD as undemocratic; yet at that time, they had already decided that they would eventually rule in an even more authoritarian fashion than the GMD had adopted.

Countering a request some persons put forward in I98I to draft a PRC press and publication law, Chen Yun sent down a written directive for internal circulation only - in which he clearly rejected this reasonable request. ${ }^{8}$ Chen Yun wrote: "In the past, it was precisely the GMD's Press and Publications Law that we took advantage of to struggle legally against the GMD. Nowadays, we absolutely will not permit others to similarly take advantage of this sort of thing to struggle legally against us as well."9 With a frankness that is rarely observed in CCP officialdom, this written directive reveals the inner world of the CCP leadership. This directive informs us that long before the CCP seized political power, in actuality they had already determined that they did not want freedom, democracy, or the rule of law. Back then, at a superficial level CCP operatives were speaking out in opposition to the GMD's hegemonic ways, but were secretly sneering at the stupidity of the GMD: they sneered at the GMD for having become enmeshed in a web of its own spinning - for still having scruples in dealing with the law it had passed, thereby leaving an opening for its opponents to struggle legally against it. ${ }^{\text {IO }}$

At that time, while CCP operatives were mouthing their drummedup opposition to the GMD for being undemocratic, inwardly they were thinking: "Just wait till we seize power, at which point we absolutely will 
not allow even this little bit of democracy - we won't be as stupid as you are now!"

Of course, this is a typical form of cynicism. To supplement the account above, it is widely known that Chen Yun is a famous "Old Rightward-leaning" official within the CCP. When Mao Zedong launched the Great Leap Forward, Chen Yun was one of the very few high-ranking CCP officials who did not gather around Mao and follow him in feverish support of this movement. During the Cultural Revolution, Chen Yun was even keener to stand aside and let others take center stage from the very beginning of this movement. Obviously, the question of whether or not one is a cynic has nothing at all to do with the so-called ultra-leftist line.

\subsection{What Does "the Transition from a Revolutionary Party to a Ruling Party" Mean?}

The later its stage of development, the more cynical the CCP has become. After the June Fourth Incident and the Soviet and Eastern European Incidents, ${ }^{\text {II }}$ the CCP's cynicism grew so obvious that a Young Turk faction in the Party could not repress its urge to put this in writing and make it their program for action. A case in point is the so-called "Program of the Princelings' Party" (namely, an article entitled "China's Realistic Responses and Strategic Choices in the Wake of Drastic Changes to the Soviet Union").

The author of the "Program of the Princelings' Party" raised a concern: "An important issue facing our Party is the transition from a revolutionary party to a ruling party. After the Soviet Union Incident, this transition has become even more urgent." ${ }^{\text {I2 }}$ When reading this passage for the first time, I was totally baffled. By this point, the CCP had already been ruling China for over forty years; why would they only now suddenly raise the issue of transitioning to a ruling party? I suppose they could respond that during the Mao Era, the CCP had all along been holding the big banner of "Revolution" aloft, continuously engaging in revolution and launching political movements - to the extent that the country's economic buildup had been greatly damaged. Yet wasn't this sort of situation long ago brought to an end after the collapse of the "Gang of Four" - and especially ever since Deng Xiaoping took charge of the government? ${ }^{\mathrm{I3}}$

If you were to analyze that article carefully, you would find the excerpts from it in the next two paragraphs well worth pondering. The author criticized the CCP in two particular areas: first, in "using populist sentiments found among the masses to tie up the hands and feet of the Party": and second, "the policy over the past few decades of inculcat- 
ing arrogance amongst the people - of daring only to emphasize honest rule and diligent rule when addressing the masses, while not daring to emphasize strict rule." According to what the author believes, "Experience from the Soviet Union and Eastern European Incidents, along with China's June Fourth Incident, shows that the textual weapons deployed by the political opposition to vilify the CCP were sometimes precisely the same as some of the revolutionary theories that the CCP has not yet subjected to effective transformation"; moreover, "the favorite slogans of the liberalizing elements include their opposition to official profiteering and corruption, along with their claim that mass movements are natural and reasonable." ${ }^{14}$ Some of the statements quoted above are completely untrue. For example, when did the CCP ever carry out a policy of "inculcating arrogance among the people"? When did it ever "not dare to emphasize strict rule"? Let us not bother with delving further into such untruths. The key issue is what, after all, was the author attempting to express through all this confusing and ambiguous verbiage?

In fact, the meaning of the "Program of the Princelings' Party" is simply as follows. Previously, the CCP had in theory always professed that its power came from the masses of the people (as in the excerpt from the Sayings of Mao Zedong: "Who gave us our power? The people gave it to us"). ${ }^{\mathrm{I}}$ Moreover, the CCP has always been ordering everyone around in the name of the people, so the concept of the people became sacred and inviolable. Because of this, the Party had never previously dared to crack down on the people in an open and aboveboard manner and with the assurance that justice was on its side. The CCP's only way of dealing with views from the people that ran counter to CCP doctrine was to claim that the other party was not in actuality part of the people, but instead was "counterrevolutionary," amounted merely to "a small handful," or else "had been hoodwinked" - it was only through such means that the CCP was able to obtain an aura of legitimacy and legality in its crackdown on the other party. This body of doctrine revolving around the people is precisely what is known as "populism," "the policy of inculcating arrogance among the people," "not daring to emphasize strict rule," and the sense that "mass movements are natural and reasonable." This body of doctrine might have been beneficial and necessary, provided it was unleashed during the early era of revolution; yet during the subsequent era of CCP rule, it has become useless, and even harmful. If the Party continues to utilize this body of doctrine, it will only get entangled within a web of its own spinning, providing opposition factions with ideological weapons to wield against it.

We should acknowledge that the above-mentioned viewpoint indeed makes sense. This proves once again that communist authoritarianism differs from traditional authoritarianism. Under traditional authoritar- 
ianism, the ruler and the populace under his rule have been two separate entities that could not be confused with one another. Neither side would regard both parties as equal. The emperor was the Son of Heaven, not the Son of the People. Local officials were called "parent officials," not "servants of the people." No doubt that while the ruler needed to keep abreast of popular sentiment, he did not necessarily need to abide by popular sentiment, because "you could make the people obey your command, but could not make them understand the rationale behind it"; popular opinion thus did not amount to some sort of ultimate reliability. The common folk could present their views to the higher-ups, but must never "wreak havoc and go against the higherups." The people were not in charge of the country, and there was no concept of "sovereign rights in the hands of the people."

Modern communist authoritarianism is very different. Communist parties took on board a few concepts of democracy, at least nominally. Communist countries were even more enthusiastic than democratic countries about raising the position of the people in an abstract fashion. For example, they took pains to include such terms as "the people" and "democratic" within the official names of their countries so as to indicate that their superseding of the "bourgeois democratic system" was both reasonable and historically inevitable. Yet by having done so, just as explained in the "Program of the Princelings' Party," the communist parties also made themselves come up against a huge danger: if a day dawned when the broad masses of the people were to arise and join in an outcry that they refused to acknowledge the popular nature of the people's government, the ground on which our "people's government" had been standing on would suddenly cave in. In the Soviet Union and East European Incidents, some demonstrators carried signs that said: "It is only we who are the people!" Such a simple one-line slogan as this, and there would then be nothing left of a communist regime's legitimacy.

Precisely because he had a profound sense of this internal weakness of the communist regime, the author of the "Program of the Princelings' Party" recommended that the CCP must change its own doctrine, abandon its out-of-date revolutionary slogans, and clearly assume a posture of "we rule you" toward the common people. This is exactly what is meant by the so-called "transition from a revolutionary party to a ruling party." For example, in Orwell's Animal Farm, a few pigs hoist up high a big revolutionary banner that proclaims "all animals are equal," lead the other barnyard animals to overthrow the rule of Farmer Jones, and establish a new society that claims all of the animals are now in charge of the farm. ${ }^{16}$ Not long afterward, the clever pigs revise their original revolutionary slogan: "All animals are equal, but" - the pigs add a new clause - "some animals are more equal than others." ${ }^{77}$ This 
then prevents the other animals from taking advantage of the outdated revolutionary slogan "All animals are equal" to turn around and challenge the pigs' prerogative to rule. This is what is known as having completed the "transition from a revolutionary party to a ruling party" in a timely fashion.

Most of us still recall that after the June Fourth Incident (I989), it was widely believed that the CCP had lost the legitimacy of its rule over China. In other words, all manner of original doctrinal foundations for CCP rule had by then been revealed as thoroughly bankrupt, such as "the people in socialist countries enjoy a high social status," "a communist society is the greatest type of democracy," and "the Communist Party represents the objective laws of humankind's historical development." Of course, I am not arguing that the legitimacy of CCP rule was not lost until the very day of June Fourth. In theoretical terms, the legitimacy of CCP rule has never been achieved. Long before June Fourth, more and more people had already seen through hollow CCP claims of legitimacy. The Democracy Movement in I989 itself was a magnificent feat of the people's challenge to the legitimacy of CCP rule. I am merely trying to say that after all is said and done, the June Fourth Incident was an obvious sign of this loss of legitimacy: "the People's Government" had brazenly ordered "the People's Army" to massacre the people. This could not help but lead to the total bankruptcy of all of the excuses offered up in defense of the legitimacy of CCP rule. Yet the issue before us now is that a regime which lost the legitimacy of its rule in this way did not actually collapse as a result, but instead remains up and running. What on earth exactly happened?

Some people have explained that after the June Fourth Incident, the CCP continued to launch its economic reforms and managed to achieve remarkable success. In doing so, it thus won back the legitimacy of CCP rule. Yet another explanation goes like this: the CCP nowadays has been playing a role as the defender of China's national interests, and its rule thus possesses legitimacy. This sort of explanation misconstrues what it means for a regime to possess legitimacy. It is one thing for a regime to have established a record of achievement; it is quite another thing for a regime to possess legitimacy. As Lucian Pye once remarked: "No government has been so foolish as to make the success of its policies the basis for the legitimacy of its rule, since the very essence of legitimacy is that a government continues to be recognized as such, no matter what sort of erroneous policies it may have been implementing." ${ }^{18}$

As for the present time, the CCP has already lost the legitimacy of its rule. The reason the CCP is still ruling is merely due to the fact that it is holding onto the power to rule; there are no other grounds whatsoever for its rule. The term "power" has been used in a very indiscriminate and generalized fashion. People often refer to the possession of 
any coercive force as "power," thereby making it indistinguishable from the term "violence." Strictly speaking, power is not the same thing as violence. In broad outline, any force that is acknowledged as legitimate by those on the receiving end of such compulsion is referred to as "power"; and any force that we do not acknowledge as legitimate is considered "violence." Russell explained it very well: "If the only reason why a form of power is respected stems entirely from the fact that it is power, and there is no other reason for it, then this form of power is nothing other than violence. Because of this, once people no longer acknowledge a given tradition, the power of the original tradition then turns into violence." 19

We have now at long last come to understand the true implications of the "Program of the Princelings' Party." When it professed that it wanted to complete the "transition from being a revolutionary party to a ruling party," it was in point of fact acknowledging and proclaiming the transition from power to violence. According to the author of the "Program," the cloak of legitimacy for CCP rule has become tattered and riddled with holes regardless. The CCP might as well speak frankly from this point forward and clearly indicate that we (the CCP) rely upon violence to maintain our rule. Violence has its own advantages, since when the CCP no longer dolls itself up with its ideology, at the same time it also avoids getting entangled in a web of its own spinning, and can thus handle matters in a more convenient way. Once the CCP has gotten to this point in its thinking, its cynicism has also reached an extreme.

\subsection{Why is It "No to Reform and Wait for Death; Yes to Reform and Court Death"?}

After the Soviet Union and Eastern European Incidents, somebody came up with a witty remark: "No to reform and wait for death; yes to reform and court death." The first half of this remark is simple to comprehend, but the latter half merits pondering. Why was it that those communist countries who took the initiative to carry out political reform not only did not prolong the reign of their single-party authoritarian regimes, but on the contrary hastened the demise of these regimes?

Roughly speaking, there are two reasons for this. One reason is generic among all authoritarian regimes, while the other reason is particular to communist regimes alone. The generic reason amounts to the socalled "law of rising expectations": once you have obtained one thing, you would generally expect to obtain something else that is better. The more freedom people have gained in certain spheres, the more intolerable they find the lack of freedom in other spheres, and thus the greater 
demands they make for even more freedom. Precisely as Tocqueville pointed out, the weakest point of authoritarian rule from a ruler's perspective is often not when the regime's political achievements are at their worst, but instead when it has begun to reform and thus has been uncovering and exposing its corrupt practices to the public.

The particular reason for reform backfiring on communist regimes is that even if a given communist party's reforms are limited to the economic realm and in their initial stages, the reform processes themselves signify an undermining of the regime's own foundations and the digging of its own grave. This is because a communist party's economic reforms drop socialism and introduce capitalism. Its reforms do not amount to self-improvement, but to self-negation instead. When the Mao-era CCP repressed freedom and democracy, its only magic weapon was to besmirch the other side with an epithet such as "bourgeoisie" or "capitalist roader." Once it became clearly known to bystanders as well as tacitly understood within the CCP itself that the Party was now leading the way in taking the capitalist road and now functioning as the bourgeoisie, what justification did it still have for insisting on the socalled "dictatorship of the proletariat" and for repressing so-called "bourgeois" liberalization?

Therefore, in tandem with the increased deepening of economic reforms day by day, a split within the communist party has also become ever more prominent. As far as the relatively upright type of CCP members are concerned, since they have advocated economic reform and approved of private ownership and market economics, in the political realm they have naturally favored political openness and identified with the values of freedom and democracy. Thus on the one hand, there has been greater and greater pressure from the populace in their demands for freedom and democracy; and on the other hand, there have been more and more Party members who support and sympathize with the movement for liberalization in society - or at least have been unwilling to strictly suppress the liberalization movement on account of feelings of guilt and a realization that the CCP has been in the wrong. As the two sides interact in this way, mutually strengthening each other, they have consequently accelerated the process of the defeat and toppling of communist authoritarianism.

We know that during the early stages of reform, the economic reform faction within the CCP often amounted to the moderate faction in politics. Conversely, the faction of political hard-liners often amounted to the conservative faction in economics. In fact, the reason why conservatives in the Party opposed economic reform was not primarily related to economic factors, but instead was due to political considerations. They worried that economic reform would break apart the ideological foundations of CCP rule, thereby directly endangering the CCP's authoritarian 
power itself. It is said that when the Shekou Special Economic Zone was yielding vivid and dramatic results in production, this caused a group of "older-generation proletarian revolutionaries" to become very heavy-hearted. ${ }^{20}$ They asked: "Do you mean all this can still be called socialism?" Someone came up with a marvelous rejoinder: "As long as the CCP exercises control, it is called socialism." Consequently, these "older-generation proletarian revolutionaries" also came to feel at ease.

This episode can help us clear up a popular misconception. Many people have characterized Deng Xiaoping's line as "pragmatism." In actuality, we should assert that Deng Xiaoping's line is not pragmatism, but instead is cynicism. This is because pragmatism emphasizes the identity between theory and practice, while the peculiarity of Deng Xiaoping's line consists precisely in the deviation of practice from theory. This situation has been aptly illustrated by a jingle that has become very popular with CCP cadres in recent years: "Who professes socialism while doing socialism? The Ultra-leftist Faction. Who professes capitalism while doing capitalism? The Liberalization Faction. Who professes socialism while doing capitalism? The Deng Xiaoping Faction." At this late hour, the common people have long since seen through the deceit inherent within the Deng Xiaoping Faction's "professing of socialism." Normally speaking, as soon as a lie has been seen through, it no longer has any effect on a listener. Yet the curious thing is that the Deng Xiaoping Faction's lies about "professing socialism" still seem to be just as effective as ever, and the CCP can still suppress so-called "bourgeois" liberal thought in the name of "professing socialism." What exactly accounts for this? The reason for it may be found in the widespread and popular mentality of cynicism.

Hannah Arendt arrived at a discovery about the totalitarian system: "Its ingeniousness rests precisely in its nullification of the reality that either unmasks the liar or else forces him to live up to what he professes." This is because "the cynicism among numerous Party members and other members of the elite eliminates the danger that the Leader will ever be forced by the weight of his own propaganda to make good on his own statements and feigned respectability." ${ }^{\text {II }}$ These people would not only refrain from exposing the leader's lies or hoisting him by his own petard, thereby prompting a transformation in the nature of power, but on the contrary would also lavish praise upon this sort of "hanging up a sheep's head and selling dog meat in place of mutton," 22 and show great admiration for the current situation in which power has degenerated into naked violence, regarding that as ingenious, sophisticated and politically sagacious. One can see the extent to which the bane of cynicism has already become deeply entrenched.

The result of the implementation of reform by the communist countries led to the bankruptcy of their original ideology - i.e. their tradi- 
tional belief system. Throughout the Soviet Union and the various Eastern European countries, authoritarian rule was transformed into democratic rule. In contrast, the PRC's Democracy Movement of ig89 fell short of success for lack of a final effort, thereby allowing the CCP to temporarily avoid the calamity of "yes to reform and court death." The June Fourth Massacre thoroughly dispelled the legitimacy of the CCP rule, prompting the transformation of the CCP regime from a basis in power to a basis in violence. In a speech during his Royal Tour of the South in $1992,{ }^{23}$ Deng Xiaoping publicly proclaimed that there was no need to inquire whether reform was socialist or capitalist in nature. Having arrived at this point, the CCP no longer needs to worry about other people hoisting it by its own petard, because it no longer needs to doll itself up with the make-up of ideology. Nowadays, the only thing that remains for maintaining its rule of violence is violence itself; and the only mentality that remains for cooperating with this type of rule is cynicism.

\subsection{Cynicism and Fear - and the Notion that You Are "Better-Off Muddleheaded"}

Were we to locate the origin of increasing cynicism within the CCP in the mindset of "power for the sake of power," then the origin of growing cynicism amongst the populace is fear.

Communist authoritarianism amounts to lies plus violence, along with the corresponding attributes of credulity plus fear amongst the people under its rule. Strictly speaking, credulity and fear are mutually contradictory. When we mistakenly identify lies as truth, and at the same time mistakenly identify violence as the strength of justice, thereby confusing it with the people's own strength, we would thus not feel afraid of it. If we feel apprehensive in the face of the "dictatorship of the proletariat," this goes to show that we regard it as something alien, and in fact do not regard it as part of our own strength. In everyday life, however, people in general are indeed both credulous and fearful, harboring both of these mutually contradictory reactions at the same time. This is what Orwell termed "doublethink." Here, credulity appears at a surface level of consciousness, while fear exists within the subconscious.

There would be no harm in citing a couple of examples. If back during the Mao era somebody amongst our various relatives and friends were branded a rightist element, we would usually react with heightened caution and avoid having extensive contacts with him. Very seldom would we earnestly ask him why he had been denounced as a rightist. Based on our intuition, we did not actually quite believe that he 
could have truly been an "enemy," but neither did we exert ourselves at all to try to figure out the truth of the matter. This indicates that we were subconsciously afraid of learning the truth of the matter, because we were apprehensive that the truth might shake our faith in the Party.

At other times, we clearly knew that someone else had been treated unjustly, yet we did not openly voice any grievances on his behalf at all, owing to our fear of being implicated in his case. This indicates that in our heart of hearts, we did not actually believe that our system was a just system, a reasonable system - a system that protects good persons. In other words, even when we assumed that our faith in the communist system was at its strongest, in actuality our faith was very superficial, for fear lay hidden beneath the outer shell of our faith. The reason that credulity and fear could co-exist inside the same person's brain is none other than the fact that ordinarily we were always shooing our fear off into the basement in order to prevent it from coming into direct contact with our credulity.

This already amounts to cynicism: we do not subconsciously believe in what our surface consciousness believes. Were we to argue that the rulers' cynicism is expressed in the way they do not actually believe in the principles they orally profess, but merely use those principles as a means of safeguarding their power, then the people's cynicism is expressed in our lack of faith in the principles that we claim to believe in, while drawing upon this claim of faith merely to cover up our fear and rationalize our submission to authority. Because of this, it is not at all strange that in tandem with the populace's increase in experience and with the growing revelations about the totalitarian rulers' lies, many people actually refrain from rising with force and spirit to resist the regime. Obviously, from the very beginning they had not been genuinely fooled, and their former credulity had not actually been pure credulity at all. Many persons would only become even more passive, even more worldly-wise, and even more careful to avoid transgressions, to the point of strenuously exerting themselves to adapt to this world of lies. How could people have arrived at this sorry condition if they had not been in a situation where their credulity was decreasing at the same time that their fear was increasing?

People in general often overestimate the ability of the CCP's ideology to deceive the populace. They always assume that the only reason people have not arisen to oppose authoritarianism is that they have not seen through the regime's lies and have not realized that authoritarianism is indeed authoritarianism. In actuality, this assumption is off base. Sometimes, the situation is exactly the opposite. Precisely because the people have more or less realized that the regime's lies are indeed lies and that its authoritarianism is in fact authoritarianism - and that if they were to oppose the regime they would be subject to a crackdown - 
owing to their fears of such a crackdown they have not dared take a stand against the regime.

The Cultural Revolution is an example of this. The Cultural Revolution not only reached a point of perfection of totalitarian rule, but was also an unprecedented self-exposé of totalitarian rule. Nowadays, many people offer merely a one-sided emphasis on the Cultural Revolution's role in emancipating thought - the Cultural Revolution indeed prompted broad swaths of the populace to see through the lies of the authoritarian system, giving rise to a small group of true rebels - yet they overlook the Cultural Revolution's effect of intimidating people. For at the same time, the Cultural Revolution also transformed most of the populace into a "Free-and-easy Faction" whose members strove to avoid politics.

As someone who was involved in the Democracy Wall Movement, I noticed that the movement at that time included very few participants and among those participants, most were relatively youthful. ${ }^{24}$ The thought and viewpoints of most of these participants could not be considered penetrating, and some of them obviously still harbored various illusions about the regime - in other words, they were relatively credulous. Compared with them, the other group of somewhat older friends whom I had come to know back then had much more in-depth and incisive views about the CCP, including about Deng Xiaoping. Regrettably, the latter group would usually not participate in any movement, but would merely offer up their deep concerns to us while keeping their distance from the movement, wishing our movement success and yet maintaining a pessimistic attitude.

The same sort of contrast also emerged in Beijing University's election campaign of $1980 .{ }^{25}$ The younger and inexperienced undergraduate students who did not feel that the authorities were so authoritarian were considerably more involved in the campaign than were the graduate students. As for the Hundred Flowers Movement of I957, its "rightist" views were the most numerous and of more incisiveness when coming from younger members of the intelligentsia instead of their elder peers. ${ }^{26}$ To a large extent, this was because they got ensnared in Mao Zedong's scheme - in other words, because they had regarded the CCP with more credulity than their older peers had. It was not difficult for us to point out after the fact that some of the student leaders in the I989 Democracy Movement were unable to prevent the June Fourth Massacre from occurring because they had not clearly fathomed the essential cruelty of communist authoritarianism (this statement is in fact merely partially true, but I will not go into detail about the matter here). Yet if we think about this question from the opposite angle, if the students had been fully aware of the authorities' cruelty from the very beginning, how many of them would have dared to initiate this movement 
or engage in it? Was it not precisely because many adults had witnessed the regime's cruelty all too clearly, and only on this account stayed aloof from the movement and urged the students not to go out onto the streets?

Fear is not at all the same as cynicism. It is merely a bridge to cynicism. In a totalitarian society, fear penetrates the human psyche. Yet the issue that arises here is that if only people were capable of directly confronting their own fear, this would be a good thing, after all. Since fear and hatred are two sides of the same coin, fear is nothing other than hatred. To acknowledge fear and become acquainted with fear would surely prod us toward the standpoint of dissidents and resisters, even if we were merely to hide this dissent in our heart. Precisely because such a confrontation with our fear would necessarily stimulate our conscience, leading to an awakening and rebellion of our conscience, many people thus intentionally or unintentionally evade fear, avert their faces from it, pretend that they cannot see it, pretend that no such thing exists, and prefer to let their conscience remain in a muddled condition. This is what is known as the notion that we are "better off muddleheaded."

I heard that after the June Fourth crackdown, Zheng Banqiao's calligraphic scroll that reads "better off muddleheaded" became popular for a spell. This should not be viewed as a mere coincidence. This sort of expression, "better off muddleheaded," is nothing other than cynicism. It is only after switching from a state of intelligence to a condition of muddleheadedness that you can say you are "better off muddleheaded." "Better off muddleheaded" suggests that an intelligent person has become foolish and that a clear-headed person has grown muddleheaded. After all is said and done, however, "better off muddleheaded" amounts to muddleheadedness and foolishness. Only a person who is willing to think would become a cynic, yet once you become a cynic, you no longer need to think. Only intelligent people need to become muddleheaded: this requires you to fasten a halter over your own intelligence, not allowing it to ponder those real-world problems that can give rise to annoyance or difficulties for you. As time passes, your intelligence will regress and thus you will eventually cultivate this quality in yourself to the point of achieving a rare state of muddleheadedness indeed. The type of cynicism known as "better off muddleheaded" is no different from mental self-castration. It is a betrayal of reason and a betrayal of intelligence. 


\subsection{The Idea of Liberal Democracy - Only with Faith in it is it Efficacious}

The Democracy Movement in 1989 was a great expression of reasoned resistance. After the Democracy Movement in 1989 was violently put down, some students angrily commented: "You could not defeat us in debate, while we could not defeat you in battle." Reason won - the reasonable side defeated the unreasonable side in debate. However, reason also lost - reason lost to violence. During the Democracy Movement of I989, the demonstrators gained extremely broad-ranging and enthusiastic support. When the army of 200,000 soldiers reached the city gates, they were simply unable to enter the city because their routes into it had been blocked by a million or more of the common folk who had organized themselves. At that time, the populace firmly believed that concepts were forceful, reason was formidable, and ideas were capable of making weapons crumble.

However, the June Fourth Massacre cruelly put down the people's protest. The direct consequence of the June Fourth Massacre was to stir up even greater resentment and outrage in people. "Whoever loses the hearts of the people will lose their reign over the empire." Many people believed that it was completely impossible for such a murderous regime to last long. Subsequently, the great changes that occurred in rapid succession across the Soviet Union and Eastern Europe further intensified this belief. However, many years and even decades have passed since then, and it seems as though nothing at all has happened in China. The CCP regime did not collapse and remains in place as it had been before. This cannot help but stir up feelings of despair and disappointment in many people. This situation gave rise to another consequence of the June Fourth Incident: many people consequently lost their faith in ideas and in reason. No matter how much we have repeatedly argued and explained that there was absolutely nothing inevitable about the final outcome of the June Fourth Incident - in our hope that by doing so we might rebuild people's faith in rational resistance - yet the pity is that most people would simply not view matters this way for the time being. Still in a state of shock, most people would instead more readily reach the simple conclusion that ideas cannot defeat weapons, nor can reason defeat violence.

What is faith? Faith is not only knowledge, but even more importantly is volition. Faith in a given idea not only means that you know that sort of idea is good and correct, but also means that you want to practice it and achieve it. The reason why ideas and reason are powerful is that people have faith in them and put them into practice; otherwise, ideas and reason would not be powerful. As for the idea of liberal democracy, if you have faith in it, then it is efficacious, but if you do not, 
it is not efficacious. The problem now is that from the perspective of knowledge, many people still regard the idea of liberal democracy as something good, but they no longer have faith in it, participate in it, or put it into practice. They have sunk into a state of cynical pessimism a sort of vicious cycle of downwardly spiraling pessimism. Because they have no faith that the ideal of liberty can be realized, they do not exert themselves on behalf of this ideal, so of course this ideal would not be achieved; they would thus harbor even less faith in the ideal, and thus exert themselves even less on its behalf, and would thus harbor even less faith still in the ideal; the vicious cycle would continue on in this manner.

They know that the reality of their situation is ugly, but because reality is reality after all, and they do not consider themselves capable of changing it, they thus continue to acquiesce to it. They know that ideals are beautiful, yet an ideal is an ideal after all; an ideal does not exist in reality, cannot be achieved, and is always being rebuffed, so they abandon their ideals. Once people abandon their own ideals, they are no longer willing to listen to somebody else's voicing of an ideal. They think that all that is merely empty verbiage, is utterly useless, and would do nothing more than merely add to their vexation. A friend who teaches at a university told me that back in the past when he ascended the rostrum to expound upon the ideal of liberty, every seat in the classroom had been occupied each time; yet when he lectures on the same content nowadays, there are very few students in attendance. "Young people these days are too practical-minded," he said. "No," I replied, "young people these days are too cynical." The way young people have turned into cynics is truly the saddest of developments. Even before they have ever pursued something, they have already abandoned it; even before they have grown up, they have already become old and decrepit; and even before they have come to know something, they no longer believe in anything.

Let us discuss basic ethical training, which tells people what is good and what is evil. The presupposition implied here is that once people know what good is, they would then do what is good, and once they know what evil is, they would then resist evil. Yet basic ethical training appears to be bereft of significance to cynics. A cynic does not distinguish the good from the evil, though it is not as if he does not know what is good and what is evil. A cynic knows what is good, but does not cherish the good; he knows what is evil, but does not detest the evil.

Some cynics stray even further. They not only refrain from opposing a given evil, but even pander to the evil, as long as the evil is powerful and influential. They thus become very snobbish. In actuality, a cynic is not necessarily completely snobbish at the outset, but since he obliter- 
ates the distinctions of good versus evil and right versus wrong, nothing remains but snobbishness.

Other cynics are full of aggression. They not only have abandoned their ideals, but conversely mock the ideals of others. Indeed, the people who pour cold water on those who strive after an ideal are often not individuals who have never striven after an ideal, but instead are persons who once strove after an ideal, but later gave up after meeting with failure. When they cannot stretch high enough to grasp and eat the grapes, they then complain that the grapes are sour. When they no longer strive after an ideal and yet notice someone else who is still striving after an ideal, they jeer at him. This is mostly a strategy of using aggression as a type of defense mechanism. A cynic of this sort defends his lack of striving after an ideal by jeering at others who engage in such efforts.

A cynic's jeer also has its own logic. Since a cynic does not acknowledge any ideal but merely acknowledges reality, he would regard other people's insistence on pursuing an ideal in spite of being rebuffed by reality as "idiotic" - especially in China nowadays. After all, back in the Mao era, the CCP practiced "all-out authoritarianism," to wit, "with machine guns aiming at you from three sides, you are allowed to head off in only one direction" - thereby leaving people an overly narrow escape route. ${ }^{27}$ Yet nowadays, the situation is "with machine guns aiming at you from one side, you are allowed to head off in any of three different directions" - as long as you do not raise a political challenge to the autocratic regime, you are permitted to do whatever you want. Yet you have deliberately bumped into the muzzle of a gun - if you are not an "idiot," then what are you, anyway? Life is so short, and all of us have suffered from poverty for half of our lives; now that we finally have an opportunity to strike it rich, why must we struggle for liberal democracy or whatnot?

Let us refute an oft-repeated hypothesis in passing. Quite a few people believe that the reason it has been difficult to get a democracy movement off the ground again in mainland China can be summed up as follows. Because the economic reforms have achieved positive results and the populace has grown wealthy and prosperous, consumerist materialism has run wild, thereby diluting demands for political change even the intelligentsia has obtained relative freedom and more room in which to maneuver and is relatively satisfied with current conditions.

This seemingly sound hypothesis is actually wrong. If you think back to the period right on the eve of the eruption of the Democracy Movement in I989, were the economic reforms at that time not also proceeding quite well? That period was still within the honeymoon stage of the economic reforms when everybody had candy to eat, and the difference was merely that some people had more of it than others. It was not like 
nowadays, when untold thousands of workers have been fired from their jobs, with some families full of joy while others are mired in sorrow. As far as the circumstances of the intelligentsia are concerned, it was precisely on the eve of the Democracy Movement of 1989 that the circumstances of the intelligentsia peaked, and this sector of society generally enjoyed a very good self-image at that time. As far as the general populace is concerned, the eruption of the Democracy Movement in I989 was mainly the result of their ever-rising expectations of improvements in life, not the product of absolute or relative deprivation (as explained in Section I.7 above). This conversely explains that the main reason for the decline of the democracy movement is that the political ideals and political enthusiasm of the populace have been severely suppressed, chilled and driven away in a most severe manner; it is not due to people becoming satisfied with profit, but because their expectations for political change have shrunk; and it is not due to consumerist materialism running wild, but because of the spread of cynicism.

\subsection{Hip Cynicism}

Mill said that authoritarianism causes people to become cynical. Lu Xun said that in China, authoritarianism makes people numb. Cynicism is probably better than numb insensitivity. From this, we can see that we have improved. Many people find the term "cynic" unfamiliar. Yet were we to mention the term "hipster" - wanzhu (fop) - everybody would find it very familiar. ${ }^{28}$ In fact, a "hipster" is a cynic.

Some years ago, the sardonic argot-laden literature represented by Wang Shuo's novels became fashionable for a time. ${ }^{29}$ As we know, a writer is greater than his novel, a novel is greater than its animating concept, and the interpretation of a novel is greater than the novel itself. Here we shall discuss neither Wang Shuo nor his novels, but instead focus solely upon the socio-cultural phenomenon of the popularity of Wang Shuo's novels.

Among the many opinions about this issue that various scholars and experts have expressed, quite a few have hit the mark. One scholar pointed out that although Wang Shuo's novels initially appeared quite early on in the I980s, it was not until the following decade that the PRC's special socio-cultural milieu allowed his novels to start selling briskly as a sort of "hip" current of thought; in actuality, his novels reflect a cynical and nihilistic sensibility that was pervasive throughout every level of society in the early i990s. Another academic mentioned "defeatist sentiments permeating the lower social strata about the lack of any viable alternative in contemporary life." These sentiments point to the June Fourth Incident and its aftermath. Obviously, cynicism is 
what occurred after idealism suffered a grievous setback. The cynical mentality is what took place after serious aspirations for betterment had been cruelly trampled upon.

Huge psychological pressures can lead people to feel severely exhausted. The simplest way of shaking off your exhaustion is to toss the vitality of your spirit aside and then laugh at it. Why would you want to "shrink from loftiness of character" and "hanker after decadence" in this way? Because "as long as you don't regard yourself as human, nobody else would regard you as human, either; you'd then become joyful, for there'd no longer be a threshold anywhere in the world that you couldn't leap across" (quoted from a novel by Wang Shuo). Whenever Ah $\mathrm{Q}$ encounters a setback, he either imagines he has actually triumphed at the spiritual level, or else berates himself at length; either approach is effective as a release from his frustrations. In fact, it is not only $\mathrm{Ah} \mathrm{Q}$ but even some persistent idealists who are inclined to engage in extensive self-mockery after having met with a rebuff. Selfmockery amounts precisely to self-palliation. If you are in the position of a bystander, it would be even easier for you to mock other people's setbacks. The reason for this is that solemnity is but a step away from risibility.

A "hipster" wields many barbs. Yet there are two types of barbs. "As for a bee's barb, once its stinger is used, the bee forfeits its own life; as for a cynic's barb, once it is used, the cynic would prolong his muddling through life." This is because of the fact that after a reader has read a cynic's barbed remark, "the reader would feel that none of the affairs of this world has any significance or is worth engaging in" (in the words of Lu Xun). A hipster's ridicule and satire belong to the category of throwing out the baby along with the dirty wash basin..$^{30}$ While making official dogma appear laughable, it also makes serious resistance to the status quo appear ridiculous at the same time. However, the powersthat-be do not care if you ridicule them, since their hold on the levers of power was originally something that they forcibly imposed on people without having obtained the people's consent beforehand. It is as if the powers-that-be are saying: "You can revile me however you like, while I continue to run things my own way as usual - what can you do about it, anyway?" On the other hand, the wash basin can survive the impact that results from being thrown outside, while the baby cannot. A cynic's ridicule of the powers-that-be does them no harm to speak of, yet a cynic's ridicule of those who resist the status quo does great harm to their resistance. This is because the strength to resist comes from moral justice and from gaining others' support and sympathy.

The cynic exposes the true colors of the CCP, yet that is not equivalent to intentionally giving the CCP a hard time, since the cynic believes that even if the CCP were eventually replaced by others in the seat of 
authority, it would not make any difference. In a similar vein, the cynic does not consider the democracy movement acceptable. He believes that the participants in the democracy movement wish merely to replace the CCP in a takeover. When the CCP suppressed the democracy movement, the cynic's attitude was dismissive: "Neither side is any good. I wouldn't aid or abet either side." In actuality, the cynic was not responding to what we requested, since we had not requested that you turn around and help the democracy movement suppress the CCP. Instead, we had merely requested that you function as an impartial judge, ensuring that neither party suppressed the other side. Struggling for liberty and striving for democracy do not amount to the same sort of thing as the conquest and domination of a country. ${ }^{3 \mathrm{I}}$ The cynic will always confuse the two, whether intentionally or unintentionally.

\subsection{Doctrinal Cynicism}

Owing to the bankruptcy of the CCP's official ideology since the I99os, all sorts of unofficial currents of thought have emerged in accordance with the times. According to a summary in Chen Kuide's essay, "Hail to the New Era of Numerous Different Thinkers,"32 contemporary China boasts as many as fourteen varieties of relatively influential political thought, including democracy, democratic socialism, liberal constitutionalism, what Li Zehou has expounded as "Classic Marxism," the "Third Path" of Cui Zhiyuan et al., ${ }^{33}$ neo-Marxism, neo-Confucianism, Christian democracy, the Three People's Principles of Sun Yat-sen, neoconservatism, the "nationalism" of the Princeling Party's Program, Realpolitik Realism, the Maoism of Deng Liqun et al. and anti-Western nationalism. ${ }^{34}$ Most of the currents of thought listed above have departed entirely, or at least in part, from the path of the official ideology. While some of these currents of thought such as Li Zehou's "Classic Marxism" and neo-Marxism have continued to utilize various concepts and the overall framework of the official ideology, their content is nonetheless not altogether in line with that of the official ideology. Some currents of thought such as neo-conservatism defend the status quo of the CCP's single-party autocracy, yet have completely abandoned the usual run of Marxist-Leninist jargon, turning instead to such "bourgeois" scholars as Burke, Yan Fu and Hayek for their theoretical foundations. ${ }^{35}$

What is worth noting is that most of the above-mentioned currents of thought do not at all negate such basic values as liberty, democracy, human rights and the rule of law. For example, very few people nowadays would openly object to the principle of freedom of speech. The gaggle of absurd doctrines about "not bestowing freedom of speech upon counterrevolutionary speech" has long since been scathingly refuted - 
and to the extent that even the CCP regime had no choice but to delete the articles related to "counterrevolutionary crimes" from its legal code. ${ }^{36}$ Normally speaking, since there have been so many currents of thought nowadays that have arrived at a common understanding with respect to the issue of the freedom of speech, they could have and should have converged to exert strong pressure in demands for the freedom of speech and in opposition to punishment on the basis of speech alone. However, the reality has actually not been like this at all. When skimming through the major writings of the various new thinkers, we find that many of them either refrain from even mentioning the issue of freedom of speech, or else merely touch lightly upon the issue in a perfunctory manner. This cannot help but make me wonder if they are seriously committed to the principle of the freedom of speech as well as to the various theories they advocate - or if they even take these matters seriously.

As we know, the CCP's official Marxism has all along been a sort of cynical Marxism. It has merely taken advantage of Marxism, but has not been faithful to Marxism. The authorities have all along merely been cherry-picking and overemphasizing those components of Marxism that are in their own best interest, while evading and blotting out those components that are not beneficial to them. Quite a few among the multitude of "isms" prevalent in China's intellectual arena nowadays have generated similar defects. Certain proponents of these "isms" do not pay the slightest heed to the comprehensiveness or logical coherence of their doctrines, instead merely choosing to voice the sort of remarks that the powers-that-be love to hear. For example, some of these proponents stirred up a hue and cry that we must strengthen the nation's capabilities. Were you to examine this piece of advice in isolation, it is not too far off the mark, since as far as China's current problems are concerned, on the one hand the government is administering many matters that it should not in fact be administering, and on the other hand it is refraining from administering many matters that it should in fact be administering. However, these providers of advice discussed only the latter situation, without breathing a word about the former situation; they discussed only how the government must be effective, yet did not mention that the government needed to observe some limits to its authority. While frequently quoting remarks by Burke and Yan $\mathrm{Fu}$, the neo-conservatives quoted only their statements about safeguarding authority, but did not quote any of their statements about safeguarding freedom. The ultra-nationalists attacked only the ideas of freedom and democracy for having been imported from foreign countries, but did not criticize Marxism or single-party authoritarianism, both of which were similarly imported here from foreign countries. 
Speaking of the bane of cynicism in China's intellectual arena, one may well say that the New Leftists and the neo-authoritarians provide two prominent examples of this. The PRC New Left borrowed a huge assemblage of doctrines and theories from the Western Left. At first glance, this seems very odd. Western Leftism originally belonged to the radical spectrum of the Western intelligentsia, yet after it was introduced to China, it nonetheless underwent a transformation into a brigade that was allied with China's Conservative Faction. Of course, this is related to the nature of the Western Left itself. Simply put, the theory of the Western Left bears a strong resemblance to Marxist theory; both originated from within Western civilization, yet adopted a fervidly critical attitude toward Western civilization, and thus could be borrowed without difficulty by China's New Left and utilized to boycott the Western concept of liberal democracy. Furthermore, the mechanical importing of theories from the Western Left into China can easily lead to the absurd effect of one thing turning into something very different if transplanted to a different locale. ${ }^{37}$ More importantly, China's New Left (though of course not all of them) and the Western Left in actuality are not one and the same thing. The Western Left embraces idealism for the most part, while China's New Left is nonetheless completely imbued with cynicism. China's New Left delights in exposing the hypocrisy of Western liberal democracy; it is not at all content merely to denounce Western societal realities, but is also involved in negating the Western ideal of liberal democracy. Once such ideals have been rejected, no matter how awful reality might be in China, it can still be excused. The logic of China's New Left goes as follows: since all crows in the world are equally black, for anyone to criticize China would at most be merely a case of "the pot calling the kettle black" - why would we need to be hard on this black crow of a CCP, anyway?

Let us now turn to so-called neo-authoritarianism. Neo-authoritarianism indicates that it also aspires to freedom and democracy. However, it calls for first carrying out market-based economic reforms under the leadership of the authoritarian government, and only afterwards implementing the reforms of liberalization and democratization. On this account, it accepts the reality of authoritarian politics and furthermore regards authoritarian politics as an indispensable transitional stage between totalitarian politics and democratic politics. In order to justify their own doctrine, Neo-authoritarians often cite the experience of Taiwan's transition to democracy as an example. However, the problem is that the CCP is not the same as the GMD. The GMD recognized the principle of constitutional democracy from the very beginning and clearly proclaimed that authoritarian rule was merely a temporary expedient. The GMD even put forward a timetable for implementing the constitution, clearly stipulating concrete steps for gradual reform. 
This was not the case with the CCP. Even up to the present day, the CCP still refuses to make a clear promise to put liberal democracy into practice, while repeatedly proclaiming that it adamantly opposes socalled "Western-style democracy." To be sure, the CCP also talks about democracy sometimes, claiming that it will gradually expand and develop democracy. Yet the sort of democracy the CCP talks about is its own set of neologisms or "Newspeak" - the so-called "socialist democracy with Chinese characteristics." Moreover, the CCP has never mentioned any timetable for implementing democracy. In fact, during the thirteen years following the June Fourth Incident, the number of Chinese people who were persecuted on account of their political views or religious beliefs was far greater than the number of those who were persecuted during the thirteen years prior to the June Fourth Incident. Neo-authoritarianism tolerates or tacitly consents to this pattern of cruel persecution by the CCP, while at the same time insisting that the CCP is gradually leading China in the direction of liberal democracy. This is obviously deceitful verbiage. In fact, this is exactly why neo-authoritarianism became popular after the June Fourth Incident - many people felt the need to deceive themselves. Since they were embarrassed to go public with their abandonment of the idea of liberal democracy, they instead exiled this idea to an arbitrarily distant future.

\subsection{The Political Game of Pretending to Obey}

Word has it that in recent years, someone in the intellectual arena put forward the slogan: "Turn your back on the authorities." (This reminds me of a popular saying in Chengdu during the earlier I970s: "You'll lose out if you pay attention to him.") Of course, this is a call for people to boycott the authoritarian regime, even if merely to do so in a passive manner. We should acknowledge that the CCP's authoritarian rule nowadays is already much slacker than it had previously been. At a superficial level, the central authorities are in charge of everything, and their commands are heeded throughout the entire country. Yet in reality, their subordinates at the local level would often stick to their own way of doing things; when approaching a red light just ahead, they would do an end run around it in order to keep moving forward. "The higher-ups have their policies, but the subordinates have their own counter-policies." 38

As long as these subordinates do not openly challenge the government, it would simply turn a blind eye to them. This has given rise to the situation summarized as follows: "The CCP puts on an act of ruling, while ordinary people put on an act of submitting to its rule." Consequently, some persons have proposed that since direct resistance 
against the authoritarian regime would incur a crackdown, why must one directly resist it? Instead, if you perfunctorily go along with the regime at a superficial level while actually ignoring it, would this not be a wiser course of action? Some others have even gone so far as to claim that because more and more people have adopted this sort of attitude in China nowadays, what remains of the CCP autocracy is but a husk of its former self, and even that is gradually dissolving into thin air. In contrast, neither the continuous outcry from liberal intellectuals nor the arduous resistance by democracy movement activists has achieved much in the way of practical results.

This sort of viewpoint has a clear ring of cynicism to it. It attempts to make us believe that the absence of resistance is nothing other than resistance itself and even surpasses resistance in its efficacy. Those who hold this viewpoint appear to be unaware that history reveals this pattern of "putting on an act of either ruling or else submission to rule" has actually been the normal state of affairs for China's authoritarian rule. Lucian Pye has remarked upon this pattern:

One secret of the unity of China has been a conspiracy of makebelieve, which masks the strengths and limitations of both the state and society. The Chinese state, both imperial and communist, has always pretended to omnipotence, but in reality its policy-implementing authority has been surprisingly limited. Chinese society for its part has gone along with the pretense of official omnipotence while following its own lead and making almost no demands on the government. Rulers and subjects have thus tended to keep their distance from each other while pretending to be harmoniously close. ${ }^{39}$

Simply put, a peculiarity of Chinese authoritarian rule from the outset has been identified in the saying: "The government puts on its act of ruling; ordinary people put on their act of submission to its rule."

There have only been certain unusual historical stages in Chinese authoritarian rule - such as the certain phases during the Mao Era when "the dictatorship of the proletarian class" was implemented all the way down to the most basic level of society such as each factory, people's commune, neighborhood committee and school - in which the entire society resembled a huge prison like the one described in Orwell's novel Nineteen Eighty-four, whereby the top leader's "highest decrees" could be enforced all the way down to the grassroots level with little room left for local officials or other individuals to make any adjustments (actually it was not entirely like this, strictly speaking). Under most circumstances, however, Chinese-style authoritarianism has always had its flexible and adaptable side. Admittedly, no criticism of the 
regime's highest-level decrees and policies has been permitted, but these rules have usually been so vague and sweeping that subordinates have usually been able to stretch the rules and use their own discretion in implementing them in ways that suit local circumstances. Even when there have been clear-cut laws, these have rarely been strictly enforced.

The authoritarian system is rigid and inflexible by its very nature. Precisely for this reason, it cannot help but retain a certain degree of flexibility in practice, or else it would be like a string stretched too tightly and thus easily broken. This is similar to a traditional large family in China. According to an old proverb, "a patriarch will struggle to preside over his family unless he is a bit dull-witted and deaf." The ruler of the country resembles the patriarch of a family. If he takes everything so seriously and leaves his subordinates no room for maneuvering, he would certainly stir up direct conflicts with his subordinates; in the end, either the fish would die or else the fishnet would become torn. This is precisely the way the situation unfolds from the perspective of the ruler.

As far as the ordinary people under authoritarian rule are concerned, they would of course strive to work on behalf of their own interests and in general would always be capable of satisfying their own interests to a certain degree - though in general usually not by means of openly and self-assuredly insisting on their own legitimate rights, but instead through such methods as pretending to comply with a given directive or policy while actually violating it, taking advantage of any and all available loopholes, shirking responsibilities, and foot-dragging. When ordinary people are at odds with their authoritarian rulers and thereby encounter problems, they either rely on requesting the rulers' subordinates to intercede on their behalf, or else depend upon bribing the officials in charge - instead of negotiating and communicating directly with the higher-ups, going to court, or putting pressure on the government. To be sure, a saying such as "when meeting up with a red light, you go around it" expresses the fact that people can achieve some of their goals in a roundabout manner; yet at the same time it also signifies that people avoid going against the despot's authority, thereby acknowledging his authority. You could say that the ruler's authoritarianism is very superficial here, yet it is still authoritarian after all. You could also say that the submissiveness shown by ordinary people is merely feigned, yet it is still submissiveness after all. Authoritarianism is not being dispelled from this feigning; on the contrary, authoritarianism is able to muddle through and stay intact precisely on account of the lack of any head-on challenges to it.

Of course, "soft" authoritarianism is always better than "hard" authoritarianism. Under the soft variety, people can do pretty much what they please under the façade of feigning submission - this is un- 
derstandable and is not bereft of positive significance. The issue here is that we must not overestimate the positive significance of feigning submission. If we keep playing this game of feigning submission until we become so addicted to it that we come to regard head-on resistance as pedantic, foolish, or even extraneous, then the termination of authoritarianism, the establishment of civil rights, the implementation of the rule of law and the realization of a free and democratic system would be unachievable within the foreseeable future.

\subsection{The Cynic's Self-deception and Deceiving of Others}

Analogous to the problem discussed in the above section, another sign of the bane of cynicism is that in the process of achieving liberal democracy, the cynic tends to exaggerate the significance of behavior in pursuit of private interests, while denying the irreplaceable function of ideas and idealism.

Some people have argued that since the system of liberal democracy is based upon private interests, there is not much need for a spirit of idealism, for as long as every person pursues his own private interests, this will naturally evolve into a liberal democratic social order; since the market economic order evolved in this way, the political democratic order can also evolve in a similar manner. According to this viewpoint, the system of liberal democracy is nothing more than a set of rules of the game about the collision of various conflicting interests. Therefore, as long as reality presents us with the collision of various conflicting interests, this set of rules of the game will naturally come to gradually establish itself eventually. For example, the power structure of communist countries has from its very outset contained a certain type of democratic façade - the National People's Congress appears to be the equivalent of a parliament in a democratic system. ${ }^{40}$ Based on the logic that "the buttocks decide what the brain will do," some people expect that the National People's Congress would be motivated by private interests to strive to expand its own power, thereby unintentionally creating the conditions for the division and balance of power.

Under the circumstances in which head-on attacks by the democracy movement have repeatedly failed to dislodge authoritarianism, the above viewpoint certainly gives people a measure of solace. If we consider the fact that in real life there are often such cases of "unintended consequences" whereby "when intentionally planting a flower, it did not survive, yet when inadvertently planting a willow shoot, the willow grew into a big shade tree" - or think of cases in which someone scored a lucky hit - the above viewpoint even appears somewhat credible. 
However, I have profound doubts about this viewpoint. My reason is quite simple. Ever since time immemorial, people have been pursuing private interests. How come the social order of liberty and justice did not already evolve a long time ago? Why would the social order of authoritarianism and repression nonetheless still be in existence nowadays? It is precisely because people have all along been pursuing their own private interests, which have in turn led to collisions among them. The result of this sort of collision does not always lead to an order of liberty and justice. It could very well lead to one side's oppression of the other side, or one side's submission to the other side. Unless individuals acknowledge other individuals' private interests at the same time they pursue their own private interests - and, conversely, unless people dare to take risks fearlessly and rise to resist when their interests are ruthlessly and unjustly violated - what will be formed is an order of oppression rather than an order of justice. When it comes to rules of the game, there can also be two types of rules of the game. Collisions between various interests could indeed gradually evolve into a set of rules of the game, but there is nothing inevitable about this naturally turning into a set of good rules of the game, as such collisions could very likely evolve into a set of bad rules of the game. Unless we insist upon correct ideas and also struggle tirelessly on their behalf, we cannot possibly obtain the good rules of the game that we need.

Let us take the situation in contemporary China as an example. Many CCP officials take advantage of their special privileges to engage in graft and corruption, converting public property into private gain. Everyone is aware that it is only by eliminating special privileges and implementing the rule of law that we can safeguard the public interest. This requires that the populace arouses itself to participate in the struggle to bring an end to single-party authoritarianism. However, participating in the struggle against authoritarianism entails extremely grave risks; it may bring on cruel repression by the state, and in the end the populace might suffer even greater losses. Therefore, if your motivations have arisen solely from your private interests, you would probably consider yourself better-off in terms of security and tangible benefits if you were you to abandon the struggle against authoritarianism and conversely follow others in getting up to some profiteering. If everybody were to abandon demands for social justice and merely chase after the pitiful scraps of profit left over from the extortions of those with power and influence, how could we ever attain an order of liberty and justice? From this we can see that throughout the process of promoting a systemic transformation, we definitely must have idealism and heroism.

Among those viewpoints I have criticized above, none has abandoned its yearning for the ideal, yet all have abandoned the struggle on behalf of the ideal, based on the assumption that an ideal society could be 
achieved without first going through a period of arduous struggle on behalf of the ideal. This is obviously a cynic's way of deceiving himself as well as others. When persons separate themselves from the ranks of struggling for the ideal on account of their frustration, despair, fear or temptations, they are unwilling to be seen by others as having betrayed the ideal, but would instead claim that they are in the midst of "saving the country by way of a circuitous route," while contending that nonresistance is even more effective than resistance. When they cannot eat the grapes that are out of reach, they claim that the grapes will eventually drop down to the ground of their own accord, and thus there is no longer any need to jump up in an attempt to pull the grapes down.

When discussing the various conditions required for achieving a liberal democratic system, scholars have referred to many factors such as economic development, the universality of education, and the rise of a middle class. These factors are undoubtedly beneficial, but experience proves that not all of them are necessary. I am even more inclined to emphasize the factors of ideas, ideals and resistance. Without the idea of freedom, there will be no free society; without a democratic wing in the political system, there will be no democratic system. 



\section{Struggling for the Freedom of Thought}

\subsection{Quandaries of Existence}

When all is said and done, control over thought amounts to control over the expression of a person's thought. Therefore, the struggle for freedom of thought is in actuality a struggle for the freedom of expression in thought.

A few years ago, a Chinese novelist went on a trip overseas. When someone abroad asked him if Chinese writers enjoy the freedom of expression, he tersely responded that they do. This reply immediately led to reproaches from a few of his literary peers back home. The novelist later explained in his defense: "What I said is that Chinese writers enjoy the freedom of expression; I didn't say that we have the freedom to publish what we have written." While this sort of self-justification is shrewd, it is a conceptual muddle, since what we call the freedom of expression refers to nothing other than the freedom to publish what we have written.

To struggle for the freedom of expression in thought under the communist system is an extremely arduous endeavor. The most distressing aspect is that the more you struggle for the freedom of expression in thought under such a system and thus likely incur suppression by the regime, the more likely it is that you would eventually lose whatever limited freedom of expression in thought you enjoyed at the outset. Conversely, if you have never directly and publicly struggled for the freedom of expression in thought, you are likely to have preserved opportunities that you had at the outset for expressing your thought; you would thus be able to express your thought more than various other persons would.

Just take a look at China nowadays: many people who have striven to advocate in favor of the freedom of expression and daringly voiced their political dissent have been imprisoned, exiled, or else forbidden to make an appearance at public forums, thereby appearing to have already lost their own voice and ability to appeal to the broad masses in China. At the same time, those people who have never (or hardly ever) participated in the struggle for the freedom of thought have all along maintained opportunities to address the Chinese public, thereby bring- 
ing their continuous and broad-ranging influence to bear on the scene. This phenomenon serves to create the impression that the latter type of people appear to have made considerably more important or effective contributions than the former type of people to the promotion of $\mathrm{dy}$ namic thought among the Chinese people.

However, the problem here is when coming face to face with the CCP's net of thought control, if everyone is merely calculating how to slip through the mesh of the net instead of marshalling a great effort to destroy the net, what would prevent this net from managing to last forever? This is one angle of the problem. With respect to the other angle of the problem, as far as the individuals who are determined to destroy the authoritarian net are concerned, we cannot simply rest satisfied in the knowledge that our behavior is justified, but must also consider how our behavior can produce the greatest results. Experience has proven that even under the regime's strictest thought control, it is not as difficult for a person to generate free thought as certain individuals outside of the system have imagined. The genuine difficulty is just how to enable free thought to get publicly expressed and widely disseminated, along with finally achieving victory.

In his concise treatise, Exit, Voice, and Loyalty, the American scholar Albert O. Hirschman writes that when people are dissatisfied with their organization, company, party or nation, they can express their dissatisfaction by adopting the method of "exiting" the unit, or by remaining within the unit to "voice" their dissenting views. ${ }^{\text {I }}$ What is known as "loyalty" refers to a situation in which a person is clearly capable of "exiting" the unit, yet still remains "within the system" to seek out ways of improving it. In this scenario, "exit" means that there is a replacement or a competitor, while "voice" means that there is discursive space for expressing a critical viewpoint. It is self-evident that these measures can achieve their full effect only within an environment that is competitive, transparent and large in scale. Hirschman offers excellent and richly insightful interpretations of the performance, effect and interaction of these measures of resistance under various circumstances.

The pity is that Hirschman's analysis barely touches upon the situation in a totalitarian society. As he sees the matter, a special characteristic of totalitarian rule and single-party authoritarianism is that it contains neither an exit nor a voice, and naturally no loyalty to speak of, either. Of course, this is merely a simplistic generalization. Since a totalitarian system is a man-made entity, it could certainly not be flawless. Moreover, to borrow an observation from Solzhenitsyn: "Even a flawless system must depend upon people with flaws for its execution." ${ }^{2}$ Therefore, it is still possible to engage in highly effective resistance under a totalitarian system. The changes in the former Soviet Union and Eastern Europe have already provided us with successful 
cases in point. Although the Chinese totalitarian system has not yet undergone a fundamental transformation, it is undoubtedly in the midst of a process of decline. And though Hirschman's treatise does not go into detail about the situation in a totalitarian society, there is still a great deal from which we can profit in the concepts and mode of thought he offers up.

In some of my previous writings, I have already discussed to some extent the methods and significance of people who engage in rebellion under a totalitarian system. I plan to analyze this again below.

\subsection{An Analysis of Some Peculiar Phenomena}

There are many peculiar phenomena in communist countries. What I mean by "peculiar" is these phenomena obviously come into conflict with various down-to-earth beliefs held by ordinary people. For example, ordinary people would think that a political party could garner the populace's participation and support only if its previous political achievements were praised by the populace, and only if the ideas it upholds meet with the populace's approval. From this perspective, the CCP obviously enjoys no such advantage - at least that is the case with the CCP of today. Yet it is precisely such a party that still maintains its status as the world's largest party, even while all sorts of its appallingly destructive misdeeds are becoming more and more widely known today. Is this not a most extraordinary and peculiar event? What we must ask is: why even up till now are there still persons who want to join the Party? Why are even those few dissidents still within the Party happy to remain in the Party? Why do those Party members who have been repeatedly persecuted by the Party still want to express their loyalty to the Party again and again? Why is it that many benevolent persons who are concerned about national affairs always place their hopes in the CCP? Why is it that when many Party members' political views directly conflict with those of the Party's top leaders, there are still very few Party members who withdraw from the Party?

Let us explain these issues one by one.

\subsection{Why Are There Still People Who Want to Join the Party?}

People generally believe that a given person joins a certain political party because he both agrees and identifies with that party's ideas. Yet this is true only on condition that there are two or more parties competing with one another. Following the establishment of the CCP's singleparty autocracy, the issue of agreeing with the Party's ideas is no longer 
a necessary condition in a person's decision about whether or not to join the Party, while other factors play an increasingly significant role in leading to that particular decision.

First, by joining the Party you can enhance your practical private interests. In a society ruled by the Communist Party, only Party members are well-connected, so naturally there are many persons who join the Party so that they can get well-connected. Normally, a Party member must supposedly "first endure hardship and only later enjoy happiness," 3 so on the face of it there would not seem to be much profiting at other people's expense that could be achieved by joining the Party.

Yet the reality of the situation is not as simple as this. Since a communist society emphasizes political criteria as its top priority in all respects, it would be difficult to avoid determining people's social status in accordance with how "advanced" they are politically. The higher a person's political status, the more likely he would obtain special consideration and perquisites, in accordance with "the requirements of the revolution." ${ }^{4}$ During the Cultural Revolution, the denunciation of the phenomenon of "joining the Party in order to become an official" was merely saying that a person's motive for joining the Party should not be the desire to become a government official. ${ }^{5}$ However, since the Communist Party assigns numerous official posts only to "our own people" - that is, Party members - how could you avert a situation in which people are joining the Party primarily for the sake of becoming an official? Even though there are certain times when Party members or those who are applying to join the Party must work with greater enthusiasm or effort, paying a higher price on the job than others, it still remains the case that Party membership always gives you far more advantages than what non-Party members enjoy under the actual conditions of the CCP monopolizing all societal resources. Liu Shaoqi once frankly characterized this state of affairs as "suffering minor losses, but gaining huge advantages."

We know that under CCP rule, anyone who takes up one of a wide variety of different government jobs, great or small, including those that are purely professional and technical, is called a "cadre." In other words, even if you are merely a professional and seek nothing more than a promotion within your professional career, political criteria are still extremely important; and your status as being either inside or outside of the Party can lead to very different results.

Of course, it is not the case that each and every person who wants to join the Party is merely pursuing materialistic gains or hankering after a promotion in his career. If some persons desirous of joining the Party may be said to be motivated by their idealism, it is because they wish to achieve something in the realm of public affairs. 
Joining the Party is useful for carrying out many sorts of significant undertakings. The Communist Party has monopolized all political power within society, thereby monopolizing almost all of the opportunities to perform any deed within the public realm, whether for good or for ill. Without the "entrance ticket" of Party membership, it is practically impossible for you to acquire any political power, and thus you cannot possibly achieve anything significant in the realm of public affairs.

This is quite similar to the civil service examination system in premodern China. Of course, relatively intelligent men in pre-modern China knew how meaningless and useless "eight-legged essays" were, yet it was only by means of passing the civil service examinations that a man could possibly serve in the political arena and perform some deeds that were useful to the country and the people. ${ }^{6}$ The "Party's dominion over the entire country" embodies a system that is far more broad-ranging and intricate than the old civil service examination system ever was. ${ }^{7}$

Consequently, there are many people who are willing to join the Party because they wish to put their abilities to good use, even though they do not have the slightest interest in the CCP's political ideas. The problem does not lie in whether the CCP provides you with satisfactory conditions for you to give free play to your high aspirations, but in the fact that you have no other choice. This resembles a shoe factory that monopolizes all the shoe-making materials and tools, and naturally also monopolizes all the shoemakers and buyers. If you would like to work as a shoemaker and thus enable everyone to have shoes to wear, you have no alternative but to join the workforce of this factory.

If we further extend the above-mentioned metaphor, we can arrive at an even more embarrassing inference. For instance, what if you discover that the boss of this factory is quite nasty in the way he treats his employees; that the management of the factory is a big mess; that the quality of the shoes the factory manufactures is extremely poor; and that you are thus unwilling to join the workforce of this factory? Nevertheless, in light of the circumstances in which this is the one and only shoe factory in the entire region, even if you can let your talent as a shoemaker go to waste and abandon your craft, you still cannot spend the rest of your life walking around barefoot and thereby avoid purchasing shoes manufactured by this factory. In other words, although you yourself can refrain from joining the Party, as long as you are still living in this territory of mainland China, you cannot help but fall under the control of the CCP. This being the case, you might think that instead of letting that gaggle of present-day Party members commit all sorts of outrages and make yourself suffer disastrous consequences as a result, you would be better off joining the Party so that you could still be in a position to improve matters a bit. 
Following the calamity of the Cultural Revolution, the prestige of the CCP nosedived; there was a marked decrease in the number of younger-generation Chinese who enthusiastically drew close to Party-sponsored organizations or wholeheartedly strove to join the Party. However, it was exactly at this point of time when some persons put forward the following viewpoint: it is precisely because some miscreants snuck into the Party and committed evil deeds that the Party especially needs us good people to join the Party and improve it. During the election campaign at Beijing University in I980, a young teacher named Fan Liqin put up a big-character poster entitled, "The Necessity that the Intelligentsia, Especially University Students, Join the Party." ${ }^{8}$ The author pointed out that because our country in actuality has a single-party political system, the intelligentsia and student youth must take the initiative to join the Party in order to bring about national prosperity and a democracy under the rule of law. ${ }^{9}$ The CCP was naturally unhappy to hear individuals such as Fan Liqin make such a clear and public statement about joining the Party in order to transform it, and thus would not very likely induct them into the Party, either. However, what we can say with conviction is that the reason many persons strove to join the Party at that juncture was indeed that they wanted to alter the composition of the Party and launch a reform of it.

We can thus understand why the CCP has been able to maintain its huge organizational scale all along: it is not due to some measure of open-mindedness, but on account of its authoritarianism; nor is it due to some sort of wide exercise of benevolent rule, but instead because it is ruthlessly tyrannical. The reason quite a few good people wish to join the Party is that they discovered there are already too many bad people inside the Party, it is precisely because they are not satisfied with the Party in its present state that they try to come up with ways of getting themselves inducted into it.

We can arrive at two more inferences from the discussion above. First, if the CCP remains as authoritarian as ever, but no longer "leads everything" - that is to say, if a person neither needs to be a Party member or else under the control of the CCP in certain domains of life then the number of people desirous of joining the Party would definitely drop steeply. In fact, this sort of situation has already materialized. In accordance with the deepening progression of economic reform, the scope of what is under the direct control of the CCP has been reduced, and thus the spread of Party-run organizations has either stalled or slowed down. Second, if the CCP were someday to abandon authoritarianism and implement democracy instead, we can be certain that the number of Party members would only decrease and not increase. 


\subsection{Why Some Dissidents Are Willing to Remain in the Party}

Aside from the reasons for joining or staying in the Party mentioned in the previous section, there might be still other reasons for this. It is interesting to note that if you want to struggle for a liberal democracy, or if you want to oppose the Communist Party, it seems to be even more convenient if you happen to be a Party member.

The reasons for this are embodied at two levels. First, as a political organization, the CCP naturally places strict requirements about thought and discipline on its members. According to this line of reasoning, a person who is outside the Party would expect to enjoy more freedom of thought and action than a Party member has. Unfortunately, this is not the case, as the CCP rules the nation mostly as if it were indistinguishable from the Party, treating all citizens as if they were Party members. A citizen without Party membership can at most be a little more inactive and sluggish than a Party member. If he wants to be actively involved in public life and vigorously express his opinions on political issues, then he would be treated every bit as harshly as a Party member would. Second, while a citizen without Party membership does not enjoy any more freedom than a Party member has, it is nonetheless possible that a Party member would enjoy more power and opportunities for advancement than someone outside of the Party would.

This state of affairs leads to two consequences. First, in publicizing the same sort of "liberalized" discourse, you have more opportunities to speak out and a more formidable stature from which to speak out if you are a Party member rather than an ordinary citizen. Because of this, it is possible to make your voice have a greater impact. And when other people realize that you are a Party member, it is easier for them to indicate that they concur with your views. Second, if a day dawns when you happen to stir up some trouble, such as if the Party decides to oppose "liberalization," then much like an official post, your Party membership can more or less downgrade the seriousness of your "crime." In a society where people are not equal in front of the law, the higher a person's political status, the lighter the punishment he incurs. When committing the same kind of "political error," perhaps you would merely be dismissed from your post if you are a cadre; perhaps you would merely get expelled from the Party if you are a Party member; but if you are an ordinary citizen, you would lose your means of livelihood or be put in prison. The situation is usually like this, even though naturally there are occasional exceptions.

As is widely known, Fang Lizhi played an important part in the Liberalization Movement of $1986 .{ }^{10}$ We should note that this had something to do with Fang Lizhi's special status as both the Vice President of the University of Science and Technology as well as an internationally 
renowned scientist. Fang Lizhi has said that although the viewpoints he expressed at that time were about the same as those that Wei Jingsheng had expressed a few years earlier, the authorities could not come down hard on Fang due to his high social status. ${ }^{\text {II }}$

Let me cite another example. During the spring of I995, a group of intellectuals and dissidents inside China disseminated one petition after another calling for the freedom of speech and demanding a re-assessment of the June Fourth Incident. Among these various petitions, the one signed by more than thirty famous scholars and scientists that called for more tolerance on the government's part garnered a disproportionate degree of attention. After all, in any activity of political protest, the circumstance of its being led by a famous personage would necessarily create a greater impact. In addition, because such a person enjoys considerable fame and influence, there would be greater repercussions that would necessitate paying a relatively heavy price if the regime were to crack down on him. The regime would thus be more hesitant in deciding whether or not to crack down; and it would generally be relatively restrained in its repression if it did choose to crack down.

However, were we to sweepingly argue that great fame results in but a minor risk on your part, that would not be accurate, either. It depends on the nature of the fame you have. If the regime has previously pigeonholed you as belonging to a dissenting faction, your public participation in a certain protest activity would instead allow the regime to even more easily announce that this activity belongs to the sort that is "hostile in nature," and thus even more conveniently get their crackdown underway. This is one of the reasons that numerous participants in various protest activities do not welcome the open involvement of well-known dissidents. Yet if your fame belongs to the type that has been established within the political system, or in other words has been approved by the political system, the situation is entirely different. Under these circumstances, the regime would find it relatively difficult to initiate the suppression of your activities, and even if they did, their means of suppression would not be overly strict. Since in any type of resistance activity the leader has all along been the person who bears the primary risk and even the leader is not taking a major risk, then the risk for rank-and-file participants or those who merely follow along would naturally be relatively slight. There is also the type of situation during certain group expressions of dissent in which group members of high status are pushed by the others up to the frontline of the struggle for safety's sake - even when the high-ranking individuals were not originally important figures in the endeavor. In brief, when a person who already has obtained a certain status within the Party and the political system is engaged in resistance to it, he not only takes on a relatively 
small risk at a personal level, but can also more effectively bring others along to participate in group dissent due to his ability to reduce the risks of those who are echoing the calls of the leading dissenters; in this way, he further strengthens the overall power and influence of such resistance.

\subsection{Why Some Persons Severely Persecuted by the CCP Would Continue to Express Their Loyalty to the CCP}

In I985, Professor Yue Daiyun of Beijing University wrote an autobiography entitled To the Storm. ${ }^{\mathrm{I} 2}$ In this book, the author reminisces upon the bitter frustrations she experienced from the Anti-rightist Movement on down through the Cultural Revolution. The point worth noting is that after having recounted the details of a nightmare that is almost unbearable to think back on, Yue Daiyun concludes her autobiography by noting that she has rejoined the very same Communist Party that had expelled her in 1958. In fact, among those persons who had been expelled from the CCP during the various Mao-era political campaigns, most (if not all) rejoined the Party in the aftermath of having been exonerated and thereby regaining their good repute. One individual after another who had not originally been a Party member also put forward a request to join the Party following the removal of his label as a "rightist" or a "counterrevolutionary"; many were indeed inducted into the Party. This leads us to a profound question: since these people had been severely persecuted by the CCP, why is it that in the end they still wanted to identify themselves with that Party and pledge their allegiance to that Party?

The reasons for this are relatively complex, and cannot be lumped together into a single mold. One of the reasons might be for the sake of self-preservation and to obtain a greater sense of security. On the face of it, if a person has been so cruelly persecuted by the CCP and yet winds up pledging allegiance to it, how would he not be considered an out-and-out masochist? In actuality, the issue is not as straightforward as this. When a person suffers cruel persecution at the hands of the Party, two types of emotion can easily arise within him: one is to hate the Party for its cruelty, while the other is to gain a deep impression of how powerful the Party is. The former emotion spurs you to resist the Party, while the latter emotion prompts you to yield to it. Were you to discover that you lack either the courage or the strength to resist your persecutors, you would consequently feel that the most reliable way of avoiding persecution is to gain the persecutors' acceptance and join the ranks of the persecutors as a member in your own right. Joining the ranks of the persecutors does not necessarily mean that you must parti- 
cipate in the persecution of others - after their re-admission into the Party, many former victims of persecution have refused to participate in the persecution of others. All they are after is for the Party to no longer regard them as alien elements and instead for the Party to consider each of them to be "one of us."

It is likely that the situation is even more complicated for such persons as Yue Daiyun. You were once a Party member, but then the Party expelled you. Yet the Party now admits that it made a mistake and has thereby exonerated you; it follows as a matter of course that your Party membership will be reinstated. It is not as if you requested to be readmitted into the Party, since you may well have had no intention whatsoever of reinstating your Party membership. Instead, it is a case in which the Party has simply presented you with the reinstatement of your former Party membership. This puts you in an awkward position, for you realize that were you to refuse to accept the reinstated Party membership with which the Party has presented you under these circumstances, this would be tantamount to a public expression of resentment or disdain toward the Party.

The original intent of the saying, "refuse a toast, only to be forced to drink a forfeit," was to poke fun at someone who is ignorant of acting in his own best interests - a person who rejects polite requests while submitting only to pressure. However, under authoritarian political rule, if you turn down a request from the authorities, they would right away compel you to do whatever you had initially declined to undertake. You lack any middle-of-the-road alternative. To all intents and purposes, you have no choice other than either drinking a toast or else drinking a forfeit. ${ }^{\mathrm{I3}}$

There is an old story about how county magistrates in pre-modern China would sometimes ruin a family in their jurisdiction. A certain newly-appointed magistrate was fond of posing as a lover of culture, but in actuality was narrow-minded in spirit. He took the initiative to invite an eminent scholar in the locale to a banquet at his residence. ${ }^{\mathrm{I}}$ For one reason or another, the scholar did not attend the magistrate's banquet. Having set his mind on the belief that the scholar had ignored him out of contempt, the magistrate flew into a rage over this loss of face. This official racked his brains to come up with a scheme to frame the scholar and kept at it until he eventually indeed brought ruin to the scholar and his family. This is an example of how someone can "refuse a toast, only to be forced to drink a forfeit."

In its overweening self-importance, the CCP erroneously thinks that everybody should draw close to it in support. If you were not originally a Party member and had never shown any intention of drawing close to the Party, you would still be able to justify yourself. For the Party could assume that owing to your sense of inadequacy and inferiority, you 
would not dare aspire to something as exalted as Party membership; your deference even serves as a foil to the greatness of the Party, or at least would not detract from the greatness of the Party. However, if the Party was now extending its own hand to present you with a reinstatement of Party membership and yet you nonetheless refused to accept this reinstatement, would this not amount to an open affront to the Party? In light of the way the Party once mishandled your case in the past, how could your refusal not be interpreted as an indication that you still harbor a grudge toward the Party? Yet precisely because the Party wields such immense power, you could well imagine how dangerous your situation would be. Seen from this perspective, it is difficult indeed for a former "anti-Party element" whose derogatory label has been removed and who has been offered coronation by the Party not to go ahead and accept the coronation.

I recall how on one day in I985, a friend told me about a troublesome matter he had experienced. This friend was a standout in his profession and well-liked in his work unit. Someone within the Party organization earnestly sought him out for a chat about encouraging him to strive for induction into the Party. After the fall of the "Gang of Four," the CCP guiding organizational principles underwent considerable change. Prior to 1976 , the CCP had raised the standards for admission to the Party so high that no matter how arduously a lot of people strove to join the Party - particularly those within the intelligentsia - they still could not manage to attain Party membership. Yet in order to improve its own image, ever since 1976 the CCP has increasingly paid attention to individuals who are both standouts in their profession and well-liked in the community, trying to recruit this type of person into the Party. The liberal-minded faction within the Party also hoped to make use of this opportunity to increase its faction's clout. While never unaware of the multifarious advantages that Party membership brings, the nature of his own political convictions and ethics was such that there was no way that this friend could declare his allegiance to the Party. Nevertheless, this friend was also anxious about whether the Party would discern a "rebellious streak" in him if he were to bluntly reject the offer and thereby needlessly bring trouble upon himself instead. Consequently, he adopted a posture of silence, responding to the Party's invitation with the absence of a reply. I have also encountered a similar situation. Obviously, when the Party is beckoning you to approach, it is not an easy matter for you to decline its invitation.

On the other hand, I have a few other friends who formerly participated in the Democracy Movement and whom the Party relegated to its "other register" as "objects of domestic control," yet who took the initiative to fill out an application form in pursuit of admission into the Party. ${ }^{15}$ In fact, they knew fully well that the Party apparatus would not 
approve their applications, nor did they ever have the slightest inclination to join the Party. The reason they did this was merely to create a diversion so as to make it more difficult for the Party to crack down on them: "We're the ones who enthusiastically strove to be admitted into Party, how can you still accuse us of being anti-Party?" This is another type of situation in which joining or attempting to join the Party is a method of self-protection.

Of course, there is yet another situation that we cannot exclude. Among those persons who were politically victimized over many years and yet still hope to join or rejoin the Party, some of them might have still preserved a certain fraction of the romantic and idealistic motivation of their earlier years. In the finale of To the Storm, Yue Daiyun reinstates her Party membership. In the final sentence of this book, she writes: "I know I must try." This sentence more or less reveals the psychology of a person who has an unwillingness to give up in spite of having experienced her fill of disappointment.

What I said about an "unwillingness to give up" embodies two levels of meaning. The first level of meaning is an unwillingness to give up hope in the Party. We know the general reason that a large group of persons who had previously been expelled from the Party or prevented from joining the Party were capable of either initiating or reinstating their Party membership was that the Party's political line had been greatly modified. The hopes of these persons were thus rekindled; although the past performance of the Party was disappointing, now that it had more or less come to its senses already, perhaps it would even change for the better in the future.

The second level of meaning is an unwillingness to give up the dreams and enthusiasms from one's youthful days. Humans have a tendency to maintain a sense of consistency in the self and are unwilling to negate themselves. For many people, the CCP was like the object of their very first love interest. No matter how many tremendous changes and huge upheavals they experienced after this first love affair, and in spite of their inability to turn the clock back to the long-gone ways of the world during their youth, many people still yearned to resume dreaming their old dreams if given a chance, and would seize any opportunity to give this a try. As Hirschman pointed out, the more expensive an organization's membership fee is, the more unwilling any given member would be to quit the organization lightly, since he hopes to prove that he was correct in having paid such a high fee at the outset. ${ }^{\mathrm{T}}$ Bacon long ago remarked that ne'er-do-well husbands often have loyal and worthy wives. Of course, these husbands must have been ones whom the wives themselves chose without having paid any heed to the opinions of their relatives and friends. ${ }^{17} \mathrm{~A}$ wife of this sort would thus spare no effort to preserve her marriage, devising all sorts of stratagems 
to help her husband improve, thereby proving that her own choice in this matter had not been wrong in the least.

Speaking of loyalty, we might as well add a few more comments. Loyalty is a kind of enthusiasm offered by someone on his own initiative. A prerequisite for loyalty is that the person who is directly involved enjoys the freedom to choose. Hirschman's comment is apt: “Just as it would be impossible to be in a world without evil, so it makes no sense to speak of being loyal to a firm, a party, or an organization with an unbreakable monopoly." ${ }^{18}$ In the past, commentators often referred to the behavior of an individual who continued to pledge their loyalty to the Party in spite of having suffered severe persecution at its hands as "foolish loyalty." In actuality, the term "foolish loyalty" is not accurate here. For example, during the Anti-liberalization Movement of 1987 , the CCP ordered that Party membership be stripped from such intellectuals as Fang Lizhi, Liu Binyan and Wang Ruowang. ${ }^{19}$ While Fang Lizhi expressed no qualms about this measure, Liu Binyan appeared somewhat reluctant to accept it. As a consequence, various commentators criticized Liu Binyan for being too "foolishly loyal" to the CCP. Yet the situation was not actually as simple as they claimed. Liu Binyan noted that his circumstances differed from those of Fang Lizhi. After the Party expelled him, Fang Lizhi could continue his work as a scientist and keep pursuing his astrophysical research - in relative terms, the impact of the Anti-liberalization Movement in 1987 was not too harsh on Fang. In contrast, Liu Binyan was an author and journalist. Once he had been denounced by the regime's top authorities and expelled from the Party, it signified that from that point forward he had lost any chance to speak in public forums or to publish his writings in the PRC, and thus was no longer able to function as a writer and journalist in the PRC. From this it is evident that the main consideration in Liu Binyan's hope to retain his Party membership was to preserve his qualifications to express his views publicly in the PRC. This does not necessarily have anything to do with "foolish loyalty," after all. Under the circumstances of "you are useless unless you are loyal," there is no such thing as true loyalty; and to behave as if you are loyal is not necessarily foolish.

\subsection{Why Do Party Members Rarely Withdraw from the Party, and Why Do Officials Rarely Resign?}

Based on the analysis above, we can readily understand why Party members rarely quit the Party and officials seldom resign from their government posts under single-party authoritarian rule.

During a speech in 1980, Deng Liqun cited an example of the oh-so single-minded devotion and loyalty that all Party members showed to 
the oh-so great, glorious and correct CCP. ${ }^{20}$ His example was that even during the "ten-year calamity" of the Cultural Revolution, not a single Party member nationwide requested that his Party membership be terminated. However, what has this example actually explained, after all? Does this example provide a genuine indication of the Party's exalted status and tremendous cohesiveness within the minds of all Party members? Precisely the opposite; it is merely an indication of the CCP's authoritarian tyranny instead. As is widely known, it is easy to enter the criminal underworld, but very difficult to withdraw from it. Compared with the criminal underworld, it is difficult to gain entry to the CCP, but it is even more difficult to withdraw from the CCP. Despite the fact that the Party Charter clearly stipulates that Party members enjoy the freedom to withdraw from the Party, who would dare indicate that they are voluntarily withdrawing from the Party in light of the fact that the CCP has regarded everyone whom it suspects of disloyalty as enemies and put them through the gauntlet to the very brink of death (especially during the "ten-year calamity" of the Cultural Revolution)?

Even those "landlords, rich farmers, counterrevolutionaries, bad elements and rightists" whom the Party had labeled as criminals and demoted to the "other register" have repeatedly sworn that they were "determined to follow the Party." If a bona fide Party member were to openly express his desire to withdraw from the Party and no longer follow the Party, would that not be like providing home delivery of the goods and just waiting there to be put through the gauntlet? After the June Fourth Incident, a few Party members withdrew from the Party in outrage. Normally, you might assume that if these people had withdrawn from the Party, then they would have had nothing more to do with this Party of yours by that point. Yet the Party was unwilling to drop the matter right then and there, and felt it absolutely had to formally "expel" each of these persons who had already withdrawn from the Party. From this example, we can see what intense rancor the Party harbors for persons who dare to extricate themselves from the Party.

There are two issues that require further explanation. First, why is it that nobody withdrew from the Party during the Cultural Revolution, while there were actually persons who withdrew from the Party after the June Fourth Incident? This does not at all mean that the June Fourth Incident was nastier than the Cultural Revolution. Of course, since the June Fourth Incident came across as more focused and public, and the responsibility for its occurrence was more clear-cut, it was easier for it to give rise to a more direct and ferocious shock to the human mind than those atrocities of the Cultural Revolution that were relatively dispersed and hidden from public view, and for which the responsibility for their occurrence was relatively indistinct and ambiguous. Yet 
two even more important reasons for the contrasting reactions were changes in people's thinking and changes in the overall circumstances over the two decades separating the two upheavals. The factors behind this are obvious, and need no further explanation.

Second, why did the CCP still feel the need to formally "expel" those persons who had already withdrawn from the Party? The CCP did not do this merely for the sake of venting its hatred, but also because it wanted to strengthen its control. Some Party members did not engage in any conspicuous activities at all during the I989 Democracy Movement, yet in the wake of the June Fourth Incident expressed their protest by withdrawing from the Party. This created an extremely thorny problem for the regime. Since these persons were not "turmoil elements," ${ }^{2 \mathrm{I}}$ you could not punish them as violators of "the nation's laws"; and because they had already withdrawn from the Party, you could not punish them as violators of the Party's disciplinary sanctions. However, if you allowed these persons who withdrew from the Party to express their own oppositional standpoint and then depart the scene in a free and easy manner, that would be the same as acknowledging the legitimacy of this means of expressing opposition. This is why the regime has felt it must go ahead and "expel" these persons from the Party even after they had withdrawn from it, and prefers handling things this way in spite of the fact that some people ridicule such expulsions as absurd. The significance of such expulsions is no longer expulsion itself, but is instead a variety of punishment and retribution, the purpose of which is to discourage other people from imitating these persons.

The issue of quitting your job bears a general resemblance to the issue of withdrawing from the Party. Speaking of quitting your job, we can find an interesting contrast. We know that quitting your job differs from being dismissed from it - the first is voluntary, while the second is involuntary. However, the distinction between the two is not necessarily quite so clear-cut. Under certain circumstances, quitting your job is nothing other than a disguised version of being dismissed from your job; a common scenario is that you would have originally been forced to step down, but the other party is willing to allow you to voluntarily submit a request to resign from your job. Handling things this way makes you seem relatively dignified and makes the other party appear relatively moderate. During the Cultural Revolution, Liu Shaoqi wanted to resign, but the CCP would not accept his resignation, determined as they were to resolve the matter by overthrowing him. The situation after the end of the Cultural Revolution changed to a certain extent. For example, the cases of both $\mathrm{Hu}$ Yaobang in the Anti-liberalization Movement of I987 and of Chen Xitong in the Anti-corruption Campaign of I995 were in actuality involuntary dismissals, yet in each of these cases the external form of voluntary resignation was adopted (Zhao Ziyang's 
resignation was somewhat different since it was actually voluntary to a certain degree). ${ }^{22}$

Hirschman has compared scenarios for the resignation of British political figures with their U.S. counterparts. He discovered that in Britain, a cabinet minister who feels that there is no way to reconcile his own political agenda with the cabinet's policy decisions would sometimes express his opposition by resigning from his position. However, cabinet officials in the U.S. very seldom adopt the same course of action. This has to do with the different governmental systems in the two countries. Britain follows the parliamentary system, in which a cabinet minister is a Member of Parliament who holds a cabinet post concurrently. When a British minister resigns from his cabinet post, he still retains his post as a Member of Parliament. He can thus forcefully engage in oppositional activities through his position as a Member of Parliament. In contrast, the U.S. follows the presidential system, in which no official can hold an executive post concurrently with a legislative post. Once a cabinet official resigns from his post in the cabinet, he instantly reverts to the status of an ordinary citizen, and thus becomes an insignificant figure whose views count for little in the political arena. That is why he would prefer to remain within the cabinet in hopes of making incremental improvements there.

Since China is under the authoritarian rule of a single party, if an official there were to express his dissent from the top rulers' policy decisions through the method of resigning from his post, he would not only lose all of his power, but would often encounter even harsher treatment than an ordinary dissenting citizen would receive. An obvious example is that even though Zhao Ziyang managed to hold onto his Party membership after resigning from his official post, he was still placed under house arrest for the rest of his life. ${ }^{23}$ This served the same purpose as the CCP's insistence upon "expelling” those who already voluntarily withdrew from the Party.

We should note that the motivations for such actions as withdrawing from the Party and resigning from one's post are generally not at all simple, especially under a single-party autocracy. The CCP has committed so many wrongful acts that anyone with even the slightest twinges of conscience cannot help but be at loggerheads with the Party to some degree. If a person has gone through great exertions in order to join the Party and then toiled unremittingly in order to attain a certain degree of power, there is no way he could have avoided experiencing mental torture on numerous occasions throughout this process. If such a person were intent upon acting solely in accord with the dictates of his conscience, nobody but an idiot could possibly manage to stay on within the Party or the system over a long period of time. Since you chose the reform line within the Party or the system from the very out- 
set, this indicates that for the sake of exerting what you believed to be an even greater impact on promoting reform, you were willing to go against your conscience for a period of time. This also demonstrates that when you eventually decided to withdraw from the Party or resign from your post, your attempt to come to peace with your conscience was not necessarily your only motivation; you surely would have also considered whether quitting right at this time would be more advantageous to the larger enterprise of reform itself.

To put it colloquially, withdrawing is nothing other than pulling the rug out from under someone else's feet. Withdrawing from the Party is to pull the rug out from under the Party's feet - in other words, to weaken the Party's strength while strengthening the forces outside of the Party. Resigning from one's post without withdrawing from the Party is to pull the rug out from under the feet of the faction in power within the Party, while buttressing the strength of the opposition faction within the Party. The person who withdraws has no expectation whatsoever that on account of his withdrawal, the organization to which he originally belonged would become better - if that were to be the case, he might as well not have withdrawn in the first place. On the contrary, the person who withdraws always hopes that as a result of his withdrawal, he could cause the circumstances of the other party to become even worse: "We've all gone away. You'll find it even more difficult to muddle through now." Understandably, there is nobody who withdraws who does not hope that more people could adopt an action similar to his own. The more people there are who withdraw, the greater the effect of pulling the rug out from under the other side's feet. Naturally, this a risky measure to take. If there are few people who withdraw and their influence is so weak that it cannot surmount the original authoritarian status quo in which there is no party other than the ruling Communist Party and there is no opposition faction within the Communist Party, in the end this would merely cause you to lose whatever advantageous position you once held - the result being to lower your actual influence on the status quo, while making it convenient for persons who are far inferior to you to occupy a more advantageous position. Would this not be even more regrettable? This is indeed a difficult choice. No wonder so few people choose to resign from their posts.

\subsection{Why Would Many Persons Still Remain Within the System Even When Various Exits are Available?}

There are no exits from within a totalitarian society. Consequently, many persons with reformist aspirations have little choice other than to join the Party or the system. However, there is not sufficient space for 
dissent within the Party or the system. In this setup, the regime extends its control by means of their weapon of expulsion. As soon as a view you express exceeds the boundaries of the permissible, the regime will send down an order for you to be exiled and driven outside of its circle. Originally, expulsion from an organization could not be considered a severe punishment, as long as competitor organizations existed within the society: "If this place won't keep me on, some other place naturally will." However, under the circumstances in which there is no other competitor organization in society, your expulsion from the organization would in actuality cause you to disappear from the public scene. It is only for this reason that expulsion has become so terrifying a prospect. If a superseding organization were to appear one day, why would a person bother to remain within his original organization? However, even though we may put forward such an argument, the reality is that many people are sometimes even more willing to remain within their old organization when one exit or another has already become clearly visible. How can this be explained?

Let us examine the Democracy Wall period as an example of this phenomenon. ${ }^{24}$ This was a period of time when the regime adopted an attitude of approval or at least tolerance toward Democracy Wall. Yet very few persons were already willing to directly participate in activities related to Democracy Wall during this period. Most people still preferred to submit their essays to official publications for publication. The explanation for this is simple: whenever one exit or another appears on the outside, the space for permissible discourse on the inside is also bound to become relatively broader. During the Democracy Wall period, the yardstick for determining the acceptability of ideas in official publications was also rather flexible. Since in terms of material resources, official publications have enjoyed incomparably greater advantages in terms of material resources at their disposal, the influence of a given essay can be ten thousand times greater when it is published in an official journal than when it appears in a non-official journal. Therefore, many persons submit their essays to official publications instead of non-official publications.

Let us now examine the issue of going abroad as another example of this situation. The PRC formerly resembled all the other communist regimes of the world in sealing off its borders and forbidding most of its populace from traveling abroad freely. Beginning in the late I970s, the CCP started to dispatch students to study abroad in the West. During the earliest stages, the CCP rigorously checked the political background of such students and strictly monitored their visits to overseas relatives out of fear that they might "defect overseas and never return."

Yet the CCP's approach to this issue gradually changed over time. Nowadays, it is already relatively easy for ordinary Chinese people to 
obtain passports for going abroad, as long as they have formal invitations or guarantees of economic support from overseas. Normally, a communist country does not permit its people to freely choose their way of life - so why does the Party-state no longer seem to mind its people "voting with their feet" and heading overseas? In addition, a group of Democracy Movement activists eluded the regime's pursuit and attempts to arrest them, escaping to the West after the June Fourth Incident; this greatly infuriated the regime. Yet in later years, the regime would sometimes go so far as to voluntarily send some dissidents abroad - in the name of allowing them to go abroad either for medical treatment or else to accept an invitation to visit a foreign academic institution. We generally call this "exile." Though it is not wrong per se to call it exile, there still seems to be a problem with this. In the past, exile was obviously a form of punishment, since it was always a case of dispatching a person from a relatively civilized and prosperous locale to a noticeably backward and impoverished region. Nowadays, exile seems practically the opposite of this, especially for a "liberalized element." To dispatch a person who seeks Western-style freedom to exile in the free West seems tantamount to tossing a fish into the water. How could this be considered punishment? In fact, do we not also frequently regard the CCP's exiling of several dissidents to the West as its having made a concession instead of acting violently? Why do we call it exile at the same time? All of these questions are in need of detailed analysis.

Theoretically speaking, the freedom to leave one's own country can constitute a severe challenge to a vile authoritarian regime. Yet in actuality, the degree of severity of this challenge varies a lot from one country to another. Comparatively speaking, a big country with a large population can have a somewhat stronger capability of withstanding a situation whereby many of its people "vote with their feet." This principle is aptly encapsulated in the proverb: "A large store can afford to deceive its customers." Furthermore, the degree of difficulty in adapting to life in a foreign country also varies a great deal from one nationality to another. Even in such a highly inclusive country as the U.S., the Chinese residents there have all along been one of the nationalities that have found it relatively difficult to blend in. The obstacles to adaptation arising from differences in ethnicity, skin color, language and culture are often easy to underestimate by those who have never lived abroad. Consequently, when a Chinese person comes to the West, he would often have such feelings as "though this place may resemble an imperial garden, in the end it's not where I wish to settle down for good," or "even a dwelling decked out in gold or silver can't compare with my own doghouse." Even if China's border gates were thrown wide open, not a whole lot of its citizens would leave their country for good. 
However, the very same freedom to leave one's homeland can constitute a fatal blow to such countries as East Germany (the former GDR). As the population of East Germany amounted to only a little more than I6 million, it was as if a huge loss of blood occurred when several hundred thousand of its most talented and capable citizens left the country. In addition, since West Germany was two and a half times larger than East Germany in surface area and was separated from East Germany by nothing more than a wall, it could readily accommodate the refugees from East Germany. Furthermore, because the people of both East and West Germany were of the same ethnic group and an identical cultural background, there seemed to be hardly any problems of adapting to a new abode. When understood in this way, how could anyone be surprised that the tide of refugees pouring out of East Germany in the autumn of I989 shook the whole country and finally became the fuse that set off East Germany's democratization?

The situation of dissidents and democracy movement activists presents a problem of a different nature. There are two ways of expressing a devotion to liberty. Our forerunners long ago pointed out that remaining inside the country to resist authoritarian rule and struggle for the achievement of liberty is one way of doing this, while leaving the country and venturing afar to lead a life of liberty beyond the influence of authoritarian rule is the other way. Most dissidents are subsumed within the first way of devoting themselves to liberty. Their cause is in China, so they would not regard their stay in the West as if it amounted to ending up in a new homeland. Precisely on this account, to allow them to go abroad and yet forbid them from returning to China is in actuality a form of punishment and persecution. It is merely the case that exile to a foreign country is at least less cruel than being imprisoned or put under house arrest in China. In choosing the lesser of two evils, we sometimes also conditionally affirm the regime's move when it imposes exile instead of imprisonment.

The world today has already become a "global village." A person residing in a foreign country can still wield a certain amount of influence back in his home country. This state of affairs prompted the emergence of the special mode of resistance that we refer to as the overseas Democracy Movement. If China were totally blocked off from the rest of the world, the overseas Democracy Movement would not be possible; yet if China were completely open to the rest of the world, there would be no need for the overseas Democracy Movement. It is precisely under the circumstances in which China is halfway open and halfway closed to the rest of the world that the overseas Democracy Movement is both necessary and possible. In the Democracy Movement of contemporary China, overseas forces have also given full play to their strong points. Due to high-pressure tactics from the regime back in mainland China, 
it has been very difficult for voices of liberty to call out; even when they have called out, it has been very difficult to spread their message widely. On the other hand, the overseas Democracy Movement can more fully and explicitly articulate our common ideals, while helping our comrades back in China expand their influence. Particularly after the June Fourth Incident, many activities related to the struggle for liberty in China have depended upon this method of "selling goods for export back into the home market" in order to be capable of dissemination amongst the people in China.

The role played by the overseas Democracy Movement cannot be denied. However, we must recognize the fact that the overseas Democracy Movement is of little significance in and of itself, and is merely an auxiliary to the indigenous Democracy Movement within China. If the overseas Democracy Movement had not originated from the indigenous Democracy Movement or had not kept providing support to its indigenous counterpart, it would have been like a river without headwaters or a tree without roots. It is said that in various Latin American countries, some of those in power go so far as to deliberately encourage their political enemies to depart their homeland in self-imposed exile. Just as Hirschman has pointed out, it is not necessarily the case that competition always constitutes a threat to a monopoly. On an occasion in which some sort of exit or replacement appears and thereby leads a minority of disgruntled activists to go off somewhere else, the internal pressures faced by the monopoly would instead decrease. This is precisely why some authoritarian rulers have adopted the practice of sending dissidents away into exile in order to weaken the power of the opposition and to preserve their own rule. Under such circumstances, dissidents would naturally become even more insistent upon remaining within their homeland to engage in resistance, while exiles would naturally need to exert themselves even more diligently in the struggle for the right to return to their native land.

At first glance, exile means the provision of a way out for dissidents. Yet in reality, exile is not at all considered a genuine way out for them. What is exile? Exile means to deprive a person of the right to be a civilian in his own country. Theoretically speaking, this is even harsher than depriving a person of the right to be a citizen of his own country. Under what sort of circumstances would a ruler adopt a measure such as exile? When a society is completely closed to the outside world (such as during the Mao Zedong era), exile will not be imposed. When a society is completely open to the outside world, exile will not be imposed, either. Exile occurs only under the circumstances in which a society is open to the outside world at the same time it is subject to authoritarian rule internally. Because such a society is open to the outside world, its ruler cannot avoid encountering pressure from the international com- 
munity, and he cannot refrain from making some minor concessions from time to time. Yet because he imposes authoritarian rule throughout the country, he would never abandon his continuous efforts to prohibit and shut down dissident activities. This measure of exile is not only a prohibition against dissident activities, but also steers clear of direct personal persecution; that is why exile is able to help the CCP achieve the twin effects of coping with pressure from the international community and preventing a loss of strict control over the domestic realm. Here, exile amounts to both a certain softening of repressive measures and simultaneously a sort of adjunct to repressive measures. On the one hand, the present-day CCP continues to implement its direct and violent repression of dissident activities, while on the other hand it sporadically and selectively resorts to exile under various special circumstances.

Finally, I wish to emphasize that in the history of society worldwide, the right to leave one's country freely was originally humankind's most ancient right. In the past, it practically never emerged as a problem. Not until the advent of modern-day communist totalitarian regimes did rulers openly forbid their populace from exiting the national borders freely. Nowadays, the CCP regime has begun to cast aside its restrictions against going abroad. However, this does not indicate that the regime has become open-minded, but merely shows that it is no longer as tyrannical as it used to be. Moreover, the CCP's exiling of a minority of its dissidents is admittedly not as cruel as such measures as imprisoning dissidents or putting them under surveillance, yet it is ultimately a brazen violation of the most basic right of an individual - to live in his own country. Therefore, we still cannot regard the CCP's recent embrace of exile as a sign that the Party has mended its ways. We must remember that there is an absolute demarcation between good and evil. A burglar formerly burglarized ten houses per day, but now he burglarizes only two houses per day. We cannot say that he has mended his ways, but merely that he has become less evil than he used to be. There is a famous Tang poem about how hard it is to be impressed by ordinary rivers and lakes once you have seen the vastness of the ocean - or by ordinary hillside mist once you have seen the spectacular mist of Sichuan's Wu Mountain Gorge. ${ }^{25}$ After having experienced the extreme cruelty of the Mao Era, the mistake that people in general are most likely to make is to forget that there are absolute standards of good versus evil. Therefore, they are apt to view a relatively scaled-back form of authoritarianism as open-minded rule; they are inclined to see a relatively narrow form of oppression as freedom; and they tend to look upon the struggle for the most basic human rights as a luxury. 


\subsection{Why Do Quite a Few People Always Place Their Hopes in the CCP?}

There is an old scholar who has always directed trenchant criticism at the CCP. Yet he has also proclaimed that we should still place our hopes in the CCP "because our country is in the hands of the CCP." There seem to be quite a few people who hold a similar view. They say that we have to place our hopes to change China in the CCP, because the CCP is the only organized political force in present-day mainland China.

At first glance, the above-mentioned viewpoint is rather incomprehensible. If we say that we place our hopes in a certain person, we ordinarily mean that in comparison to other people, this person's behavior has more fully satisfied our expectations; he has done a better job of accepting our viewpoints and conscientiously exerting himself along the lines that we had been anticipating. However, the persons who maintain the above-mentioned viewpoint do not in any way believe that the CCP possesses these virtues. In fact, most of these friends agree that the CCP lacks these virtues. The only reason they place their hopes in the CCP is that they have no other choice. As I previously discussed, there is no sense whatsoever in talking about your loyalty or disloyalty to a monopolistic organization. Similarly, there is no sense in talking about whether you place your hopes in a severely authoritarian political party. In this situation, there is no difference between "hope" and "despair." Here, the expression of "placing hopes" in such an organization merely indicates the ineffectuality, powerlessness and helplessness of the speaker.

\subsection{Rational Choice Theory}

An American scholar named Mancur Olson Jr. published a book entitled The Logic of Collective Action in the $1960{ }^{26}{ }^{26}$ In this book, he points out all actions that are performed in order to benefit the group as a whole produce results that are in the public interest. For example, the result of struggling for the freedom of expression is that each and every person can be relieved of the fear of being punished for what he has expressed. Although this sort of matter requires everyone to accomplish it collectively, as long as anyone or any organization within the group has achieved success through due diligence, every person in the group will wind up benefiting from this success, whether or not he himself has worked diligently or otherwise contributed to this success. As a rational being, everyone naturally wants to pay fewer of the costs and reap more of the benefits. In any action undertaken in order to 
benefit the group, every person would thus attempt to expend the least possible amount of effort and make the smallest possible contribution while enjoying the fruits of others' labor (i.e. get a free ride). This leads us to a thorny problem: if everybody harbors the motivation of paying as little as possible of the costs while enjoying the fruits of others' labor, how can collective endeavors be initiated in the first place? How can goals that are in the public interest still be struggled for and obtained?

It is not difficult to notice that the questions raised by Olson in this case bear some resemblance to the dilemma we face whenever struggling for the freedom of thought. Through our analysis in a previous chapter, we explained that many seemingly peculiar phenomena that occur in communist countries are actually quite reasonable at some level. In point of fact, because many dissidents have chosen this or that mode of rational behavior, they subsequently made an important contribution to the enterprise of struggling for freedom. However, we must also realize that some choices can be said to be reasonable from the perspective of an individual, but are unreasonable from the perspective of a group - or else not advantageous to the achievement of a certain collective goal. This requires us to engage in a deeper level of discussion about the various questions raised above.

\subsection{Normative Theory}

We know that before Olson advanced his theory (this theory is also called rational choice theory), quite a few Western scholars had already undertaken various types of research on related problems and proposed different theories in order to explain them. Two of the most important types of theories among them are normative theory and structural theory.

Normative theory believes that the initiation and persistence of collective action are dependent upon civic-mindedness and various moral restraints within society. These behavioral norms can result from either individual reflection or social education. Once people have firmly established these sorts of norms, they will self-consciously engage in collective action, thereby relegating their individual gain or loss to a subordinate status; at the same time, there is no need for their group to provide them with either a reward or punitive coercion.

In my view, normative theory touches upon an extremely important aspect of collective action. Above all else, the reason people voluntarily engage in a certain collective task is that they firmly believe that the goal they are pursuing is correct, so they regard active participation as their own responsibility or duty. Although the participants all know that they would be entirely within their rights to adopt a posture of standing by with folded arms, of getting a free ride from others, or of enjoying 
the fruit of others' labor, they believe that comporting themselves in such fashion would be dishonorable. This conviction is thus more forceful in spurring people to engage in collective action than any external reward or punishment could be.

The moral sensibility plays an extremely important role in the struggle for freedom of thought. Its function is so important that many people characterize a campaign of struggling for freedom as a moral campaign.

Needless to say, if people want to regard plunging into the struggle for freedom of thought as one of their moral responsibilities, a prerequisite would be that they have a profound grasp of the value and significance of the freedom of thought. We realize that during a very long stretch of time in the past, many people took the initiative to participate in political movements that suppressed the freedom of thought and sincerely supported the totalitarian system that suppressed the freedom of thought. Instead of claiming that this indicates people's moral depravity during that time, it would be better to say that this is more indicative of people's erroneous cognition back then.

To be sure, communist ideology negates freedom; yet it does not simplistically or straightforwardly reject freedom. Instead, communist ideology draws upon a series of complicated arguments to distort the original meaning of freedom, thereby negating freedom itself under the pretext of achieving "a greater freedom" and "true freedom." We must admit that during those years, many people took the initiative to devote themselves to thought remolding on the basis of their lofty moral passions; we can only regret that their passions were misguided. Mill puts the matter most aptly: "Under most circumstances, it is simpler to alter the direction of one's emotional enthusiasm than for emotional enthusiasm to emerge from a previous state of inactivity." ${ }^{27}$ Consequently, it is not at all strange that for many persons who had conscientiously engaged in thought remolding back in the past, as soon as they came to a clear understanding of the true meaning of freedom of thought, they underwent a transformation into opponents of cognitive despotism and became courageous warriors in the struggle for freedom of thought.

Two issues arise from this. First, we need to reject the thoughtremolding movement, but we should avoid any sweeping rejection of the sort of enthusiasm for advancement that prompted persons to engage in thought remolding back during those years. This is exactly analogous to the way we reject the communist revolution without repudiating the ardent spirit of self-sacrifice embraced by many Communist Party members during those years. Our duty is to draw that spirit of enthusiasm away from the wrong track and lead it back in the right direction. If at the same time we were rejecting the thought-remolding movement we were also to reject that spirit of enthusiasm associated 
with it, we would be bound to sink into moral nihilism and political apathy and would instead diminish the impetus of our struggle for the freedom of thought.

Second, since the Communist Party achieved their goal of negating the freedom of thought by distorting the meaning of the principle of freedom of thought, the first step in struggling for the freedom of thought is to rediscover the original meaning of this principle and further clarify the meaning of this great principle. Just as Richard Cobden aptly noted, the only way to arouse the soul of a great country is to awaken the sympathies of the populace by means of a simple, unadorned and correct principle. ${ }^{28}$

\subsection{The Power of Example}

History tells us that a correct principle can seldom automatically prevail merely by virtue of its own persuasiveness, for it requires "living testimonials." For a principle to have the power to inspire, it can seldom manage without a flesh-and-blood model character.

It is precisely from this starting point that we can fully appreciate the great effects of those freedom fighters. At first glance, the behavior of a freedom fighter seems downright self-contradictory; for the sake of struggling to acquire more freedom, this person is willing to lose what little freedom he still has. Is this not a self-contradictory act? According to rational choice theory, is this sort of behavior not very irrational and foolish?

In actuality, such behavior precisely embodies the power of character, the power of example and the power of principle. Some individuals have been shut out of public life due to their initiatives on behalf of the freedom of expression; it might look as though they have thus lost their voice, but in point of fact, "silence speaks louder than words at such times." Other individuals refused to take part in the system on account of holding fast to their principles, or else they voluntarily withdrew from the Party or resigned from their posts; it might look as though they lost a relatively good opportunity to use their advantageous position to achieve some sort of undertaking, but in this instance "refraining from something" surpassed "stopping at nothing."

The effect of setting an example resides in arousing other people's admiration and their desire to emulate an exemplar. The existence of an exemplar is a sort of pressure, which can achieve its effects in a variety of ways. Let us take the issue of withdrawing from the Party as an example. After the June Fourth Incident took place, a group of Party members announced their withdrawal from the Party. Because those who quit the Party were few in number and had little clout, their action 
was not of sufficient weight to achieve a breakthrough in the authoritarian status quo, in which there is no other party to challenge the ruling Party and there are no well-defined factions within the Party. At a superficial level, their action of withdrawal thus did not achieve any significant effect at all.

In actuality, however, their action delivered a heavy psychological blow to those who remained within the Party. Some individuals remained within the Party because of their muddled awareness of its true nature; when they saw how willing others were to abandon their grand career prospects as well as all kinds of other advantages of Party membership by resolutely withdrawing from the Party, they felt compelled to reconsider which path after all was right and which path was wrong. Other individuals stayed in the Party because they wanted to continue to follow the path of internal Party reform; they believed that by remaining within the Party to promote reform, they would bring about greater results, and thus they were willing to temporarily go against their conscience somewhat. However, those who quit the Party indicated through their action that the CCP's misdeeds had exceeded the limits of what a person's conscience could endure. Those who quit the Party saved their own souls; this caused the souls of those who remained within the Party to sink into a suspicious limbo. The existence of those who quit the Party no doubt saddled the Party hangers-on with a moral interrogation: "We've quit the Party; why haven't you quit yet?"

You could retort that staying in the Party has its own usefulness; you could even go so far as to retort that staying in the Party would enable you to bring even more of this usefulness into play. Nevertheless, no matter what sort of reply you might come out with, you would discover that you truly needed to achieve more accomplishments. Unless you could exert more effort and promote reform more effectively within the Party from that point on, you would not be able to prove that you have a clear conscience.

We can see from all this that even though the voluntary withdrawal of a small group of members from the Party could not amount to a severe blow to the Party over the short term, it would at least accelerate changes in thought within the Party, as well as spur on the Party reform faction's desire for reform and their determination to get on with it. As for the argument that the action of quitting the Party would heighten the strength of the democratic faction outside the Party, lower public trust in the Party even further and elevate democratic awareness and the concept of liberty among the broad masses - that would be even more of a cinch. 


\subsection{Structuralist Theory}

As has been previously discussed, the effect of moral norms is undoubtedly extremely important in the struggle to win the freedom of thought. However, we must not overestimate the effect of moral norms. After all, it is not at all the case in everyday life that everyone's behavior is merely in deference to moral rights and moral wrongs. Structuralist theory believes that the reason why individuals participate in collective action is not that they have moral norms in common, but that they have individual interests in common. Marxism emphasizes that social existence determines social consciousness and stresses that class distinction and class struggle are inevitable; to a large extent, Marxism can thus also be classified as a variety of structuralist theory.

We entirely agree that a shared or common interest is an essential element in any collective action. If two or more parties have no common interests, they will take no joint or collective action. The more common interests a given group shares, the greater the cohesiveness that group brings to its collective action. The stronger a given group's self-awareness as to its common interests, the higher the likelihood that the group will plunge into practical collective action. In the struggle of lobbying for the freedom of thought, the level of the intelligentsia's participation is often higher than what other groups in society exhibit. To some extent, this can be explained as due to the fact that the freedom of thought has a greater impact on the self-interest of the intelligentsia. Student youth often play a vanguard role in this sort of struggle. This is obviously related to their location on campus and frequent interaction with one another, thereby more readily giving rise to a sort of group awareness on their part. According to structuralist theory, we can discover that the more widespread an authority's ideological oppression is, the greater number of people there are who would be prompted to struggle for the freedom of thought, and thus the greater likelihood that this would lead to large-scale collective action in struggling for the freedom of thought. It cannot have been by chance that a large-scale movement for the liberalization of thought occurred in the wake of China's Cultural Revolution. Yet on the basis of similar reasoning, we cannot help but raise the question that follows. Once totalitarian rule has become relatively softened, once the net of restrictions on thought has become more relaxed, and once many people no longer feel that their immediate interests are being directly suppressed, would the strength of the struggle for freedom of thought be somewhat diminished as a result?

Speaking of how interests function, the following questions deserve analysis. 
First, instead of saying that people take action on the basis of their own interests, we might as well say that people take action on the basis of what they understand to be their own interests. Both Zhang Third and Li Fourth are workers, though Zhang believes that public ownership and a planned economy make for the path to wealth of the working class, while Li believes that a free-market economy can best advance the interests of workers. Because their understanding of the interests they have in common differs, they may not necessarily participate in joint collective activities; sometimes they would even separate into opposing camps over a given issue. It cannot be denied that the reason why many manual laborers supported and joined the communist revolution back during those early years was to pursue their own interests. Yet when they later turned around and opposed the communist system, was it not also for the sake of pursuing their own interests? Structuralist theory has ignored the thousands of differences and transformations in human cognition. This is a major shortcoming of structuralist theory.

Second, short-term interests are not necessarily always identical to long-term interests, nor are individual interests necessarily always in accord with collective interests. As a writer, you are completely aware of how creative freedom is in accord with your individual interests. However, if you feel that the clout of an autocratic ruler is still very formidable and that creative freedom does not seem achievable within the foreseeable future, then you might consider it better to refrain from involvement in the movement for liberalization at this point; it would be far more advantageous to adopt the posture of "maintaining unity with Party Central." All sorts of people say that the freedom of expression is a shared interest and joint demand of the intelligentsia. This is not actually the case. After all, placing a ban on the freedom of expression has never amounted to placing a ban on the freedom of any and all expression. It has always been to place a ban on the freedom of certain forms of expression; the purpose of this ban has always been to protect the monopoly of other forms of expression. Consequently, when a person's thought and views happen to belong within the ranks of these protected forms of expression, he would not necessarily be willing to plunge into the collective activity of striving for the freedom of expression; he would even be likely to go over to the opposite side and stand together with the persons who oppose the freedom of expression. It is not at all the case that the same sort of social existence necessarily gives rise to the same type of interest-based demands. Here, an individual has the capacity to make a choice.

Third, structuralist theory ignores the analysis of individual behavior and thus can neither explain nor resolve the issue of a person who "gets a free ride," that is, who enjoys the fruits of others' labor without having contributed anything himself. Assuming we acknowledge that people in 
the same situation would necessarily have the same interest-based demands in common, were someone merely to think in terms of his individual interests, his most rational behavior would not be to actively plunge into collective action; instead, he would merely stand by with folded arms and enjoy the fruits of others' labor without contributing anything himself. To a large extent, in fact, Olson's rational choice theory was put forward in order to rectify this flaw in structuralist theory.

\subsection{Coercion and Incentives for By-Products}

According to Olson, if various individuals wish to form an alliance to promote a certain common interest they share, there are two different approaches that they can adopt. One approach is to utilize force. The state forces its citizens to pay taxes, thereby using part of everyone's income on public construction projects that no individual would be willing to fund out of his own pocket. Similarly, the methods adopted by trade unions include forcing workers to join a union and setting up picket lines to prevent those who are unwilling to participate in strikes from enjoying the fruits of others' labor. A second approach is to provide by-products. For example, the American Medical Association provides various services, but limits the availability of these services to members only, thereby making it an attractive option to join the association.

However, these two approaches also have their own problems. First, if you are using force, who will apply the force? To execute the task of applying force is also a variety of collective action. How will this collective action be brought about? Where will its power to force something on someone come from? Second, what about increasing the attractiveness of collective action by offering by-products? If the value of the byproduct is lower than the price people have paid for their participation in the collective action, their participation in the collective action will still not amount to a worthwhile trade-off. In that case, how much significance would still remain in the by-product's attractiveness? Furthermore, even if the by-product were sufficiently attractive, where would the by-product come from? These are but a few of the problems involved.

In general, it would be relatively easy for a violent resistance movement to adopt both of the two approaches described above. A revolutionary party has strict discipline; those who desert or stray from the fold receive punishment. We all now understand how during those years when the CCP mobilized ordinary people to participate in the Red Army and provide material support to the revolution, it was not at all like the way it has been described in revolutionary literature as entirely 
based on the willingness of people to join, but in actuality required coercion of one type or another. In the Ming dynasty novel The Water Margin, many heroes are forced to join the Liang Mountain rebel group. Some of them are forced into it by the government, while others are actually pressured into it by the rebel warriors; still others are coerced into it by both parties to the struggle.

Furthermore, revolutionary parties generally follow the logic of "ruling over the realm after having conquered it," ${ }^{29}$ and either openly or covertly promise participants in the revolution that once the realm had been conquered, they could all receive a share of power in the new regime - while those who did not join in the revolution would be excluded from the new power structure. This can be regarded as a sort of by-product incentive. To be sure, back when the CCP started the revolution, it never made any public promise that those who helped the CCP conquer the realm would go on to rule over the realm. Quite the contrary - the CCP has all along emphasized that it will allow the people to reign as masters of the country. However, once the revolution was victorious and various members of the eight democratic parties proposed the establishment of a "Political Design Institute" that would enable the various parties to take turns in ruling the PRC, CCP representatives reacted to this proposal with extreme disgust. ${ }^{30}$ One of the reasons for their disgust was precisely the idea that since they had gone to such great effort and trouble to conquer the realm, how could they allow others outside the CCP a free ride to enjoy the fruits of the CCP's labor?

It is relatively more difficult for non-violent collective action aimed at liberty and democracy to adopt the two approaches described above. It is very difficult for non-violent collective action to exercise strict discipline, for it lacks coercive measures. Even when it does manage to implement one coercive measure or another, it actually depends upon persuasion and moral pressure. During the Democracy Movement of I989, some of the students who participated in boycotts of classes and street demonstrations set up picket lines in front of entrances to libraries and classrooms. There they confronted other students heading indoors who were unwilling to join the boycotts or demonstrations, explaining the importance of the student movement and persuading or even criticizing and ridiculing student non-participants. Yet the student activists did nothing more than this in the way of coercive measures. Any large-scale non-violent collective action would probably need to adopt similar types of coercive measures. In actuality, because this kind of coercive measure applies mere psychological pressure instead of physical pressure, it does not contradict the non-violent nature of the movement. Furthermore, since the goal of the democracy movement is not to seize political power, but is instead to initiate equal participation 
in politics, the movement cannot directly offer its participants any special by-product incentives. Of course, we can reasonably infer that once the democracy movement wins, those who have made greater contributions and paid a heavier price in the movement are very likely to win the respect and trust of others; in this way, they are very likely to be elected by the voters to serve in public office or to receive an award in some other form. Yet this is far from certain, after all, and is by no means such a sure thing as the revolutionary party's "ruling over the realm after having conquered it."

We should note that the provision of appropriate by-product incentives is indeed an important type of measure for strengthening collective action. Since the goal of doing this is to discourage the unethical practice of enjoying the fruits of others' labor without contributing anything oneself, it tallies with the principle of fairness. Who would be able to claim that it is unreasonable to reward someone according to his merit? However, since a democracy movement neither can nor should implement the practice of "ruling over a realm after having conquered it," how can we provide appropriate by-product incentives on behalf of the movement? Strictly speaking, the assumption that those who conquer a realm should go on to rule it actually still differs somewhat from a by-product incentive. This is because the incentive of the reward can be awarded only after the collective action has achieved its final success. During the lengthy process of struggling for their goal, participants are unable to obtain any advantages, not to mention the fact that the value of their future rewards can seldom match the price they must pay for their present-day risks. If you were to claim that the individuals who launched a revolution at the risk of their own lives did so merely for the sake of getting hold of a measly government post sometime in the future, that is obviously not in accord with reality. From this, we can see that while by-product incentives have a positive effect on strengthening collective action, they are seldom of much use when the collective action entails major risks. In the absence of the selfless spirit of devoting oneself to a struggle on behalf of collective interests, it would have been impossible for this type of collective action to occur.

\subsection{The Impact of Societal Scale on Collective Action ${ }^{31}$}

As for our non-violent collective action in the struggle for liberty and opposition to authoritarianism, if we can neither bring much of any powerful coercion to bear nor provide any effective by-product incentives to speak of, then how should we reduce the negative effects of the human tendency to sit idly by in the hope of enjoying the fruits of others' labor? In a relatively small-scale societal community, this prob- 
lem will be somewhat easier to handle. Yet in an overly large-scale community, one cannot easily discern the behavior of any given individual while a collective goal is being pursued, so it is easier for an individual to avail himself of a loophole or get a free ride at the expense of others.

Within a small-scale community, people have a greater degree of interaction with one another, and thus a more in-depth understanding of others in the community. While involved in activity to advance the public interest, everybody would develop a clear sense of precisely who was working hard, who was slacking off, who was working conscientiously and who was dawdling on the sly. In consideration of their own reputation and future relations with other members of the group, people would not venture the risk of becoming the sort of slacker who would just sit idly by and enjoy the fruits of other people's labor. Subsequently, this would naturally give rise to a sort of tacit agreement of coordination between the individual and the other relevant parties. This is precisely the theory of customary contracting as put forward by the American scholar Hardin. ${ }^{32}$ In actuality, Olsen himself has also discussed the principle of how it is advantageous for a collective action to be undertaken by a small-scale community. We know that even if individuals who participate in a collective action out of a sense of justice or responsibility can look upon a gain or loss in their own material interests with indifference, in general they still always hope that their contributions would be affirmed by others. In other words, they hope to receive spiritual encouragement from society. This sort of affirmation or encouragement can be more easily obtained and more fairly distributed in a small-scale society.

The occurrence of liberalization movements in China is often concentrated in big cities, especially Beijing. This is not necessarily because of any lack of awareness or courage in residents of other parts of the country. To a large extent, this is due to the fact that they live in remote areas and thus cannot attract the outside world's attention when they initiate a public movement; at the same time, the risks they shoulder by engaging in such activity are not at all lowered as a result (and can sometimes even loom higher). This not only weakens the impact of their activity, but is also likely to influence the vigor with which they thrust themselves forward in their activity. Moreover, there is also the problem of what has been called the fragmentation of China's liberalization movements. There is very little continuity noticeable between earlier movements and later movements; participants in later movements often lack an understanding of the circumstances in earlier movements. What should be pointed out is that this has a certain connection with the fact that Chinese society is too massive in scale.

Under such circumstances, veteran participants in these movements often do not receive the recognition they deserve. On the one hand, 
nobody but the Public Security Bureau remembers all the details of their previous accomplishments, and thus the risks they shoulder are even greater. $^{33}$ On the other hand, because the participants in later movements know so little about them, it is very difficult for them to play an important role in these new movements. If a new movement turns out to be more influential, the young and inexperienced new participants who are just setting out in their careers can actually acquire in one fell swoop a loftier reputation than the veterans. We know that a mature political movement requires that continuity be maintained: first, it is beneficial for the passing on of experience; and second, it is beneficial for the establishment of an internal ethical order within the group.

Admittedly, it is no good for a group to be focused solely upon seniority and hierarchy. Yet it is even worse if a group altogether ignores the role of seniority or the role of hierarchy. Once this creates a situation in which it is more advantageous to join a later movement than an earlier one, or to wait until an opportune moment to join a movement instead of participating from the very beginning, then the phenomena of people taking a free ride and sitting on the sidelines to enjoy the fruits of others' labor would become rampant, while the ability to engage in collective action would be weakened in turn.

\subsection{The Necessity and Limitations of Drawing on Official Mass Communication Outlets}

As to the influence that a larger-scale or smaller-scale society brings to bear on collective action, I could still probably put forward a couple of points to supplement my overall argument. Political scientists have long ago pointed out that it is easier to implement authoritarianism in a large-scale society than in a society of smaller scale. One of the reasons for this is that authoritarians can more easily give full play to their organizational advantages within a large-scale society. A special feature of authoritarian societies is that their rulers have organizational support, while the ordinary people do not. Authoritarian rulers naturally profit at the expense of ordinary people on account of the mismatch between their organizational support and the people's lack thereof, as well as the mismatch between the collective approach of the rulers versus the atomized condition of ordinary individual citizens.

Yet what is an organization? An organization is nothing other than a group of people who have similar ideas and who can take action jointly. The smaller in scale a society is, the lower the cost (in both energy and time) that is required for the interflow of information and the coordination of activities; precisely the opposite relation holds in ever larger-scale societies and their ever higher costs. It is difficult for three armed sen- 
tries to keep thirty prisoners under guard, since it would take only three to five or at most seven or eight prisoners to gang up and simultaneously all spring into action to subdue the three sentries. However, it is much easier for 30,000 sentries to keep 300,000 prisoners under guard, because you would have a very hard time making tens of thousands of prisoners all spring into action simultaneously; this is the first factor to ponder. Second, the larger in scale a society is, the more dependent people are on mass communication outlets if they wish to acquaint themselves with the news reported from other locations. Since the rulers have monopolized the mass communication outlets in authoritarian societies, it would be very difficult for voices of opposition to reach the entire society. The smaller in scale a society is, the more modest the effect of mass communication outlets - and the larger the effect of such primitive modes of communication as the local grapevine.

Once we have comprehended the principles at work in the cases above, we can more clearly understand some of the peculiar phenomena mentioned in Section 7.2. For example, under the circumstances in which Democracy Wall and various unofficial publications were allowed to exist for a limited period of time, why is it that most people still preferred to submit their article manuscripts to official periodicals instead? The reason is that the print runs of official periodicals far exceeded those of unofficial periodicals. An unofficial periodical would at most have a print run of merely several hundred or several thousand copies. In a country with a population in excess of one billion such as China, the impact of such a small print run is truly too miniscule. If this were to have happened in a country with a population of merely ten million such as Hungary, the impact would have been a hundred times greater than was likely to occur in China. From this perspective, the fact that China's unofficial periodicals (or underground periodicals) actually exerted a modestly significant influence is a truly remarkable achievement.

Precisely because China is huge in both its territorial expanse and population, the impact of its mass communication outlets is especially important. This in turn compels many people to rack their brains to come up with ways of expressing their own ideas via official mass communication outlets. If you want to take advantage of official mass communication outlets, you have to come up with ways of getting past official political censorship; this requires you to have a high level of political skill in your mode of expression. We should note that Chinese dissidents have done remarkably well in this regard. A great deal of indepth and incisive thought achieved widespread dissemination on account of dissidents having successfully taken advantage of official mass communication outlets. This includes such classic critiques of totalitarianism as 1984 and The Gulag Archipelago, which were formally 
published by official publishing houses in 1978 and I982, respectively, under the pretext of "for research purposes" or "for the purpose of denouncing its ideas." (In the former Soviet Union, these two books were not published until as late as 1989.) The astonishing momentum of the Democracy Movement in 1989 was sufficient to prove that the trend of liberalization in thought has a rather broad foundation in China. I find it very difficult to voice my approval of the view that exaggerates the significance of the Democracy Movement in 1989 and regards it as the main factor that drove the cataclysmic changes in Eastern Europe. However, I find it similarly difficult to go along with the view that not only underestimates the contribution of Chinese dissidents, but also underestimates the strength of liberal thought in China.

There is yet another method of taking advantage of official mass communication outlets: namely, taking advantage of the regime's public denunciations of liberal thought in order to achieve the effect of counterpropaganda. The stronger the populace's mistrust of the regime, the greater the effect of counterpropaganda resulting from the regime's public denunciations. This is especially the case with those rebellious voices and activities that have arisen from unofficial venues and were originally of merely slight influence; their impact as counterpropaganda has instead been greatly amplified by the regime's public denunciations of them. An example of this occurred during the Anti-liberalization Movement of 1987. The regime assembled a number of speeches by various dissidents and handed them down to the masses as material for denunciation. Among the speeches were those that had originally been presented to small-scale audiences in unofficial venues, so few people had actually listened to them. Now that the regime had assembled and distributed these speeches, this actually had the effect of allowing even more persons to broaden their awareness of these issues; after reading these speeches, readers tended to feel that these denounced views were in actuality more reasonable than the standard fare they encountered in the PRC.

On the other hand, no matter whether it comes to utilizing mass communication outlets to openly advocate liberalization or conversely to use them as counterpropaganda for liberalization, these methods have their limitations, after all. For the final decision-making power here is still in the grasp of the regime. Relying upon their quick wit, courage and ever-changing strategies, as well as the broad masses' ability to take a hint, dissidents have borrowed official mass communication outlets to explain the concept of liberty and awaken the populace's critical consciousness, thereby creating a latent oppositional force that is ready to launch at an opportune moment. However, the effort of a "final kick through the goalposts" is indispensable in the end. There still needs to be a final crossing of swords with the conservative forces of the regime. 
It is only when we emerge as victorious over our enemy in this crossing of swords that we can we truly succeed in winning freedom.

There are similar problems in borrowing official mass communication outlets for the counterpropaganda of liberal thought, because the regime is not at all so easily fooled. On the one hand, the regime will openly suppress dissident political views in order to achieve the effect of intimidating a hundred by killing one person as an example. On the other hand, the regime will do all it can to distort and seal off those suppressed views and their concrete content so as to reduce the contagious effects of liberal thought. Furthermore, when suppressing dissident activities, the regime often selects its targets for attack carefully, aiming its attack precisely at its opponent's Achilles heel. From this, we can see that we must not overestimate the counterpropaganda effect from mass communication outlets. We must still work hard to open up an independent and autonomous public sphere for interaction.

\subsection{A Struggle for Recognition}

The theories of collective action put forward by the several Western scholars mentioned above are all basically aimed at a free society. In this type of society, people can freely set up organizations and freely express their own demands. People are fully protected when participating in these activities. A totalitarian society is quite different. Totalitarianism denies people the right to express dissenting political opinions. To participate in a struggle for freedom in a totalitarian society is to take great risks. If the behavior of people was based merely upon individual interests, they would not get involved in such a struggle at all. However, such struggles have still occurred, after all. That is obviously difficult to explain if we are following the theory of rational choice. Because of this, we must further explore the motivation or impetus for people to participate in the collective action of struggling for freedom.

In his book, The End of History and the Last Man, Francis Fukuyama pointed out that human history is built upon the principle of "struggling for human dignity." ${ }^{4}$ The chief pursuit of humankind is to "treat a human being as a human being," which is to say, to require other people to respect you as a human being. What makes a person human consists of his courage to survive, namely, to have the capability of risking the dangers of life in order to achieve self-actualization. It is exactly this sort of desire for recognition - not anything else - that is the motive force driving the history of humankind forward.

Let us take as an example some workers who are going on strike to demand an increase in wages. According to the theory of rational choice, this amounts to nothing more than a conflict between the two 
interest groups of workers and management; and by means of rational calculation, each side diligently keeps costs to a minimum while maximizing benefits. As Fukuyama has noted, this sort of explanation is a "considerable simplification of the psychological process that goes on internally on both sides":

The striking worker does not carry a sign saying "I am a greedy person and want all the money I can extract from management" (...). Instead, the striker says (and thinks to himself): "I am a good worker; I am worth much more to my employer than I am currently being paid (...). I am being unfairly underpaid (...)."35

Indeed, a raise in wages can go a long way towards satisfying the desires of workers for material things, but what is just as important - if not more important - is that such a raise would make workers feel that their dignity and worth as human beings have been recognized. Adam Smith long ago pointed out that the reason men seek riches and shun poverty is seldom for the sake of meeting plain material needs, but has more to do with satisfying the self-esteem, pride and even vanity in their psychology. ${ }^{36}$ Often, poverty is merely a relative concept for people nowadays, since it no longer refers to someone who lacks clothing and food and must endure hunger and cold. Why would this sort of poverty make you feel that it is so intolerable? Because it makes you feel that other people look down on you. This is a more profound motivation for people nowadays to be anxious to shake off poverty.

\subsection{Desire, Reason and Spiritedness}

According to Fukuyama, while the viewpoint regarding the desire for recognition as the primary force driving the history of humankind forward comes from Hegel, “the concept underlying 'recognition' was not invented by Hegel. It is as old as Western political philosophy itself, and refers to a thoroughly familiar part of the human personality." 37 It is merely the case that this concept has been couched in various terms depending on which philosopher was writing on it at a given time. Plato believes that a person's soul consists of three parts: desire, reason and spiritedness (thymos).$^{38}$ Here, spiritedness is the basis of the concept of desiring recognition. "Machiavelli [spoke] of man's desire for glory, Hobbes of his pride or vainglory, Rousseau of his amour-propre, Alexander Hamilton of the love of fame and James Madison of ambition, Hegel of recognition, and Nietzsche of man as the "wild beast with red cheeks.' "39 (What is referred to as the "wild beast with red cheeks" is the fact that man is an animal whose face can blush, and this means 
that man is an animal who has passion, anger and a sense of shame.) All of these various terms refer to something that they have in common with one another.

In China, we can also find many similar ways of illustrating this idea. One example is the claim that all humans have a sense of shame, which is an important distinction between humans and beasts. Another example is the saying: "When a wild goose passes by, it leaves behind the sound of its honking; when a man passes by, he leaves behind his reputation." Yet another example is the saying: "What a person strives for is but a measure of success, while what Buddha strives for is but a burning incense stick." ${ }^{\circ}$ Still another example is the record of humankind's pursuit of immortality. Finally, there are also examples of illustrating such qualities as the sense of commiseration, courage and uprightness. This sort of thing is obviously part of human nature. It cannot be reduced to either a mere matter of desire or a mere matter of reason.

\subsection{Knowledge and Behavior}

Let us begin with an illustration. If a brigand robs us of our belongings, we not only feel sad - because we suffer a blow to our self-interest, specifically suffering a loss of the belongings that gratify our desires - but we also feel indignant. This differs from an instance in which we lost some belongings on account of our own carelessness. The reason for our indignation is that we feel our dignity has been violated. From examples such as these, it is obvious that Homo sapiens is by no means an animal that is merely concerned with self-interest.

It hurts to fall down; it also hurts to get punched in the face. Yet the feelings that result from these two experiences are very different. Under the latter sort of circumstances, we also feel humiliated; you cannot help but want to hit back at the person who punched you. The purpose of retaliation is not necessarily for self-defense, since the person who punched you may well not have any intention of injuring you further. Retaliation is for the purpose of proving that you are not someone who can be wantonly bullied and for proving that your self-worth cannot be casually negated by others. We are well aware that in the process of retaliating, you might not be able to avoid getting punched a few more times. As the saying goes: "Your side killed three thousand enemy soldiers, but eight hundred of your own soldiers were wounded." Even if you were to vanquish your adversary in the end, you would have only added to the aches and pains in your own body. Yet it is only after we have aroused ourselves to retaliate against our adversary that we can feel pleased with ourselves. This is because we would have thereby defended our dignity and proved our own self-worth. 
If a human being cared about nothing other than self-interest, then the only rational choice after you had been punched one time would be that you would try your best to avoid getting punched a second time unless the defeat of your adversary could somehow provide you with more in the way of material advantage. Nevertheless, we are willing to be punched several more times just because we want to strike back at that adversary, even though we are aware that we indeed cannot obtain any material advantage from defeating that adversary. Once we are on the receiving end of a blow, we have an impulse to strike back at the attacker; upon seeing blows rain down on other people, we have a similar impulse to strike back at the attacker. This is what is meant by the saying: "If you witness an injustice on the road, you'll feel an impulse to draw your sword to help the wronged person." If someone slips and falls into a river or lake, we cannot help but try to pull him out to safety; if an innocent person is struck a blow, we cannot help but step forward to protest this injustice. In both cases, our response derives from our feelings of sympathy, yet in the latter case, our sympathy is complemented by feelings of indignation as well. This is what is generally referred to as "moral indignation." Moral indignation can spur a person on to willingly engage in certain risky activity, even for the sake of something that has no direct connection to his own self-interest. This sort of activity might not provide you with any advantage, but might well cause you some type of harm. However, it is your involvement in precisely this sort of activity that would give rise to an intense feeling that you are an upright and respectable person.

The matters I have discussed in the paragraphs above are nothing more than the ordinary experiences that all people have encountered in everyday life. This clearly indicates that everybody believes that they have a certain value as a person. What is known as self-esteem refers precisely to the subjective affirmation of this type of value; at the same time, it demands that it obtain an acknowledgement of this value from other people. If someone's behavior toward me is aimed at denying my value as a person, I would feel indignant. If I were unable to accomplish things in keeping with my own value as a person on account of being pressured by other persons, I would experience suffering. If this sort of futile act of mine were made public, I would feel ashamed. Yet were I to resist pressure from others and insist on taking an action in keeping with my own value as a person, preferring to pay a price in terms of my desires and self-interest, I would then feel a sense of pride and honor, and would be praised and affirmed by public opinion. Just as Fukuyama has stated, a person who has nothing but his desires (or more precisely, a person whose desires have suppressed his spiritedness) is doomed to a life that cannot break free of the constricting boundaries "within the system." However, a spirited or courageous per- 
son would instead venture boldly into the great struggle of resistance to oppression for the sake of his own dignity and the dignity of his compatriots.

A person is willing to lose what little bit of freedom he already has in order to make an effort to obtain a larger share of freedom. This is by no means self-contradictory, since he is not merely trying to gain more elbow room. More importantly, he is unwilling to surrender to oppression by others, is defending his own dignity and is displaying his own independent and autonomous will. In the U.S., the blacks have been a minority, while the whites have been the majority. If the whites had always defended nothing but the interests of other whites, there would have been practically no hope for success in the blacks' struggle for freedom. Precisely because the blacks' struggle aroused the whites' sympathy and sense of justice, the U.S. finally achieved ethnic equality. Clearly, the struggle to secure freedom cannot be merely boiled down to the coordination of competing interests, but should be summed up as a victory for humanity in general. This is the basic reason why many Communist Party members and even Party leaders choose the standpoint of sympathizing with the democracy movement and opposing a violent crackdown on it when a struggle in opposition to communist authoritarianism breaks out in a communist country.

Marx has a famous saying: "The philosophers have only interpreted the world in various ways. The point, however, is to change it." Actually, this is not an even-handed remark, since many philosophies that have interpreted the world have in reality also played some kind of role in changing the world. In other words, interpretation often serves as guidance.

Socrates once said: "Know thyself." ${ }^{41}$ However, once the "self" has come to be known, this very "self" would be quite different from the original "self" that had not known itself. Once we have realized that a human being is not at all merely the vehicle for a bundle of desires, that reason is not at all merely an instrument of calculation for achieving one's desires, and that dignity and the sense of justice (or the wish for recognition) indeed exist within the human mind, we would find it even more difficult to endure authoritarian oppression, even if we ourselves belong to the clique of rulers rather than to the multitudes under authoritarian rule. We would also give rise to an even more intense pursuit of freedom, as well as a willingness to pay a price for it; we would even more resolutely cast ourselves into the struggle of securing our freedom. 


\subsection{The Special Features of Late Communist Totalitarian Rule}

The special feature of early communist totalitarian rule was that under the cover of violence and by leading human reasoning astray, the regime repressed human desire under the pretext of upholding spiritedness, and subsequently repressed spiritedness itself. Communism paraded a sort of idealism, demanding that we transform ourselves into selfless paragons - the type of individuals who have separated themselves from coarse hankerings, instead working non-stop to benefit all the people. However, it made us believe that the only way of achieving such a transformation was to obey the Party and to remold ourselves by means of adopting a proletarian weltanschauung. Yielding to these exhortations with a certain reluctance, we accepted these sorts of ideas; that is to say, we accepted the values that the CCP stipulated for us. Consequently, we suppressed the pursuit of our own desires, looking upon the independent will that appeared half-distinctly in the depth of our hearts as an obstacle we had to overcome; we thus wound up negating spiritedness by means of spiritedness itself.

Late communist totalitarian rule has nonetheless changed over to a different approach. "Communism, in a much more thoroughgoing way than 'bourgeois' liberalism, fortified the desiring part of the soul against the thymotic part ... It did offer them these things in a Faustian bargain, requiring them to compromise their moral worth in return. ${ }^{42}$ And in making this bargain, the victims of the system became its perpetuators, while the system itself took on a life of its own independently of anyone's desire to participate in it." 43 The reason why the CCP's totalitarian rule has managed to remain in existence up to the present day is not at all because of many people still supporting it and defending it, but merely because there have not been very many people who have actively opposed it. When you ask other people why they have not risen up in opposition to it, some of them would probably even turn around and ask you why you necessarily have to oppose it: "Can't we still get on with our lives pretty well as long as we don't provoke it?"

Drawing a lesson from this, today we are more than ever in need of raising high the banner of idealism, promoting exemplars of heroism, and upholding human dignity and justice. We must not erroneously assume that individuals' pursuit of personal desire and private gain would necessarily lead to their struggle for freedom and democracy. To be sure, liberalism and individualism are indeed interconnected. However, individualism is not equivalent to egoism. Egoism merely values the self of an individual person, while individualism instead requires us to value the self of every single person.

Eric Hoffer summed it up very well: "One of the chief objectives of freedom is to make it possible for a person to feel himself a human 
being first. Any social order in which people see themselves primarily as workingmen, businessmen, intellectuals, members of a church, nation, race, or party is deficient in genuine freedom." 44 I certainly do not deny the significance of private interests in the struggle for freedom. The point is that we must help people understand that rights are the safeguard of interests; we must grow adept at rechanneling people's pursuit of private interests to the pursuit of freedom. In order to accomplish this, we must venture beyond our own interests and we must nurture public-spiritedness. Just as we discussed previously, if there is no self-awareness of human dignity and if there is no strong desire for recognition, there will not be any collective action in the struggle for our economic interests.

Spiritedness, self-esteem, a sense of justice and the desire for recognition are all part of our original human nature. These attributes of human nature can be temporarily obscured by desires running wild, or hoodwinked by misleading and confused reasoning, but they will never vanish. We should notice that under the confusing and chaotic circumstances of the present day, confusion in reasoning has again been playing an important role. With equal parts of gullibility and doubt, many people have accepted the theory of materialistic consumerism, while regarding any and all varieties of social idealism as clichéd ideological preaching and thus committing them to oblivion; at the same time, people cannot help but feel that they seem to have lost something of value. Our duty is to clear up this sort of confusion, bring the loftier pursuits of the human mind into focus, and reawaken people to the meaning of life.

We know that authoritarian rulers are always mouthing their fervent sermons about moral ideals and the spirit of self-sacrifice, while in actuality brimming with hypocrisy in their behavior, thereby giving rise to legitimate feelings of disgust among the people. Conversely, in a democratic society, people talk a great deal about interests - of course, these are interests that accord with rationality. Tocqueville long ago discovered that Americans like to explain practically all of their actions by means of the principle of "correctly understood interests" - even including those actions involving a certain amount of self-sacrifice on behalf of the community and the state. Tocqueville said:

As to this point, I believe that Americans' evaluation of themselves is often not entirely correct, since just as in other countries, there are also cases among U.S. citizens in which they feel duty-bound not to turn back from taking actions stemming from the selfless passions of their own nature. However, Americans would never acknowledge that they have been motivated by these sorts of emotional impulses; they would prefer to let their own philosophy shine, rather than glorify themselves individually. ${ }^{45}$ 
That is to say, what Americans do in actuality tends to be better than what they say.

The principle of "correctly understood interests" is no doubt correct to a large extent, yet in the end it is incomplete. When people struggle for freedom and rights, they are of course doing this on behalf of their own interests. Yet at the same time, this is also a case of "applying a moral concept to the political realm." It is only after coming to a clear understanding of this dynamic that we can finally shake off that sort of unreasonable moral preaching, while at the same time avoiding a fall into the trap of a similarly unreasonable and narrow egoism, thereby achieving a more complete life by way of a more robust attitude.

\subsection{Dauntlessly Moving Forward in a Measured Stride}

In actuality, it is not quite fair to blame the running wild of desires for having obscured spiritedness. Looking back at the history of the last two decades of the 2oth century, we can see that economic development forcefully stimulated demands for political reform at one juncture, while the increase of individual interests provided strong stimulation to the sense of human dignity and the desire for recognition at one point. This is an important factor behind the eruption of the democracy movement in 1989 . To a large degree, the political apathy and decline in public-spiritedness manifested by the Chinese populace these days are consequences of the June Fourth Incident. In other words, these societal problems are the products of fear. It is due to fear that the populace has remained aloof from the democracy movement. Taking advantage of the populace's evasiveness, the regime has grown even more brazen in its crackdown on the democracy movement (and has become especially brazen in recent years). This sort of brazen crackdown has in turn intensified fear among the populace. It is not a case in which people merely covet materialistic well-being while ignoring freedom of the spirit, but is rather a case in which pursuing freedom of the spirit requires people to pay an excessively high price in terms of materialistic wellbeing. This situation thus makes most people hesitant about moving forward, while also causing viewpoints that rationalize evasion to spread far and wide, owing to the ability of such viewpoints to numb wounded self-esteem by means of self-deception.

Under these circumstances, I am afraid that it would not be very realistic to expect that simply by calling out loudly for heroic spiritedness we would be able to inspire most of the populace to throw themselves once again into the great enterprise of struggling for freedom. If we are unwilling to wait passively for a breakup and other changes within the 
ruling clique itself, we must offer practical and workable methods of trying to encourage the participation of the broad masses.

This state of affairs requires that we rediscover weak links within the chains of totalitarian rule, choose a new and achievable goal that is limited from the very outset, and avoid encountering overly severe repression from the very outset. From the vantage point of the authoritarian rulers, if they have not emerged victorious in the struggle of the people against authoritarianism, it means that they have lost; from the vantage point of the people, if they have not lost, it means that they have won. Many people know only that courage is a prerequisite of victory, but they do not realize that courage is actually a result of victory as well. When morale has sunk to a mood of despondency in the wake of a defeat, success is the only thing capable of reviving morale. Even if one wins only minor victories, as long as they continue to accumulate in number, they will eventually serve a major function in restoring morale.

Consequently, we should not underestimate the seemingly ordinary and insignificant forms of struggle that have taken place in China during recent years. No doubt the appeal of these forms of struggle was low-key and the success they achieved may have been limited, but they have awakened people to the opportunities and possibilities of struggle and resistance; because of this, they have been able to draw in even wider sections of the populace to follow their example and thereby rebuild their self-confidence. Modest demands make for modest risks; modest risks make for higher rates of participation; and higher rates of participation make for more telling results. This lays a firm foundation for even larger-scale initiatives, as well as for endeavors aimed at achieving even higher goals. If we adopt this strategy of dauntlessly moving forward in a measured stride, we shall discover that freedom is indeed not so very far from our grasp. 



\section{About the Author and the Translators}

Hu Ping is past president of the Chinese Alliance for Democracy and currently Editor-in-chief of the New York-based journal of contemporary Chinese thought and politics, Beijing Spring. He has a graduate degree in philosophy from Beijing University, and has published over ten books as well as several hundred articles. Considered by Nobel Peace Prize Laureate Liu Xiaobo to be "an inspirational figure," $\mathrm{Hu}$ is a prominent commentator on contemporary Chinese society and politics for Chinese-language media outlets.

Philip F. Williams has held the position of Professor of Chinese studies at a number of research universities in the U.S. and Australasia, and is currently a professor at Montana State University in the upper Rocky Mountain region. Williams' ten books include Village Echoes (Westview Press, I993), The Great Wall of Confinement (University of California Press, 2004), and Asian Literary Voices (Amsterdam University Press, 2OIO).

Yenna Wu is Distinguished Teaching Professor and Director of Asian Literatures and Cultures at the University of California, Riverside. Wu has published many articles, books, book chapters, translations, and reviews in both English and Chinese, including The Chinese Virago (Harvard University East Asian Series, I995), Remolding and Resistance Among Writers of the Chinese Prison Camp (Routledge, 2006), and Human Rights, Suffering, and Aesthetics in Political Prison Literature (Lexington Books, 20II). 



\section{Notes}

\section{Preface}

I [Translator's note:] Like a great majority of Chinese-language treatises by authors from mainland China, Hu Ping's book does not include a bibliography. Instead, full citations of sources quoted in the text are given in the endnotes upon their first occurrence, and thenceforth are cited in abbreviated form.

2 [Translator's note:] The generalizations included in this sentence have been made with the People's Republic of China (PRC) in mind, as has most of the rest of the preface.

3 Irving Howe, An Image of Hope (New York: Harcourt Brace Jovanovich, I982), p. 35I. [Translator's note:] Unless an endnote is specifically identified as the translator's, it should be assumed to be the author's endnote.

4 [Translator's note:] The standard translation of jianchaguan is "procurator," a PRC government prosecutor whose investigatory functions are broader than most prosecutors in Western legal systems. Within the context of this sentence, however, the rendering of "interrogator" expresses the author's intent more clearly.

5 [Translator's note:] This old Chinese proverb suggests that a person who is involved in some sort of situation often finds it difficult or impossible to develop a comprehensive grasp of the overall situation.

6 [Translator's note:] The PRC's "Great Proletarian Cultural Revolution," usually referred to simply as the "Cultural Revolution," is generally considered to have lasted from May 1966 until October 1976. This political campaign's most virulent phase came to a close in 1969 , and the Cultural Revolution entered another period of decline after the abortive coup d'état and death of Lin Biao in I97I. However, the campaign did not come to a formal end until after the death of Mao Zedong and the subsequent arrest of Mao's "Gang of Four" in the autumn of 1976.

7 [Translator's note:] Chou lao jiu, or "Stinking Number Nine," was a scornful epithet used for intellectuals during certain Maoist purges and campaigns such as the Cultural Revolution. This epithet hearkens back to Mongol rule during the Yuan dynasty (I279-I368), when much of the Han Chinese intelligentsia temporarily lost their elite social status and were cast down to the strata of the most disfavored groups in society, such as itinerant laborers and boat people.

8 [Translator's note:] "Scar literature" peaked in the late I970s, and dealt mainly with personal suffering caused by the Cultural Revolution. "Rusticated youth literature" mostly portrayed the difficulties encountered by urban youth who had been pressed to migrate permanently to the countryside during the I960s and I970s by Maoist policies. 


\section{Chapter 1}

I [Translator's note:] The pronunciation of xi'nao resembles "she now."

2 [Translator's note:] Yang Jiang (b. I9II) is a teacher, playwright, translator, essayist and novelist, as well as the widow of the famous scholar and writer Qian Zhongshu (I9IOI998). Her novel Xizao (Hong Kong: Sanlian shudian, I988) was reprinted in both the PRC and Taiwan in I989, and was translated into English under the title of Baptism by Judith M. Amory and Yaohua Shi (Hong Kong: Hong Kong University Press, 2007). For a brief summary of this novel, see Geremie Barmé, In the Red: On Contemporary Chinese Culture (New York: Columbia University Press, 1999), pp. 2-3.

3 [Translator's note:] Liu Qingfeng (b. I945?) is a social scientist and professor who lived and worked in the PRC up to 1989 and in Hong Kong and Taiwan during the years since the Tiananmen Crackdown. Aside from writing her own publications, she has also collaborated with her husband and fellow social scientist Jin Guantao (b. 1947) on a number of jointly authored publications such as an influential study on the "ultrastable" traditional Chinese political system.

4 [Translator's note:] In his books, Edward Hunter (I902-I978) pointed out that the term xi'nao was a grassroots Chinese coinage that many Chinese informants had reported to be in frequent use among non-officials during the thought remolding campaigns that Mao's government launched soon after formally establishing its control over the mainland in October 1949. Though not an officially approved term in the PRC, xi'nao was clearly not a loanword from North America, either.

5 Edward Hunter, Brainwashing in Red China: The Calculated Destruction of Men's Minds (New York: Vanguard Press, I951); Brainwashing: The Story of Men Who Defied it (New York: Farrar, Straus \& Cudahy, I956); Robert Jay Lifton, Thought Reform and the Psychology of Totalism (New York: W.W. Norton, I969). [Translator's note:] In the latter book, Lifton (b. 1926) recounts many of his interviews in Hong Kong with refugees from the PRC.

6 [Translator's note:] During this "bathing," the individual undergoing thought remolding typically makes a public display of washing away or purging ideological impurities such as a "bourgeois" viewpoint or divergence from the Party line.

7 [Translator's note:] According to CCP historiography, the Revolutionary War Era (I92II949) dates from the founding of the CCP in Shanghai in I92I until the CCP's midcentury victory in the civil war against the Guomindang or Nationalist government.

8 [Translator's note:] Though these methods began to take shape in the I930s, they developed more rapidly and thoroughly during the i940s.

9 [Translator's note:] The hilly provincial town of Yan'an in northern Shaanxi province served as the CCP's wartime capital from the latter half of the I93os until the midI940s. The Yan'an Rectification Campaign peaked in I942, and led to the purging and silencing of many CCP members and fellow travelers alike who were deemed to have committed the offense of straying from the Party line.

Io [Translator's note:] The proverbial exhortation to "foster heavenly principles and discard human desires" comes from the Buddho-Daoist strain of traditional Chinese thought.

II [Translator's note:] What the author means by "Marxism" in this chapter are the actual I9th-century writings of Karl Marx (I818-I883) and Friedrich Engels (I820-I895), as opposed to 2oth-century elaborations and revisions of Marxian postulates by Soviet Russian and Chinese communist authoritarians such as Lenin, Stalin and Mao.

I2 [Translator's note:] David Hume (I7II-I786) was a Scottish philosopher.

I3 [Translator's note:] The Russian Ivan Pavlov (I849-1936) and the American B.F. Skinner (I904-I990) are both associated with the behaviorist movement in psychology, they de-emphasized the psyche in favor of a focus on stimulus-response mechanisms. 
I4 [Translator's note:] As noted earlier, references to "Marxism" in this chapter refer to the body of Igth-century Marxist theory adumbrated by Marx and Engels, not the 2oth-century elaborations and variations that arose in countries such as Russia and China.

I5 [Translator's note:] The comparison here is with Skinnerian behaviorism, though there are several other philosophies of determinism that are not as rigidly hard-line as Marxist dialectical materialism, either.

I6 [Translator's note:] Each of the quoted exhortations in this sentence was commonly leveled at persons undergoing thought remolding during Mao Zedong's rule in China.

I7 [Translator's note:] Chou laojiu or "stinking number nine" was a common term of abuse for the intelligentsia during China's Cultural Revolution. The term suggests that intellectuals deserved their ranking near the bottom of the social hierarchy during that tumultuous decade. During less chaotic times in Chinese history, the intelligentsia has generally been close to the top of the social hierarchy, as most government officials have typically been recruited from the well-educated elite.

I8 [Translator's note:] Since Jiefang or "Liberation" in CCP discourse has been pegged at the founding of the PRC on I October I949, a Chinese person's class ranking was originally based on the Party officials' judgment about that individual's economic mode of existence during the late I940s.

I9 [Translator's note:] According to Maoist rural-class doctrine, an agricultural "landlord" did not personally farm his own land, but instead earned a living by renting his land out to tenant farmers or hiring farm laborers to handle all the farm chores. In contrast, a "rich farmer" owned more land than he could farm on his own, meaning that he would have to hire laborers to join him in handling the farm chores on his relatively extensive acreage. In contrast, "middle farmers" and "poor farmers" handled all of the farm chores on their relatively meager plots of land; poor farmers would occasionally also hire themselves out as part-time farm laborers in their spare time.

20 [Translator's note:] The "seventeen years" refers to the period from I949 to I966.

2I [Translator's note:] In other words, one cannot find a solid basis for this Maoist notion of a stubbornly persistent and noxiously infectious bourgeois ideology within the actual igth-century writings of Marx and Engels.

22 [Translator's note:] In other words, according to Lenin, the proletariat cannot give rise to a proletarian weltanschauung without guidance from the Communist Party, which supposedly has the wherewithal to properly immerse the proletariat in a proletarian weltanschauung. The author suggests that this conjecture on Lenin's part diverges from Igth-century Marxist thought as originally developed by Marx and Engels.

23 [Translator's note:] The term for "contradiction" or maodun in Chinese is a compound that combines the sinographs for "spear" and "shield."

24 [Translator's note:] Liang Qichao (I873-1929) was a major Chinese social theorist and journalist during the late Qing and early Republican eras.

25 [Translator's note:] Lei Feng (I940-I962) was a young PLA soldier who died in a motor vehicle wreck and left behind a diary full of accounts of his good deeds and adulation for Mao. A sort of Communist boy scout, Lei Feng viewed himself as a screw that was happy to be placed anywhere within the vast machine of the Party that the leaders might deem useful. State-controlled PRC media canonized Lei Feng as an exemplar whom all citizens should emulate. Jiao Yulu (1922-1964) was a less prominent canonized exemplar who has been eulogized for living frugally and working day and night on behalf of the people over whom he ruled as a local Party official. At middle age, the overworked Jiao died of cancer; like Lei Feng, his nationwide canonization as an exemplar began only after he was safely dead.

26 [Translator's note:] The dissident intellectual and essayist Chen Shizhong (b. I937) was praised by the dissident journalist Liu Binyan (I925-2005) in Liu's mid-I980s re- 
portage narrative "The Second Type of Loyalty" for having bravely spoken out against misguided policies of the Party-state during the Mao era, knowing full well that he would be punished for his outspokenness. Chen was confined for many years in prison camps.

27 [Translator's note:] Wen Tianxiang (I236-I283) was a scholar-official and famous Song dynasty (960-1279) loyalist, while Kubilai (1215-1294) was the most prominent Mongol emperor of the succeeding Yuan dynasty (I279-1368).

28 [Translator's note:] Lin Biao (I907-I97I) was a Chinese Communist military leader and the officially anointed successor to Mao Zedong when he died during an alleged coup d'état attempt.

29 [Translator's note:] The 2oth-century Chinese philosopher Liang Shuming (I893-I988) has sometimes been dubbed "the last Confucian."

30 [Translator's note:] To punish this educated youth for having dared to publicly argue against the Maoist bloodline theory of determining one's political status, Yu Luoke (I942-I970) was imprisoned and subsequently executed during the final decade of Mao Zedong's dictatorship.

3I [Translator's note:] The Liar's Paradox in its present form has been originally attributed to the 4 th-century BCE Greek philosopher Eubulides of Miletus.

32 [Translator's note:] Bertrand Russell (I872-1970) was a British philosopher and mathematician.

33 [Translator's note:] Max Weber (I864-I920) was a German sociologist and economist.

34 [Translator's note:] Unlike in previous portions of this chapter, here "Marxism" is used by the author to refer to the sort of 2oth-century Marxist-Leninist authoritarian ideology that has been adapted by Mao Zedong and other CCP leaders to suit their own needs as absolutist rulers over China. In other words, this use of "Marxism" does not refer merely to the ideas in the igth-century writings by Marx and Engels.

35 [Translator's note:] "Party Central" [Dang Zhongyang] is an abbreviation for the Central Committee of the Chinese Communist Party [Zhongguo Gongchandang Zhongyang weipuanhui].

36 [Translator's note:] The final use of "Marxism" in this paragraph refers to its reinterpretation as a legitimization for endless one-party authoritarian rule by such unelected 2oth-century Communist authoritarians such as Lenin, Stalin and Mao. The earlier uses of "Marxism" in this paragraph have more to do with the ideas in the I9th-century writings by Marx and Engels.

37 [Translator's note:] In other words, the Party's demand that you submit to thought remolding is not so much a demand that you accept one or another form of MarxistLeninist ideology as it is a demand that you submissively align your views with those of Party Central and obey the Party on all occasions, no matter how much the Party line may twist, turn, or even reverse its course - and that you never express any reservations or doubts about the "great, glorious and correct" CCP on any occasion whatsoever.

\section{Chapter 2}

I [Translator's note:] Unless otherwise indicated, the author's use of "Marxism" in this chapter refers to 2oth-century versions of Marxist-Leninism that were promoted under authoritarian single-party state-socialist regimes such as the former USSR and the PRC.

2 [Translator's note:] Supported by the relatively youthful Guangxu emperor and designed to transform traditional dynastic rule into a modern constitutional monarchy, the Hundred Days' Reform movement was crushed in September 1898 by a faction 
of Manchu court elders led by Empress Dowager Cixi. She placed the Guangxu emperor under house arrest for the remainder of his life, and was the de facto ruler of the Chinese empire for the rest of her life.

3 [Translator's note:] Hou Baolin (I9I7-I993) was a famous author and stage performer of numerous comedians' dialogues or "crosstalks" in Beijing.

4 [Translator's note:] In other words, CCP propagandists claimed that China's intelligentsia had been "completely convinced" that the CCP's replacement of the Nationalist Party as China's ruling party for the foreseeable future was "historically inevitable."

5 [Translator's note:] Under the watchful eye of the Ministry of Propaganda in the PRC, the Chinese Communists' military victory over the Chinese Nationalists in the civil war of the late I940s is nearly always couched in the self-congratulatory phrase of "Liberation," as if the Chinese Nationalists had been some sort of foreign occupier.

6 [Translator's note:] An example of such an accomplishment by the Communists in the early I950s was in bringing China's runaway inflation under control. This is something that the Nationalists had failed to achieve during the late I940s, and was a contributing factor in their defeat by the Communists in the civil war.

7 [Translator's note:] The CCP's Land Reform Campaign peaked in the PRC during the I95OS, and involved the confiscation of land and other property from "landlords" and "rich farmers," frequently accompanied by cruel punishments of these two groups.

8 [Translator's note:] Both located within Shaanxi province, Xi'an was associated with Nationalist rule, while Yan'an was associated with Communist rule.

9 [Translator's note:] This is pressure on the intelligentsia for deferential submission to Party rule.

IO [Translator's note:] Agricultural collectivism, the People's Commune campaign, and the partial and later complete nationalization of industry and commerce all took place in China under CCP rule in the I950s.

II [Translator's note:] The Yan'an Rectification Campaign of I942-I944 was Mao Zedong's first truly large-scale purge of the Party and society in general, though at this point it was still limited to a remote upland corner of northwestern China. Starting in I949, Maoist purges and campaigns were extended throughout mainland China.

I2 [Translator's note:] The Campaign to Suppress Counterrevolutionaries lasted from I950 to I95I, and along with the Land Reform Campaign and the Campaign to Resist America and Aid Korea (i.e. PRC military participation in the Korean War as North Korea's key ally), amounted to the CCP's three major campaigns dating from just after the founding of the new regime in I949. The number of individuals punished in this campaign of $1950-5 \mathrm{I}$ was at least three million.

I3 [Translator's note:] The absolutist founding emperor of the Qin dynasty (22I-206 BCE), Qin Shihuang (259-2IO BCE), ordered the banning and burning of most books on topics other than astrology, divination, medicine, agriculture and the history of the state of Qin. He reportedly had 460 scholars executed by burying them alive for having owned books on banned topics.

I4 [Translator's note:] "Killing a monkey to scare the chickens" is Hu Ping's inversion of the common Chinese expression sha ji jing hou [killing a chicken to scare the monkeys], in which the ruthlessness of the butcher serves as a warning to an audience of monkeys to behave themselves or else risk suffering the butchered chicken's fate.

I5 [Translator's note:] Yang Jiang's I980s novel Bathing was initially published in Hong Kong, thus eluding the restrictions of censorship and self-censorship that would have probably applied had it been published in the PRC at that time.

I6 [Translator's note:] William Huang (b. I925) is a writer and professor of political science who lived in the PRC throughout the I950s before emigrating to the US during the following decade. Under his Chinese name Jiang Wen, he wrote a Chinese novel 
based on what he knew about the trials of life as an intellectual in the PRC during the I950s, Wave-washed Sands [Lang tao sha] (I964; rpt. Taipei: Pami'er Bookstore, I986).

I7 [Translator's note:] The Three-Antis Campaign and the Five-Antis Campaign were launched by the CCP in China during I95I-I952. The Three-Antis Campaign punished individuals in Party organizations who were accused of corruption, waste or "bureaucratism." The Five-Antis Campaign cracked down on those employed in commerce who were supposedly involved in bribery, tax evasion, embezzlement of state property, shoddy workmanship or industrial espionage. Most of the millions of Chinese who were caught up in the net of these two campaigns would be considered innocent if judged in accordance with international standards of legality and due process.

I8 [Translator's note:] Fei Xiaotong (I910-2005) was a noted Chinese sociologist.

I9 [Translator's note:] This variation on the common Chinese expression explained above indicates how the CCP could intimidate the intelligentsia into terror-stricken submissiveness by dragging out one of its prominent members for particularly harsh denunciation and punishment - in this case, Hu Feng (1902-1985).

20 [Translator's note:] Hu Feng was a famous leftist literary critic and Party member, whose close connections with many key cultural figures in modern China such as Lu Xun (188I-I936) might have afforded him some protection even from the ferocity of Maoist purges. Yet along with various scholarly associates, Hu Feng was shrilly denounced and subsequently imprisoned as a thought criminal in a nationwide CCP vilification campaign that began in I955. He was not exonerated and freed from prison until I980.

2I [Translator's note:] Liu Yong (987-1053) was a lyric poet of the Northern Song era (960-II25).

22 [Translator's note:] The Communist Youth League is a nationwide organization that prepares its youthful members for likely recruitment into the Communist Party. It is the PRC's organizational equivalent of the former USSR's komsomol.

23 George Orwell, Nineteen Eighty-four (New York: Harcourt, Brace \& World, I949), p. 215 .

24 [Translator's note: ]The literal meaning of the "he-said, she-said" Chinese proverb quoted is "The father-in-law says that he is correct, while the mother-in-law says that she is correct."

25 [Translator's note:] Zhao Kuangyin (927-976) is the original name of the Taizu emperor who founded the Song dynasty in 960.

26 [Translator's note:] This is a reference to the alleged coup attempt by Marshal Lin Biao (1907-I97I) and his subsequent death in a jet crash on I3 September I97I.

27 [Translator's note:] "Party Central" is a common abbreviation for the Central Committee of the Chinese Communist Party.

28 [Translator's note:] June Fourth is shorthand for the 4 June I989 CCP crackdown on demonstrations and dissent in the PRC.

29 [Translator's note:] Immanuel Kant (I724-I804) was a German philosopher.

30 [Translator's note:] This Confucian version of the Golden Rule is a direct quote from The Analects of Confucius.

3I [Translator's note:] Hannah Arendt (I906-I975) was a German-American political theorist and philosopher.

32 [Translator's note:] Another version of this Chinese proverb is as follows: "There is nothing to debate over the question of what piques someone's interest."

33 [Translator's note:] Xi Shi (506 BCE-?) was a legendary beauty and favorite consort of the king of the Chinese state of Wu during the Eastern Zhou dynasty (77I-256 BCE).

34 [Translator's note:] Galileo Galilei $\left(\mathrm{I}^{6} 64-\mathrm{I} 642\right)$ was a prominent Italian astronomer and physicist. 
35 [Translator's note:] Although the influential philosophical doctrine of "Social Darwinism" bears the name of the famous British biologist Charles Darwin (I809-I882), Darwin repeatedly cautioned against wantonly applying his theory of biological natural selection to spheres of knowledge for which it was neither designed nor intended, such as the history of the rise and fall of human societies and governments. The British philosopher most notorious for ignoring Darwin's warning and doing precisely this was Herbert Spencer (I820-I903). It would thus be more accurate to refer to "Social Darwinism" as "Spencerism," since Darwin himself never endorsed Spencer's doctrines.

36 [Translator's note:] The crudely oversimplified and yet surprisingly influential Marxist five-stage theory of humankind's historical development deterministically insists that human societies "inevitably" develop along the following five stages, from beginning to end: "primitive communism" (i.e. bands of hunters and gatherers); a "slave society"; a "feudal society"; a "capitalist society"; and a "communist society."

37 [Translator's note:] Also known as the New Culture Movement, China's May Fourth Movement was a response to China's treatment as a second-class nation by the Treaty of Versailles that brought a final settlement to World War I; Germany's special extraterritorial privileges in China's Shandong province were initially transferred to Japan instead of being nullified in favor of a return to full Chinese sovereignty over Shandong's "treaty ports" such as Qingdao, as had been widely anticipated. Although this situation was eventually rectified in China's favor by the I920s, shock waves from the Versailles Treaty's unfavorable terms for China led to mass demonstrations there and a widespread determination among the educated elite that various aspects of anachronistic Chinese cultural traditions needed to be jettisoned in order to preserve China as a viable nation-state in the modern world.

38 [Translator's note:] Alexis de Tocqueville (I805-1859) was a French statesman and political theorist.

39 [Translator's note:] Ancient Greek mythology includes the story of a sinister son of the sea god Poseidon named Procustes, who forces wayfarers to fit into his notorious bed by either stretching their limbs on a rack or else cutting off part of their feet or legs.

40 [Translator's note:] Jean-Paul Sartre (1905-1980) was the French philosopher and writer who founded existentialism.

\section{Chapter 3}

I Robert M. Goldenson, ed., The Encyclopedia of Human Behavior: Psychology, Psychiatry, and Mental Health, Vol. I (New York: Doubleday \& Company, Inc., I976), p. I76.

2 [Translator's note:] The CCP implemented its campaign to "peacefully remold industry and commerce" during the I950s. Private enterprises were at first partially nationalized, and later completely nationalized.

3 [Translator's note:] Pei Wenzhong (I904-I982) was a noted archeologist and paleobiologist. Zhang Zhizhong (1895-1969) was a prominent military official for the Nationalists initially, and later the Communists. Luo Changpei (I899-1958) was a leading linguist. Xiao Qian (I9I0-I999) was a famous essayist and literary translator. Li Ziying (I92I-I998) was a noted specialist in Islamic studies. Feng Youlan (I895-I990) was a major scholar of Chinese philosophy. Xie Fengwo is a prominent educator.

4 Pei Wenzhong, Zhang Zhizhong, Wu Han, Feng Youlan, Wang Yunsheng, Ye Qianyu, Fei Xiaotong, Luo Changpei, Xiao Qian, Li Ziying and Xie Fengwo, Wode sixiang shi zenyang zhuanbian guolai de [How My Thought Has Been Transformed] (Beijing: Wushi niandai chubanshe, 1950), p. 46.

5 Ibid., p. 95. 
6 Zhou Duo, "Wo muqin de zisha - yige anli de yanjiu," in Mingbao yuekan (Hong Kong), August I99I.

7 [Translator's note:] Zhou Duo (b. 1947) is a scholar of philosophy and became one of the "four noble-minded" middle-aged hunger strikers during early June 1989 on the eve of the Party-state's violent military crackdown in the vicinity of Tiananmen Square. Zhou's mother Yang Jushu (I9I7-1978) was a well-educated professional who was either stuck in menial jobs or imprisoned for years on end in the PRC due to the Party's mistrust of her "bourgeois" associations and foreign connections.

8 [Translator's note:] GMD is short for Guomindang (the Nationalist Party).

9 [Translator's note:] The quoted line is paraphrased from "The Fisherman," a piece of classical prose by the ancient southern Chinese poet Qu Yuan (340-278 BCE).

Io [Translator's note:] The type of "Marxist theory" utilized by the CCP in thought remolding and propaganda in general has actually been Marxist-Leninism, with its emphasis on the absolute authority of the Party vanguard in a one-party authoritarian system. The very structure of the CCP is Leninist, as was the case with the Nationalist Party or Guomindang until the democratization of Taiwan near the end of the 2oth century.

II [Translator's note:] Mao Zedong's selected works may be consulted online from the following site: http://www.marxists.org/reference/archive/mao/selected-works/index. htm.

I2 [Translator's note:] This old Chinese proverb describes learning or scholarship as a lifetime endeavor. The CCP reinterpreted the proverb to mean that accepting admonishment or reproof from the Party is a lifetime duty.

I3 [Translator's note:] This is a common idiomatic expression in German: "Aller Anfang ist schwer."

I4 [Translator's note:] As indicated in a previous note, Hu Ping's references to "Marxism" in this chapter should be assumed to refer to the CCP's "Marxist-Leninism" unless specifically indicated otherwise.

I5 [Translator's note:] The phrase that has come to mean "first impressions are the strongest" originally derived from the idea that the first rebel military leader to march into the Qin dynasty capital as a conqueror (in $206 \mathrm{BCE}$ ) would probably be the next ruler of the Chinese empire. As it turned out, however, the rebel leader who did this, Xiang $\mathrm{Yu}$ (232-202 BCE), lost out to Liu Bang (256?-I95 BCE) as the founder of the Chinese empire's second dynasty.

I6 [Translator's note:] This metaphor also resonates with the Maoist military strategy during the late-I940s civil war of capturing all of the countryside around a Nationalistheld city before besieging the city itself.

I7 [Translator's note:] This proverb dates back to imperial times, referring literally to a third-level degree holder or xiucai under the old civil-service examination system.

I8 [Translator's note:] As is further explained in endnote twenty-six, the ideologically "correct" view in the Mao Era was that "Any entity divides into two" [yi fen wei er].

I9 [Translator's note:] In other words, there was no more possibility of the criticized person being able to speak up in defense of his position.

20 See Pei Wenzhong, et al., Wode sixiang shi zenyang zhuanbian guolai de, pp. 2-3. [Translator's note:] A "sedan-chair bearer" is a flatterer of the powerful.

2I [Translator's note:] It was on I3 September I97I that the jet carrying Lin Biao and some of his family members crashed in Outer Mongolia. Some months passed before the CCP-controlled media finally announced its claim that Lin Biao had attempted to flee to the Soviet Union after his coup plot to assassinate Mao Zedong failed. However, the eradication of all laudatory references to Lin Biao in print and broadcasts began in mid-September. Millions of "little red books" were yanked off of store shelves and pulped. 
22 [Translator's note:] For biographical information about Liu Qingfeng and her husband Jin Guantao (b. I947), see http://www.zaobao.com/special/face2face/pagess/face2faceogo4I9.shtml.

23 Liu Qingfeng, "Shi lun wenge qian Zhongguo zhishifenzi daode yongqi de lunsang," Zhishifenzi (U.S.), Winter I990, p. 44.

24 [Translator's note:] "Leaning to one side," a CCP slogan used during most of the I950s, meant learning from and favoring the Soviet Union and the rest of the "socialist camp" at the expense of the U.S. and other "capitalist" and "imperialist" nations.

25 [Translator's note:] The author is implicitly comparing the absolutist authority of 2othcentury communist dictators such as Stalin and Mao Zedong to that of emperors in imperial China.

26 [Translator's note:] Mao Zedong simplified the three principles of Engels' dialectics of Nature into one principle: the principle of the interpenetration of contraries or opposites [maodun tongyi lun]. He claimed that without exception, all things contain within themselves eternal contradictions and struggle, and thus "any entity divides into two."

27 [Translator's note:] In this parable, a man whose axe goes missing suspects that a neighbor's child has stolen it. Though the man has no evidence to back up his suspicion, he observes that this child seems to walk and talk like somebody who would steal an axe. When the man subsequently discovers that his axe had been lying in an obscure part of his own garden all along, he no longer thinks that the child walks or talks like someone who would steal an axe. This parable has been traditionally ascribed to the Warring States Daoist philosopher Liezi, who lived sometime in the $4^{\text {th }}$ or 5 th century BCE.

28 [Translator's note:] In Maoist ideological discourse about writings and various other cultural artifacts, "fragrant flowers" [xiang hua] are praised for having supposedly helped consolidate the dictatorship of the proletariat and advance the cause of socialism, while "poisonous weeds" [ $d u c a o]$ are condemned for having had precisely the opposite effect.

29 Hu Ping, Gei wo yige zhidian (Taipei: Lianjing chuban gongsi, I988), p. 72.

30 [Translator's note:] Hu Shi (I89I-I962) was a leading Chinese liberal intellectual.

3I [Translator's note:] “The Three Family Village” refers to Wu Han (I909-I969), Deng Tuo (I9I2-I966), and Liao Mosha (I907-I990), who under a collective pseudonym wrote various essays critiquing Party policies and satirizing Party leaders from I96 I to 1964. At the beginning of the Cultural Revolution, these three writers were purged and denounced by the Party as the "Three Family Village Black Inn." "The Four Stalwarts" were the playwrights Yang Hansheng (1902-1993), Tian Han (1898-1968), and Xia Yan (1900-1995), along with Minister of Culture Zhou Yang (I908-1989) - four high-ranking Party intellectuals who were all purged during the Cultural Revolution.

32 [Translator's note:] Referring to "Zhang Third and Li Fourth" is equivalent to mentioning "every Tom, Dick and Harry."

33 [Translator's note:] In Chinese, literally "the love for a person extends even to the crow on his roof."

34 [Translator's note:] "Everyone" here refers largely to PRC urbanites and townsfolk, because the CCP has been less concerned about instilling and enforcing ideological conformity in rural areas, where the population is less concentrated and more atomized.

35 [Translator's note:] The English philosopher and Franciscan friar Roger Bacon (I2I4?I294) is commonly credited as having coined the saying, "Scientia potentia est" [Knowledge is power]. However, this exact phrase cannot be found in Bacon's writings, having apparently first appeared in the 1658 treatise De Homine by Thomas Hobbes (I588-1679).

36 [Translator's note:] The White-Haired Girl [Baimao nü] is a melodrama constructed around Maoist notions of violent class struggle. It was collectively authored and ini- 
tially performed at the Lu Xun Academy of Arts and Literature in the CCP wartime capital of Yan'an in I945. It became part of the standard dramatic repertoire during the Mao Era, and was considered one of the Model Operas during the Cultural Revolution.

37 [Translator's note:] Among the rural landlord Huang Shiren's evil deeds in this melodrama are to dispatch his debt collector to kill the heroine Xi'er's father and to abduct Xi'er into service as Huang's concubine. Huang also works Xi'er like a slave, locking her into a room at night to prevent her from escaping his clutches.

38 [Translator's note:] Mao Zedong convened the highly prescriptive Yan'an Forum on Literature and Art [Yan'an wenyi zuotanhui] at the CCP's wartime capital in I942.

39 Pei Wenzhong, et al., Wode sixiang shi zenyang zhuanbian guolaide, p. IoI. [Translator's note:] Marking the formal beginning of China's War of Resistance to Japan [Kangri zhanzheng] during World War II, the Marco Polo Bridge Incident included the exchange of gunfire between Japanese and Chinese soldiers on the outskirts of Beijing (generally referred to as Beiping during the Republican era of I9II-I949) on 7 July I937.

40 Ibid., p. II8.

4I Ibid., p. 7I.

42 Cited in Kaifang [Openness Monthly] (Hong Kong), March I994, p. 52. [Translator's note:] Wang Ruoshui (1926-2002) was a former secretary of Mao Zedong, as well as a journalist.

43 [Translator's note:] Hua Guofeng (pseud. of Su Zhu, I92I-2008) was the transitional paramount leader of the Party-state after Mao Zedong died in September 1976 and before Deng Xiaoping took over as the de facto leader late in I978. Hua Guofeng lost his post as Premier in I980, and was stripped of his role as Party Chairman in I98I.

44 [Translator's note:] Whereas many Chinese emperors under the ancien régime had been willing to openly admit responsibility for a serious error, top CCP leaders have typically been unwilling to make such a public admission of responsibility.

45 [Translator's note:] The Mandate of Heaven was thought to have shifted away from the last emperor of a defeated dynasty and to the first emperor of a founding dynasty.

46 [Translator's note:] As is the case with other single-party Leninist authoritarian regimes, the PRC government is totally controlled by the Communist Party, which enforces a permanent de facto ban on opposition parties. Therefore, the paramount leader of the Communist Party is automatically the top leader of the government as well.

47 [Translator's note:] Chen Duxiu (I879-I942) was one of the founders of the CCP in I920 and led the CCP as General Secretary from I92I to I927. Qu Qiubai (I899-I935) became the top leader of the CCP in I927-1928, following Chen Duxiu's downfall. Li Lisan (I899-1967) emerged as the CCP's top leader from I928 to I930. Wang Ming (1904-1974) was a senior leader in the CCP during the I930s and early I940s, though the last two decades of his life were spent in exile in the USSR. Zhang Wentian (I900-I976) was the CCP's General Secretary from I935-I945, a period when Mao Zedong's ascendancy as the CCP's paramount leader became increasingly entrenched. Zhou Enlai (1898-1976) was de facto leader of the CCP for much of the early I930s, making the transition from Mao Zedong's boss to that of Mao's top lieutenant during the middle and latter part of that decade.

48 [Translator's note:] The "Great Airing of Views Campaign" of 1957 is also known as the "Hundred Flowers Campaign," which Mao Zedong launched in order to encourage what he assumed would be mild criticism of bureaucratism and other minor problems within the Party. When the resulting criticism of CCP misrule turned out to be far more thoroughgoing than what Mao wanted, he launched a severe crackdown known as the Anti-Rightist Campaign of I957-I958, consigning hundreds of thousands within the intelligentsia to prisons and labor camps. In July 1959, at the Eighth 
Plenum of the Eighth Central Committee of the CCP, also known as the Lushan Conference, Mao publicized and denounced a private letter that Marshal Peng Dehuai (I898-I974) had written him to criticize problems associated with the implementation of Mao's newest extreme-leftist policies known as the Great Leap Forward of 1959. A wide-ranging purge within the CCP ensued.

49 [Translator's note:] The Three-family Village was a series of early-I96os topical essays written by Wu Han, Deng Tuo and Liao Mosha. Although the satire found in many of these essays was quite mild and often Aesopian in its indirectness, this collection was denounced and its authors were vilified and cruelly punished. Of the three writers, only Liao Mosha survived the Cultural Revolution.

50 [Translator's note:] To "execute one person as a warning to a hundred" is ancient Chinese tradition whereby a ruling elite maintains its control over society through violence and the threat of violence. The CCP adopted this tradition in its rule over China.

5I [Translator's note:] The quoted proverb refers to criticizing someone obliquely; Chinese Buddhist monks are typically shaven-headed and thus appear to be bald.

52 [Translator's note:] The CCP typically denounces any assemblage of persons who challenge its policies or legitimacy as "a small handful" of troublemakers.

53 [Translator's note:] The campaign to denounce the famous liberal scholar Hu Shi occurred in the PRC shortly after the regime was founded in I949.

54 [Translator's note:] The proverb's point is that if you do not voluntarily drink a toast, you will be forced to drink a "forfeit" anyway, you thus might as well adopt the former course of action.

55 [Translator's note:] Cao Yu (I9I0-I996) wrote his most famous plays before 1949, but Bright, Sunny Skies was a relatively undistinguished play that came out in the midI950s.

56 [Translator's note:] Donald Gibbs is an emeritus professor of Chinese at the University of California at Davis.

57 See Shui Jing, Wusi yu Helasi (Hong Kong: Sanlian shudian, 1987), pp. 53-54.

58 [Translator's note:] Mao Zedong's fourth wife Jiang Qing (pseudonym of Li Shumeng, I9I4-I99I) took the CCP's ambition to micromanage PRC literature and the arts to a new peak of absurdity during the Cultural Revolution.

59 [Translator's note:] The Great Leap Forward lasted from 1959 to 1962 . One catty [jin] is 0.5 kilogram, or I.I pounds. One mou is 0.0677 hectare, or one-sixth of an acre.

60 [Translator's note:] Zong Pu (pseudonym of Feng Zhongpu, b. I928) is a PRC fiction writer.

6I Zong Pu, "Sansongtang duanyi," in Zhe yeshi lishi (Hong Kong: Oxford University Press, 1993), p. 35 .

62 [Translator's note:] The "emancipation of thought" took place among many PRC intellectuals during the post-Mao cultural thaw of the late i970s and early i980s. It refers to freeing the mind from the confining strictures of Maoist thought and venturing into "forbidden zones" that had been off limits during the Mao era.

63 Cited from Weilian S. Sahajin [William Sahakian], Shehui xinlixue de lishi yu tixi, trans. Zhou Xiaohong et al. (Guiyang: Guizhou renmin chubanshe, I991), p. 676. [Translator's note:] See William S. Sahakian, History and Systems of Social Psychology (New York: Hemisphere Publishing Corp., I982), p. 439.

64 [Translator's note:] Millions of PRC educated urban youth were sent away on what was designed as a one-way trip to resettle permanently in rural areas during the late Ig6os and the early-to-mid-I970s. Most are thought to have eventually returned to one or another urban area.

65 [Translator's note:] Robert Jay Lifton, Thought Reform and the Psychology of Totalism: A Study of "Brainwashing" in China (New York: W.W. Norton, 1969), p. 388. Hu Ping's 
paraphrase differs slightly from Lifton's original wording; the former is what is translated in the text.

66 Robert Jay Lifton, Thought Reform and the Psychology of Totalism: A Study of "Brainwashing" in China (New York: W.W. Norton, 1969), p. 396.

67 [Translator's note:] Most scholars believe that Master Sun's Military Strategy [Sun Zi bingfa] was written sometime during the fourth-to-third century BCE.

68 [Translator's note:] Both Luo Guanzhong's Three Kingdoms and Shi Nai'an's Water Margin were novels written during the first half of the Ming dynasty (I368-1644).

69 [Translator's note:] This is the traditional Chinese equivalent of the Greek parable of the Procrustean bed.

70 [Translator's note:] Cited from William S. Sahakian, History and Systems of Social Psychology, p. 439.

7I Mao Zedong xuanji (Beijing: Renmin chubanshe, I968), p. 786.

72 [Translator's note:] "Issuing someone tiny shoes" that pinch the feet is a metaphor for intentionally making things difficult and painful for a subordinate while pretending that everything is business as usual.

73 [Translator's note:] During the Qing dynasty, the names of its imperial subjects whom the state considered disreputable and untrustworthy were recorded "in the Other Register." This is a close equivalent to the contemporary practice of blacklisting.

74 [Translator's note:] Zang Kejia (I905-2004) was an establishmentarian PRC poet and May 7th Cadre School "alumnus." By I968, Mao Zedong ordered the establishment of May 7 th Cadre Schools as holding pens for cadres and other trained personnel who had received downward transfers for manual labor in the countryside. These shortlived institutions were named after a letter Mao wrote Lin Biao on 7 May 1966 about how the PLA was like a gigantic "school" in which subjects like politics and military affairs could be studied while soldiers simultaneously engaged in industrial and agricultural production.

75 [Translator's note:] Yao Wenyuan (I93I-2005) was one of Mao's “Gang of Four." See Philip Williams, "Wu Han, Chinese Dramatist, 1909-1969: Hai Rui Ba Guan, Opera Script, I960," in Censorship: An International Encyclopedia, ed. Derek Jones (London: Fitzroy Dearborn Publishers, 200I), pp. 2660-266I.

76 [Translator's note:] Peng Zhen (I902-I997) was one of the top CCP officials purged during Mao Zedong's Cultural Revolution (1966-1976).

77 [Translator's note:] These are two commonly repeated and self-glorifying slogans of the CCP Party-state.

78 [Translator's note:] CCP tracts often refer to the CCP as "the Organization."

79 [Translator's note:] This crude imperative was commonly directed at CCP targets of denunciation, especially during the I950s.

80 [Translator's note:] The first phrase is a traditional Confucian injunction, while the second is a modern Chinese Communist admonition. The author emphasizes how the spirit of the first contrasts with that of the second.

8I [Translator's note:] Eric Hoffer (I902-1983) was an American writer and commentator about problems in society, such as fanaticism.

82 Eric Hoffer, The True Believer (New York: Harper \& Row Publishers, I95I), p. 62.

83 [Translator's note:] Objects of reverence or worship are often capitalized, hence the rendering in this sentence of the phrase, "the Lord, the Party, the People, or History..."

84 [Translator's note:] Nikolai Bukharin (1888-1938) was one of many high-ranking "Old Bolsheviks" whom Josef Stalin purged and executed as "traitors" in the late I930s.

85 Suoerrenniqin, Gulage qundao, xiajuan, trans. Chen Hanzhang and Tian Dawei (Beijing: Qunzhong chubanshe, I982), p. 399. 
86 [Translator's note:] Both Qu Yuan and Hai Rui were exemplars of virtuous resistance who sacrificed their official posts in the effort to ameliorate the ruler's flawed policies by means of frank criticism. Qu Yuan was banished from his post as a court official for having remonstrated forthrightly with his muddleheaded monarch and committed suicide in exile rather than compromise his integrity. Hai Rui was similarly cashiered from his official post for having remonstrated on behalf of the local people with his negligent and irresponsible emperor.

87 [Translator's note:] The period referred to is the heyday of PRC thought remolding during the i950s and i96os.

88 [Translator's note:] The translator has slightly modified the pronouns in the last two sentences in this paragraph in order to make the overall argument in this paragraph more consistent.

89 [Translator's note:] The original version gave this as Section 2.I4; it is actually the following section.

90 [Translator's note:] The Scottish philosopher David Hume (I7II-I776) expressed skepticism for the idea that the bundle of thoughts and impressions in a person's mind at any given time constituted a unitary and well-defined self.

9I [Translator's note:] Because the literal meaning of the English word "individualism" does not share the decidedly pejorative connotations of the Chinese term gerenzhupi, I have translated the latter term as "a spirit of everyone out for himself" (and to the Devil the hindmost).

92 Liu Binyan, "Zouchu huanxiang," in Beijing zhi chun (U.S.), combined issue of December 1993 and January I994, p. 22. [Translator's note:] By signing the copies of his Rightist Verdict, Liu Binyan was acknowledging his new label as a thought criminal.

93 [Translator's note:] In the PRC under CCP rule, a person who is pejoratively labeled by the authorities is considered to have been "capped" by them.

94 [Translator's note:] The "tail" and "burden" refer generally to a remoldee's negative ideological baggage and non-Communist ideas that they inherited from the "bad old society" in China prior to "Liberation," or the CCP's military victory and rise to a monopoly of authority over mainland China in 1949.

95 [Translator's note:] Much like its imperial antecedent during the Qing dynasty, the "Other Register" lists local people whom the PRC Party-state has considered disreputable and untrustworthy.

96 [Translator's note:] The Hungarian author and journalist Arthur Koestler (1905-I983) wrote his most famous novel, Darkness at Noon, in I940.

97 [Translator's note:] Nie Gannu (1903-1986) was an independent-minded PRC essayist.

98 [Translator's note:] Creon, the tyrannical ruler who succeeded King Oedipus in Sophocles' (495-406 BCE) play Antigone, indeed condemned Antigone to death and confined her in a cave without providing her with any food. However, Antigone committed suicide, and thus was not actually executed by anyone.

99 [Translator's note:] Hegel's "pure will of all" refers to the accepted conventions of society in general.

I0० [Translator's note:] The famous Han dynasty historian Sima Qian (ca. I45-86 BCE) wrote the classic autobiographical prose piece "Letter to Ren An" in 93 BCE.

IOI [Translator's note:] Zhang Xianliang (b. I936) wrote the novel Mimosa in I984; it came out in English translation the following year.

IO2 [Translator's note:] Alexei Tolstoy (I882-I945) was a Soviet Russian novelist.

I03 [Translator's note:] Ding Ling (pseudonym of Jiang Bingzhi, I904-I986) was a major PRC novelist who was severely punished for two decades as the alleged leader of a socalled "anti-Party clique." 
IO4 [Translator's note:] When undergoing punitive exile to the northwestern grasslands as a rightist, Qu Xiao spent a number of years herding horses, and thus emerged his jocular characterization as a "horse herder."

I05 [Translator's note:] According to the logic behind this Confucian distinction, if the monarch is virtuous and capable, then anyone who kills him is committing the worst sort of heinous crime. However, if the monarch is incompetent and lacking in virtue, then to kill him is as wholly justifiable as to kill any other guy who amounts to a petty rogue.

Io6 [Translator's note:] A key Confucian exemplar was the Duke of Zhou, who served as regent to an early Zhou dynasty monarch a good millennium before the Common Era.

IO7 [Translator's note:] During the latter half of the I96os, the self-styled dialectical materialist, Mao Zedong, showered praise upon his brainchild, the "Great Proletarian Cultural Revolution," as a "big campaign that touches people to their very souls."

Io8 Ruth Benedict, The Chrysanthemum and the Sword: Patterns of Japanese Culture (Boston: Houghton Mifflin Company, I946), p. 233.

I09 [Translator's note:] Richard Pierce and Margaret Singer are social scientists who have written about coercive persuasion, of which PRC thought remolding is an example.

IIo [Translator's note:] Ambrose Yeo-ji King (Jin Yaoji, b. I935) is a sociologist of Weberian bent. King's academic positions were capped by a stint as Vice-chancellor of the Chinese University of Hong Kong (2002-2004).

III [Translator's note:] These remarks by the famous sociologist Fei Xiaotong refer to events occurring in the PRC around the middle of the 2oth century.

II2 Pei Wenzhong, Zhang Zhizhong, Wu Han, Feng Youlan, Wang Yunsheng, Ye Qianyu, Fei Xiaotong, Luo Changpei, Xiao Qian, Li Ziying and Xie Fengwo, Wode sixiang shi zenyang zhuanbian guolaide, pp. 74-75.

II3 Yang Jiang, Xizao, p. 207. [Translator's note:] This novel, Bathing, has been translated into English as Baptism.

II4 [Translator's note:] The reference is to German philosopher Ludwig Feuerbach (1804$1872)$.

II5 [Translator's note:] The Yan'an Rectification Movement began in 1942 in northern Shaanxi.

II6 Xiao Qian, "Yige lao zhishifenzi de xinjing sumiao," in Zhe yeshi lishi (Hong Kong: Oxford University Press, I993), p. 2 IO.

II7 [Translator's note:] The Herdsman (Muma ren, I982), a film directed by Xie Jin (19232008), was based on a short story by Zhang Xianliang entitled "Body and Soul" (Ling yu rou, 1980).

II8 [Translator's note:] The "Five Black Categories" established during the Mao Era included rural landlords, rich farmers, counterrevolutionaries, bad elements and rightists - along with their children. The "Seven Black Categories" that became especially prominent during the Cultural Revolution included those five types of miscreants plus capitalists and "stinking number nines" (reactionary academic authorities).

II9 [Translator's note:] The quotation is from Section 2.7.

I20 [Translator's note:] This is an old Chinese proverb about how easily communication can break down between well-educated degree holders and minimally educated soldiers and other working-class types.

I2I [Translator's note:] For example, see Robert Jay Lifton, Thought Reform and the Psychology of Totalism, pp. 36I-367.

I22 See Guwen guanzhi, vol. 2, ed. Wu Chucai and Wu Tiaohou (Beijing: Zhonghua shuju, I978), p. 43I. [Translator's note:] The English translation here is from Ronald C. Egan, The Literary Works of Ou-yang Hsiu (1007-72) (Cambridge: Cambridge University Press, 1984), pp. 72-73. 
I23 Xiao Qian, "Yige lao zhishifenzi de xinjing sumiao," p. 2І6.

I24 Xiao Qian, "Yige lao zhishifenzi de xinjing sumiao," p. 2I7.

I25 [Translator's note:] Pang Xunqin (I906-I985) was a famous Chinese painter.

I26 [Translator's note:] Cheng Yingliu (I916-I994) was a noted Chinese historian.

I27 Quoted from Cheng Zhaoqi, "Zhuxin de shilu," in Minzhu Zhongguo (Japan), February I994, p. 53.

I28 [Translator's note:] The Beijing student demonstrators were indignant about a 26 April I989 editorial in the CCP newspaper People's Daily that had mischaracterized a peaceful and orderly student march in Beijing as "turmoil."

I29 Hu Ping, Zhesi shouzha (Taipei: Yuanshen chubanshe, I987), pp. 33-34.

I30 [Translator's note:] Wu Zuguang (I9I7-2003) was a noted playwright who was unusually outspoken about the rampant use of censorship by the PRC Party-state.

I3I Wu Zuguang, "Zhangwo ziji de mingyun," in Dushu (Beijing), November I994, p. 57.

\section{Chapter 4}

I [Translator's note:] The quotation marks suggest that Hu Ping is citing something he wrote previously.

2 [Translator's note:] During the first few years of the Cultural Revolution in the late I960s, mention of "young generals" is usually a reference to Red Guards.

3 [Translator's note:] Liu Shaoqi (1900-1969) initially presented this treatise about how to transform yourself into a good Chinese communist as a group of lectures delivered at Yan'an's Institute of Marxist-Leninism during the summer of I939. It soon became a major component of the indoctrination materials circulated among CCP members, especially new recruits.

4 [Translator's note:] The "Incantation of the Golden Fillet" refers to a magical phrase used by the head Buddhist monk Tripitaka to control and discipline his disciple Monkey (Sun Wukong) by painfully constricting the metal fillet or headband around the latter's head in Wu Cheng'en's (ca. I500-I582) I6th-century novel Journey to the West.

5 [Translator's note:] As the Party's personnel wing, the CCP Organization Department has routinely appointed Party generalists without specialized training to head up institutions manned by those with such professional training, such as universities and state-owned enterprises. The CCP insists that generalists should reign over specialists.

6 [Translator's Note:] These "favorite sons" were mainly the younger male relatives of medium-level and high-ranking Party officials, especially their sons. The highest-ranking sons among this privileged group with inherited elite status are sometimes referred to as "princelings" of the Party-state. The first princeling slated to hold the job of paramount leader of the PRC Party-state is Xi Jinping (b. 1953), National Chairman (Guojia zhuxi, usually mistranslated as "President"), starting in $20 \mathrm{I2}$.

7 [Translator's Note:] The phrase in quotation marks is part of the CCP's formulaic verdict on Lin Biao. Lin Biao's alleged attempt to escape to the USSR in I97I failed, as there were no survivors from the crash of his military jet into the remote steppe lands of the Republic of Mongolia, or Outer Mongolia. Furthermore, Lin Biao's alleged escape attempt is more understandable as a desperate move to escape an imminent harsh purge by Mao Zedong than as some sort of carefully orchestrated rebellion against the Party.

8 [Translator's note:] Any further mention of "the Great Leader" in the book is a reference to Mao Zedong unless otherwise indicated. Just as Benito Mussolini reveled in the title of "Il Duce" and Adolph Hitler basked in the title of "Führer," Mao Zedong gloried in the title of "Great Leader" (weidade lingxiu). 
9 [Translator's note:] The locus classicus of the time-honored phrase, "the preservation of heavenly principles and the elimination of human desires," is the Northern Song Neo-Confucian philosopher Cheng Yi (I033-IIO7).

Io [Translator's note:] This traditional Chinese proverb has been quoted in the fiction of PRC writers such as Gu Ligao (1923-2007).

II [Translator's note:] During the Cultural Revolution, everybody was supposed to gaze reverently at a portrait of Mao Zedong at least twice daily, asking him for instructions in the morning and reporting on the day's activities in the evening. This resembles a religious novice's daily request to a saint or other senior holy figure for the latter's blessings.

I2 [Translator's note:] Some of these novels that had met with denunciation by Party propagandists had been published before the Cultural Revolution or even prior to I949; others were hand-copied volumes.

I3 [Translator's note:] Literally, "white and professional," whereby "white" is shorthand for "reactionary."

I4 [Translator's note:] Literally, "only professional, but not red," whereby "red" is shorthand for "revolutionary."

I5 [Translator's note:] This is a reference to Section 2.8.

I6 [Translator's note:] As one of the PRC government's mechanisms for maintaining control over discourse and thought, the Party-state vets and distributes lists of approved concepts and formulations [tifa 提法] to supervisory personnel in the media and publishing circles.

I7 [Translator's note:] The "Four Upholds" were written into the I982 PRC constitution, and have been given a de facto interpretation as trumping all of the freedoms of speech, press, speech and assembly that were set out in Article Thirty-five. The Four Upholds include the "leadership" (monopolistic control) of the CCP, the "socialist path," Marxist-Leninism and Mao Zedong Thought and the notoriously oxymoronic notion of the "people's democratic dictatorship."

I8 [Translator's note:] Ever since the founding of the CCP regime, a giant portrait of Mao Zedong has been prominently displayed in the central square of the PRC's capital, much as a giant portrait of North Korea's founding dictator Kim Il-Sung has been continuously on display in the central square of Pyongyang, the DPRK's capital.

I9 [Translator's note:] Karl Marx, Rheinische Zeitung für Politik, Handel und Gewerbe, no. I35 (I5 May I842). See also http://www.marxists.org/archive/marx/works/I842/freepress/cho5.htm.

20 Tuokeweier [Alexis de Tocqueville, I805-1859], Lun Meiguo de minzhu, xiajuan, trans. Dong Guoliang (Beijing: Shangwu yinshuguan, I993), p. 673.

2I [Translator's note:] Deng Lijun was a sentimental pop singer from Taiwan who became immensely popular in the PRC during the early decades of the post-Mao era.

22 [Translator's note:] During Deng Xiaoping's rule, the Party-state launched propaganda campaigns against "spiritual pollution" (October-December I983) and "bourgeois liberalization" (January 1987-Spring 1988), both of which targeted Western and other "bourgeois" cultural and political influences.

23 [Translator's note:] Charter 77 was a Czechoslovakian dissident grass-roots campaign for human rights and constitutional governance that the playwright Vaclav Havel (1936-20II) helped organize in 1976 and launch in 1977 in the wake of the Helsinki Accords. Havel was imprisoned for a number of years after a period of being kept under surveillance by the authoritarian communist regime of Czechoslovakia.

24 [Translator's note:] Friends and especially relatives of a person who had been labeled a thought criminal by the CCP regime were commonly pressured by the Party-state to "draw a clear line of demarcation" between themselves and the demonized culprit. Though this sort of pressure has never been absent from the PRC, it reached its ze- 
nith during the Anti-Rightist Campaign of 1957-1958 and the Cultural Revolution of 1966-1976.

25 [Translator's note:] Jan Hus (ca. I369-I4I5) was a Czech religious reformer who was burned at the stake as a heretic by the Catholic Inquisition. "Sancta Simplicitus!" is Hus's Latin phraseology, in Czech, it is Svatá prostota!

26 [Translator's note:] The English version of the letter from Joseph Brodsky (I940-1996) is at this URL: http://www.nybooks.com/articles/archives/r994/feb/I7/the-post-communist-nightmare-an-exchange/?page $=\mathrm{I}$

27 Buluociji, Haweier [Joseph Brodsky and Vaclav Havel], Guanyu hou gongchanzhupi emeng de zhenglun, in Qingxiang [Hong Kong], no. I (I994): I62.

28 [Translator's note:] Wojciech Jasinski (b. I948) is a Polish diplomat and human rights proponent.

29 Wawensa [Lech Walesa], "Xiang renquan doushi Fang Lizhi zhijing," in Zhongguo zhichun [U.S.] (Jan. 1990).

30 [Translator's note:] That is, silent indignation could be transformed into tacit consent.

3I See the extracts of the dialogue of Li Zehou and Liu Zaifu, "Benmo daozhi de shiji," in Zhongshi zhoukan [Taiwan], nos. I47, I48, I49.

32 [Translator's note:] The Manchu writer Lao She (1899-1966) satirized the use of this admonition against discussing national affairs in his three-act play Teahouse (I957).

33 Tuokeweier [Tocqueville], Lun Meiguo de minzhu, xiajuan, trans. Dong Guoliang (Beijing: Shangwu yinshuguan, I993), p. 630.

34 Ibid.

35 [Translator's note:] Hu Ping inserts a parenthetical question mark "(?)" after the word "liberalist," possibly suggesting that Yan Jirong's self-characterization as a liberalist is doubtful.

36 Yan Jirong, "Zhengzhi lengmo shibushi huaishi," in Dushu [Beijing] (Oct. I995), p. 78.

37 [Translator's note:] Those who can read Chinese may wish to consult Hu Ping's essay at the following URL: https://sites.google.com/site/hupingwenji/book/minyun

38 [Translator's note:] The three lines quoted are from an anonymous and undated Chinese folk poem written well before the first unification of China in 22I BCE. The subsequent line about ruling through inaction is taken from Laozi's 6th-century BCE Daoist classic, The Way and its Power.

39 Hu Ping, Zhongguo minyun fansi (Hong Kong: Niujin Daxue chubanshe, 1992), p. I64.

40 [Translator's note:] Deng Xiaoping (I904-I997) first issued his formal command, "No Arguing," in the PRC about issues such as whether the CCP's economic reforms were socialist or capitalist during his 1992 nanxun or Imperial Progress to the South especially Guangdong province.

4I [Translator's note:] The maxim in favor of focusing on practical results (e.g. micecatching) instead of evaluating the features of the participants who achieve those results (e.g. a white cat and a black cat) was repeated on numerous occasions by Deng Xiaoping since he first said it in I962. However, a much lower-ranking CCP official is reported to have uttered exactly the same black-cat, white-cat remark in I96I, a year earlier than Deng first said it. See Roderick Macfarquhar and Michael Schoenhals, Mao's Last Revolution (Cambridge: Belknap Press of Harvard University Press, 2006), p. 69 .

42 Wang Meng, "Buzhenglun de zhihui," in Dushu [Beijing] (June I994).

43 Chen Kuide, "Yingjie xin zhuzi shidai," in Minzhu Zhongguo [U.S.], no. 26.

44 [Translator's note:] Some Chinese with political grievances have utilized slogans of the Extreme Left to rebuke the Party-state - not that they actually believe in Extreme Leftist thought (i.e. the cup of liquor), but because it is relatively safe to use Extreme Lef- 
tist rhetoric. Their aim is actually to criticize the present CCP regime. The "No Arguing" directive clamps down on even Extreme Leftist rhetoric, thus leaving aggrieved citizens with practically no outlet for venting their political frustrations.

45 [Translator's note:] The essays of Lu Xun (I88I-I936) were famous for sardonic comments such as this.

\section{Chapter 5}

I [Translator's note:] The prominent literary essayist and commentator Hu Feng (1902I985) was denounced and jailed as the head of an enemy "counterrevolutionary clique" by the Party-state in I955 for having published a 300,000-word report that was critical of Mao Zedong's excessive regimentation and control of PRC art and literature. Hu Feng served his 25-year prison sentence before being exonerated and released in I980. Also, over sixty of his "clique" associates were sentenced to imprisonment in labor camps.

2 [Translator's note:] Internal circulation refers to readings that are circulated only within a limited circle of individuals instead of by means of free and open public dissemination.

3 [Translator's note:] Aleksandr Solzhenitsyn (1918-2008) received the Nobel Prize in Literature in 1970 for such masterpieces as the prison-camp novel One Day in the Life of Ivan Denisovich (1962).

4 [Translator's note:] This sentence refers to a Io,०००-word private letter Marshal Peng Dehuai (I898-I974) wrote Mao Zedong in I959 to recommend Mao's abandonment of Great-Leap-Forward policies that were causing acute economic privation and even starvation in the countryside. Mao angrily publicized and denounced Peng's letter at a major Party congress in Lushan that same year, and Peng was soon stripped of all his posts in the military and Party. Peng Dehuai was punished severely, especially during the Cultural Revolution, when he was frequently tortured and "struggled" while imprisoned.

5 [Translator's note:] Rosa Luxemburg (I87I-I9I9) was a Polish communist who became a naturalized citizen of Germany, where she co-founded the leftist anti-war Spartacus League in I9I5. Though echoing Marx's call for a "dictatorship of the proletariat," Luxemburg criticized the Russian Bolshevik or Leninist model of a one-party dictatorship as unnecessarily restrictive toward dissenting views.

6 [Translator's note:] "Rebelling is justified" was probably the most widely mouthed four-sinograph slogan uttered during the Cultural Revolution.

7 [Translator's note:] The Party-state's two major violent crackdowns on nonviolent protestors in or near Tiananmen Square took place in April I976 and June I989.

8 [Translator's note:] This traditional proverb indicates that an emperor or paramount leader would typically have little idea of what was actually taking place on the ground throughout his vast empire.

9 [Translator's note:] This is a meteorological metaphor for corrupt officials - especially at the local level of government - abusing their power and deceiving the emperor.

Io [Translator's note:] In this paragraph, "the emperor" should be understood figuratively to refer to the paramount leader in the Chinese government - who in the single-party Leninist authoritarian regime of the PRC is also always the top CCP leader.

II [Translator's note:] Li Qinglin (1936-2004) was an obscure primary schoolteacher in a small Fujianese town before catapulting to fame as a result of his letter to Mao Zedong.

I2 [Translator's note:] Mao Zedong's slogan of "going against the tide" [fan chaoliu] marked the campaign he launched in I973 in order to revive the Cultural Revolution's 
crusade against "Rightist adverse currents," "revisionism," and other bête noires of Maoist radicalism.

I3 [Translator's note:] Zhang Tiesheng (b. I950) leaped into the national spotlight as a model of "going against the tide" after Mao Zedong publicly lauded him for having dared to hand in a blank answer sheet for the chemistry portion of his 1973 college entrance exam in Liaoning province. Huang Shuai (b. I96I) became a poster girl for "going against the tide" after her 1973 denunciation of what she saw as reactionary educational methods were printed in the Beijing Daily and lauded by Jiang Qing and other radicals around Mao Zedong.

I4 [Translator's note:] The pen-name Li Yizhe is a composite of the three co-authors of the famous poster in downtown Guangzhou in November 1974: Li Zhengtian (b. I942), Chen Yiyang (b. I947), and Wang Xizhe (b. I948).

I5 [Translator's note:] The Fourth National People's Congress, largely a rubber-stamp and ceremonial legislative organ, was in session from I975 to I978. Its one and only plenary session was held in January I975. Dedicating the Li Yizhe poster to the Fourth National People's Congress was a way to signify that the poster writers remained loyal supporters of the PRC government in spite of having outspokenly criticized the Cultural Revolution.

I6 [Translator's note:] The astrophysicist Fang Lizhi (I936-20I2), the poet Bei Dao (pseudonym of Zhao Zhenkai, b. 1949), and the essayist and activist Chen Jun (b. I958) were among the dozens of intellectuals in Beijing who early in 1989 petitioned the government to release the dissident Wei Jingsheng (b. 1950) from prison. By this time in the spring of 1989 , Wei Jingsheng had already been locked up as a political prisoner for a full decade - two-thirds of the draconian I5-year term that he wound up serving.

I7 [Translator's note:] Ordinary citizens are contrasted here with Party cadres such as Peng Dehuai.

I8 [Translator's note:] Mao Zedong's first high-profile promotion of the slogan, "Rebelling is justified," was in early August I966 during the Eleventh Plenum of the CCP Central Committee.

I9 [Translator's note:] The Democracy Wall Movement took place from November 1978 to December 1979 in the Xidan district in central Beijing, as well as at similar central urban sites in various other cities such as Guangzhou, Shanghai and Wuhan. Participants in the movement would have continued with their critiques of despotism and lawlessness and calls for human rights and justice if the Party-state under Deng Xiaoping had not stepped in to shut the movement down forcefully in December I979, arresting anyone who attempted to continue or revive it.

20 [Translator's note:] Many commentators during the post-Mao cultural thaw of the late I970s and early I980s called for the "emancipation of thought" from the rigid emphasis upon class struggle and other outworn ideological imperatives that characterized the Cultural Revolution.

2I [Translator's note:] For further discussion of the concept of "the preservation of heavenly principles and the elimination of human desires," see Section 4.4.

22 [Translator's note:] The "Grand Inquisitor" chapter of Fyodor Dostoevsky's famous novel about the murder of the head of a fascinating I9th-century Russian family is one of the Western literary tradition's most memorable parables.

23 [Translator's note:] Deng's concept of "socialism with Chinese characteristics" could be more accurately described as "state-guided capitalism" or "market-oriented Leninism." Yet the latter two terms stray too far from the CCP's ideological inheritance, and thus have been passed over in favor of Deng's intentionally vague formulation.

24 [Translator's note:] The Monash University economist Yang Xiaokai (pseudonym of Yang Xiguang, I948-2004) spent a decade in prison (I968-1978) as punishment for 
having written and circulated the aforementioned pamphlet as a Red Guard in I967. Yang argued in his pamphlet that the genuine conflict in the PRC was mostly between the "new red class" of CCP cadres and ordinary PRC civilians - not, as had been generally claimed, between Mao Zedong and the so-called "capitalist roaders" (or "revisionists") within the Party.

25 [Translator's note:] The "New Era" is a PRC "Newspeak" term often used to refer to the post-Mao era.

26 [Translator's note:] This statement comes from Mao Zedong.

27 [Translator's note:] Maoism's "five black categories," which could be paraphrased as the five evil political identities, are village landlords, rich farmers, counterrevolutionaries, bad elements and rightists.

28 [Translator's note:] These "revisionists" are the German social democratic theorist Eduard Bernstein (I850-I932), the Czech-German philosopher and politician Karl Kautsky (I850-I932), the Yugoslavian leader Josip Tito (I892-I980), the Soviet leader Nikita Krushchev (I894-I97I) and the Soviet leader Leonid Brezhnev (I906-I982).

29 [Translator's note:] After an extended period of silence about Marshal Lin Biao's sudden disappearance from the PRC political scene in mid-September I97I, official PRC media outlets claimed that the PLA Marshal had attempted to assassinate Mao Zedong in an unsuccessful coup plot on September I3th, and had died later that day in a plane crash in Outer Mongolia while trying to escape to the Soviet Union.

30 [Translator's note:] The "Five-Seven-One Project" was allegedly a code-based scheme for Lin Biao and his cronies to assassinate Mao Zedong and take over the leadership of the Party-state. "Five-Seven-One" is a pun on the phrase, "armed uprising."

3I [Translator's note:] Mao's formerly private letter to Jiang Qing expressed doubt about Lin Biao's loyalty long before the latter's alleged assassination attempt on Mao in I97I. The regime appears to have hoped that the publication of this letter would assuage the populace's growing skepticism about Mao's discernment and ability as a leader, but it did not appear to have the desired effect.

32 [Translator's note:] "Phony politics" was epitomized by the radical politics of the Cultural Revolution's most avid proponents, such as Mao and his "Gang of Four."

33 [Translator's note:] "Stinking Old Number Nine" refers to the unusually low social status to which much of the Chinese intelligentsia had sunk during the Yuan dynasty (I279-1368) and the Mao Era (I949-1976).

34 [Translator's note:] The PRC Fourth National People's Conference was held in January I975.

35 [Translator's note:] The "Gang of Four," the top-ranking radical proponents of Mao's Cultural Revolution, were arrested and imprisoned about a month after Mao's funeral in September 1976. The CCP "Whateverist Faction" insisted that whatever Mao had said and advocated was entirely correct; it was led by Mao's successor, Hua Guofeng, who was already playing second fiddle to Deng Xiaoping by December 1978. Hua lost his remaining significant posts in the government during I980 and I98I to protégés of Deng.

36 [Translator's note:] In reaction to widespread suffering from Mao Zedong's extreme over-indulgence in stirring up ideological struggle during the Cultural Revolution, the new Deng Xiaoping leadership took as its watchword the pragmatic formulation, "Practice is the sole criterion for determining the truth."

37 [Translator's note:] A "cowshed" refers to any improvised lock-up used during the Cultural Revolution to confine targets of persecution on an informal, extralegal basis.

38 [Translator's note:] The book was originally published as V.I. Lenin, Materialism and Empirio-criticism: Critical Comments on a Reactionary Philosophy (Moscow. Zveno Publishers, 1909). 
39 [Translator's note:] Mao Zedong's speech at the 7000 Cadres Conference of 1962 was less self-important and dogmatic than usual, for he made a rare admission of having erred in some aspects of the Great Leap Forward's implementation. At the same time, it is doubtful how sincere Mao was about even his tepid self-criticism here, for he expressed his avid approval for Lin Biao's speech at the same conference; Lin had gone to great lengths to shower Mao with fulsome praise.

40 Solzhenitsyn, Gulage qundao, shangce, trans. Chen Hanzhang and Tian Dawei (Beijing: Qunzhong chubanshe, 1982), p. 352.

4 I [Translator's note:] The Cultural Revolution's slogan about cow demons and snake spirits is a call for dealing out harsh punishment to anyone who was ideologically "incorrect" or had a bad or "black" class background.

42 [Translator's note:] Francis Fukuyama (b. I952) puts forward this somewhat Hegelian argument about the final ascendancy of liberal democracy in his book, The End of History and the Last Man (New York: Free Press, I992).

43 Thomas Sowell, "The Road Back to Serfdom," cited in He Xinquan, Haiyeke ziyou lilun yanjiu (Taipei: Lianjing chubanshe, I988), p. 202.

\section{Chapter 6}

I [Translator's note:] The remark comes from the British philosopher John Stuart Mill (1806-1873).

2 [Translator's note:] Wang Fuzhi (I6I9-1692) was a great scholar and philosopher within the humanistic soft-authoritarian tradition of Confucian statecraft. Shen Buhai (ca. 385-337 BCE) and Han Fei Zi (ca. 280-233 BCE) were both leading advocates of the rival hard-authoritarian Legalist school, which emphasizes controlling the populace through the strict enforcement of often harsh laws, along with concentrating an immense amount of power around the ruler and wielding that power aggressively. Shen Buhai is best known for his Legalistic approach to statecraft when serving as prime minister of the pre-imperial state of Han. Han Fei $\mathrm{Zi}$ is famous for his codification of Legalist doctrines in his treatise, the Han Fei Zi. The subordinates' turning to the relatively otherworldly or ethereal traditions of Buddhism and Daoism is a sign of their disillusionment with a hard-authoritarian Legalist socio-political order.

3 Irving Howe, A Margin of Hope: An Intellectual Autobiography (New York: Harcourt Brace Jovanovich, 1982).

4 [Translator's note:] Leonid Brezhnev (I906-I982) was the top authoritarian leader of the USSR during the Brezhnev Era (1964-1982).

5 [Translator's note:] Hedrick Smith (b. 1933) was a correspondent for the New York Times and the author of The Russians, rev. ed. (New York: Ballantine Books, I984).

6 [Translator's note:] Wang Zhen (I908-1993) and Deng Xiaoping made comments along these lines in 1989 .

7 [Translator's note:] For example, the GMD censorship of the media was much less thorough and strict than that of the CCP once it seized national power in I949.

8 [Translator's note:] Chen Yun (pseudonym of Liao Chenyun, 1905-1995) was known as a leading economic planner in the PRC Party-state.

9 [Translator's note:] Internal-circulation documents such as this memo from Chen Yun have often been leaked to Chinese-language media outlets in Hong Kong or overseas, for they could not be published in the Party-supervised media of the PRC.

Io [Translator's note:] CCP denunciations of the GMD peaked in the mid-to-late I940s, and could find airings in the Chinese press due to the fact that GMD-regime censorship was spottier and less thorough than CCP-regime censorship has been. 
II [Translator's note:] The "Soviet and Eastern European Incidents" is equivalent to what is known in the West as "the fall of the Berlin Wall" - the collapse of the various single-party Leninist authoritarian regimes throughout the former USSR and the rest of Eastern Europe, and their replacement by elected governments of a largely parliamentary or democratic nature. To be sure, some of the former "Soviet republics" in Central Asia and in places like Belarus have remained largely authoritarian in their manner of rule in spite of either the absence or the marginalization of the formerly allpowerful communist party.

I2 "Sulian jubian zhihou Zhongguo de xianshi yingdui yu zhanlüe xuanze" was an essay written by the bureau, Sixiang lilunbu, of the newspaper agency Zhongguo qingnianbao, for internal circulation only. It was reprinted in its entirety in Zhongguo zhi chun (Jan. I992). The "Soviet Union Incident" refers to events contributing to the breakup of the Soviet Union in I99I. The author of this essay remains anonymous.

I3 [Translator's note:] The "Gang of Four" collapsed in 1976, and Deng Xiaoping had consolidated his leadership of the Party-state by November I978, having marginalized the transitional leader, Hua Guofeng.

14 Ibid.

I5 [Translator's note:] This volume is also known as Mao Zedong's Little Red Book.

I6 [Translator's note:] George Orwell (I903-I950), Animal Farm: A Fairy Story (London: Secker and Warburg, 1945).

I7 Qiaozhi Aoweier, Dongwu zhuangyuan, trans. Zhang Yi and Gao Xiaoxian (Shanghai: Renmin chubanshe, 2000), p. I23.

I8 Lucian W. Pye, "China: Erratic State, Frustrated Society," Foreign Affairs 69.4 (Fall I990), p. 6r.

I9 Luo Su, Quanlilun - xinshehui fenxi, trans. Wu Yousan (Beijing: Shangwu yinshuguan, I99I), p. 69.

20 [Translator's note:] The Shekou Special Economic Zone is in Shenzhen, Guangdong. This is not far from the border with the New Territories of Hong Kong.

2I Hannah Arendt, The Origins of Totalitarianism (New York: Harcourt, Brace, Javanovich, Inc., I973), p. 384.

22 [Translator's note:] The traditional Chinese proverb about trying to pass dog meat off as mutton to an unsuspecting customer describes a situation of knowingly deceiving someone in order to profit at his expense.

23 [Translator's note:] The term for Deng's 1992 southern tour, nanxun, is identical to that used only by Chinese emperors for their royal or imperial tours of the south.

24 [Translator's note:] Beijing's Democracy Wall Movement began in November 1978, but was shut down in December 1979 by the Party-state after barely a year in operation.

25 [Translator's note:] Urban university campuses were temporarily selected as sites for experimenting with grassroots elections at the beginning of the Deng era. Most subsequent PRC experiments with grassroots elections have been limited to rural villages.

26 [Translator's note:] Although Mao Zedong urged the intelligentsia to criticize the government's shortcomings so that the latter could be addressed during the Hundred Flowers Campaign, after people did so he launched the Anti-Rightist Campaign to punish those who had spoken out.

27 [Translator's note:] The Mao-era CCP's approach of providing only one escape route is analyzed in Section 3.I.

28 [Translator's note:] The original term for "hipster" in Chinese is wanzhu.

29 [Translator's note:] Wang Shuo (b. 1958) is a Beijing-based novelist and scriptwriter.

30 [Translator's note:] This is a Chinese variation of the English-language proverb about throwing out the baby with the bath water (once the bath water has become dirty from repeated use). 
3I [Translator's note:] The reference to the "conquest and domination of a country" refers to what the CCP has done since the late I940s.

32 [Translator's note:] Chen Kuide (b. I946) is a well-known scholar and activist.

33 [Translator's note:] Cui Zhiyuan (b. 1962) is a professor at Tsinghua University.

34 [Translator's note:] Deng Liqun (b. I9I5), a Maoist ideologue, is a retired high cadre.

35 [Translator's note:] Edmund Burke (I729-I797) was a conservative Anglo-Irish political theorist and philosopher. Yan Fu (I854-I92I) was a Chinese scholar and translator. Friedrich Hayek (I899-I992) was an Austrian economist and philosopher.

36 [Translator's note:] The PRC criminal code substituted "endangering state security" for "counterrevolution" in the mid-I99os.

37 [Translator's note:] The original phrase is quoted from a narrative classic written over 2000 years ago, and refers to the way a tangerine sapling from south of the Huai River would supposedly turn into a citron tree if transplanted north of the Huai River.

38 [Translator's note:] This contemporary Chinese proverb illustrates how local PRC officials often give mere lip service to central government policy - if not ignoring it altogether - when such policy seems to go against their own local interests.

39 Lucian W. Pye, "China: Erratic State, Frustrated Society," Foreign Affairs 69.4 (Fall I990), p. 59.

40 [Translator's note:] The National People's Congress is the PRC's largely ceremonial parliamentary organ.

\section{Chapter 7}

I [Translator's note:] Albert O. Hirschman (b. I9I5), Exit, Voice, and Loyalty: Responses to Decline in Firms, Organizations, and States. Cambridge: Harvard University Press, I970).

2 Suoernirenqin [Solzhenitsyn], Gulage qundao, shangjuan, trans. Chen Hanzhang and Tian Dawei (Beijing: Qunzhong chubanshe, I982), p. I37.

3 [Translator's note:] The CCP has a pro forma requirement that applicants for Party membership must first prove their mettle before being allowed entrance into the Party. However, this requirement can sometimes be waived if the applicant has good personal connections or skills that the Party is anxious to bring into its ranks.

4 [Translator's note:] Party members have often cited the vague and sweeping phrase, "the requirements of the revolution," to justify a plethora of special perquisites that are not available to ordinary civilians outside of the Party.

5 [Translator's note:] The widespread phenomenon of joining the Party in order to become an official is similar in spirit to the traditional Chinese saying: "Get rich by becoming an official" [zuoguan facai].

6 [Translator's note:] The "eight-legged essay" was a type of prose that successful candidates for imperial China's civil service exam needed to master during the last several centuries that this examination system was in effect, i.e. the Ming-Qing period.

7 [Translator's note:] The phrase "the Party's dominion over the entire country" [dang tianxia] reflects the actual situation in which the CCP utterly dominates the PRC government as well as riding herd on Chinese society. However, it is an unofficial phrase that cannot be used in public without the risk of harsh punishment by the Party-state.

8 [Translator's note:] Fan Liqin (b. I944) was a classmate of Deng Pufang (Deng Xiaoping's eldest son, b. I943) at Beijing University before and during the Cultural Revolution, when both were attacked verbally and physically and imprisoned by Mao Zedong's Red Guards. Fan later joined the faculty at Beijing University.

9 Cited in Hu Ping, Wang Juntao, et al., Kaituo - Beida xueyun wenxian (Hong Kong: Tianyuan shuwu, I990), p. 294. 
IO [Translator's note:] Fang Lizhi (I936-20I2) is an internationally renowned astrophysicist and political dissident who is sometimes likened to Andrei Sakharov (I92I-I989).

II [Translator's note:] For making comments that were similarly critical of CCP authoritarianism, Wei Jingsheng received a 15-year prison term in 1979, while Fang Lizhi was merely expelled from the Party in 1987.

I2 [Translator's note:] Yue Daiyun (b. I93I) and Carolyn Wakeman, To the Storm: the Odyssey of a Revolutionary Chinese Woman (Berkeley: University of California Press, I985).

I3 [Translator's note:] That is, your only choice is between agreeing to a request or else following a command.

I4 [Translator's note:] The eminent scholar had no official rank or post, and thus was at a disadvantage once the narrow-minded magistrate decided to persecute him and his family.

I5 [Translator's note:] Qing dynasty (I644-I9II) officials kept lists known as "the other register" of imperial subjects whom they regarded as miscreants to watch out for, and the CCP regime has engaged in similar forms of blacklisting. PRC police and other security personnel draw upon such lists of suspect individuals in prioritizing their surveillance and control measures over the populace, subjecting such individuals to heightened measures of "domestic control."

i6 [Translator's note:] Albert O. Hirschman, Exit, Voice, and Loyalty (Cambridge: Harvard University Press, I970).

I7 [Translator's note:] Roger Bacon (I2I4-I294) was a British philosopher.

I8 Albert O. Hirschman, Exit, Voice, and Loyalty (Cambridge: Harvard University Press, I970), p. 82.

I9 [Translator's note:] Wang Ruowang (I9I8-200I) was a writer and political dissident.

20 [Translator's note:] Deng Liqun (b. I9I5) is a high-ranking Maoist propagandist. The adjectival puffery that the CCP has most commonly indulged in when engaging in braggadocio is "great, glorious and correct." This phrase has been attributed to the top-ranking Party ideologue Hu Qiaomu (I9I2-I992).

2I [Translator's note:] "Turmoil elements" is CCP jargon that denounces individuals who were involved in the Spring 1989 demonstrations in favor of liberty and democracy.

22 [Translator's note:] Chen Xitong (b. I930) had been Mayor of Beijing and a member of the Politburo before being forced to resign in 1995 due to charges of corruption. Chen received a I6-year prison sentence in 1998 , but was released in 2006 on medical parole.

23 [Translator's note:] Although there was no legal sanction or justification for having kept Zhao Ziyang under house arrest for the last sixteen years of his life (1989-2005), the Party has never been constrained by legal niceties, for it controls the government and is essentially above and beyond the law.

24 [Translator's note:] Beijing's Democracy Wall period extended from November 1978 to December 1979 .

25 [Translator's note:] The paraphrased couplet is from a poem by Yuan Zhen (779-83I).

26 [Translator's note:] Mancur Olsen, Jr. (I932-1998) developed rational choice theory. See his book, The Logic of Collective Action: Public Goods and the Theory of Groups, 2nd ed. (Cambridge: Harvard University Press, I97I).

27 J. S. Mier [J. S. Mill], Daiyizhi zhengfu, trans. Wang Xuan (Beijing: Shangwu yinshuguan, I984), p. 57.

28 [Translator's note:] Richard Cobden (I805-I865) was a liberal English statesman.

29 [Translator's note:] Some CCP elders such as Wang Zhen (I908-I993) directly referred to the concept of da jiangshan zuo jiangshan (ruling over the realm after having conquered it) as having undergirded the legitimacy of the CCP's unremittingly authoritarian rule over China. This mode of thought differs little from that of rebel leaders and 
dynastic founders over the past two millennia in imperial China. The main difference is in the mode of leadership succession, which is no longer from father to son, as in imperial China and contemporary North Korea.

30 [Translator's note:] China's eight democratic parties of "fellow travelers" that have been affiliated with the CCP ever since its civil war with the Nationalist government have been aptly characterized as "satellite parties" that revolve around the CCP, which monopolizes political power in the PRC at least as completely as the imperial court in the capital city did during previous dynasties. At most, the eight democratic parties exercise a consultative function when directed to do so by the ruling CCP - none of them has any ability at all to serve as a locus of political opposition or to have any other actual political clout in the face of the CCP's monopoly over political power in the PRC.

3I [Translator's note:] "Societal scale" refers to the size or scale of a given society or community, it is commonly used in connection with the impact that relatively large-scale societies or communities have on strategies for solving a given problem.

32 [Translator's note:] Regarding contract theory, see Russell Hardin, Indeterminacy and Society (Princeton: Princeton University Press, 2003).

33 [Translator's note:] The Public Security Bureau is the PRC's nationwide police force.

34 [Translator's note:] Francis Fukuyama, The End of History and the Last Man (New York: The Free Press, 1992).

35 [Translator's note:] Francis Fukuyama, The End of History and the Last Man (New York: The Free Press, I992), pp. I72-I73.

36 [Translator's note:] Francis Fukuyama, The End of History and the Last Man (New York: The Free Press, I992), pp. I73-I74.

37 Francis Fukuyama, The End of History and the Last Man (New York: The Free Press, I992), p. I62.

38 [Translator's note:] Plato (429-347 BCE), an ancient Greek philosopher, stood at the forefront of the tradition of Western thought.

39 Ibid., pp. I62-I63. [Translator's note:] Niccolò Machiavelli (I469-I527) was an Italian expert on statecraft; Thomas Hobbes (I588-1679) was a British philosopher; JeanJacques Rousseau (I7I2-I778) was a Franco-Swiss writer and philosopher; Alexander Hamilton (1755-I804) was an American economist and statesman; James Madison (I75I-I836) was an American statesman and constitutionalist; and Georg Hegel (I770I83I) and Friedrich Nietzsche (I844-I900) were German philosophers. Amour-propre means "self-esteem" or "self-respect."

40 [Translator's note:] Both of the quoted Chinese proverbs suggest that human beings typically seek recognition for their accomplishments.

4I [Translator's note:] Socrates (469-399 BCE) was a Greek philosopher and a teacher of Plato, but his ideas are only known from the accounts of others, as he left no writings of his own.

42 [Translator's note:] The thymotic part of the soul is its spirited or heroic component.

43 Fukuyama, The End of History and the Last Man, pp. I68-169.

44 Eric Hoffer, Reflections on the Human Condition (New York: Harper \& Row Publishers, I973), pp. 35-36.

45 Tuokeweier [Tocqueville], Lun Meiguo de minzhu, xiajuan, trans. Dong Guoliang (Beijing: Shangwu yinshuguan, I993), p. 653. 



\section{Index}

absolutism I95

absurdity 2I-22, 3I, 34

"academic authorities, bourgeois class" 92

accusations, groundless Io6

activists, fake 66

adjustment to change $\quad 6 \mathrm{I}-\mathrm{G}_{3}$

adversity, meek submission to I23I25

advertisements, commercial I4, I5

agrarian revolution 32

Ah Q 2I8

ambiguity, fact-based $\quad 47-50$

ambiguity, value-based 5I-53

Animal Farm 205-206

anonymous protest I8I

"anti-communism," suspicions of I4

Anti-Liberalization Campaign I83

Anti-Rightist Campaign 40, I76, I80, I94, 286, 298

anti-traditionalism $\quad 55-56$

anti-Western nationalism 2I9

anti-Western thought 3I-32

Antigone I20, 289

Antigone I20, 289

arbitrary justice 39

Arendt, Hannah 5I, I5I, 209, 282

"arguing," Deng's prohibition of I76-I77, 293-294

Aristotle 79

armed struggle, CCP's lengthy 2OI assassination attempt, alleged I92, 296

Auschwitz Io authoritarianism 48-49, I42-I43, I66, I68, I97, I99, 201, 204-205, 207-208, 2II, 2I6, 220, 222-225, 230, 234, 242, 247, 248, 250, 262, $27 \mathrm{I}$

authoritarianism, soft vs. hard 224225

autocracy 42, I74, I80-I8I, I82, I97 avant-garde art $\mathrm{I} 67$

Bacon, Roger 77, 240, 300

banalities of evil I5I

baptism, revolutionary I34

"bathing" I3-I4

Bathing I3, 38, 278

behaviorist psychology I6-I7

Bei Dao I83, 295

Beijing University 34

Benedict, Ruth I28

Bernstein, Eduard I9I, 296

bifurcated thought $42-43$

Big Bang Theory 167

Big Brother 148

bloodline theory $26-27,280$

boasting, governmental 89

"bourgeois educational line" 20

bourgeois vs. proletarian I5, I6, I920

bourgeois weltanschauung I6, I9-2I, $28, \mathrm{I} 32, \mathrm{I} 58, \mathrm{I} 88$

brainwashing I3-I4, 6I

Brainwashing 13

Brezhnev, Leonid I9I, 200, 296

bribery 224

Bright Sunny Skies 88, 287 
Brodsky, Joseph I70, I72, 293

Brothers Karamazov I86, 295

Bukharin, Nikolai II2-II3, 288

Burke, Edmund 219, 220, 299

burning books 37

burying scholars 37

by-product incentives $258-260$

Cao Cao 96

Cao $\mathrm{Yu} 88$, 90, I50-I5I, 287

Catholic Church 53, I69

Catholics II4

characteristics, Chinese I8

Charter 77 Movement I69, 292

chastity, an abducted woman's 93

Chen Duxiu 83, 286

Chen Jun I83, 295

Chen Kuide 219, 299

Chen Shizhong 24, 279-280

Chen Xitong 243, 300

Chen Yun 202-203, 297

Cheng Yingliu I47, 29I

Chinese Communist Party (CCP) I4, I8, I9, 23-24, 29, 39, 4I, 43-44, 84, 86-87, 89-90, 95-96, 97-99,

IO4-IO6, IO8-III, II2-II3, II4-II7, I2I, I22-I25, I27-I28, I29-I30, I32-I34, I44-I46, I55-I58, I67I68, I80, I83-184, I86-187, I93, I96-I97, 200-207, 208-210, 2182I9, 230-234, 235-236, 237-24I, 24I-245, 246-250, 25I, 254, 258259, 270

Chinese Writers' Association I45

Christianity 20, I26-I28

civil rights 225

civil service exam system 233

clapping, ferocious $\mathrm{IO} 4$

class labels, Maoist i9

class struggle 84

coercion I5, 43, 6I, 84, I02, I04

collectivism, agricultural 37

commune system 37

Communist Youth League 4I, IOI comparative advantage $4 \mathrm{I}$

Confucian thought 23, 25-26, I26I27, 290

Confucius 35

concentration camps, Nazi Io

conclusions, pre-ordained 22

Conference of 7000 Cadres I95, 297

confession II, I26-I28

conformity $53-56$

conscience, CCP official with a $244^{-}$ 245

Conservative faction, Red Guard I53, I95

consistency, pursuit of $56-57,240-$ 24I

"contradictions among the people" I05

control over others' minds I4

control over writers see writers

cooperatives, agricultural I9

correctness, ideological 33

corruption, government 226

counterrevolutionaries 204, 219220, 237, 242, 28I, 299

"counterrevolutionary clique" I79

“cowshed" I94, 296

credibility, blow to system's I92

credulity, surface-level 2IO-2I2

Creon I20, 289

criminal underworld 242

criticism of CCP 35

Critique of Judgment 50-5I

Critique of Practical Reason 50-5I

crude phrases, deliberate use of Io6IO7

cruelty, regime $35,39,200,201$, 2I2-2I3

Cui Zhiyuan 219, 299

Cultural Revolution II, 20, 3I, 40, 7I, 83, 89, 99, Іог, Іі8-Іі9, І22, I35, I53, I57, I58, I59, I62-I64, I73, I76, I80, I84, I87, I89, I94, 
203, 212, 232, 234, 237, 242, 243, 256,277

"cure the illness," slogan of Ioo

cynicism, political IO, I99-227

dance, "loyalty"-character 79

“dangerous" ideas 85

Darkness at Noon II9

death-row prisoners 86

demarcation, clear line of 169 , 292293

democracy 202, 205, 219

democracy, cunning opposition to 222

Democracy Movement I67, 206, 2IO, 2I2, 2I4, 2I6-2I7, 239, 243,

247, 248-249, 259, 263, 264, 272 Democracy Wall Movement I85, I96, 246, 263, 295

democratic socialism 219

demotion at work IO2

Deng Lijun 167,292

Deng Liqun 219, 24I-242, 299

Deng Tuo 285

Deng Xiaoping 82, I76-I77, I83, I87, 203, 209-210, 212, 286, 293

Deng Xiaoping Era ${ }^{1} 6_{5}$

denunciation 66, 97-IOI

despotism I97

determinism vs. free will I7

determinism, historical 54-55

Diary of Severity and Castigation I47

dictatorial measures IOI

dictatorship, ideological I8

dictatorship, proletarian 39, I02, 208, 210

Ding Ling I24-I25, 289

directives, authoritarian 7I

disappointment with citizenry $20 \mathrm{I}$

discourse, punishment of 48-49

dissident, keeping distance from I69-I70

dissidents, characterization of $\mathrm{I} 8$, I79-I8I "doctor," CCP as 99-100

doctrinaire thinking 33, 66

documentation IO-II

dogmatism, Leninist I95

donations, secret to soliciting 9I-92

double-think, Orwellian 42-43, 210

downward transfer IO2-IO4, I36-I39

East Germany (GDR), exodus from 248

Eastern European Incidents 203205, 207, 2IO, 2I4, 230-23I, 298

educated urban youth 7I, I59-I62, 287

eight-legged essay 233, 299

"Eliminating Spiritual Pollution" I67

Emperor's New Clothes 28, 49

end justifying means 200

End of History and the Last Man 265266

enduring hardship, meekly 58-59

enemies, class I8, Io8

enemies, "small handful" of 86 , 204, 287

Engels, Friedrich 43

Eternal Flow 50

eulogies to CCP 35

eulogizing vs. exposing 79

Europe, Eastern I8

evasion (of remolding) IO, I54-156,

I59, I68

evasion, rationalization of I72-I77

exaggerating problems Io6

examples, living 254-255

excuse for persecution, History as

83,124

exhortations, CCP 35

Exit, Voice, and Loyalty 230

expulsion from Party IOI, 246

expression, freedom of 229

fabrication, historical 49

face, loss of I28, I30

facts see ambiguity, fact-based 
Fairbank, John K. I28

faith in democracy 2I4-2I7

Fan Liqin 234, 299

fanaticism, political I0, I99

fanfare, political 37

Fang Lizhi I83, 235-236, 24I, 295, 300

Farewell to Revolution I72

fatalism 59

fear, regime-induced $85,210-2 \mathrm{I} 3$

fear see also punishment

Fei Xiaotong 38, 80, I32, 282, 290

Feng Youlan 62, 90, I49, 283

Festinger and Carlsmith, 94-95, 99

Feuerbach, Ludwig I34, 290

filial devotion I4O-I42

Five-Antis Campaign 38,282

Five Black Categories I36, 290

flattering oppressors I23

foot-dragging I53-I55, 224

forfeit, drinking a $87,238,287$

forgetfulness, political I72

format of dissent I84-I85

formulaic speech 67,292

"Four Clean-ups" campaign I3

"Four Modernizations" I93

"Four Upholds," slogan of I65, 292

Free-and-easy faction I53, I59, 2I2

freedom 202, 219, 227, 229, 254

Freud, Sigmund I27, I67

"frightening monkeys" 37-39

Fromm, Erich I42-I43, I5I

Fukuyama, Francis I97, 265-266, 268, 297

GMD (Nationalist Party) 22I, 284

GMD repression III

Galilei, Galileo 52-53, 282

game, establishing rules of the 225226

"Gang of Four" I6I, I93, 203, 239, 296

Gibbs, Donald 88, 287

graft, government 226
Grand Inquisitor I86, 295

"great, glorious, and correct" I05

"Great Harmony," idea of 32

“Great Leader" IO, 7I, 99, 29I

Great Leap Forward 82, 89, 286-287

"Great Victorious Escape" I59

Grossman, Vasily 50

guilt culture I28

Gulag Archipelago I07, 263-264

Gulag prison camps, Soviet Io

Hai Rui I05, II2, 289

Hai Rui's Dismissal from Office I05

Hamilton, Alexander 266, 30I

Han Fei Zi I99, 297

Havel, Vaclav I69-I70, 292

Hayek, Friedrich 219, 299

Heaven, Son of 205

heavenly principles vs. human desires

I5, 292

Hegel, Georg I20, I22, 266, 289, 301

"help," CCP-led condemnation as IOO, I05

hierarchy, social 75, 262

hip cynicism 2I7-2I9

hipster 2I7, 2I8, 298

Hirschman, Albert O. 230, 240, 24I, 244,249

"historical inevitability" 32

History see excuse for persecution

Hoffer, Eric III, 270-27I, 288

homelessness, spiritual II2-II4

Hong Chengchou 97

Horse Herder I35-136, I39, 290

Hou Baolin 33, 28I

How MY Thought Has Been

Transformed 6I-62, 66, 80

Howe, Irving I66, I99, 277

$\mathrm{Hu}$ Feng, denunciation of 38 , I79, 282

Hu Shi 84, 86, I5I, 285, 287

$\mathrm{Hu}$ Yaobang 243

Hua Guofeng 82, 83, 286 
Huang Shiren, arch-villain landlord 78,286

Huang Shuai I82, 295

Huang Wenbing 137

Huang, William 38, 28I-282

human nature, dark CCP view of 202

human rights 219

Hundred Days Reform 3I, 280-28I

Hundred Flowers Movement 22-23, I94, 2I2, 285, 286-287

Hunter, Edward I3, 278

Hus, Jan I69, 293

idea, victory of an 3I, 33

idealism and cynicism, CCP's 200

ideology, bourgeois I9-2I

ideology, fading of communist 210

illness, mental II

"immersion," ideological 20-2I

Incantation of Golden Fillet 156, 29I indifference, political Io, I7I-I76, I99

indignation, moral 268

inevitability, historical 55

inner conflict, shrinking from I49

inoculation, preventative $72-75$

intelligentsia I5, I8-I9, 4I

interrogation II

intimidation, government 85,88 ,

$$
\text { I43-I46, I48 }
$$

"iron rice bowl" 40

isolation, strategy of IO8-II2

Japanese culture I28

Jasinski, Wojciech I7I, 293

Jefferson, Thomas 35

Jiang Qing 89, 192, 287

Jiao Yulu 23-24

Jin Guantao 25, 285

joining CCP, motivations for 23I234

June Fourth crackdown 49, 85, I67, I73-I74, I8I, 20I, 206, 2IO, 2I2-
$214,222,236,242,243,247,254$,

272, 282

just world, belief in a 57-59

justice, sense of $\mathrm{I}^{2} 2$

Kant, Immanuel 50-51, 282

Kautsky, Karl I9I, 296

Khrushchev, Nikita I9I, 296

"killing a chicken" 37-38, 28I

"killing a guy" I26, 290

"killing a monkey" 38-39, 28I

King, Ambrose Yeo-ji I29, 290

Koestler, Arthur II9-I20, 289

Kubilai Khan 24, 280

labor camp $4^{2}$

laborers, myth about I35-138

labyrinth, conceptual 67

Land Reform Campaign I9, 35, 38, 28I

landlord "elements" I9, 35

legal procedure, lack of 39

legitimacy, CCP's claim to $29, \mathrm{I} 67$

legitimacy, CCP's loss of 205-207

Lei Feng 23-24, 279

Lenin, Vladimir $20,28,44,50, \mathrm{II} 6$, I22, I95, 200

Leninism 20

letter of dissent to rulers I8I-I84

"Letter to Ren An" I22

Li Lisan 83, 286

Li Qinglin I82, 294

Li Xiuzhi I36, I39

"Li Yizhe" big-character poster I83, 295

Li Zehou I72-I73, 2I9

Li Ziying 62, 80, 283

Liang Qichao 22, 279

Liang Shuming 25, 280

Liar's Paradox 27-28, 280

liberal democracy $4 \mathrm{I}$

liberalism I75, I94-I97

liberalization, CCP repression of

208, 24I, 243, 264 
liberalization, Soviet Russian 50

"Liberation" I9, 34, I35, I38, 279, 28I

liberty, China's prospects for I98

Lifton, Robert Jay 13, 96, 140

Lin Biao 24, 48, 67, 69, I58, I9II92, 280,284

literature, rusticated youth II

literature, scar II

literature, towering wall II

Little Red Book 79, 204, 284

Liu Binyan 24, 34, 24I, 279-280, 289

Liu Qingfeng I3, 25, 68, 278

Liu Shaoqi 42, I22, I56, 232, 243 , 29I

Liu Yong 40, 282

Liu Zaifu I72

Liu Zhidan 49

Logic of Collective Action 25I

loopholes, finding 224

loyalty, psychology of 57

loyalty to Party I4, 24I

loyalty to rulers I4O-I42

Lü Bu 96

Lu Xun I77, 2I7-2I8, 282, 294

Lushan Conference 83

Luo Changpei 62, 283

Luo River Goddess 139

Lushan Conference I83, 286-287

Luxemburg, Rosa I80, 294

Machiavelli, Nicolo 32, 266, 30I

Madison, James 266, 30I

Manchus 97

manipulation, varieties of I4

Mao Era 203, 208, 216, 249, 250

Mao Zedong I3, I8, 22, 33, 37, 39, 4I, 48, 67, 68, 70-7I, 79, 80-8I, 82-83, 84, 86, 99-100, I04, II5, I22, I4I-I43, I49, I55, I58, I6I, I76, I8I, I82, I84, I87, I92, I95, 203, 2I2

Mao Zedong Thought 2I, I9I
Maoist ideology 62, 219

Marx, Karl I86, 269

Marxism, classical I5-I7, 20, 43, 54, I65-166, I95, 219, 220, 256

Marxist intelligentsia 32

Marxist-Leninism 33, 62, 65, I9I, 202

mass communication outlets 262 265

materialism, French mechanistic I7 materialism, Marxist-Leninist I6-I7, I95

Materialism and Empirio-Criticism

I95, 296

May Day Military Parade 80, II9

May Fourth Movement 55-56, 283

May Seventh Cadre Schools I04, 288

meaning in life, pursuit of $59-60$

mendacity, regime 210

military see PLA

military victory 33

Mill, John Stuart I99, 2I7, 253, 297

Mimosa I23-I24

missionaries, portrayal of 88

Model Operas 89, 285-286

"money-first" attitude $\quad \mathrm{I} 67$

monistic values $39-40$

monopolistic control 233

monopolistic violence 29, $20 \mathrm{I}$

Mount Lu II

"muddleheaded, better off" 213

"murdering your sovereign ruler" I26, 290

name, criticizing by I04-I05

National People's Congress 225, 295

nationalizing commerce 37

Nazis IO, III

negative example, cautionary figure as 84

neo-authoritarianism, PRC 22I

neo-Confucianism 2I9

neo-conservatism 219 
neologisms, coining 67,222

neo-Marxism 219

neutral vocabulary, dearth of I26

"new Communist man" 28

"New Democratic revolution" 33

New Left, PRC 22I

"new period" (post-Mao era) II, 296

"new society" I9, 62-63, 79

"new Soviet man" I8

"newest theories," undemocratic 3I

Newton, Issac 93

Nie Gannu I20, 289

Nietzsche, Friedrich 9, 266, 30I

Nineteen Eighty-four 42, I48, 223, 282

I949 Revolution 3I

"No discussion of national affairs" I73, 293

non-negotiability 30

normative theory 252-254

nostalgia 9

obedience, CCP imperative of $\mathrm{I}_{42}{ }^{2}$ I43

“obey Chairman Mao" I4I, I42

"obey the Party" I49, I57-I58

"objects of domestic control" 239

October Revolution, Russian 3I, 2OI

Oedipus I2O, I43

"old society" I9

Olsen, Mancur, Jr. 25I-252, 258, 300

"On the Freedom of Speech" I96

"On Prison Furloughs" I43-I44

"opposing bourgeois liberalization" I67

Organization Department, CCP I45, 29I

Original Sin 20

Orwell, George 42, 205-206, 210, 223, 282

“other register," CCP's 239, 242, 289

Ouyang Xiu I43-I44

oversimplification $66,68-72$
PLA (military) 34, I38, 206, 2I4

Pang Xunqin I47, 29I

Party Central 49

Party Organization II9

Party-state, Chinese Communist Io

Party's dominion, China as 233,

299, 300-30I

"Party's tamed tool, serve as" I49

Pavlov, Ivan I6

Pei Wenzhong 62, 66, 283

Peng Dehuai I80, I83, 294

Peng Zhen I05, 288

People's Daily 75

persecuted but loyal CCP members 237-24I

persecution, revulsion for political I94

personal responsibility, avoiding I49

phony politics I73, I93-I94, 296

planned economy, centrally 2I

"poisonous weed" 27

political hardliners, CCP 208-209

political idea see idea

political imprisonment 49

political moderates, CCP 208-209

Polyneices I20

populism, CCP rule and 203-204

populism, early modern Russian 55

populism, traditional Chinese 55

power, seizure and monopolizing of

33, 201

power struggle see struggle

pragmatism 209

Press and Publications Law, GMD

202

pressure from CCP $36-37,43$

pretended obedience to rulers 222225

princelings, CCP 203-207, 29I

privacy, violations of $\mathrm{IO} 7$

private life, caring only about $\mathrm{I} 66$

Procrustean bed 57, 99, 283

professional orientation I55 
Program of the Princelings' Party

203-207, 219

proletarian weltanschauung $\mathrm{I} 6,20$ -

2I, I42, 270, 279

propaganda, affective $77-79$

propaganda, political I4, I5, 49

Prussian authoritarian rule I65-I66

psychiatric control I4

Psychology of Totalism I3

public ownership 40

Public Security Bureau 262, 301

publication, freedom of 229

punishment, fear of 85

punitive methods IOI-IO3

"putting to the test" I22-I25

Pye, Lucian 206, 223

Qin dynasty crackdown $37,28 \mathrm{I}$

Qu Qiubai 83, 286

$\mathrm{Qu}$ Xiao I25, 290

Qu Yuan II2, 284, 289

ranking, social 4I-42

rational choice theory $25 \mathrm{I}-252$

rationalizing behavior 9I, I23

"reactionary class" 24

Realpolitik Realism 2I9

Rebel faction, Red Guard 7I, 99,

I35, I53

rebellion (against taming) Io, I79-

$$
\text { I8I, } 200
$$

"rectification of attitude" I05

Red Flag, growing up beneath I4I, I88

Red Guards I35, I4I-I42, I53

"red" vs. "expert" I93, 292

reeducation through labor 7I, IOI

Reference News 75

reform, desire for political $20 \mathrm{I}$

relationships, focus on interpersonal 96

remolding (of thought) IO, I2, I3-I4, I8-2I, I4I-I42, I58, I88-I89

remolding, end of thought $\mathrm{I}_{4}-\mathrm{I} \mathrm{G}_{5}$ remolding through labor IOI

Republican Period 32

research 63

resignation, consequences of official's 244

resistance, importance of 227

reversal see standpoint

revisionism I9O-I9I

revolution, habituation to violence of $20 \mathrm{I}$

revolutionary party 203-207

Revolutionary War Era I4

reward, factor of amount of 94-95

"rich farmer elements" I9

rights, lack of concept of $\mathrm{I} 75$

rituals, collective $79-8 \mathrm{I}$

romanticized legends 49

Rousseau, Jean-Jacques 266, 30I

rule of law 202, 2I9

ruling party 203-207, 258-260

Russell, Bertrand 28, 207, 280

Russians 200

rusticated youth II, 95-96, I59-162, 287

rusticated youth literature II

rustication, resistance to $\mathrm{I}_{6} 2$

sacking public employees IOI-IO2

salary reduction $\mathrm{IO} 2$

Sartre, Jean-Paul 59, I67, 283

"save the patient," slogan of Ioo

sayings of Mao Zedong see Little

Red Book

scar literature 277

scientism, Marxist-Leninism as 32 , 33

Security Section cadres $\mathrm{I}_{4}$ sedan-chair bearer 66, 284 Selected Works of Mao Zedong $6_{3}$

self, present vs. past 22

self-castration, mental 2I3

self-contradiction 28

self-criticism 8I-83, I26-I28

self-cultivation, moral $23-26$ 
self-deception $\quad 36-37,42-43, \mathrm{I} 66$, 225, 227

self-denigration I3I

self-denunciation I3I-I32

self-discipline I29

self-incrimination I3I-I32

self-interest 268

self-protection $\mathrm{I} 69,239-240$

serfdom I97

sexual freedom I67

sexual harassment I30

shame culture I28, 267

Shen Buhai I99, 297

shirking responsibilities 224

shunning I08-I09

silent, freedom to remain 86

Sima Qian 122, 289

skepticism, spirit of I94

Skinner, B.F. I6-I7

slavish mentality I48-I49

slogans 69, 79, I95, 205

"small handful" see enemies

Smith, Adam 266

Smith, Hedrick 200, 297

social animals, humans as Io9

Social Darwinism 54, 283

societal scale 260-262, 30I

society, closed I5

society, open I5

Socrates 269, 30I

Solzhenitsyn, Aleksandr IO7, II2-II3, I79, I96, 230, 294

Song Jiang 97, 137

songs, revolutionary 67

Sophocles I2O

Soviet Russians I0, I3, I8, 96

Soviet Union Incident 203-205, 207 , 2IO, 2I4, 230-23I, 298

Sowell, Thomas I97, 297

Spartan spirit I22

Special Economic Zone 209, 298

speech, freedom of $86,219-220$

spiritedness 266-270, 272

stake, burning at the ${ }^{169}$ standpoint, reversal of 92-93

starvation, death from 49

staying in CCP, reasons for 235-237

stereotyped phraseology 67

"stinking number nine" I8, I93, 277

strictures, religious I4

structuralist theory $256-258$

struggle, class $7 \mathrm{I}$

struggle, power 42

struggle sessions 79, 86, I04-I05

"study," Maoist 62-65, 75-77

subconscious rebellion I86-I88

subconscious thought $42-43$

submissiveness, across-the-board I47

subordinates, wheedling way through 224

suicide 62

superstition 33

support, lack of spiritual II2-II4

suppressing "counterrevolutionaries"

37

taboos, primitive I4

Taiwan 22I

Taizong emperor, Tang dynasty I43I44

takeover, successful military-political 33

taming (of the human) IO, I47-I48, I49, I68

terror, political 39

terror, state Io

terrorized mindset 146

"Third Path" 2I9

thought crime 39,289

thought, development of 22-23

thought, emancipation of 92,287

thought, purification of I4

thought remolding see remolding

Three-Antis Campaign 38,282

“Three Combinings" 89

Three-Family Village, denunciation of 84,287 
Three Kingdoms 96, 288

Three People's Principles 219

Tiananmen Square 79-80, I48, 278

tiger, similarity of autocrat to 84 , 148

tiny shoes, issuing someone IO2, 288

Tito, Josip I9I, 296

To the Storm 237

toast, drinking a $87,238,287$

Tocqueville, Alexis I66-167, I74, 208, 27I, 283

Tolstoy, Alexei I23, 289

totalism 96

totalitarianism Io, I8, 39, 49, I66, I68, I80, 189, I96, I97, 209, 230-23I, 245, 265, 270

"touched to their very souls" II, 290 "toughening” I22-I25

Tour of the South, Royal 2IO, 298 true believers I34 truth, class nature of 92 truth, seen as absolute $43-46$ "two combining into one" 66, 284 tyranny 234,242

U.S.S.R see Soviet Russians ultranationalism 2I9, 220 uniformity, ideological 39, 67 unintended consequences 225 "unity with Party Central" 30 utopianism II, I99

values see ambiguity, value-based vanity, "bourgeois" IO7

victory see idea

vilification, CCP bent for 202

violence 39, I95, 207, 210

vulgarization 66

Walesa, Lech I7I

Wang Fuzhi I99, 297

Wang Ming 83, 286

Wang Ruoshui 80, 286
Wang Ruowang 24I, 300

Wang Shuo 2I7-2I8, 298

Washington, George 35

Water Margin 97, 137, 259, 288

Wave-washed Sands 38, 28I-282

"we rule you," posture of 203

Weber, Max 29, 280

Wei Jingsheng I83, 295, 300

weltanschauung, definition of I5

weltanschauung see bourgeois weltanschauung, proletarian weltanschauung

Wen Jieruo I46

Wen Tianxiang 24, 280

Wenhuibao I05

Western culture I28

Western Left 22I

"Whateverist" Faction I93-I94, 296

White-haired Girl 78, 285-286

willingness to remold thought I5 winner's history 33

withdrawing from CCP, rarity of 24I-245

world-view see weltanschauung

world wars, impact of 32

worship of the People 54, 55

writers, CCP's control over 89

"wrongly spanked her child," mother who I25, I40

Wu Han I05, 285

Wu Sangui 97

Wu Zuguang I50, 29I

xi'nao see brainwashing

Xi Shi 52, 282

xizao see "bathing"

Xiao Qian 62, I35, I45-I46, 283

Xie Fengwo $62,80,283$

$\mathrm{Xu}$ Lingjun I35-136, I39

$\mathrm{Xu}$ Yancheng $\mathrm{I} 33$

Yan Fu 219, 220, 299

Yan Jirong I75, 293

Yan Yan 96 
Yan'an Forum on Literature and Art 79, 286

Yan'an Rectification Campaign I4, 37, I34-I35, 28I

Yang Jiang $13,38,278$

Yang Jushu $\quad 62-63,284$

Yang Xiaokai I87, 295-296

Yao Wenyuan I05, I3I, 288

Young Turk faction, CCP's 203-207

youthfulness, obedience and I4I

Yu Luoke 26-27, 280

Yue Daiyun 237-240, 300

Zang Kejia I04, 288

Zhang Fei 96
Zhang Liao 96

Zhang Tiesheng I82, 295

Zhang Wentian 83, 286

Zhang Xianliang I23-I24, I35-136, 289

Zhang Zhizhong 62, 283

Zhao Guangyi 47

Zhao Kuangyin 47, 282

Zhao Ziyang 243-244, 300

Zheng Banqiao 213

Zhou Duo 62, 284

Zhou Enlai 83, I93, 286

zone, forbidden $67,73,85,287$

Zong $\mathrm{Pu}$ 90, I49, 287 

ICAS) Publications Series

\section{Monographs}

Marleen Dieleman

The Rhythm of Strategy. A Corporate Biography of the Salim Group

of Indonesia

Monographs I

2007 (ISBN 9789053560334 )

\section{Sam Wong}

Exploring 'Unseen' Social Capital in Community Participation. Everyday

Lives of Poor Mainland Chinese Migrants in Hong Kong

Monographs 2

2007 (ISBN 978905356034 I)

Diah Ariani Arimbi

Reading Contemporary Indonesian Muslim Women Writers. Representation, Identity and Religion of Muslim Women in Indonesian Fiction

Monographs 3

2009 (ISBN 978908964089 5)

Euis Nurlaelawati

Modernization, Tradition and Identity. The Kompilasi Hukum Islam and

Legal Practice in the Indonesian Religious Courts

Monographs 4

20I0 (ISBN $978908964 \circ 88$ 8)

Khun Eng Kuah-Pearce

Rebuilding the Ancestral Village. Singaporeans in China

Monographs 5

2OII (ISBN 978908964332 2)

Deborah E. Tooker

Space and the Production of Cultural Difference Among the Akha Prior to

Globalization. Channeling the Flow of Life

Monographs 6

2012 (ISBN 9789089643254 ) 


\section{Edited Volumes}

Sebastian Bersick, Wim Stokhof and Paul van der Velde (eds.) Multiregionalism and Multilateralism. Asian-European Relations in a Global Context Edited Volumes I 2006 (ISBN 978905356929 0)

Khun Eng Kuah-Pearce (ed.)

Chinese Women and the Cyberspace

Edited Volumes 2 2008 (ISBN 978905356 75I 7)

Milan J. Titus and Paul P.M. Burgers (eds.)

Rural Livelihoods, Resources and Coping with Crisis in Indonesia. A Comparative Study

Edited Volumes 3

2008 (ISBN 978908964055 o)

Marianne Hulsbosch, Elizabeth Bedford and Martha Chaiklin (eds.)

Asian Material Culture

Edited Volumes 4

2009 (ISBN 978908964090 I)

Hans Hägerdal (ed.)

Responding to the West. Essays on Colonial Domination and Asian Agency

Edited Volumes 5

2009 (ISBN 978908964093 2)

Derek Heng and Syed Muhd Khairudin Aljunied (eds.)

Reframing Singapore. Memory - Identity - Trans-Regionalism

Edited Volumes 6

2009 (ISBN 9789089640949 )

Friederike Assandri and Dora Martins (eds.)

From Early Tang Court Debates to China's Peaceful Rise

Edited Volumes 7

2009 (ISBN 978905356795 I)

Erich Kolig, Vivienne SM. Angeles and Sam Wong (eds.)

Identity in Crossroad Civilisations. Ethnicity, Nationalism and Globalism in Asia

Edited Volumes 8

2009 (ISBN 978908964 I27 4) 
Khun Eng Kuah-Pearce and Gilles Guiheux (eds.)

Social Movements in China and Hong Kong. The Expansion of Protest Space

Edited Volumes 9

2009 (ISBN 978908964 I3I I)

Huhua Cao (ed.)

Ethnic Minorities and Regional Development in Asia. Reality and Challenges

Edited Volumes Io

2009 (ISBN 978908964 ०9I 8)

M. Parvizi Amineh (ed.)

State, Society and International Relations in Asia. Reality and Challenges Edited Volumes II

2010 (ISBN 978905356794 4)

Philip F. Williams (ed.)

Asian Literary Voices. From Marginal to Mainstream

Edited Volumes I2

2010 (ISBN 978908964092 5)

Philip Hirsch and Nicholas Tapp (eds.)

Tracks and Traces. Thailand and the Work of Andrew Turton

Edited Volumes I3

20I0 (ISBN 978908964249 3)

Derek Heng and Syed Muhd Khairudin Aljunied (eds.)

Singapore in Global History

Edited Volumes I4

2OII (ISBN 978908964324 7)

Sebastian Bersick and Paul van der Velde (eds.)

The Asia-Europe Meeting: Contributing to a New Global Governance

Architecture. The Eighth ASEM Summit in Brussels (2010)

Edited Volumes I5

2OII (ISBN 9789089643438 ) 